IVAN VALEIJE IDOETA

\title{
METODOLOGIA DE ELABORAÇÃO AUTOMATIZADA DE MODELO DIGITAL DE ELEVAÇÃO E ORTOFOTO EM MÉDIA E PEQUENA ESCALA.
}

\author{
Tese apresentada à Escola \\ Politécnica da Universidade de São \\ Paulo para obtenção do título de \\ Doutor em Engenharia
}

São Paulo

2007 


\title{
ESCOLA POLITÉCNICA DA UNIVERSIDADE DE SÃO PAULO
}

\author{
IVAN VALEIJE IDOETA
}

\section{METODOLOGIA DE ELABORAÇÃO AUTOMATIZADA DE MODELO DIGITAL DE ELEVAÇÃO E ORTOFOTO EM MÉDIA E PEQUENA ESCALA.}

\author{
Tese apresentada à Escola \\ Politécnica da Universidade de São \\ Paulo para obtenção do título de \\ Doutor em Engenharia \\ Área de concentração: \\ Engenharia de Transportes \\ Orientador: \\ Prof. Dr. Jorge Pimentel Cintra
}

São Paulo 
AUTORIZO A REPRODUÇÃO E DIVULGAÇÃO TOTAL OU PARCIAL DESTE TRABALHO, POR QUALQUER MEIO CONVENCIONAL OU ELETRÔNICO, PARA FINS DE ESTUDO E PESQUISA, DESDE QUE CITADA A FONTE

FICHA CATALOGRÁFICA

Idoeta, Ivan Valeije

Metodologia de elaboração automatizada de modelo digital de elevação e ortofoto em média e pequena escala / I.V. Idoeta. -São Paulo, 2007.

$211 \mathrm{p}$.

Tese (Doutorado) - Escola Politécnica da Universidade de São Paulo. Departamento de Engenharia de Transportes.

1.Imagens digitais 2.Elevação e ortofoto I.Universidade de São Paulo. Escola Politécnica. Departamento de Engenharia de Transportes II.t. 


\section{UNIVERSIDADE DE SÃO PAULO}

Relatório de defesa pública de Tese do(a) Senhor(a) Ivan Valeije Idoeta no Programa: Engenharia de Transportes, do(a) Escola Politécnica da Universidade de São Paulo.

Aos 19 dias do mês de novembro de 2007, realizou-se a Defesa da Tese do(a) Senhor(a) Ivan Valeije Idoeta, apresentada para a obtenção do título de Doutor em Engenharia - Área: Engenharia de Transportes, intitulada:

"Metodologia de elaboração automatizada de modelo digital de elevação e ortofoto em média e pequena escala"

Após declarada aberta a sessão, o(a) $\operatorname{Sr}($ a) Presidente passa a palavra aos examinadores para as devidas argüições que se desenvolvem nos termos regimentais. Em seguida, a Comissão Julgadora proclama o resultado:

$\begin{array}{llll}\text { Nome dos Participantes da Banca } & \text { Vínculo do Docente } & \text { Sigla da Unidade } & \text { Resultado } \\ \text { Jorge Pimentel Cintra } & \text { Presidente } & \text { EP - USP } & \text { aprovado } \\ \text { Valdemar Antonio Demetrio } & \text { Titular } & \text { ESALQ - USP } & \text { apovado } \\ \text { Nicola Pacileo Netto } & \text { Titular } & \text { EP - USP } & \text { amorado do } \\ \text { Simone Sayuri Sato } & \text { Titular } & \text { Externo } & \text { aprado } \\ \text { Antonio Maria Garcia Tommaselli } & \text { Titular } & \text { UNESP - Externo }\end{array}$

Resultado Final: + aprotro do

Parecer da Comissão Julgadora *

Eu, Elisabete Aparecida F da Silva Ramos Técnico Acadêmico, lavrei a presente ata, que assino juntamente com os(as) Senhores(as). São Paulo, aos 19 dias do mês de novembro de 2007.
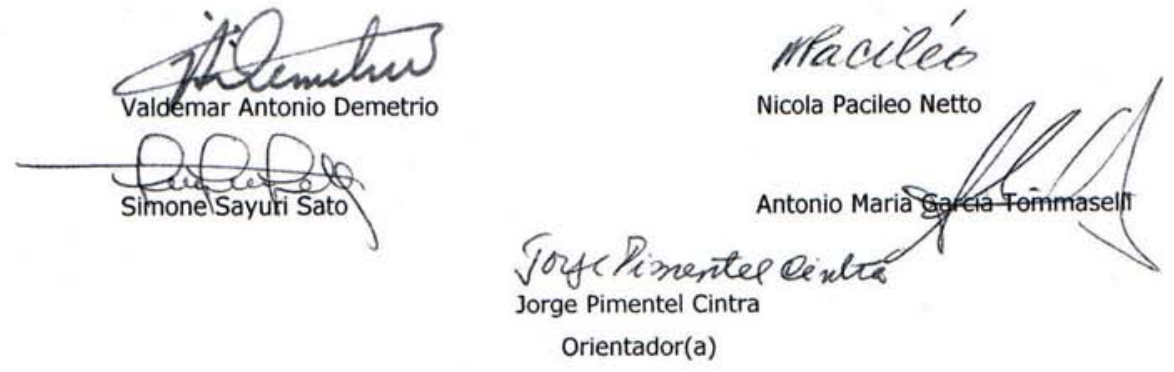

* Obs: Se o candidato for reprovado por algum dos membros, o preenchimento do parecer é obrigatório.

Título homologado pela Comissão de Pós-Graduação em

Presidente da Comissão de Pós-Graduação 


\section{Agradecimentos}

Ao Prof. Dr. Jorge Pimentel Cintra a orientação e apoio durante a elaboração deste trabalho.

Ao meu pai, Irineu Idoeta as sugestões, apoio, e principalmente incentivo.

À minha família, a compreensão no tempo roubado de convívio, em especial à Lina pelas ilustrações deste trabalho.

Aos professores, funcionários e colegas do Departamento de Transportes, em especial ao Prof. Dr. Nicola Paciléo Neto e ao Prof. Dr. Denizar Blitzkow, o apoio direto ou indireto.

Aos colegas da Base Aerofotogrametria e Projetos S.A., a amizade apoio e colaboração, em especial a Ricardo, Ayrton, Francisco, Pascoal, David e Vander, que participaram diretamente na elaboração deste trabalho.

Ao amigo e parceiro Adriano Huguet, sem a ajuda de quem, este trabalho não teria sido implementado.

Ao amigo, parceiro e colaborador Marcelo Antonio Nero.

A todos que direta ou indiretamente colaboraram na elaboração deste trabalho. 
A

Divaldo

Iracema

Irineu

Ivani

José 


\section{Sumário}

Agradecimentos.............................................................................................. 1

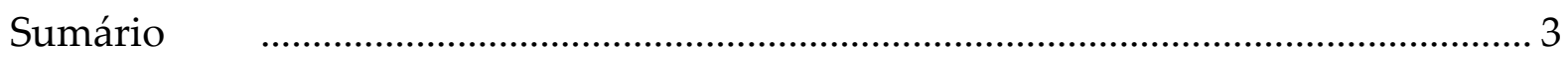

Siglas

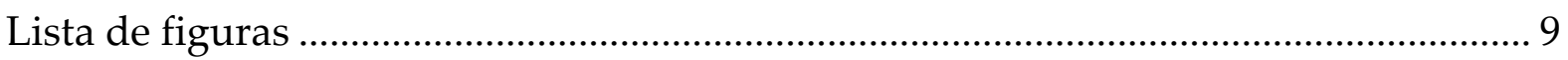

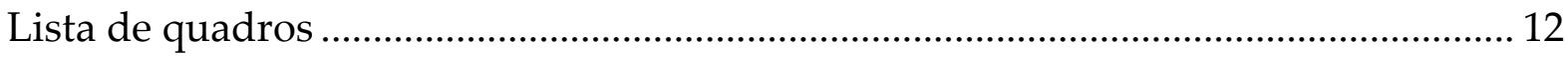

Resumo

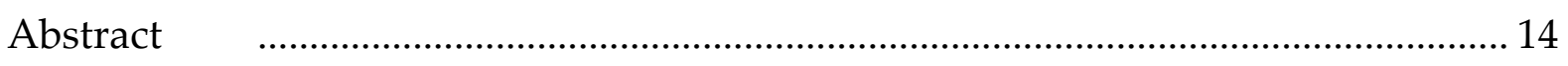

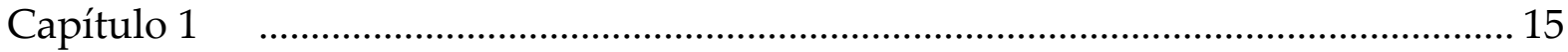

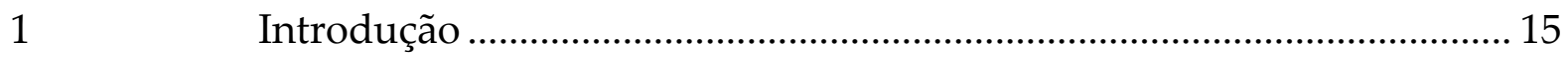

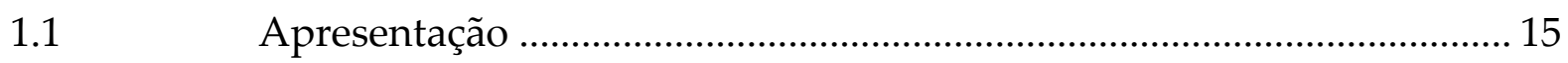

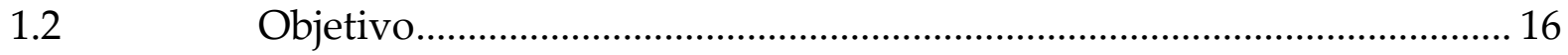

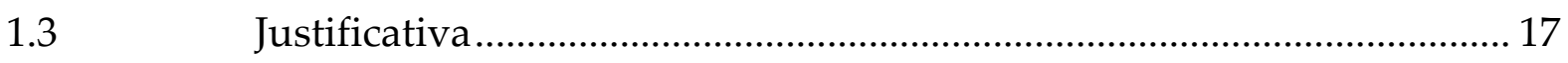

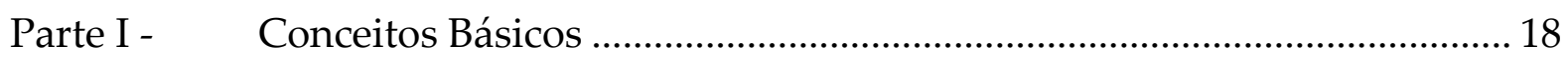

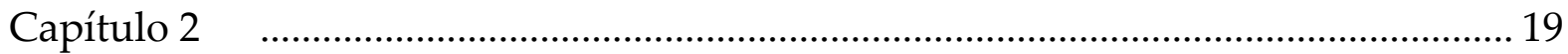

$2 \quad$ Conceitos sobre imagens digitais...................................................... 19

2.1 Resolução espacial de uma imagem digital. ............................................. 19

2.2 Exatidão posicional de uma imagem digital.......................................... 20

$2.3 \quad$ Resolução radiométrica de uma imagem digital..................................... 20

2.4 Tipos de imagens digitais e resolução espectral....................................... 21

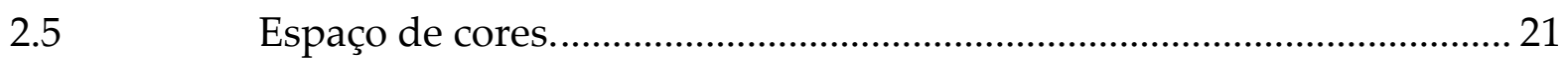

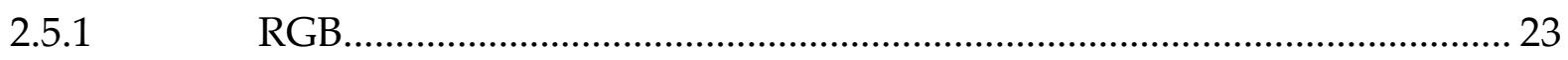

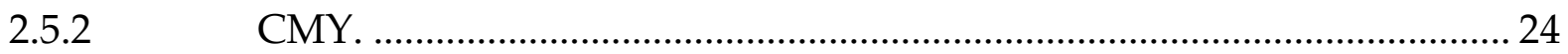

2.5.3 HSI.

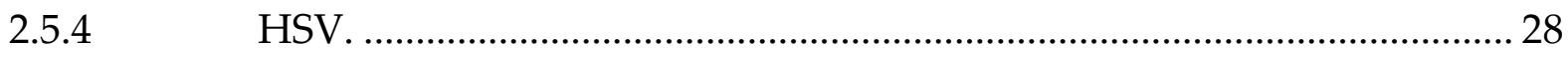

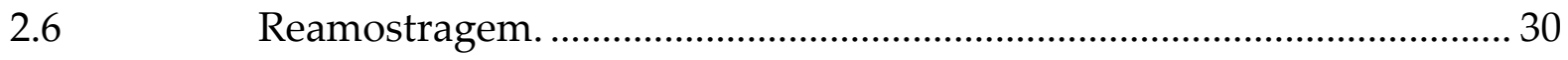

2.6.1 Vizinho mais próximo ...................................................................... 30

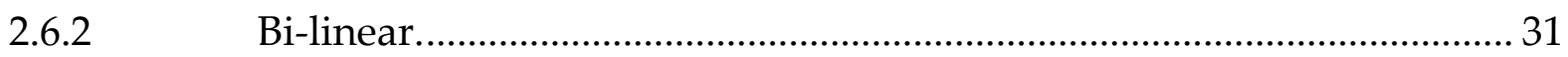

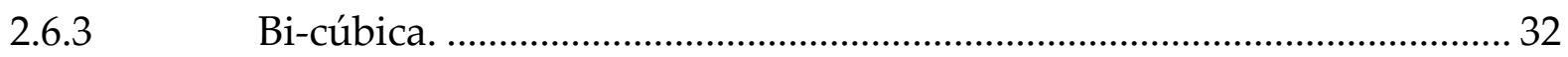

2.6.4 Considerações sobre os três métodos..................................................... 33 
2.8 Pirâmide de imagens digitais. 36

2.10 Correlação entre imagens digitais. 40

2.10.1 Correspondência baseada em área.......................................................... 42

2.10.2 Determinação das coordenadas de um ponto homólogo........................ 44

2.10.3 Métodos de busca fracionais ou sub-pixel............................................ 45

2.10.3.1 O método da adaptação de uma superfície polinomial........................... 45

2.10.3.2 Método de correspondência pelos mínimos quadrados. ....................... 46

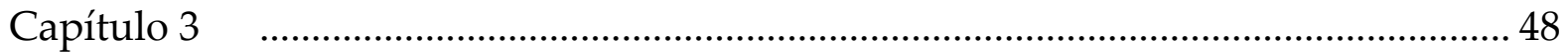

Modelos de superfície...................................................................... 48

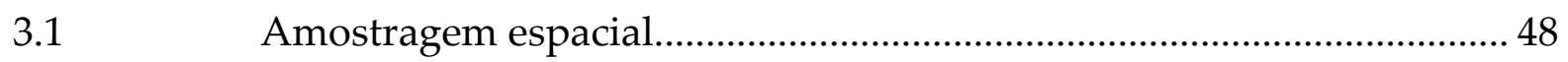

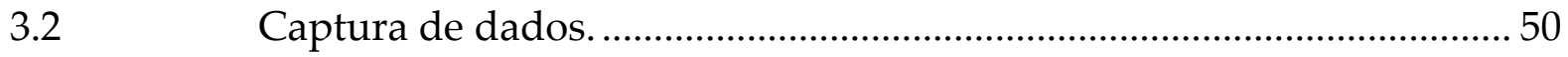

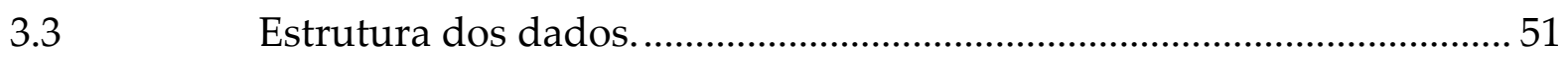

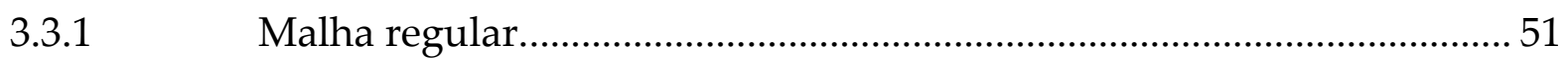

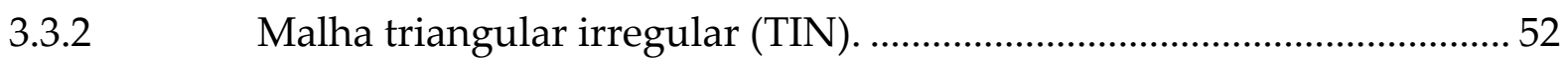

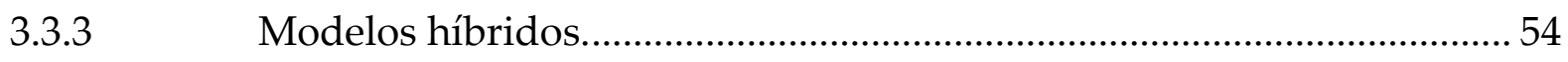

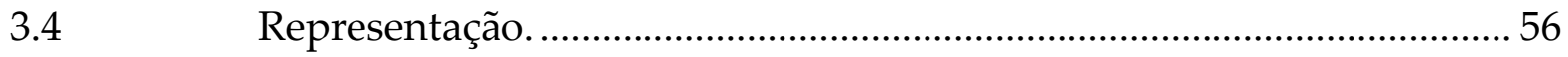

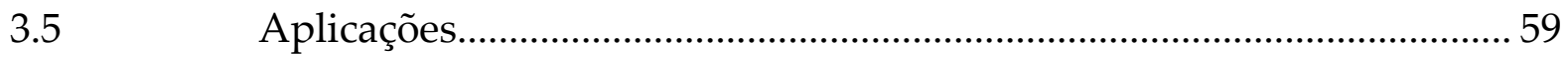

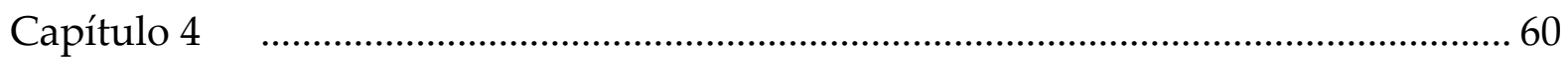

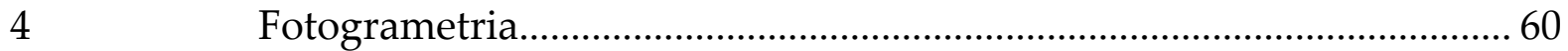

Sistemas de referência em Fotogrametria............................................... 60

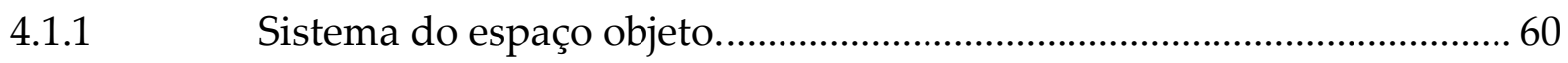

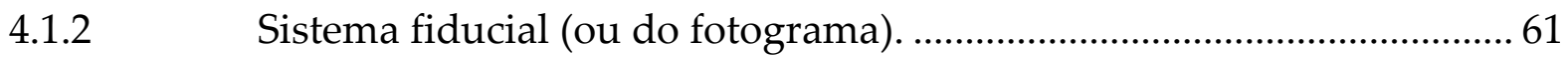

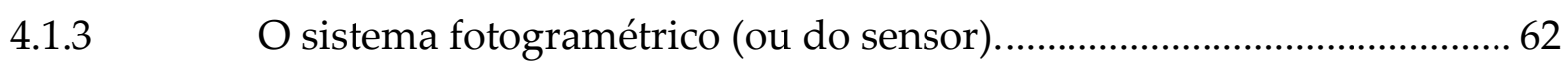

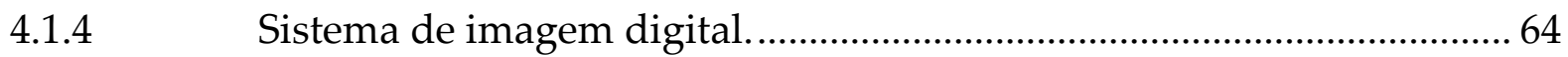

4.2 Transformação do sistema da imagem digital para o

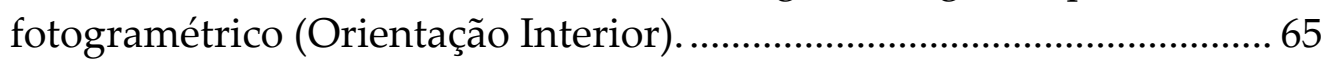

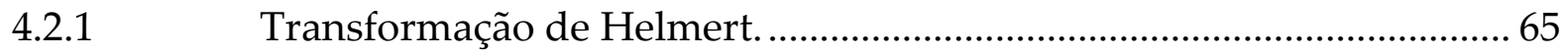

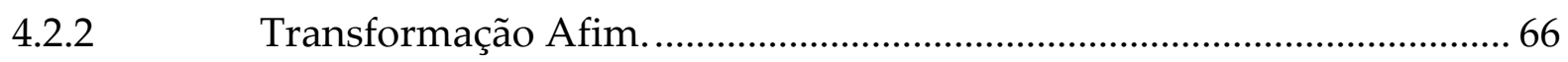

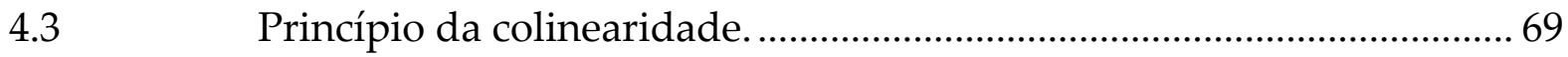


4.4 Orientação exterior

4.5 Interseção espacial de reta com plano - equações da

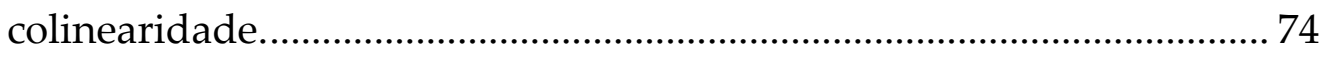

4.6 Correções ao resultado fornecido pela equação da colinearidade......... 76

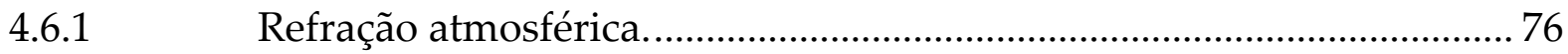

4.6.1.1 Modelo de correção da refração do ARDC/USAF................................... 78

4.6.1.2 Modelo de correção da refração do Manual de Fotogrametria da Sociedade Americana de Fotogrametria................................................79

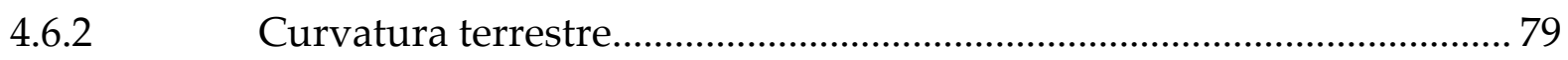

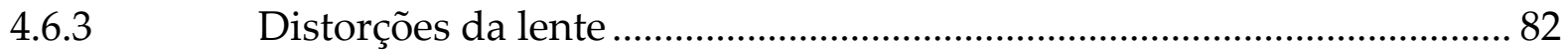

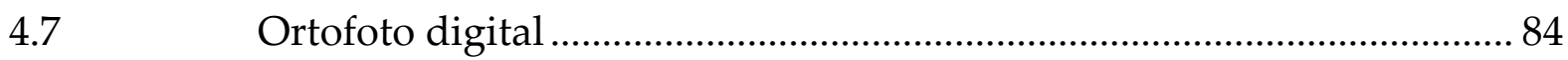

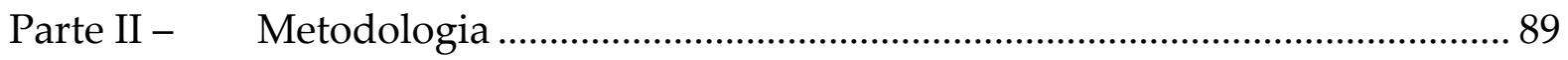

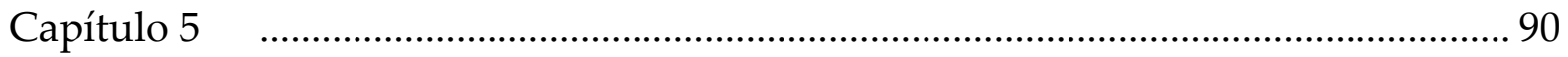

5 Metodologia para geração automática de MDE e ortoimagem em médias e pequenas escalas, utilizando correlação de imagens. ............ 90

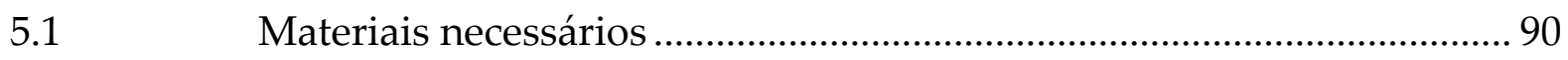

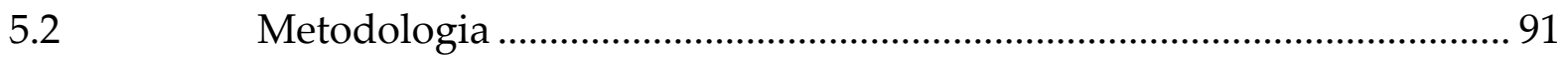

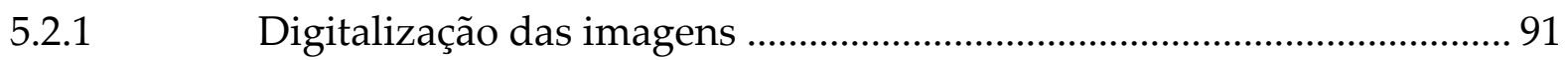

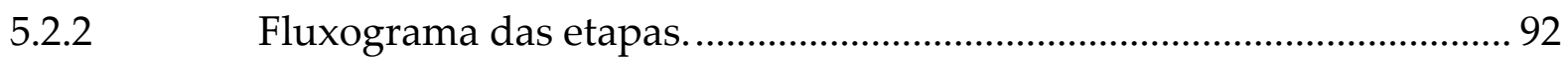

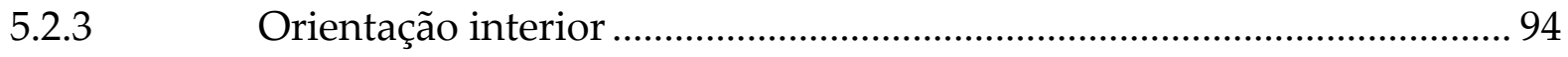

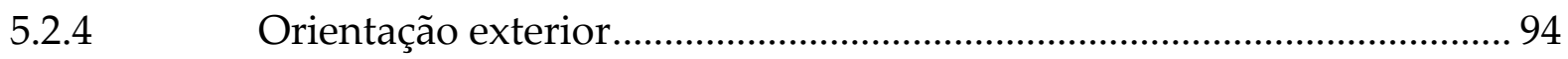

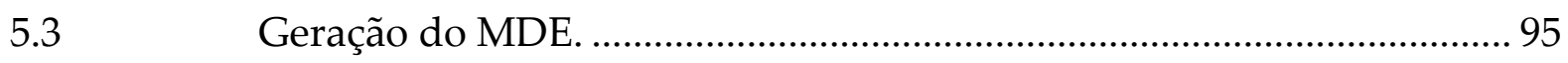

5.3.1 Estabelecimento de uma malha regular no terreno .............................. 95

5.3.2 Geração das janelas epipolares em imagens digitais. ............................. 95

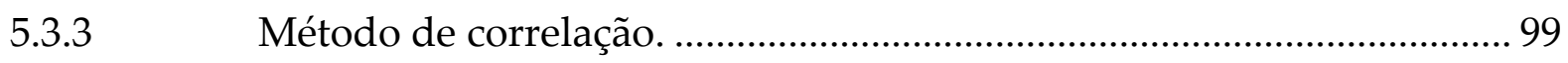

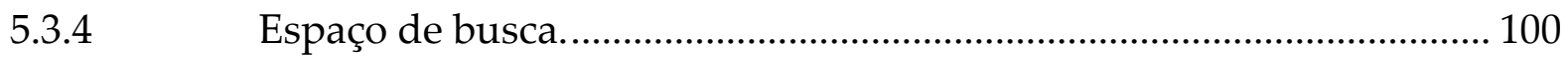

5.3.5 Considerações sobre o espaço de busca e correlação............................. 106

5.3.6 Armazenamento do MDE. ..................................................................... 107

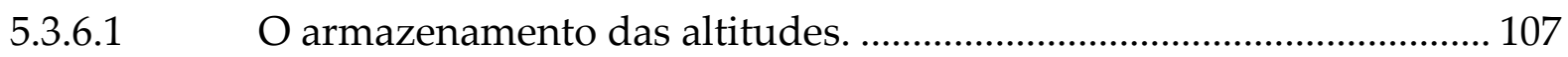

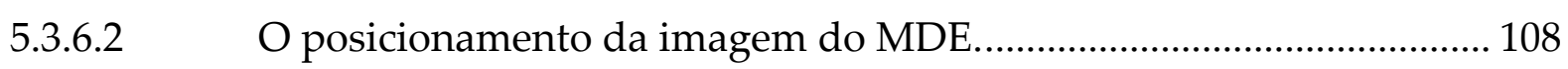

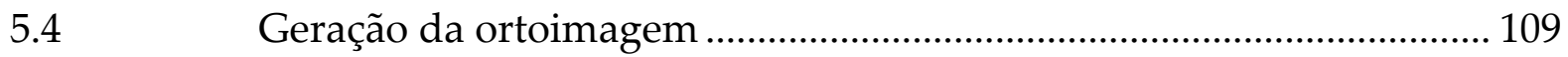

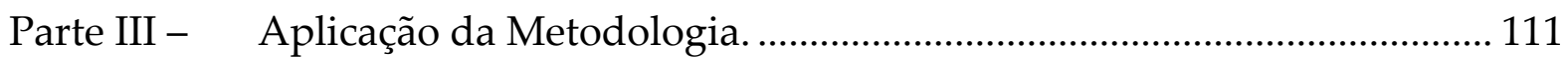


6.1.1 Referente à cobertura aerofotogramétrica na escala 1:25.000.

6.1.2 Referente à cobertura aerofotogramétrica em escala 1:5.000.

6.1.3 Considerações sobre o material recebido.

6.1.4 Características da cobertura aerofotogramétrica na escala $1: 25.000$.

6.1.5 Características da cobertura aerofotogramétrica na escala 1:5.000 .... 116

6.1.6 Sobreposição das coberturas em 1:25.000 e 1:5.000 ............................... 117

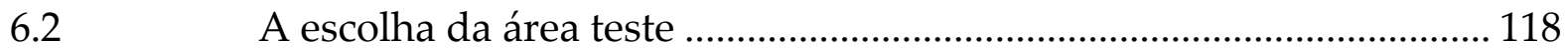

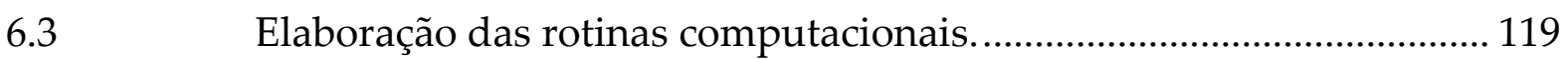

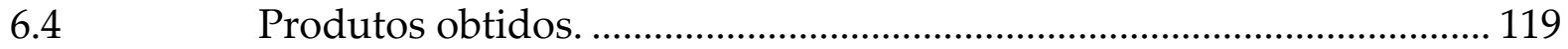

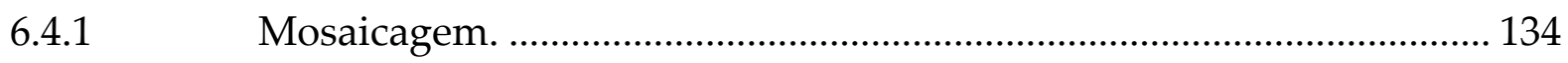

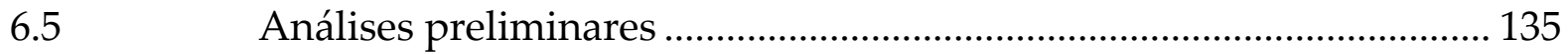

Parte IV - Validação da metodologia e dos produtos. ................................................. 139

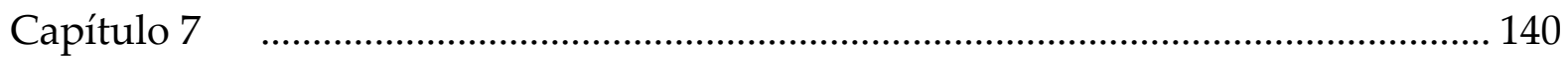

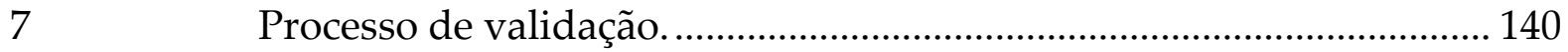

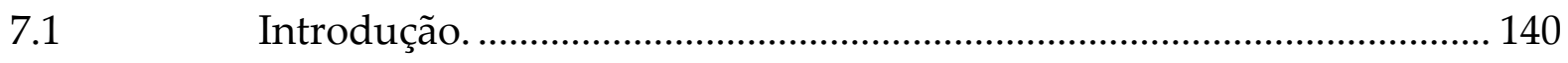

7.2 Peculiaridades dos produtos gerados e a Norma Brasileira de controle de qualidade posicional. ......................................................... 140

7.3 Processo de controle de qualidade posicional. ...................................... 145

7.3.1 Determinação da População................................................................... 145

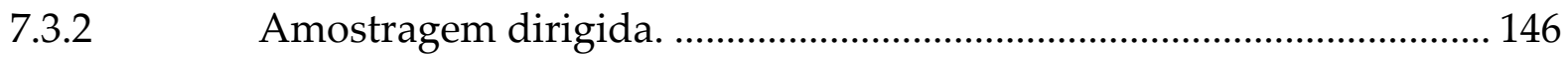

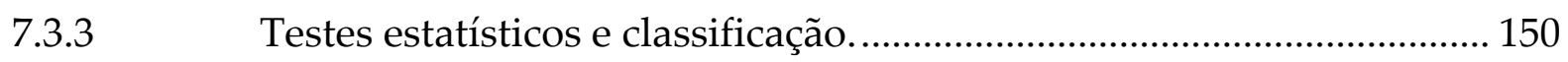

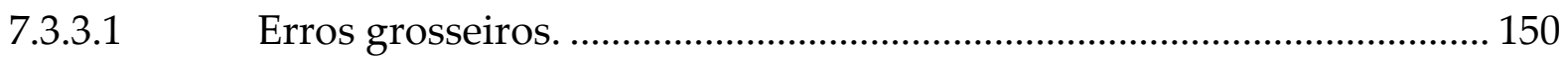

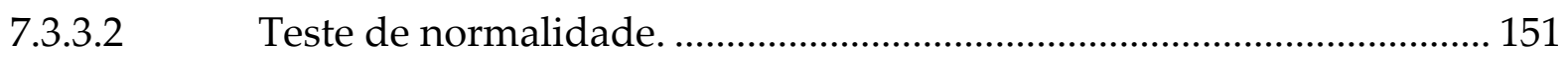

7.3.3.3 Teste de média e desvio padrão............................................................. 151

7.3.3.4 Teste de tendência (Avaliação do erro sistemático).............................. 152

7.3.3.5 Teste do Qui-quadrado (Avaliação da precisão): .................................. 153

7.3.3.6 Classificação do documento cartográfico de acordo com a Norma Brasileira ........................................................................................ 154 
7.4 Aplicação e classificação dos produtos cartográficos. ........................... 154

7.4.1 Avaliação dos dados de planimetria...................................................... 156

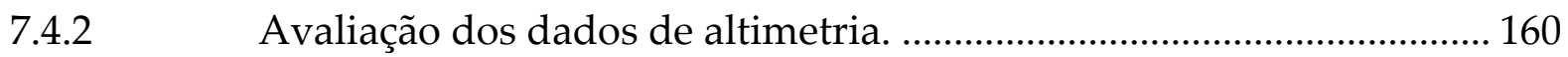

7.4.2.1 Avaliação da amostra de 205 pontos bem definidos............................. 160

7.4.2.2 Avaliação da altimetria em uma amostra em malha regular equiespaciada de 150 metros............................................................. 162

7.4.2.3 Análises e considerações quanto à altimetria ........................................ 163

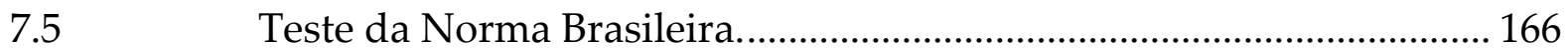

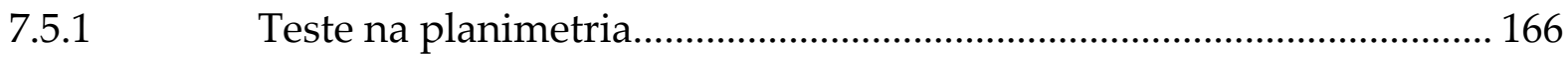

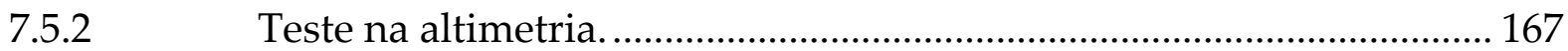

7.5.2.1 Teste na altimetria para a amostra dirigida........................................ 167

7.5.2.2 Avaliação da altimetria em uma amostra em malha regular equiespaciada de 150 metros............................................................... 168

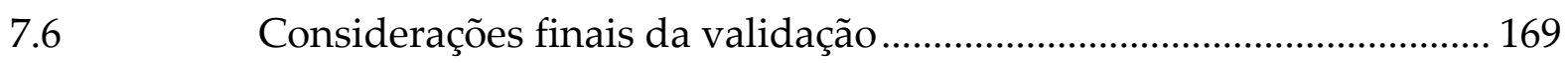

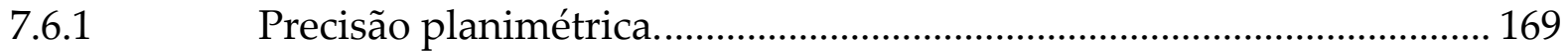

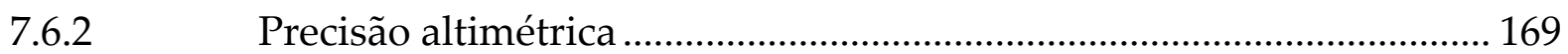

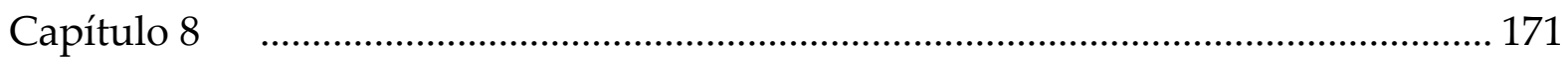

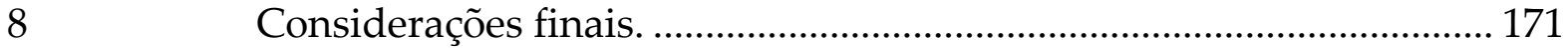

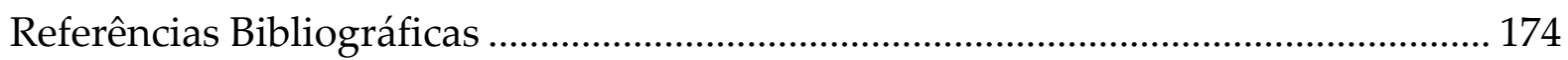

Anexo 1 - $\quad$ Progressão de cores RGB e HSV ........................................................... 179

Anexo 2 - $\quad$ Exemplos de reamostragem de imagem digita ..................................... 180

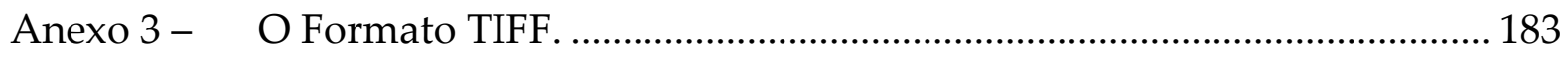

Anexo 4 - Certificado de calibração de câmara.......................................................... 193

Anexo 5 - $\quad$ Tabulação dos dados de validação.......................................................... 196 


\section{Siglas}

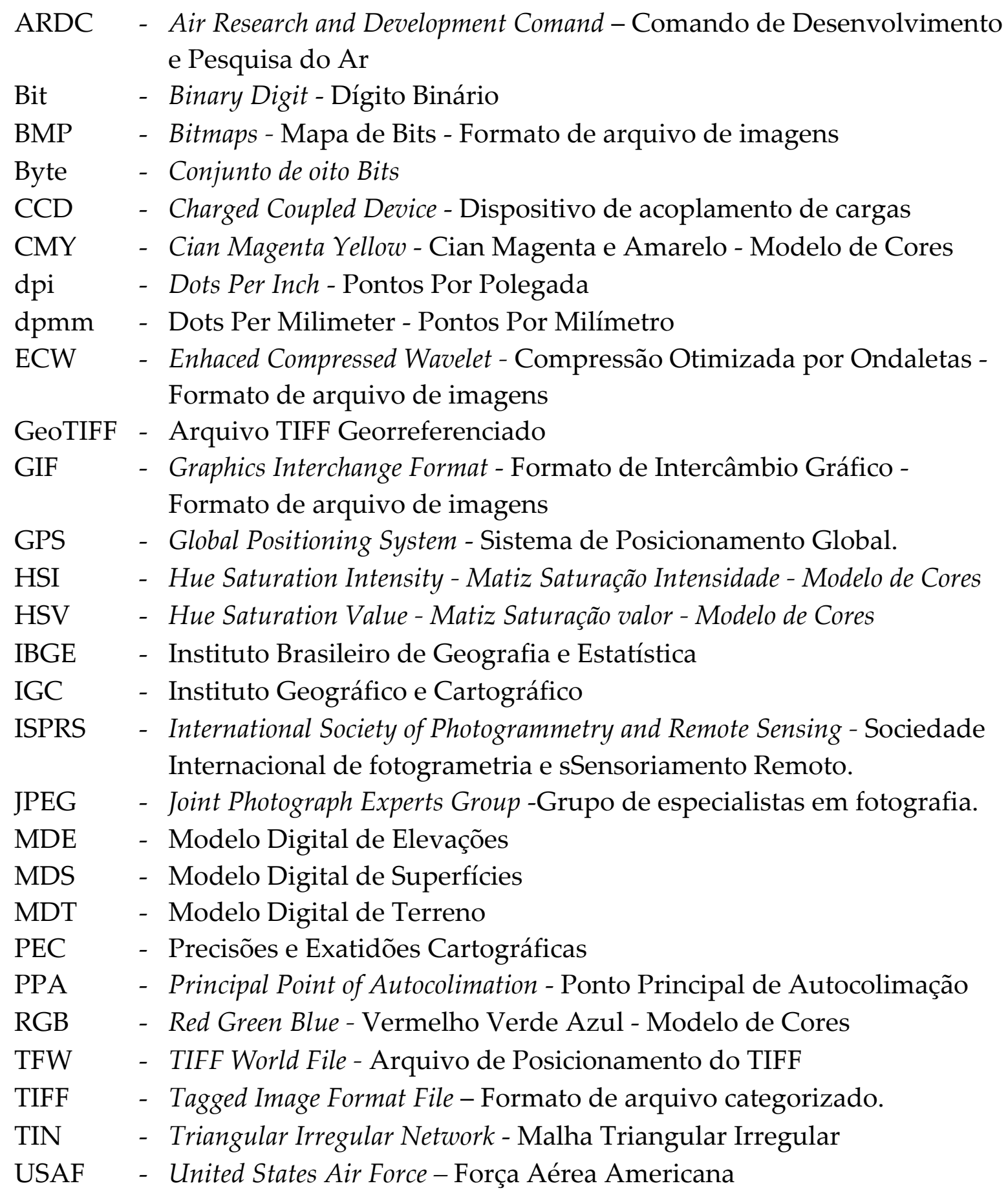




\section{Lista de figuras}

Figura 2.1 - Curvas de resposta dos sensores do olho humano (cones) em função do comprimento de onda. Adaptado de Wanderley (2002)

Figura 2.2 - Ilustração do modelo de cores aditivas RGB............................................ 23

Figura 2.3 - Ilustração do modelo de cores subtrativas CMY...................................... 24

Figura 2.4 - Representação do espaço vetorial RGB e CMY ......................................... 24

Figura 2.5 - Progressão de cores nos domínios RGB e HSV ....................................... 29

Figura 2.6 - Deslocamento da origem da imagem digital........................................... 31

Figura 2.7 - Forma da função $\operatorname{Sinc}(\mathrm{x})$ de reconstrução do sinal original ..................... 31

Figura 2.8 - Interpolação de uma mesma cena pelos três métodos de reamostragem.

(a) vizinho mais próximo; (b) bi-linear; (c) bi-cúbica................................ 33

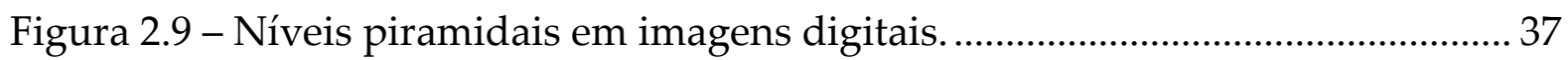

Figura 3.1 - Modelo digital de elevação representado em malha regular, em perspectiva isométrica........................................................................... 51

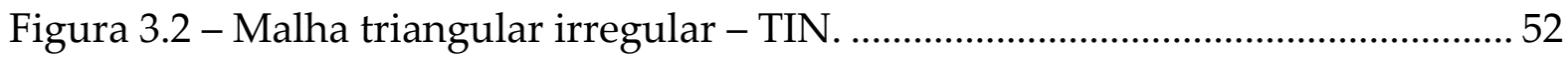

Figura 3.3 - Malha regular acrescida de feições de quebra vista de topo (a) e em

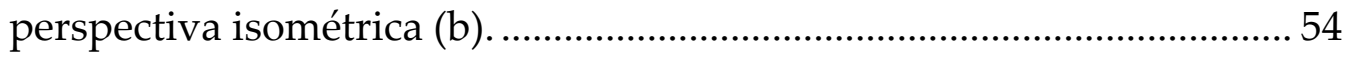

Figura 3.4 - Curvas de nível sem suavização e suavizadas............................................ 54

Figura 3.5 - Representação do MDE por mapas sombreados...................................... 55

Figura 3.6 - Mapa hipsométricos em cores. ................................................................... 56

Figura 3.7 - Mapa de curvas de nível sobre representação sombreada....................... 57

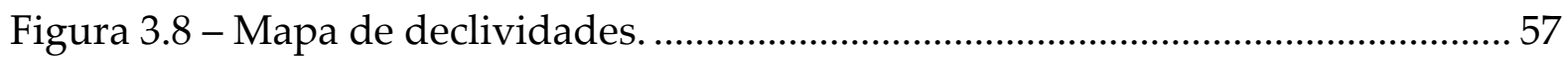

Figura 3.9 - Mapa de exposição de vertentes................................................................. 58

Figura 4.1 - Sistema de coordenadas fiduciais ou do fotograma................................ 61

Figura 4.2 - Desenho esquemático da incidência do raio óptico no conjunto de lentes de uma câmara aerofotogramétrica.

Figura 4.3 - Representação do sistema fotogramétrico................................................ 63

Figura 4.4 - Representação dos sistemas de imagem digital e fotogramétrico. .......... 64

Figura 4.5 - Desenho esquemático do princípio da colinearidade............................... 68

Figura 4.6 - Sistema de orientação do sensor........................................................... 71

Figura 4.7 - Desenho esquemático do efeito da refração atmosférica. .......................... 76 
Figura 4.8 - Desenho esquemático do efeito da curvatura terrestre........................... 79

Figura 4.9 - Deslocamentos na fotografia devido à altitude........................................ 85

Figura 4.10 - Deslocamentos na fotografia devidos a sua inclinação........................... 86

Figura 5.1 - Fluxograma das etapas do processo da metodologia apresentada......... 92

Figura 5.2 - Ilustração das janelas epipolares de comparação....................................... 96

Figura 5.3-Malha de busca no solo, simplificada. Na implementação da metodologia foram usadas malhas de 11x11 e 15x15 ................................................... 97

Figura 5.4 - Janela de busca no solo e suas respectivas janelas epipolares nas

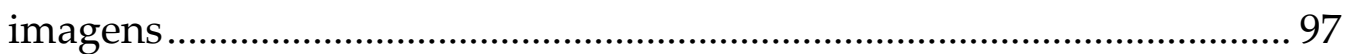

Figura 5.5 - Espaço de busca, ao longo da vertical. ..................................................... 100

Figura 5.6 - Variação da altitude de A, e respectiva variação ao longo da linha epipolar, do centro das janelas epipolares.............................................. 101

Figura 5.7 - Variação do índice de correlação em função da variação de altitude da posição planimétrica de A, indicando, onde é adotada a altitude HA em que ocorre o maior índice de correlação ................................................... 101

Figura 5.8 - MDE gerado a partir da busca em imagens piramidais. ......................... 104

Figura 6.1 - Esquema do apoio para a cobertura 1:25.000 …...................................... 114

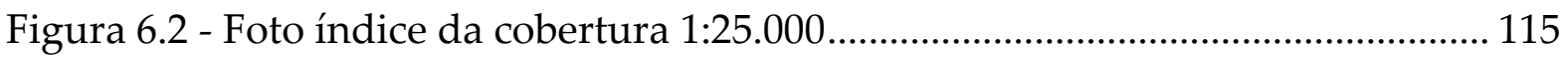

Figura 6.3 - Sobreposição das coberturas 1:25.000 e 1:5.000 e delimitação da área

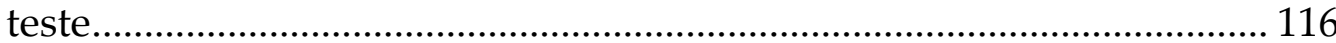

Figura 6.4 - Área teste e respectivas imagens em escala 1:25.000.............................. 117

Figura 6.5 - Modelo Digital de Elevação do modelo 0670_0669.................................. 119

Figura 6.6 - Modelo Digital de Elevação do modelo 0669_0668 .................................. 120

Figura 6.7 - Modelo Digital de Elevação do modelo 0668_0667 .................................. 121

Figura 6.8 - Modelo Digital de Elevação do modelo 0682_0683 ................................... 122

Figura 6.9 - Modelo Digital de Elevação do modelo 0683_0684 .................................. 123

Figura 6.10 - Modelo Digital de Elevação do modelo 0684_0685 ................................ 124

Figura 6.11 - Ortofoto da imagem esquerda do modelo 0670_0669........................... 125

Figura 6.12 - Ortofoto da imagem esquerda do modelo 0669_0668........................... 126

Figura 6.13 - Ortofoto da imagem esquerda do modelo 0668_0667.......................... 127

Figura 6.14 - Ortofoto da imagem esquerda do modelo 0682_0683 ........................... 128

Figura 6.15 - Ortofoto da imagem esquerda do modelo 0683_0684........................... 129

Figura 6.16 - Ortofoto da imagem esquerda do modelo 0684_0685........................... 130 
Figura 6.17 - Ortofoto da imagem direita do modelo 0684_0685 ............................... 131

Figura 6.18 - Mosaico geral do MDE produzido. .......................................................... 132

Figura 6.19 - Mosaico geral das ortofotos produzidas................................................ 133

Figura 6.20 - Visualização de amostra dos DSM de 3 modelos vizinhos pertencentes a uma mesma faixa de vôo, com exagero de cinco vezes na dimensão $Z$............................................................................ 135

Figura 6.21 - Curvas interpoladas a partir de MDE reamostrados de três modelos adjacentes.

Figura 6.22 - Visualização do MDE de modelos de faixas contíguas com exagero de cinco vezes na dimensão $Z$.

Figura 6.23 - Visualização da nuvem de pontos em uma amostra do MDE sendo que cada um de seus pixels é representado por um ponto no espaço. 136

Figura 6.24 - Detalhe da ortofoto em região de emenda de mosaicagem e ponte. .. 137

Figura 7.1 - Exemplos de pontos de controle bem definidos e extraídos da ortofoto 1:5.000 (visão em escala ampliada).

Figura 7.2 - Pontos de controle bem definidos extraídos da ortofoto 1:5.000........... 144

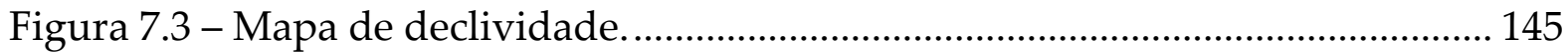

Figura 7.4 - Distâncias dos pontos de controle ao ponto de apoio mais próximo. .. 146

Figura 7.5 - Mapa das classes de criticidade amostrais segundo o índice calculado.

Figura 7.6 - Distribuição da amostra de 200 pontos de controle.

Figura 7.7 - Pontos do MDE com erros superiores a 5 metros. 162

Figura 7.8 - Pontos do MDE que apresentam erro entre 3 e 5 metros. 163

Figura 7.9 - Vista geral de pontos da amostra que apresentam erro inferior a 2.5 metros.

Figura 7.10 - Detalhe da amostra com erros inferiores a 2.5 metros em zona rural

Figura 7.11 - Detalhe da amostra com erros inferiores a 2.5 metros em zona urbana 


\section{Lista de quadros}

Quadro 4.1 - Detalhe de certificado de calibração onde se observa no item 2 os valores da distorção radial em função da distância do Ponto Principal.

Quadro 4.2 - Detalhe do certificado de calibração de câmara apresentando os valores dos parâmetros de distorção radial e descentrada.

Quadro 7.1 - Incertezas na definição de pontos de controle naturais.

Quadro 7.2 - Resumo dos parâmetros estabelecidos pela norma de controle de qualidade geométrica de documentos cartográficos.

Quadro 7.3 - Valor do PEC e EP sugeridos para a escala 1:5.000 para as respectivas classes.

Quadro 7.4 - Confrontação das observações feitas pelo operador F nas ortofotos geradas com medidas de referência.

Quadro 7.5 - Confrontação das observações feitas pelo operador A nas ortofotos geradas com medidas de referência.

Quadro 7.6 - Confrontação das observações feitas pelo operador AD nas ortofotos geradas com medidas de referência.

Quadro 7.7 - Confrontação das observações feitas pelo operador F nas ortofotos geradas com medidas de referência, sem a retirada do erro sistemático.

Quadro 7.8 - Confrontação das observações feitas pelo operador A nas ortofotos geradas com medidas de referência, sem a retirada do erro sistemático.

Quadro 7.9 - Confrontação das observações feitas pelo operador AD nas ortofotos geradas com medidas de referência, sem a retirada do erro sistemático.

Quadro 7.10 - Leituras retiradas do DSM, confrontadas com medidas altimétricas de referência 


\section{Resumo}

O presente trabalho propõe uma metodologia para a elaboração de modelos digitais de elevação e ortofotos, em média e pequena escala, de maneira automática, utilizando correlação de imagens digitais, a partir de fotografias aéreas métricas. Aborda conceitos básicos de Fotogrametria e correlação de imagens digitais, e lança o conceito da janela epipolar como ferramenta auxiliar na busca e correlação. Estas janelas permitem obter a máxima correlação simultânea entre duas ou mais imagens, como também a varredura em qualquer direção. Isso torna bastante robusto o método de elaboração dos produtos propostos. Esta metodologia foi implementada em um caso prático onde se utilizou uma cobertura aerofotogramétrica em escala 1:25.000. Os produtos foram validados, a partir de elementos de referência retirados de outra cobertura em escala 1:5.000. As precisões atenderam os requisitos do PEC Classe A para a escala 1:2.500 em planimetia, e intervalos de curvas de nível de 5 metros de eqüidistância, em altimetria 


\section{Abstract}

This work proposes a methodology for the production of digital elevation model and orthophotos on medium and small scales, with an automatic manner, using the concepts of digital image correlation. It presents basic fundamentals of photogrammetry and digital image correlation, and launches the concept of epipolar window like an auxiliary search and correlation tool. These windows allow the simultaneous multiple image correlation, in different direction scanning. This makes quite robust the production method of the proposed products. This methodology was implemented in a practical case, where 1:25.000 scale photogrammetric images were used. The products were validated using a 1:5.000 scale coverage as reference. The accuracy and precision achieved are into the Brazilian Cartography Standards as "Classe $A$ " for the 1:2.500 scale, in planimmetry, and 5 meter contour lines interval in altimetry. 


\section{Capítulo 1}

\section{Introdução}

\subsection{Apresentação}

A informação espacial atualizada do território é ferramenta indispensável para todo aquele que se propõe a realizar ações de planejamento, gestão e projetos de maneira eficaz e sustentada. Detalhando as tarefas em cada área, tem-se:

\section{Planejamento:}

Visão de futuro a partir do conhecimento das ocupações contemporâneas do território e as relações entre sociedade e o meio, com relação à infra-estrutura, meio ambiente, equipamentos sociais, circulação, armazenamento, serviços, abastecimento e logística.

\section{Gestão:}

Do território e dos elementos atuais de sua ocupação com vistas à preservação, recuperação e uso em benefício da sociedade. Levantamento de dados para planejamento futuro.

\section{Projetos:}

Levantamento das posições mais adequadas aos projetos de infra-estrutura, meio ambiente, equipamentos sociais, transportes, abastecimento, armazenamento e respectivos projetos básicos dimensionando os projetos executivos e obras.

Nestas três principais áreas de uso do mapeamento, uma ampla gama de usuários utiliza cartas de pequenas e médias escalas, que dentro do âmbito deste trabalho, que se insere nas engenharias, são aquelas menores ou iguais a 1:5 000 .

A produção de mapeamento nessas escalas, atualizados e confiáveis, é imprescindível para: Planos Diretores Municipais; Planejamento e Gestão Territorial; 
Transportes; Logística; Agropecuária; Florestal; Ambiental; Energético; Prevenção de Desastres; entre outros.

No Brasil existe uma grande carência de mapeamentos, nas diversas escalas. Por exemplo, para o Estado de São Paulo, existe o mapeamento em escala 1:50 000 (IBGE) de todo seu território, com fotos aéreas, em geral, da década de 60, e o 1:10 000 (IGC) de parte do estado, com fotos, na sua maioria, da década de 1970.

Uma das dificuldades de contar com mapeamento sistemático de todo o Estado, atualizado, e em escala mais adequada às finalidades básicas de planejamento, gestão e projetos básicos (1:5 000, por exemplo) é o tempo de produção pelos processos convencionais, e o respectivo valor do investimento necessário. É fácil quantificar o custo do mapeamento, porém é difícil quantificar, e fazer com que os indivíduos responsáveis pelas decisões entendam, o quanto custa não se ter os mapeamentos adequados, ou seja, qual o "Custo Malefício”, segundo o Prof. Irineu Idoeta, de não se ter disponível a informação.

Sendo assim o desenvolvimento de uma metodologia para a produção automatizada de Modelos Digitais de Elevações e Ortoimagens, proposta do presente trabalho, se justifica, pois vem ao encontro das necessidades atuais do país no uso de informações espaciais atualizadas e confiáveis, com presteza e custo acessível.

Esses produtos são úteis em si mesmos, exercendo em quase todos os casos as mesmas ou mais funções de um mapeamento de traços nessas escalas. Em todo o caso, a partir deles se pode gerar com facilidade mapeamentos no todo da área ou seletivamente em trechos, ou ainda, de feições relevantes e curvas de nível.

\subsection{Objetivo}

O objetivo específico do presente trabalho é o desenvolvimento de uma nova metodologia, com respectiva validação, para produção automatizada de modelo digital de elevações e ortoimagens de pequenas e médias escalas a partir de imagens 
aerofotogramétricas, com vistas a atender a crescente demanda de informações espaciais atualizadas e confiáveis, com presteza e custo acessível.

Essa metodologia utiliza a correlação de imagens com o uso de janelas epipolares, realizando uma busca, mantendo-se fixa a posição horizontal e variando a altura até a obtenção de máxima correlação.

A tese que se pretende comprovar é que a metodologia proposta, da utilização de correlação entre janelas epipolares de duas, ou mais, imagens aerofotogramétricas digitais, é eficaz para a elaboração de produtos que atingem os elementos de qualidade (PEC) previstos para os correspondentes mapeamentos nas escalas de 1:5000 e menores.

\subsection{Justificativa}

O presente trabalho justifica-se, em termos de contribuição inédita, pelo fato de apresentar uma nova metodologia para a geração de modelo digital de elevação MDE e ortofoto, em escala média, com resultados plenamente satisfatórios. O fato de serem gerados automaticamente reduz drasticamente o tempo e custo de produção. Até o presente momento não foi encontrada no meio acadêmico uma proposta nesse sentido e que tivesse detalhado os passos e mostrado produtos que atendessem os requisitos cartográficos pertinentes.

O embasamento teórico e a implementação prática são bastante simples e todo o material gerado foi validado através de outros produtos mais precisos, obtendo-se PEC classe A em planimetria até a escala de 1:2 500, e também classe A em altimetria até o intervalo de 5 metros entre as curvas de nível.

Procurou-se ao longo do presente trabalho ser bastante objetivo, no sentido de descrever da forma mais breve possível cada item, sem apresentar pesquisas correlatas e úteis para trabalhos futuros, mas que não possuam relação ou aplicação imediata com o assunto em questão. 
Parte I - Conceitos Básicos 


\section{Capítulo 2}

Nesta divisão serão apresentados somente os conceitos teóricos utilizados na presente tese, todos eles relativamente simples e disponíveis em livros e artigos publicados.

\section{Conceitos sobre imagens digitais.}

Imagem digital é uma representação discreta de uma imagem em uma matriz bidimensional finita onde a cada elemento, denominado de Pixel (abreviatura de Picture Element) é associado um ou mais valores (SCHENK, 1999). Então, define-se uma imagem digital como uma matriz $H$, bidimensional, com $l \times c$ elementos $h_{l c}$. Cada elemento da matriz $H$, $h_{l}$, é denominado de elemento de imagem ou pixel. Nessa matriz $H$ as linhas têm o índice $l$, indo de 1 a $L T$, e as colunas o índice $c$, indo de 1 a $C_{T}$, onde $L_{T}$ e $C_{T}$, são os valores totais de linhas e de colunas, respectivamente. Cada elemento da matriz, o pixel, recobre uma área $\Delta x$ por $\Delta y$, onde $\Delta x$ é o tamanho do elemento na direção das colunas e $\Delta y$ na das linhas, que podem ser iguais ou não. Cada pixel tem sua localização definida na matriz que representa a imagem por um sistema de coordenadas $(l, c)$. Dessa forma o sistema de coordenadas permite a identificação do pixel.

\subsection{Resolução espacial de uma imagem digital.}

Costuma-se falar das resoluções espacial, radiométrica, espectral e temporal. Com relação à primeira quanto menor $\Delta x$ e $\Delta y$, menor será o tamanho do pixel, e, conseqüentemente maior a resolução espacial da imagem. Ou seja, pode-se dizer que a resolução espacial é o número de elementos contido numa determinada medida linear. Sendo assim pode-se afirmar que quanto maior a resolução espacial de uma imagem digital, maior será o número de pixels, menor o tamanho dos mesmos, e, por conseguinte, mais esta se aproximará da imagem a que deve representar. Devese lembrar que, em contrapartida, quanto maior a resolução geométrica de uma 
imagem digital maior será o número de elementos para armazená-la, e maiores os arquivos digitais, o que afeta sua manipulação e tempo de processamento.

A resolução espacial, em imagens digitais, tem duas unidades de representação: a primeira por número de elementos numa determinada unidade linear, como dpi (dots per inch) ou dpmm (dots per millimeter), ou seja, pontos por polegada ou pontos por milímetro; a segunda expressa pela dimensão dos lados do elemento, em Fotogrametria usualmente dada em micrômetros $(\mu \mathrm{m})$.

\subsection{Exatidão posicional de uma imagem digital.}

O fato de uma imagem apresentar uma grande resolução, não significa que apresente uma grande exatidão posicional. Esta última refere-se à diferença de posição que um elemento da matriz encontra-se com relação a seu homólogo na imagem que representa. Quanto menor esta diferença posicional, melhor a exatidão da imagem digital.

Em escâneres fotogramétricos, a exatidão posicional é determinada por meio de calibração, e usualmente apresenta valores padrão inferiores a $3 \mu \mathrm{m}$.

\subsection{Resolução radiométrica de uma imagem digital.}

Outro conceito importante é a resolução radiométrica. Este está ligado ao número de níveis que o valor de um pixel pode assumir para apresentar o brilho da imagem, ou a intensidade de uma determinada banda. Usualmente um ser humano consegue distinguir até sessenta e quatro níveis de intensidade por cor (desde que esses níveis estejam localizados um ao lado do outro), (ROSALEN, 1997). Uma variável computacional ocupa 1 byte (8 bits), que pode assumir assim 256 níveis $\left(2^{8}\right)$. Sendo assim, por razões práticas, a resolução radiométrica usual é de 8 bits ou 256 níveis, para imagens monocromáticas, ou por banda. Ainda que algumas imagens possuam maior ou menor resolução, por exemplo, as imagens da câmara aerofotogramétrica digital modelo ADS 40 da Leica, com doze bits $\left(2^{12}\right)$. 
Quanto maior a resolução radiométrica, mais fiel será a imagem digitalizada em relação à imagem original no tocante a sua coloração. Porém, obviamente, quanto melhor essa resolução maior será o tamanho em bytes da imagem obtida, pois cada pixel ocupará um maior número de bits para traduzir essa informação pictórica.

\subsection{Tipos de imagens digitais e resolução espectral.}

Usualmente utilizam-se em Fotogrametria três tipos de imagem: imagens binárias; imagens em tons de cinza e imagens multi-espectrais.

Imagens binárias são aquelas em que a resolução radiométrica é de dois níveis, ou seja, um bit. São utilizadas em processos computacionais, geralmente transparentes aos usuários.

Imagens em tons de cinza são imagens que representam apenas a luminosidade da cena captada, geralmente denominadas de "preto e branco". Muitas das vezes são utilizadas para representar outras grandezas, tais como altitudes, declividades, intensidades, etc.

Imagens multi-espectrais são imagens em que a cada elemento é associado um conjunto de valores que representam diferentes bandas do espectro eletromagnético, ou outras grandezas.

As imagens coloridas encontram-se neste grupo. A cada pixel são associados os valores da intensidade de cada uma das bandas espectrais que representam as cores primárias, vermelho $R$, verde $G$, e azul B. São as imagens RGB, nas siglas em inglês.

Note-se que quanto maior o número de bandas (ou canais) de uma imagem maior será o número de elementos para armazená-la. 


\subsection{Espaço de cores.}

Os conceitos aqui apresentados foram extraídos e adaptados de Adelson (2000), Folley e Van Dam (1982), Oleari (1996), Sangewine e Horn (1998) e Wanderley (2002).

O ser humano percebe a cor por sensores em seus olhos, que são células fotosensíveis, denominadas de cones. Estas apresentam três curvas de resposta em relação ao comprimento de onda visível: $S_{1}(\lambda), S_{2}(\lambda), S_{3}(\lambda)$, que são a do vermelho, verde e azul, feitas pelos cones L, M e S respectivamente. A figura 2.1 ilustra essas curvas de resposta.

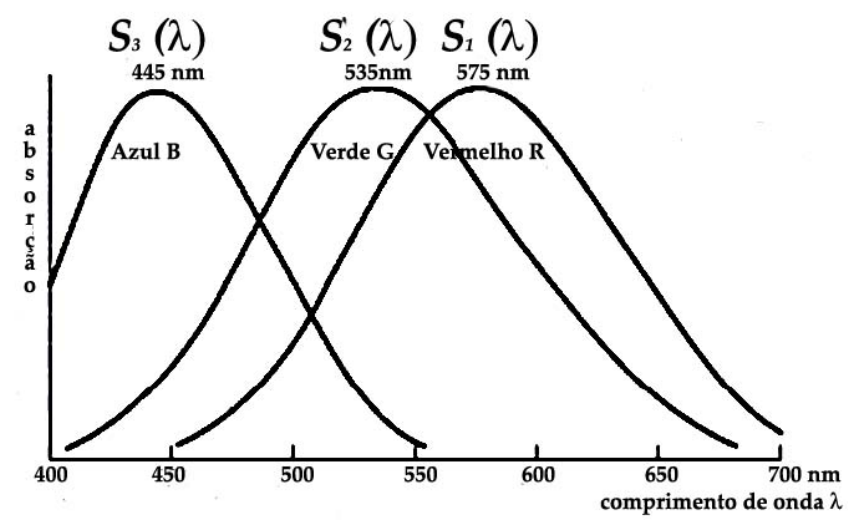

Figura 2.1 - Curvas de resposta dos sensores do olho humano (cones) em função do comprimento de onda. Adaptado de Wanderley (2002).

As cores são entendidas, então, como uma combinação variada das cores primárias, conhecidas como aditivas, vermelho, verde e azul (R,G,B). Esse processo aditivo, onde a soma de todas as máximas intensidades resulta no branco, é utilizado em TV, monitores, câmaras digitais, enfim, em todos os dispositivos que, trabalhando com imagens, emitem ou captam luz no seu espectro visível.

Quando se trata de absorção, como no caso de pigmentação, as partículas absorvem a componente de um determinado comprimento de onda e refletem as outras. Neste caso a máxima pigmentação em todas as componentes resulta na cor 
negra. Este processo é utilizado em pinturas, impressões e filmes. Aqui as cores primárias são conhecidas como cian, magenta e amarelo (C,M,Y), complementares do vermelho, verde e azul, respectivamente.

Para que se represente, matematicamente, este conceito, lança-se mão do espaço de cores.

Espaço de cores (também sistema de cores ou espectro de cores) é um modelo abstrato matemático para formalizar a descrição de cores através de conjunto de números, tipicamente formadas por três ou quatro elementos.

Um espaço de cor pode ser visto como um sistema definido por uma base representativa das componentes, de acordo com a definição do espaço considerado. A representação de qualquer cor pode então ser feita por meio de combinação dessas componentes.

O modelo matemático adequado para uma representação do espaço espectral de cor é um espaço vetorial de dimensão finita. O processo de reconstrução de cor utiliza uma base de cores primárias. Há várias maneiras de escolha dessas bases para um espaço de representação de cores, o que permite diversas possibilidades para a definição de seus sistemas de coordenadas, ampliando seu uso em inúmeras atividades, inclusive em Computação Gráfica.

\subsubsection{RGB.}

O modelo tricromático de Young-Helmholtz estabelece que o sistema de processamento de cor do olho humano é baseado na amostragem das faixas vermelha (Red), verde (Green) e azul (Blue) do espectro visível, que é feita pelas células foto-sensíveis do olho. Assim é natural que se busque uma representação tridimensional do espaço de cor, cuja base de cores primárias seria constituída por três cores nas faixas espectrais visíveis do vermelho, verde e azul. Onde, por exemplo, $\operatorname{RGB}(0,0,0)$ é a ausência de cor, $\operatorname{RGB}(100 \%, 0,0)$ é a cor da componente vermelha (R), $\mathrm{RGB}(100 \%, 100 \%, 100 \%)$ é o branco. A figura 2.2 mostra a mistura 
aditiva das cores primárias, vermelho, verde e azul, formando as secundárias, cian (verde mais azul), magenta (vermelho mais azul), amarelo (vermelho mais verde) e o branco (vermelho mais verde mais azul).

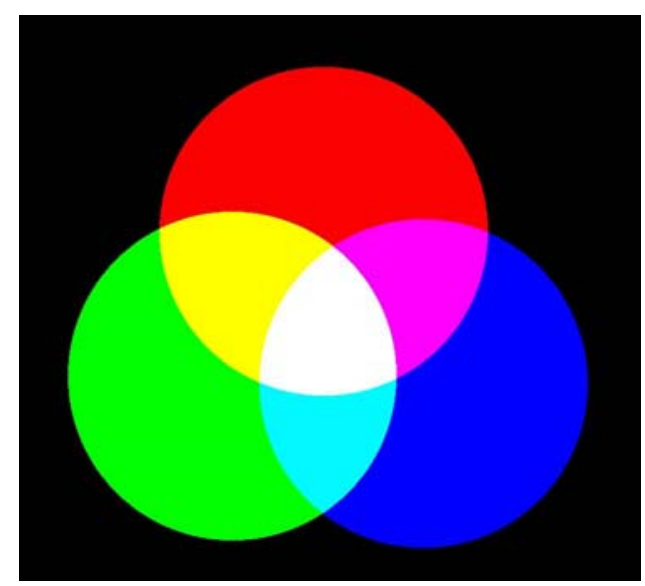

Figura 2.2 - Ilustração do modelo de cores aditivas RGB.

\subsubsection{CMY.}

O sistema CMY (cian, magenta e amarelo) é um modelo subtrativo apropriado para absorção de cores. Ao contrário do modelo RGB que determina qual o valor que será adicionado à cor negra para que se alcance uma cor, o CMY determina qual o valor que se subtrai do branco para nela se chegar. Nesse caso, as cores primárias subtrativas são o cian, magenta e amarelo.

As cores secundárias nesse sistema são o vermelho, verde e azul. Quando se ilumina com luz branca uma superfície coberta por pigmentos cian, a luz vermelha não é refletida, similarmente isso acontece com o magenta e o verde e com o amarelo e azul.

Sendo o CMY um espaço complementar do RGB, sua relação com este pode ser escrita pela equação 2.1 :

$$
\left[\begin{array}{c}
C \\
M \\
Y
\end{array}\right]=\left[\begin{array}{l}
1 \\
1 \\
1
\end{array}\right]-\left[\begin{array}{l}
R \\
G \\
B
\end{array}\right]
$$


Analogamente ao feito para o domínio RGB, mostram-se na figura 2.3 as cores primárias subtrativas cian, magenta, e amarelo, sobre uma superfície branca, formando as cores, aqui secundárias, vermelho, verde e azul, e o preto.

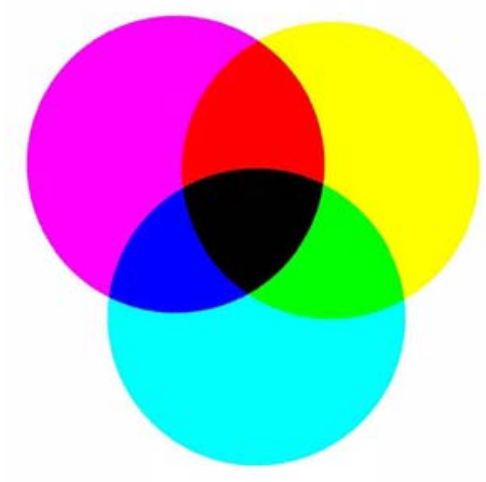

Figura 2.3 - Ilustração do modelo de cores subtrativas CMY.

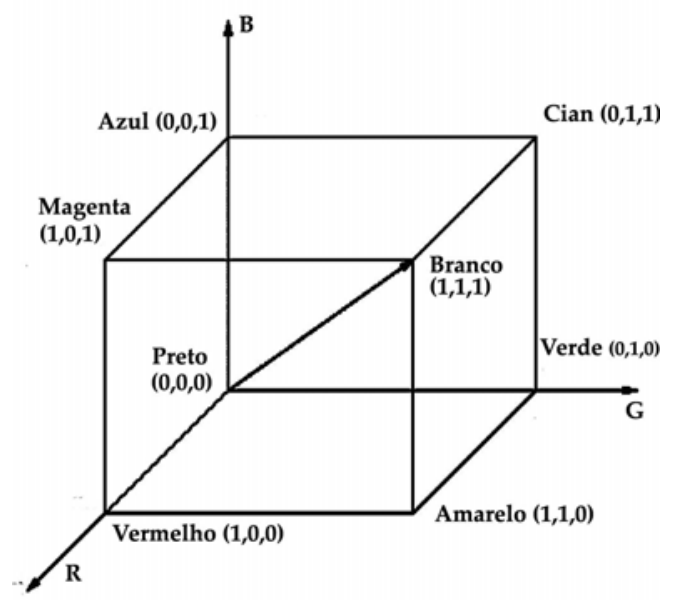

Figura 2.4 - Representação do espaço vetorial RGB e CMY.

\subsubsection{HSI.}

A descrição informal de cor pelo ser humano segue naturalmente suas capacidades de percepção que caracteriza a cor meio de seu matiz, saturação e brilho. Essa é uma das razões que fazem com que os sistemas de especificação de cor, em interfaces com o usuário, utilizem sistemas de cor com essas características.

A sigla HSI (Hue, Saturation and Intensity) significa Matiz, Saturação e Intensidade, também é conhecida como HSL (Hue, Saturation and Luminosity) onde L é a luminosidade. 
Define-se, aqui, um espaço de cores em termos de três componentes, Matiz, Saturação e Intensidade, onde:

Matiz (Hue) é conhecido coloquialmente como o tipo da cor. Significa em termos físicos, o comprimento de onda predominante do sinal. Tem como definição, neste domínio, uma variação angular onde a matiz a $0^{\circ}$ é o vermelho, a $120^{\circ}$ o verde e a $240^{\circ}$ o azul.

Saturação pode ser entendida como a pureza da cor, em analogia ao conceito de colorimetria, pureza de excitação. Relaciona-se com a dispersão das diversas componentes do sinal ao redor do comprimento de onda predominante, ou seja, com a quantidade de luz branca contida no sinal. Tem uma variação entre 0 e 1 . Quanto maior o valor da saturação, menor o espalhamento do sinal, e, por conseguinte, mais pura a cor, quanto menor, mais próximo de um tom de cinza.

Intensidade refere-se tipicamente à quantidade de energia do sinal recebido, normalizado em relação ao branco padrão. Tem sua variação entre os valores de 0 a 1 , sendo o zero referente ao preto, e o 1 , ao branco.

A intensidade é geralmente utilizada para a obtenção dos tons de cinza da imagem. A componente da cor, ou a cromaticidade, é dada, neste domínio, pela combinação polar do valor angular do matiz e do valor modular da intensidade.

Este domínio é bastante utilizado na inserção de cores, advindas de imagens de menor resolução, em imagens pancromáticas mais definidas. Essa operação é usualmente feita em imagens satelitárias, câmaras digitais e mesmo em alguns escâneres. É de simples implementação, bastando adotar para cada pixel da nova imagem colorida, o valor da intensidade do pixel da imagem pancromática de alta definição, e, para a cromaticidade, os valores interpolados do matiz e da saturação.

A transformação do domínio HSI para o domínio RGB é não linear, e pode ser vista nas equações de 2.2 a 2.5 : 
Quando $S=0$, ou $I=1$ ou $I=0$, não tem sentido o valor de $H$, adotando-se então nesses casos $H=0$.

$$
\begin{aligned}
& I=\frac{(R+G+B)}{3} \\
& {\left[\begin{array}{l}
u \\
v
\end{array}\right]=\left[\begin{array}{lll}
\frac{1}{-\frac{1}{2}} & -\frac{1}{2} \\
0 & \frac{\sqrt{3}}{2} & -\frac{\sqrt{3}}{2}
\end{array}\right] \cdot\left[\begin{array}{l}
R \\
G \\
B
\end{array}\right]} \\
& H=a \tan 2(u, v) \frac{180}{\pi} \\
& S=\sqrt{v^{2}+u^{2}}
\end{aligned}
$$

Onde atan2 é a função que retorna a tangente de um ângulo formado por duas componentes, e tem seu valor variando entre $\pi$ e $-\pi$. Na equação $2.4, H$ é dado, então, em graus decimais, e varia de $-180^{\circ}$ a $180^{\circ}$. I é a intensidade, $u$ e $v$ são as componentes do vetor do sinal, ortogonais a $I$, e $S$ é a saturação.

Para que se retorne do domínio HSI para o RGB, são utilizadas as equações 2.6 e 2.7 :

$$
\begin{aligned}
& v=S \cos (H) \\
& u=\operatorname{sen}(H) \\
& {\left[\begin{array}{l}
R \\
G \\
B
\end{array}\right]=\left[\begin{array}{ccc}
1 & \frac{2}{3} & 0 \\
1 & -\frac{1}{3} & \frac{1}{\sqrt{3}} \\
1 & -\frac{1}{3} & -\frac{1}{\sqrt{3}}
\end{array}\right] \cdot\left[\begin{array}{l}
I \\
v \\
u
\end{array}\right]}
\end{aligned}
$$

Note-se que aqui, os valores de R, G, B, I, e $S$, variam de 0 a 1, e o matiz $\mathrm{H}$ varia de $-180^{\circ}$ a $180^{\circ}$. Quando extraídos de valores discretos de imagem, estes têm suas variações de 0 a 255 (no caso de 8 bits por canal), logo, é preciso normalizar os valores para sua utilização nas equações acima. 


\subsubsection{HSV.}

O modelo HSV (hue, saturation, value), também conhecido como HSB (hue, saturation, brightness), que significa matiz, saturação e valor ou brilho, respectivamente, define um espaço de cores com respeito a essas características.

Foi criado em 1978 por Alvy Ray Smith, e representa uma transformação não linear do RGB, com utilidade apenas em progressão de cores, sem nenhuma definição física para a cromaticidade obtida. Trata-se de um domínio que, aos olhos acurados de artistas, representa cores intermediárias (ou obtidas por interpolação) mais próximas daquelas por eles percebidas.

É utilizada na representação final de trabalhos artísticos e animação gráfica, não podendo ser empregada em produtos intermediários por apresentar perdas importantes nas características do sinal recebido.

O matiz, $H$, representa o tipo da cor; a saturação, $S$, a pureza; o valor, $V$, a moda do sinal, ou seja, o maior valor, no domínio RGB, recebido. A transformação do domínio RGB para o HSV pode ser vista nas equações a seguir:

$$
\begin{aligned}
& M=\max (R, G, B) \\
& m=\min (R, G, B)
\end{aligned}
$$

Quando $M=m$, então $H$ não tem significado e adota-se $H=0$.

Quando $M=R$ e $G \geq B, \quad H=60 \frac{G-B}{M-m}$

Quando $M=R$ e $G<B, \quad H=60 \frac{G-B}{M-m}+360$

Quando $M=G$,

$$
H=60 \frac{B-R}{M-m}+120
$$

Quando $M=B$

$$
H=60 \frac{R-G}{M-m}+240
$$

Quando $M=0$,

$$
S=0
$$




$$
S=1-\frac{m}{M}
$$

$V=M$

Onde $M$ e $m$ são o máximo e o mínimo valores entre $R, G$ e $B$, respectivamente; $H$ é o matiz, em graus decimais; $S$ a saturação e $V$ o valor.

A transformação de HSV em RGB é dada pelas equações 2.12 a 2.16:

$$
\begin{aligned}
& h=I N T\left(\frac{H}{60}\right) \\
& f=\frac{H}{60}-h \\
& p=V(1-S) \\
& q=V(1-f S) \\
& t=V[1-(1-f) S]
\end{aligned}
$$

Se $\quad h=0 \Rightarrow R=V, G=t, B=p$

Se $\quad h=1 \Rightarrow R=q, G=V, B=p$

Se $\quad h=2 \Rightarrow R=p, G=V, B=t$

Se $\quad h=3 \Rightarrow R=p, G=q, B=V$

Se $\quad h=4 \Rightarrow R=t, G=p, B=V$

Se $\quad h=5 \Rightarrow R=V, G=p, B=q$

Para que se tenha uma idéia, a visualização de uma progressão de cores, partindo de $(\mathrm{RGB})=(225,108,37)$ e chegando a $\operatorname{RGB}(40,94,21)$, nos domínios RGB e HSV pode ser vista na figura 2.5. Seu cálculo pode ser visto no anexo 1. Note-se que as cores intermediárias, a penetração e a transição são bastante diferentes. 


\section{Progressão no domínio RGB}

\section{Progressão no domínio HSV}

Figura 2.5 - Progressão de cores nos domínios RGB e HSV.

\subsection{Reamostragem.}

Os conceitos aqui apresentados foram extraídos e adaptados de Wolf e Dewitt (2000) e do MANUAL OF REMOTE SENSING - ASPRS (1983) (Manual de Sensoriamento Remoto da Sociedade Americana de Fotogrametria e Sensoriamento Remoto)

O problema da reamostragem é de obter, a partir de uma amostra discreta, valores intermediários da grandeza que se observa. No caso de imagens digitais, que são amostras de uma realidade, são conhecidas intensidades de sinais refletidos em

uma ou mais bandas, dadas por valores discretos, dispostos em uma malha. É comum a necessidade de conhecer o valor da intensidade em uma posição arbitrária qualquer, intermediária a esses valores discretos. Para isto, diversos modelos estimadores são empregados, sendo que os mais usuais são: o vizinho mais próximo; o bi-linear e o bi-cúbico; que são apresentados a seguir.

\subsubsection{Vizinho mais próximo.}

A interpolação pelo método do vizinho mais próximo é a mais simples das três. Como seu próprio nome diz, o valor adotado para uma posição intermediária é aquele cujo centro do pixel é o mais próximo dela. Para tanto, basta tomar os valores 
de linha e coluna desse pixel mais próximo, e adotar o seu nível digital para a posição intermediária.

\subsubsection{Bi-linear.}

O método de interpolação bi-linear leva em conta os valores dos quatro pixels que envolvem a posição intermediária em questão. Em seguida efetua-se uma interpolação linear em ambas as direções. Neste caso tem-se:

$$
\begin{array}{ll}
f(x)=1-x & \text { para } 0 \leq x \leq 1 \\
f(x)=0 & \text { para } x>1
\end{array}
$$

$f(x)$ é o peso que se deve adotar para a posição, e $x$ é o afastamento do ponto em relação ao vizinho, numa determinada componente.

$$
V=\left[\begin{array}{ll}
P c_{1} & P c_{2}
\end{array}\right] \cdot\left[\begin{array}{ll}
V_{11} & V_{12} \\
V_{21} & V_{22}
\end{array}\right] \cdot\left[\begin{array}{l}
P l_{1} \\
P l_{2}
\end{array}\right]
$$

Onde,

$V$ é o valor do pixel, de uma posição intermediária, que se deseja determinar;

$P c_{1}, P c_{2}, P l_{1} e P l_{2}$ são os pesos obtidos por meio de $f(x)$, para a coluna anterior e posterior, e para a linha superior e inferior, respectivamente;

$V_{11}, V_{12}, V_{21}, V_{22}$, são os valores dos pixels vizinhos superiores esquerdo e direito e inferiores esquerdo e direito respectivamente.

É preciso levar em conta, aqui, o deslocamento da origem da imagem digital, que é um problema de referencial. Por exemplo, o centro do pixel 0 é 0.5, em cada direção. Para um ponto $A$, qualquer, localizado numa posição intermediária $c_{a} e l_{a}, o$ afastamento $x$ será: $x=\operatorname{abs}[c a-(c n+0.5)]$ para as colunas e $x=\operatorname{abs}\left[(l a-(l m+0.5)]\right.$, onde $c_{n} e$ $l_{n}$, são os valores da coluna e da linha anterior e superior da posição fracional em questão. Pode-se visualizar esse problema na figura 2.6. 


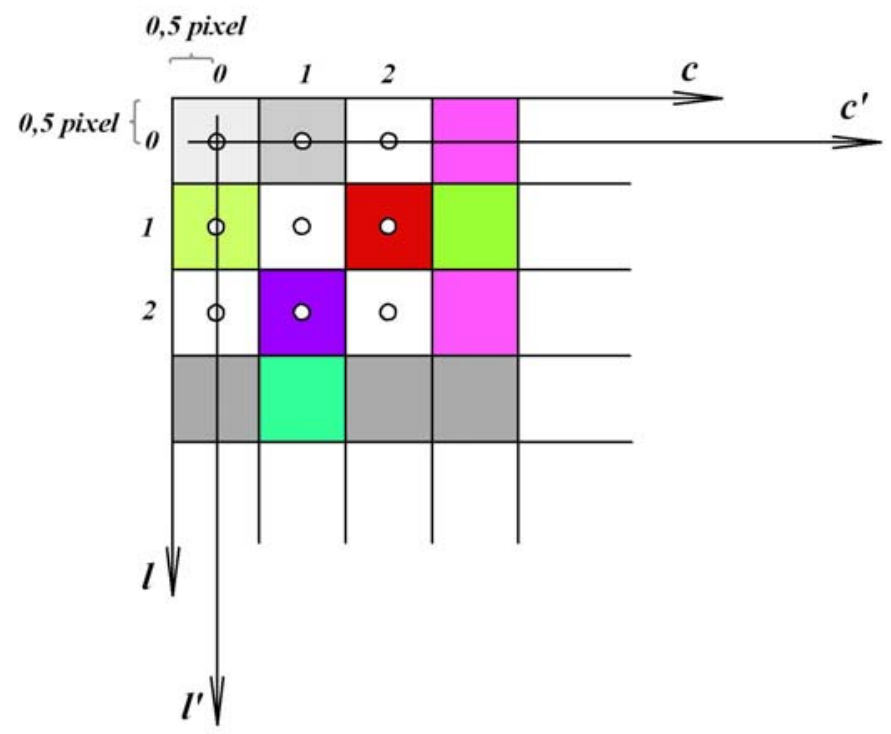

Figura 2.6 - Deslocamento da origem da imagem digital.

\subsubsection{Bi-cúbica.}

A interpolação bi-cúbica, também conhecida como convolução cúbica, é o terceiro método, entre os mais freqüentemente utilizados, aqui apresentado.

O seu entendimento requer conhecimentos de teoria amostral. Assume-se que o sinal original tenha sido amostrado segundo o princípio de Nyquist, o que geralmente é satisfeito por sensores digitais. O princípio de Nyquist diz que a freqüência de amostragem deve ser suficiente para registrar a mais alta freqüência a ser amostrada. No caso de imagens digitais, a resolução espacial deve ser superior à maior variação contida na cena. Assumido isto, a função $\operatorname{Sinc}(x)$ permite uma quase exata reconstrução do sinal original, que no caso da imagem digital, é a cena original.

$$
y=\sin c(x)=\frac{\operatorname{sen}(\pi x)}{\pi x}
$$

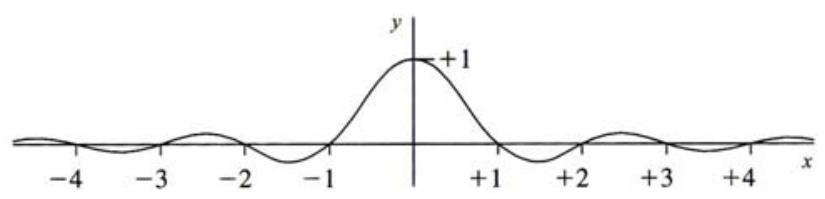

Figura 2.7 - Forma da função $\operatorname{Sinc}(x)$ de reconstrução do sinal original 
A função $\operatorname{Sinc}(x)$ é apresentada na equação 2.19, e sua representação cartesiana na figura 2.7. Verifica-se ali que se trata de uma função onde termos extremos interferem, mesmo que minimamente, para a reconstrução do sinal. $\mathrm{Na}$ prática, trabalha-se somente com a vizinhança mais próxima para interpolar o valor de um pixel. Nesse sentido uma aproximação da função $\operatorname{Sinc}(x)$ é feita por uma spline cúbica, de maneira a determinar o peso dos vizinhos na interpolação bicúbica. Assim as funções peso são apresentadas nas equações 2.20 e 2.21:

$$
\begin{array}{ll}
f_{1}(x)=(a+2) x^{3}-(a+3) x^{2}+1 & \text { para } 0 \leq x \leq 1 \\
f_{2}(x)=a x^{3}-5 a x^{2}+8 a x-4 a & \text { para } 1<x \leq 2 \\
f_{3}(x)=0 \quad \text { para } x>2 . &
\end{array}
$$

Onde $a$ é um parâmetro igual à inclinação da curva de peso para $\mathrm{x}=1$, e geralmente adotado como $a=-0.5$.

\subsubsection{Considerações sobre os três métodos.}

No anexo 2, pode-se analisar para uma determinada posição fracional de uma imagem digital, cujos valores dos pixels são fornecidos, os valores adotados pelos três métodos de interpolação aqui apresentados.

A interpolação pela técnica do vizinho mais próximo é a mais simples e rápida das três. Tem a vantagem em relação às outras de não modificar os valores da imagem original, o que é importante na área de classificação de imagens. No entanto o seu resultado implica numa imagem de aparência descontínua.

A interpolação bi-linear apresenta uma imagem de aparência mais contínua que a anterior. Porém, pela própria técnica empregada, filtra altas freqüências, gerando uma imagem sem definição de bordas.

A interpolação bi-cúbica, a mais rigorosa das três por se basear em técnicas de processamento de sinais, permite uma aparência contínua, sem sacrificar as altas 
freqüências, e, por conseguinte, definindo melhor os detalhes de borda. Essa melhor reamostragem exige, no entanto, um tempo de cálculo maior.

Para ilustrar o que aqui foi dito, apresenta-se na figura 2.8 um exemplo das três reamostragens para uma mesma cena. Visualiza-se, ali, acima e por três vezes, a imagem original. Em (a) a interpolação pelo vizinho mais próximo onde se verifica as descontinuidades das feições; em (b) a imagem interpolada pelo método bi-linear, onde se verifica a continuidade das feições e a falta de definição de bordas; e, em (c) a imagem interpolada pelo método bi-cúbico, onde se verificam a continuidade das feições e os sinais de alta freqüência, como bordas.
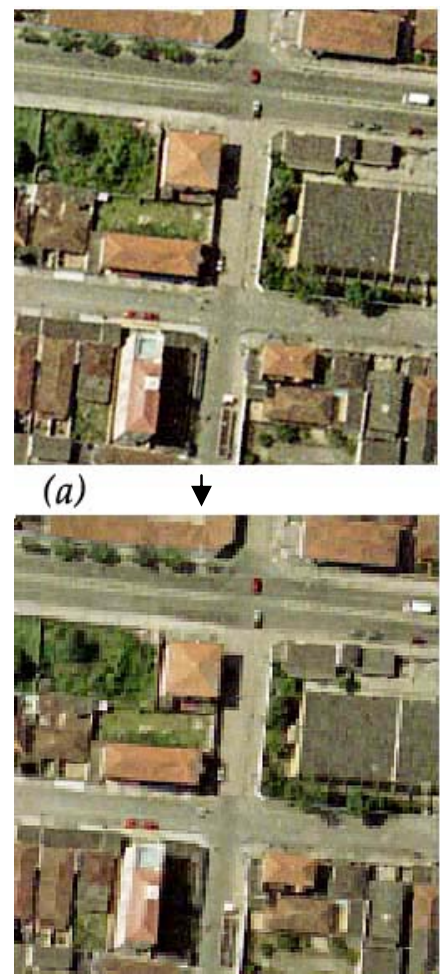

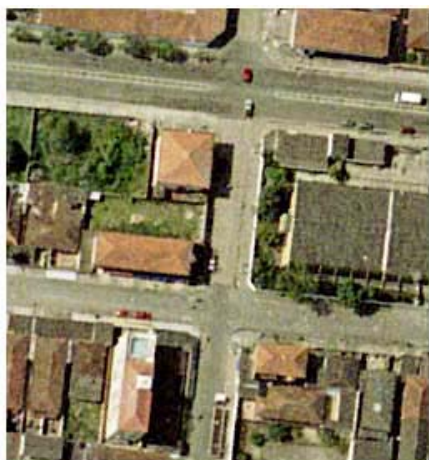

(b) $\downarrow$

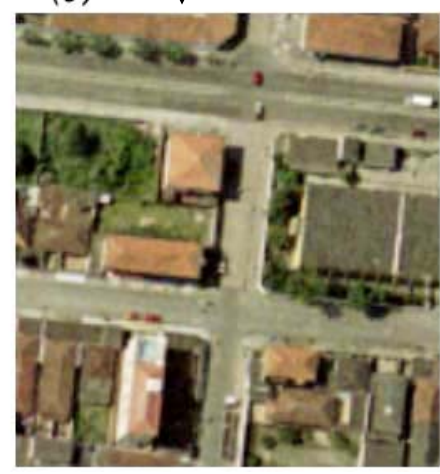

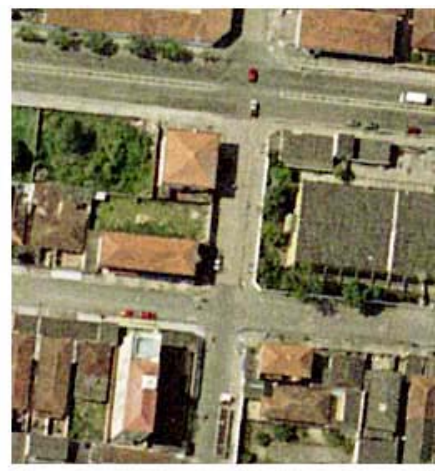

(c) $\downarrow$

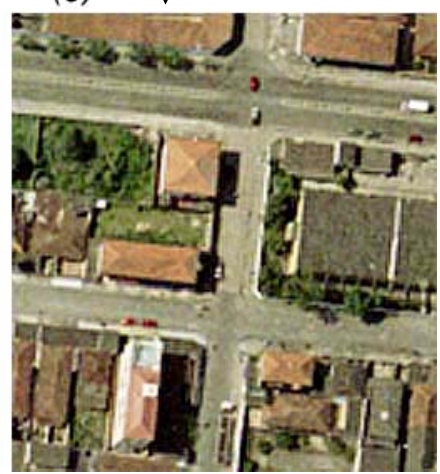

Figura 2.8 - Interpolação de uma mesma cena pelos três métodos de reamostragem. (a) vizinho mais próximo; (b) bi-linear; (c) bi-cúbica.

\subsection{Digitalização de imagens.}

A digitalização das imagens, em Fotogrametria, é feita de duas maneiras, a primeira, diretamente na aquisição das mesmas por meio de câmaras digitais, e a segunda, de maneira indireta, através de escanerização do filme aéreo. Atualmente, 
a utilização de câmaras digitais fotogramétricas começa a ser usual, porém, os sensores chamados de analógicos, que são as câmaras métricas a filme, ainda são os mais utilizados.

Quando a imagem é captada diretamente por câmaras digitais, é preciso conhecer sua geometria, que pode ser cônica ou de varredura. Quando se utilizam câmaras "analógicas", o filme é que capta a imagem, por meio do conjunto óptico mecânico das câmaras aerofotogramétricas de projeção cônica. Este filme, a seguir é digitalizado diretamente por meio de escâneres.

Tanto as câmaras digitais como os escâneres possuem o mesmo tipo de dispositivo transdutor, o CCD (charge coupled device- dispositivo de acoplamento de cargas) que é constituído num arranjo de diodos foto-sensíveis, também conhecidos como arranjos de estado sólido. A diferença principal entre uma câmara digital e um escâner encontra-se no sistema óptico, onde os mesmos são projetados para situações diversas. Por exemplo, uma câmara é utilizada para captar imagens a uma distância superior à do escâner. Outra diferença importante é que enquanto numa câmara a fonte de iluminação é externa, num escâner ela é interna, pois este necessita iluminar o filme.

Os escâneres utilizados em fotogrametria são equipamentos especialmente desenvolvidos para este fim e possuem alta resolução e grande precisão geométrica e radiométrica, pois a natureza dos trabalhos fotogramétricos assim o exige. O formato desse tipo de escâneres gira em torno de 250x250 mm, de forma a poder digitalizar perfeitamente os filmes originais fotogramétricos $(23 \times 23 \mathrm{~cm})$.

As distorções advindas do processo de digitalização das imagens podem ser agrupadas em dois grandes grupos: distorções relativas à geometria interna da imagem e distorções relativas às respostas radiométricas.

Dessa forma pode-se resumir que para a obtenção de uma qualidade adequada da imagem digital, três itens devem ser levados em conta: a qualidade 
geométrica obtida; a fidelidade à tonalidade ou às cores da imagem original e a resolução da imagem digital.

Quanto à qualidade geométrica, na fotogrametria analítica, a precisão alcançada pelos restituidores gira em torno de $\pm 3 \mu \mathrm{m}$, portanto é essa a ordem de grandeza que deve ser alcançada pelos escâneres quando o escaneio se faz a $10 \mu \mathrm{m}$, para resoluções menores necessita-se de qualidade geométrica melhor que um terço da dimensão do pixel.

Quanto à resolução das imagens, é um parâmetro relacionado com a qualidade do conjunto óptico e filme, que em câmaras analógicas de última geração apresentam resolução da ordem de 90 pares de linha por milímetro, ainda que muitas, que continuam a ser utilizadas, apresentam resolução da ordem de 50 a 60 pares de linhas por milímetro. Nesse sentido o processo de digitalização deve situarse, em teoria, na mesma faixa da imagem original, ou seja, com o tamanho do pixel variando de 10 a $20 \mu \mathrm{m}$. Deve-se lembrar que uma maior resolução espacial implica em um aumento quadrático do tamanho da imagem e que, alguns algoritmos de compressão de imagens digitais podem ser utilizados.

Quanto à reprodução de tonalidades ou cores, os escâneres devem manter uma qualidade próxima ao original fotográfico. Para isso pode-se utilizar algoritmos de compensação radiométrica, de maneira a aproximar a qualidade imagem digital àquela da cópia contato do filme quanto a este quesito.

\subsection{Pirâmide de imagens digitais.}

Os arquivos de imagens digitais são grandes para serem manipulados em computadores, exigindo-se assim, estratégias de busca e indexação que minimizem o tempo computacional para os cálculos.

O conceito de pirâmide de imagens digitais é uma estratégia de minimização de tempo e espaço de busca numa imagem digital, consistindo de acrescentar ao arquivo original, outros diretórios de arquivo imagem. 
Cada novo diretório imagem corresponde, nessa estratégia, a um nível da pirâmide de generalização. Assim, o nível 1 da pirâmide é considerado como sendo a imagem de máxima resolução, ou seja, aquela proveniente da digitalização feita por escâner, ou a original obtida pela câmara digital. O nível 2 da pirâmide é o segundo diretório do arquivo da imagem, o nível 3 da pirâmide é o terceiro e assim sucessivamente.

Os valores dos pixels do nível $n+1$ da pirâmide são obtidos seguindo os critérios:

- Cada 4 pixels da imagem do nível $n$ da pirâmide geram um pixel na imagem do nível $n+1$. Portanto o nível $n+1$ ocupa um espaço de armazenamento quatro vezes menor.

- O valor numérico do pixel de cada banda no nível $n+1$ da pirâmide corresponde à média aritmética dos quatro valores dos pixels correspondentes do nível $n$. Assim, por exemplo, o valor numérico do pixel $(0,0)$ do nível 2, corresponderá à média aritmética dos valores dos pixels $(0,0) ;(0,1) ;(1,0) ;(1,1)$; da imagem do nível 1 .

Para ilustrar o aqui explicado, apresenta-se a seguir a figura 2.9, que mostra os níveis piramidais de uma imagem digital obtida por escanerização de original fotogramétrico negativo.

Como se pode ver em Mikhail et al. (2001), teoricamente o ideal seria fazer-se uma filtragem, geralmente utilizando um filtro Gaussiano, para a posterior reamostragem, de maneira a garantir a passagem dos sinais de freqüências adequadas ao novo nível. Apesar disso, os modelos implementados, na prática, nos mais diversos sistemas fotogramétricos, são formados pela simples média e subamostragem, como no caso aqui apresentado e utilizado. 


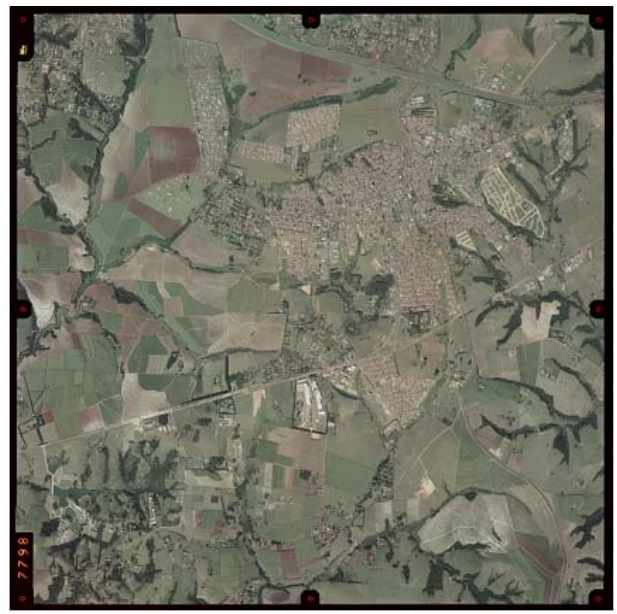

1:1

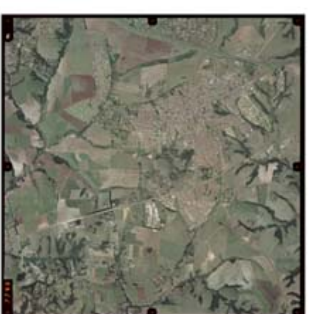

1:2

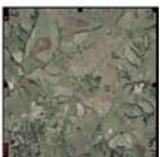

1:4
$1: 8$ 1:16

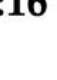

2

Figura 2.9 - Níveis piramidais em imagens digitais.

\subsection{Arquivos de imagens digitais.}

Os arquivos de imagens digitais são armazenados em formatos binários (arquivos raster), onde cada valor discreto dos pixels ocupa uma posição, a qual pode ser acessada por uma lógica pertinente à sua gravação. Dessa forma esses arquivos podem ser enviados para uma tela, para um armazenamento, para uma impressão ou mesmo para sua manipulação. O importante é que seus formatos permitem localizar o valor, ou os valores, de um determinado elemento da imagem.

Como já dito anteriormente, o aumento das resoluções espacial e radiométrica, implicam em aumento no tamanho do arquivo. Como as imagens possuem, freqüentemente, grandes áreas com cores, texturas e padrões uniformes, a aplicação de técnicas de compressão diminui o tamanho dos arquivos. Existem duas formas de compressão: a destrutiva e a não destrutiva, ou mais apropriadamente, com perdas e sem perdas, respectivamente.

A destrutiva, ou com perdas, é aquela em que a imagem obtida pela restauração dos dados comprimidos não é igual à imagem original. Por vezes, e 
dependendo da aplicação, essa perda é compensada pela alta taxa de compressão, e a conseqüente diminuição do arquivo.

A não destrutiva, ou sem perdas, é aquela em que a imagem reconstituída a partir dos dados comprimidos não se altera com respeito à imagem original.

Os arquivos de armazenamento de imagens digitais são estruturados basicamente em duas seções:

- Cabeçalho (header): onde se armazenam informações importantes como resolução, número de linhas e colunas, número de diretórios de imagens, posição e tipo de armazenamento e tamanho, entre outros.

- Mapa de bits: é a representação binária da tonalidade ou da cor em cada pixel. Em imagens coloridas são três mapas, que podem ser apresentados seqüencialmente pixel a pixel ou banda a banda.

Os principais tipos de arquivos gerados no processo de digitalização são:

- BMP (bitmap - mapa de bits) - tipo de arquivo utilizado pelo Windows; armazena os dados em mapas de bits, de forma independente do equipamento de saída, de maneira não comprimida.

- ECW (enhaced compressed wavelet - aumento de compressão por pequenas ondas) - formato criado pela ER Mapper, que usa técnicas avançadas de compressão por ondaletas. Trata-se de um formato aberto, com algoritmo disponível e forma de bibliotecas para programação em linguagem C, com capacidade de compactar imagens de até 500 MB.

- GIF (graphics interchange format - formato de intercâmbio gráfico) criado pela CompuServe, pode acomodar mais do que uma imagem por arquivo, é independente do equipamento de saída e não realiza compressão. De forma diferente de outros formatos, as informações nele contidas não estão vinculadas a posições dentro do arquivo, mas são 
baseadas em blocos descritores que, inclusos no cabeçalho, precedem às imagens.

- JPEG (joint photograph experts group - grupo de especialistas em fotografia) - também é independente do equipamento de saída, trabalha com 16 milhões de cores e possui um sistema de compressão destrutivo no qual se define a qualidade final relativa da imagem (em percentual) e a taxa de compressão é função disso.

- MrSid - formato de imagem desenvolvido pela LizardTech, utiliza-se de algoritmos de compactação de imagens por ondaleta. Até a razão de compactação de 2:1 chega a ser não destrutiva. Apresenta um formato onde a indexação é bastante eficaz em termos de busca posicional, e também com respeito a diferentes níveis de zoom.

- TIFF (tagged image format file - formato de arquivo categorizado) - criado pela Aldus Corporation para ser utilizado como intercâmbio de imagens entre programas e equipamentos. É passível de compressão e trabalha com 16 milhões de cores. Como é o formato utilizado na manipulação de imagens neste trabalho, um detalhamento de algumas de suas características, extraídas de Fernandes (2001) e de Eletrical Engineering Department of Cooper Union - EEDCU (1999) é apresentado no anexo 3.

\subsection{Correlação entre imagens digitais.}

Os conceitos, bem como a seqüência de fatos históricos, aqui apresentados foram extraídos e adaptados de Brito e Coelho (2002), Milone (2004) e Schenk (1999), aos quais se remete o leitor interessado num apanhado mais amplo do tema.

Em coberturas aerofotogramétricas, uma determinada feição no terreno é imageada de diferentes posições, e, por conseguinte, estará presente em duas ou mais imagens. Um dos problemas da fotogrametria é a localização dos homólogos dessa feição nos distintos fotogramas. 
Dotado de aparatos estereoscópicos, e visão treinada em foto-interpretação, um operador localiza tais pontos. Porém, é interessante a possibilidade de automatizar uma busca e localização dos mesmos. Para isto é necessário um processo que detecte a semelhança entre as regiões homólogas das distintas imagens.

Os primeiros trabalhos de determinação automática de entidades conjugadas foram feitos por Hobroug em 1959. A solução era análoga às atuais e a correlação entre os tons de cinza de duas imagens era feita através de hardware dedicado. Em 1968 a Wild Herbrug apresentou no congresso da ISPRS um instrumento inovador baseado nessa técnica, que à luz dos limitados conhecimentos e da tecnologia disponível na época, não alcançou muito sucesso, além de não se mostrar suficientemente flexível e confiável.

Do início dos anos setenta aos meados dos anos oitenta, foram feitas várias pesquisas relacionadas à comparação de imagens focadas em técnicas digitais de correlação. Em 1976, Kreiling estava entre os pioneiros na aplicação de correlação com a finalidade de geração de MDE e ortofotos digitais. Esforços continuaram a prover instrumentos de técnicas de correlação, como exemplo em 1978 o Helava e Hobrough. Apesar dos esforços, nenhuma solução geral foi encontrada. As pesquisas não conseguiram até o momento encontrar as regras que a mente humana utiliza para encontrar regiões conjugadas. Ainda que uma pessoa facilmente execute esta tarefa não se consegue traduzir isso em regras e algoritmos. Sabe-se, como mostraram Grimson em 1981 e Horn em 1983, que a vista estereoscópica humana não se utiliza, em absoluto, da correlação em tons de cinza, e este é apenas um exemplo da subestimação da complexidade das tarefas que o ser humano resolve facilmente.

Para que se modele o problema, métodos de correspondência em imagens conjugadas foram criados. 
Os métodos de correspondência são, basicamente, baseados em área, em feições, e em estruturas ou relações. O grau mais simples da medida da qualidade da correspondência entre entidades homólogas é a correlação. (SCHENK, 1999).

No presente trabalho foi explorada a correspondência em área que se mostra promissora em termos de robustez e precisão.

\subsubsection{Correspondência baseada em área.}

Uma vez que imagens digitais são amostras bidimensionais discretas de uma realidade, lança-se mão de conceitos estatísticos de avaliação do grau de dependência entre duas ou mais variáveis para medir a correspondência entre duas ou mais imagens.

Os coeficientes de inter-relação são adimensionais que derivam das relações possíveis entre as medidas de dispersão conjunta e individual das variáveis consideradas, acusando a tendência de elas oscilarem juntas (MILONE, 2004).

Nesse sentido tem-se:

- Coeficiente de determinação $\rho^{2}$ :

$$
\begin{aligned}
& \rho^{2}=\frac{\sigma_{x y}^{2}}{\sigma_{x}^{2} \sigma_{y}^{2}} \\
& \rho^{2}=\frac{\left[\sum\left(x-\mu_{x}\right)\left(y-\mu_{y}\right)\right]^{2}}{\left[\sum\left(x-\mu_{x}\right)^{2}\right]\left[\sum\left(y-\mu_{y}\right)^{2}\right]}
\end{aligned}
$$

- Coeficiente de correlação cardinal (ou de Pearson) $\rho$ :

$$
\begin{aligned}
& \rho=\sqrt{\rho^{2}}=\frac{\sigma_{x y}}{\sigma_{x} \sigma_{y}} \\
& \rho=\frac{\left[\sum\left(x-\mu_{x}\right)\left(y-\mu_{y}\right)\right]}{\sqrt{\left[\sum\left(x-\mu_{x}\right)^{2}\right]\left[\sum\left(y-\mu_{y}\right)^{2}\right]}}
\end{aligned}
$$


Nas quais, $x$ e $y$ são os valores dos elementos das amostras, e $\mu_{x}$ e $\mu_{y}$ são as médias das amostras.

Esses coeficientes variam entre -1 e 1, sendo que, quando negativo indica uma correlação inversa, e quando positivo, direta. Quando em valor absoluto se aproxima de 1, indica uma grande correlação, já quando se aproxima de zero, nenhuma.

Ainda segundo Milone (2004), é importante notar que o fato de as variáveis serem correlacionadas, não permite inferir jamais que entre elas haja qualquer relação do tipo causa-efeito. Tal relação só pode ser presumida com base nas características do evento com que se está tratando. Quem não observa esta restrição pode facilmente tomar por verdadeiras relações que inexistem.

Isto significa que, por vezes, pode-se estatisticamente estabelecer a correlação entre vizinhanças de regiões em distintas imagens que, aos olhos de um operador treinado em foto-interpretação ou até de um leigo, obviamente não existem, levandose a erros na determinação das posições homólogas.

Processos de minimização dessas ambigüidades serão apresentados na metodologia aqui proposta.

Outra notação para esse mesmo conceito é apresentado em Mikhail (2001), em que se apresenta como correlação normalizada, $N$, que leva em conta diferenças, normalizadas pela média e pelo desvio padrão, entre a variação de intensidade de duas regiões em distintas imagens. É mostrada na equação 2.26.

$$
N=\frac{\mu\left(v_{1} v_{2}\right)-\mu\left(v_{1}\right) E\left(v_{2}\right)}{\sigma\left(v_{1}\right) \sigma\left(v_{2}\right)}
$$

Onde:

$$
\mu\left(v_{1} v_{2}\right) \quad \text { É a média dos valores dos produtos dos termos correspondentes }
$$

entre as duas amostras;

$$
\mu\left(v_{1}\right), \mu\left(v_{2}\right) \text { São as médias das duas amostras; }
$$


$\sigma\left(v_{1}\right), \sigma\left(v_{2}\right)$ São os desvios padrão das duas amostras.

Tratando-se cada uma das amostras como um vetor, cujas dimensões são os valores subtraídos de sua média, demonstra-se matematicamente que a correlação normalizada, $N$, e o coeficiente de correlação cardinal (ou de Pearson), visto anteriormente, são equivalentes entre si, e com o produto escalar normalizado dos vetores. Logo a correlação entre duas amostras de imagens digitais pode também ser escrita como:

$$
\begin{aligned}
& N=\rho=C=\frac{\vec{v}_{1} \bullet \vec{v}_{2}}{\left|\vec{v}_{1}\right|\left|\vec{v}_{2}\right|} \\
& \vec{v}_{n}=\left[\begin{array}{c}
x_{1}-\mu_{x} \\
\vdots \\
x_{n}-\mu_{n}
\end{array}\right]
\end{aligned}
$$

Onde

$\vec{v}_{1}, \vec{v}_{2} \quad$ São os vetores, normalizados pela média, das amostras;

$N$, $\rho$ e C São iguais ao coseno do ângulo formado pelos dois vetores. Logo quanto maior o valor do coseno ou menor o valor do ângulo, maior a componente de um vetor sobre o outro.

\subsubsection{Determinação das coordenadas de um ponto homólogo.}

Como já definido, o objetivo da correlação de imagens é determinar pontos homólogos nas imagens digitais. Para isso, um recorte (template) é definido na imagem de referência. Tal processo pode ser facilmente implementado computacionalmente: escolhe-se o ponto do qual deseja extrair homólogos em outras imagens. Gravam-se numa matriz os valores dos números digitais de cor ou tonalidade do pixel central e de vários outros adjacentes a ele. Esses valores são arranjados em uma coluna, e equivalerão à amostra, ou vetor, $X$. Devem ser utilizados templates de números ímpares, para que o ponto de interesse esteja no seu centro. Em geral, usam-se matrizes de 9x9 ou de 11x11. O próximo passo é escolher 
uma janela de busca na imagem conjugada. Isso é feito por varredura utilizando-se, para otimizar o tempo de processamento, diferentes algoritmos de busca. A partir daí, dentro da janela de busca, um template equivalente em tamanho ao da primeira imagem corre pixel a pixel, da esquerda para a direita e de cima para baixo. Os valores armazenados neste segundo recorte serão equivalentes à variável $Y$.

Assim, calcula-se o coeficiente de correlação entre $X$ e cada um dos valores assumidos por $Y$. Aquela combinação que possuir o maior valor para o coeficiente de correlação definirá o ponto homólogo. As coordenadas deste ponto serão as coordenadas do pixel central de ambos os templates (X e $Y$ ).

\subsubsection{Métodos de busca fracionais ou sub-pixel.}

Da maneira como foi visto até aqui, a correspondência de imagens é feita discretamente, pixel a pixel. Porém, é natural pensar que, estabelecendo-se a posição do pixel onde ocorre a maior correlação, esta possa variar continuamente em relação aos vizinhos, apresentando o seu máximo em uma posição intermediária ou fracional.

Dessa maneira métodos de busca, denominados sub-pixel, foram criados, de maneira a determinar posições intermediárias onde a correspondência das imagens é máxima.

\subsubsection{O método da adaptação de uma superfície polinomial.}

Algumas técnicas podem ser aplicadas para obter a posição sub-pixel. Uma delas é a do ajustamento de uma superfície polinomial aos valores da matriz de correlação, na vizinhança do ponto onde esta é máxima. Quando uma superfície de segunda ordem é adotada pode-se escrever a equação 2.28:

$$
C_{i}=a x_{i}^{2}+b y_{i}^{2}+c x_{i} y_{i}+d x_{i}+e y_{i}+f
$$

Onde $C_{i}$ é o conjunto das correlações obtidas da matriz da janela de busca; $i$ é o índice desse conjunto e varia de 1 a $n^{2}$, onde n é a dimensão da janela; 
$a, b, c, d, e, f$ são os coeficientes polinomiais a serem determinados.

Para a solução aplica-se um ajuste em que as leituras são os valores extraídos da matriz de correlação da janela de busca.

Determinados os valores, tem-se que:

$$
\begin{aligned}
& \frac{\delta C}{\delta x}=2 a x+c y+d=0 \\
& \frac{\delta C}{\delta y}=2 b y+c x+e=0
\end{aligned}
$$

Onde $x$ e $y$, são as posições sub-píxel desejadas que, resolvendo-se o sistema das equações 2.29 leva a:

$$
\begin{aligned}
& x=\frac{c e-2 b d}{4 a b-c^{2}} \\
& y=\frac{c d-2 a e}{4 a b-c^{2}}
\end{aligned}
$$

\subsubsection{Método de correspondência pelos mínimos quadrados.}

Apresenta-se aqui suscintamente esse assunto. O leitor que queira se ater melhor recomenda-se a leitura em Schenk (1999) e Tommaselli (2006).

Neste caso assume-se que o ponto de correspondência máxima, obtido pelo método da correlação tenha sido encontrado com precisão de um pixel. Presume-se que a janela de referência pode ser deslocada de frações de pixel para encontrar o ponto de melhor correspondência.

Assim pode-se escrever que:

$$
\Delta g=g b-g r
$$

Onde $\Delta g$ é o gradiente de uma posição relativa da janela de busca em relação à de referência. 


$$
\begin{aligned}
& f(x)=\frac{d g_{r}}{d x} \\
& f(y)=\frac{d g_{r}}{d y}
\end{aligned}
$$

Onde $f(x)$ e $f(y)$ são os gradientes nas posições em relação às dimensões x e y, respectivamente.

Tem-se que:

$$
\left[\begin{array}{cc}
f x_{1} & f y_{1} \\
f x_{2} & f y_{2} \\
\vdots & \vdots \\
f x_{i} & f y_{i}
\end{array}\right] \cdot\left[\begin{array}{c}
\Delta x \\
\Delta y
\end{array}\right]=\left[\begin{array}{c}
\Delta g_{1} \\
\Delta g_{2} \\
\vdots \\
\Delta g_{i}
\end{array}\right]+\left[\begin{array}{c}
v_{1} \\
v_{2} \\
\vdots \\
v_{i}
\end{array}\right]
$$

Que se calculando pelo método dos mínimos quadrados resulta em:

$$
\left[\begin{array}{l}
\Delta x \\
\Delta y
\end{array}\right]=\left[\begin{array}{cc}
\sum f x_{i}^{2} & \sum f x_{i} f y_{i} \\
\sum f x_{i} f y_{i} & \sum f y_{i}^{2}
\end{array}\right]^{-1} \cdot\left[\begin{array}{c}
\sum f x_{i} \Delta g_{i} \\
\sum f y_{i} \Delta g_{i}
\end{array}\right]
$$

Onde $\Delta x$ e $\Delta y$ são as variações fracionais, ou sub-pixel, em $x$ e $y$ da posição obtida no método de correlação. 


\section{Capítulo 3}

\section{$3 \quad$ Modelos de superfície.}

\subsection{Amostragem espacial.}

As feições na natureza são, em geral, fenômenos contínuos variando de ponto a ponto. Para representá-las, lança-se mão de técnicas de amostragem espacial. Assim, por meio de uma quantidade discreta de pontos, pode-se bem representar a feição para a finalidade proposta.

Amostragem é o conjunto de atividades e procedimentos utilizados para, a partir de um subconjunto de entidades, denominado amostra, sobre a qual se farão as observações obter informações e medidas confiáveis sobre todo o conjunto de entidades, denominado população, e permitir inferências sobre o todo. (MILONE, 2004)

Uma vez que a realidade é complexa, estudos trabalham com sua representação. Amostras dela colhidas devem representá-la de forma fiel e exata para a aplicação. Nesse sentido, técnicas de amostragem devem levar em conta padrões de exatidão.

Características do mundo real existem em todo lugar e variam continuamente sobre a superfície, por exemplo, elevação, pressão e temperatura atmosféricas, vegetação natural, tipo de solo. Pode-se representar essa variação de diversas maneiras, por exemplo:

- Observando em pontos de amostragem, onde o fenômeno varia no tempo, mantendo-se fixa a posição como, por exemplo, no caso de estações meteorológicas;

- Dividindo-se a área em polígonos regulares e assumindo que a variável é constante dentro da zona como, por exemplo, em classificações de tipo de solo. 
Dados espaciais variam de três maneiras distintas:

- Espacial, quando a variável, dentro de um mesmo tema, varia de lugar para lugar como, por exemplo, a altitude;

- Temporal, quando a variável muda em relação ao tempo, por exemplo, condições climáticas;

- Temático, quando a variável muda, no espaço, de um tema para outro, como por exemplo, de pastagem natural para cultura temporária, ou, de rodovia passa para vegetação.

Uma vez que essas variações e combinações são inumeráveis, para a observação de um fenômeno, é necessário fixar um modo, controlar o segundo, e, observar o terceiro. Associa-se à variação espacial a posição; à variação temática o atributo, e, à temporal, intervalos de tempo. Como exemplo, pode-se citar um censo, onde se fixa o tempo, controla-se o posicionamento e observa-se o tema. Como outro exemplo, para controle de marés, fixa-se uma posição, e mede-se o atributo, no caso nível do mar, em intervalos controlados de tempo.

Sendo assim define-se modelo digital de superfície - MDS (também conhecido como DSM - digital surface model), como uma amostragem espacial, de uma superfície.

O MDS é um conceito genérico e serve para estudos de superfícies de qualquer natureza. Como, por exemplo, modelagem de peças mecânicas, modelagens de aerofólios para estudos de aerodinâmica, etc.

Quando essa superfície é a da Terra, geralmente é denominado de modelo digital de elevações - MDE (também conhecido como DEM - digital elevation model), onde as altitudes do dossel da superfície são amostradas. Por exemplo a superfície do dossel da vegetação, no caso de zonas rurais e o dossel das edificações no caso de zonas urbanas. 
Quando, mais especificamente, as altitudes referem-se ao terreno, denominase então de modelo digital de terreno - MDT (também conhecido como DTM - digital terrain model).

\subsection{Captura de dados.}

Vários fatores devem ser levados em conta na captura dos dados para a elaboração de um modelo numérico de elevações, tais como o método, a densidade e o padrão.

Quanto ao método, pode ser direto ou indireto.

O método direto é o de medida direta da altitude, feita no campo, por exemplo, por nivelamento geométrico, levantamentos topográficos, levantamentos barométricos, técnicas de GPS.

O método indireto é o de digitalização de cartas existentes, ou por sensoriamento remoto, utilizando-se técnicas de, por exemplo, aerofotogrametria, varredura a laser, interferometria com radares de abertura sintética.

Quanto à densidade, a amostra deve ser tal que represente bem a superfície. Pelo teorema de Nyquist, que diz que um determinado sinal limitado em banda com freqüência de corte, $f_{c}$, poderá ser restaurado se amostrado por uma freqüência amostral, $f_{a}$, com valor de, no mínimo, o dobro da de corte, ou seja, $f_{a}=2 f_{c}$. No caso de um modelo digital de superfície, deve-se determinar qual o espaçamento de amostragem no solo que permitiria a reconstrução da superfície das elevações.

Quanto ao padrão, a amostra pode ser tomada de cinco maneiras:

- Aleatória, muito usual em avaliações rápidas.

- Irregular, muito utilizada para representar feições irregulares por uma amostragem menor.

- Sistemática, quando se segue uma regra, e dessa regra se espera uma amostragem sem tendências. 
- Regular, quando se utiliza uma taxa de amostragem constante, no caso da espacial, uma malha equiespaciada.

- Estratificada, quando o pesquisador conhece que o universo contém subpopulações. Amostrando essas sub-populações levam a um melhor conhecimento do todo. Bastante eficaz no controle de qualidade.

\subsection{Estrutura dos dados.}

Para a representação de um MDE ou um MDT, as técnicas de observação podem condicionar a distribuição espacial, implicando na necessidade de diferentes estruturas de dados para sua armazenagem e manipulação.

As estruturas de dados de um MDE são: malha regular; malha irregular de triângulos (triangular irregular network - TIN); curvas de nível; modelos híbridos; e, estruturas hierárquicas.

\subsubsection{Malha regular.}

São malhas equiespaciadas no terreno (retangulares ou quadradas), onde a cada nó da malha é associada uma altitude. De todos os modelos é o mais simples, acarretando maior facilidade de programação para sua utilização, e, exigindo uma menor quantidade de armazenamento por ponto, uma vez que somente é necessário o registro da altitude e os dados de espaçamento da malha. Permite a obtenção de valores intermediários por meio de interpolações bi-lineares ou bi-cúbicas, gerando assim programas rápidos para sua manipulação. Outra característica dessa estrutura é a possibilidade de armazenagem dos valores de altitude em arquivos de imagens digitais, permitindo o uso de técnicas de manipulação e processamento destas para tratamento de altitudes.

Para que tenham uma boa adaptação ao terreno, necessitam ter uma boa resolução espacial. Segundo o princípio de Nyquist, é necessária uma amostragem com uma resolução duas vezes maior que aquela da menor variação da altitude. 
Logo, serão filtradas todas as variações em dimensões de metade da resolução da malha.

Por se tratar de uma estrutura simples, e de possibilitar a elaboração de programas rápidos para o acesso a valores das altitudes, é um modelo bastante útil para a geração de ortofotos.

Para que se tenha uma idéia da representação da distribuição da altitude em uma determinada área mostra-se um exemplo de MDE em malhas regulares na Figura 3.1.

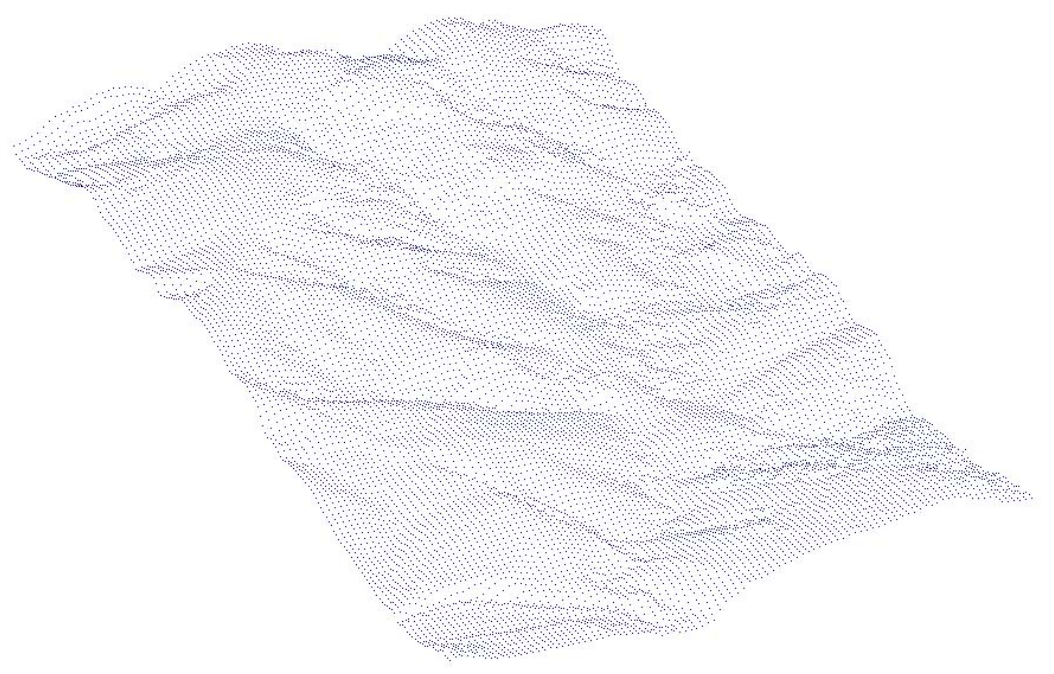

Figura 3.1 - Modelo digital de elevação representado em malha regular, visto em perspectiva isométrica.

\subsubsection{Malha triangular irregular (TIN).}

A malha irregular é formada por pontos de interesse do terreno, incluindo máximos e mínimos locais, pontos em linhas de quebra, tais como rios, talvegues, cumeeiras, sistema viário, adaptando-se melhor às características irregulares da morfologia do terreno.

Se por um lado, tem como vantagem a utilização de um menor número de pontos, em comparação com uma estrutura de malha regular, para armazenar o MDE, de maneira a adaptá-lo ao terreno, por outro lado, exige uma quantidade maior de informações associadas a um ponto. A TIN necessita para cada ponto, além 
da altitude, as coordenadas planiméticas e indexadores das arestas às quais ele pertence.

Ao contrário de uma malha regular, as amostras não estão ordenadas e a localização das arestas e a interpolação exigem maior tempo de processamento.

Para que se visualize, mostra-se a seguir na figura 3.2, as etapas de construção de uma rede triangular irregular, partindo-se de uma nuvem de pontos amostrados irregularmente (a), efetua-se a triangulação de Delaunay, de maneira que os vértices produzam uma boa conformação para a triangulação. Essa triangulação é vista em (b).

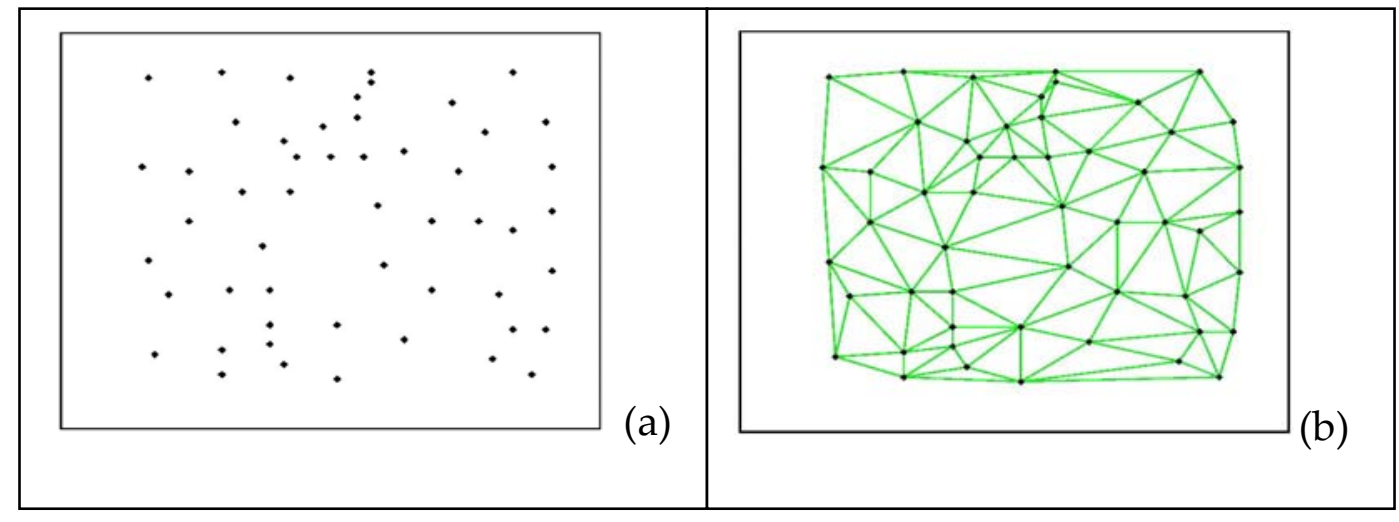

Figura 3.2 - Malha triangular irregular - TIN.

É necessário armazenar as coordenadas $(x, y, z)$ dos pontos fornecidos, bem como os vértices de cada triângulo. Existe, a partir daí, três maneiras de se armazenar uma TIN:

- Orientada aos vértices, onde são feitas as listas dos três vértices formadores do triângulo, segundo a orientação trigonométrica.

- Orientada às arestas, onde são armazenadas as coordenadas dos vértices de origem e destino de cada aresta, indicando-se, os triângulos vizinhos da direita e da esquerda;

- Orientada a triângulos, para cada triângulo, e são armazenados apontadores para os seus três vértices formadores, similar àquela da 
operação orientada aos vértices, e mais, três apontadores indicando, para cada aresta, os triângulos vizinhos.

Pelo fato de permitir a inserção de linhas de quebra, melhora a interpolação de curvas de nível, porém sem uma boa representatividade das mesmas, por se mostrarem trechos segmentados de retas. Deve-se utilizar nesses casos, algoritmos de suavização para as mesmas.

No presente trabalho será utilizada a estrutura de malha quadrada, dada a natureza do processo, e por isso deixa-se de apresentar diversos outros tipos de modelos e estruturas de dados.

\subsubsection{Modelos híbridos.}

Bastante comum é a utilização de modelos que combinem técnicas aqui descritas. Uma delas é a de se utilizar a representação em malha regular, inserindose linhas de quebra. Gerando-se aí uma triangulação, de maneira a formar um MDE que melhor se adapte à morfologia do terreno.

Um exemplo disso é apresentado a seguir na figura 3.3.

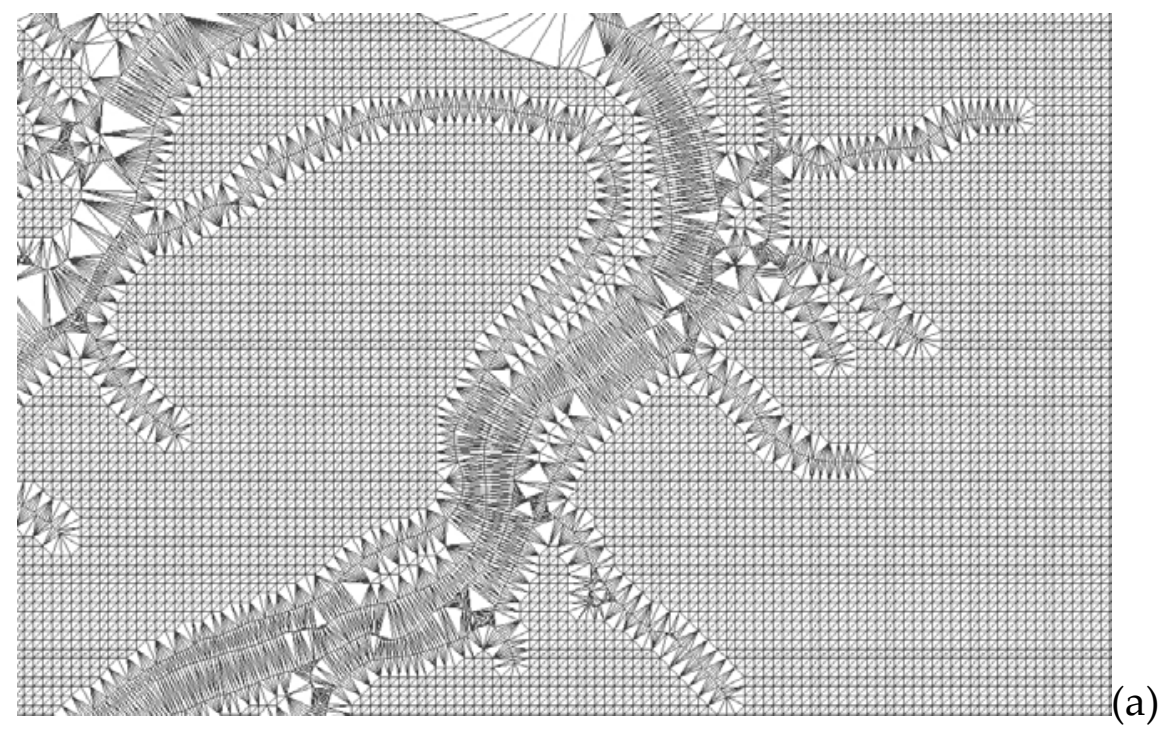




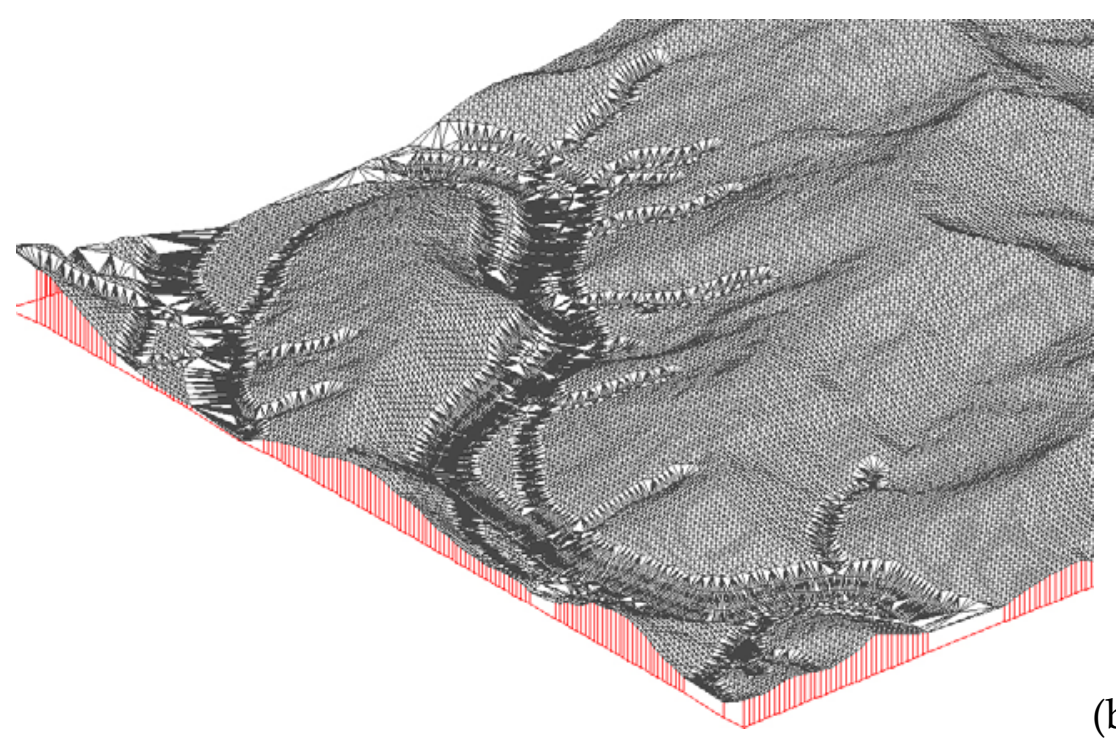

(b)

Figura 3.3 - Malha regular acrescida de feições de quebra vista de topo (a) e em perspectiva isométrica (b).

Na figura 3.4 podem-se visualizar em (a) as curvas obtidas da malha regular com inserção das linhas de quebra, e em (b), aquelas obtidas a partir de suavização da malha regular por adaptação de superfície de terceira ordem.

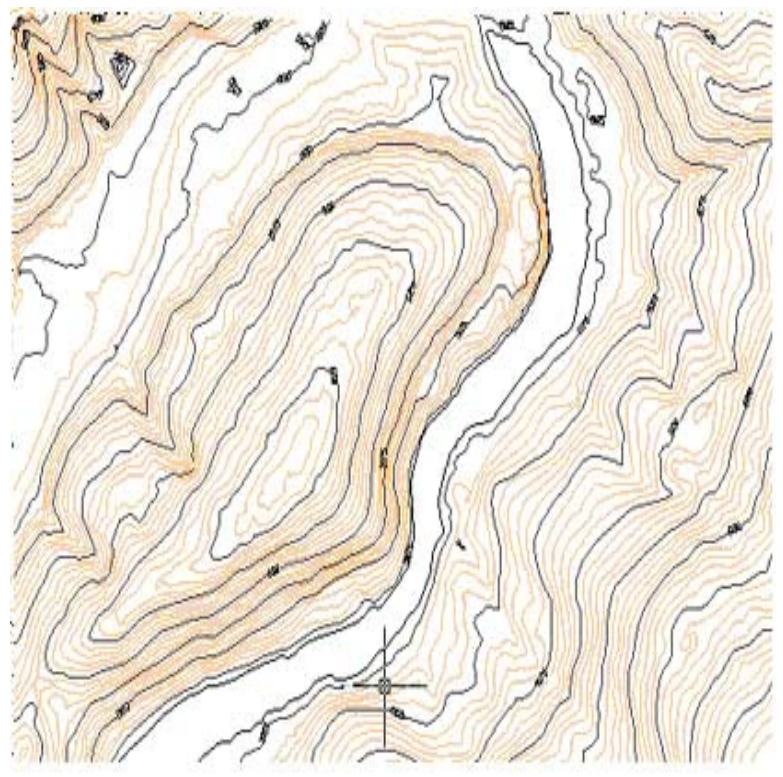

(a)

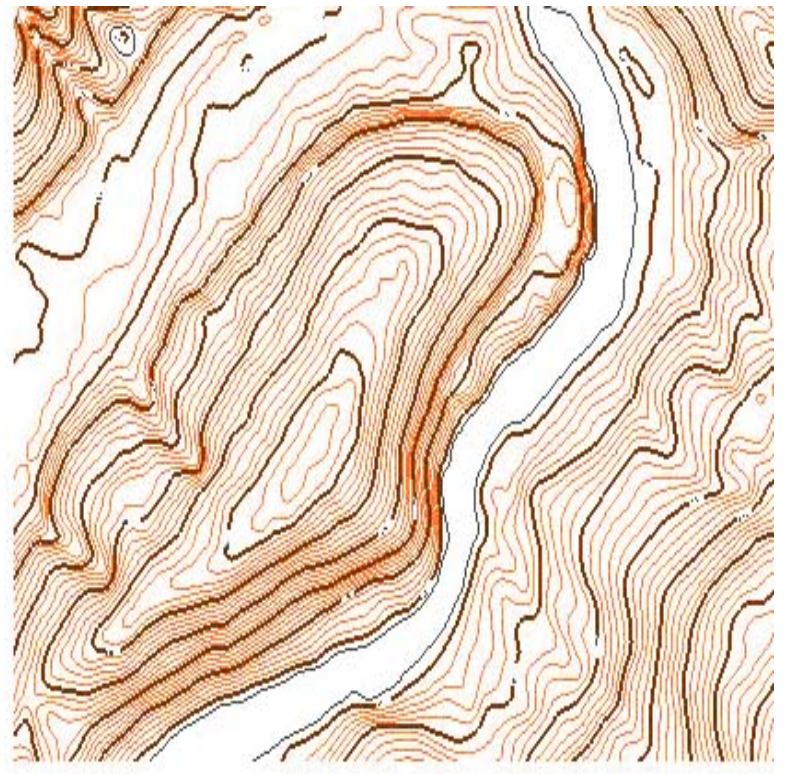

(b)

Figura 3.4 - Curvas de nível sem suavização e suavizadas 


\subsection{Representação.}

As representações dos modelos digitais de elevação são diversas. Apresentam-se a seguir algumas das mais utilizadas.

- Curvas de nível, conforme ilustrado na figura 3.4, onde o MDE é representado por curvas de nível.

- Mapas sombreados.

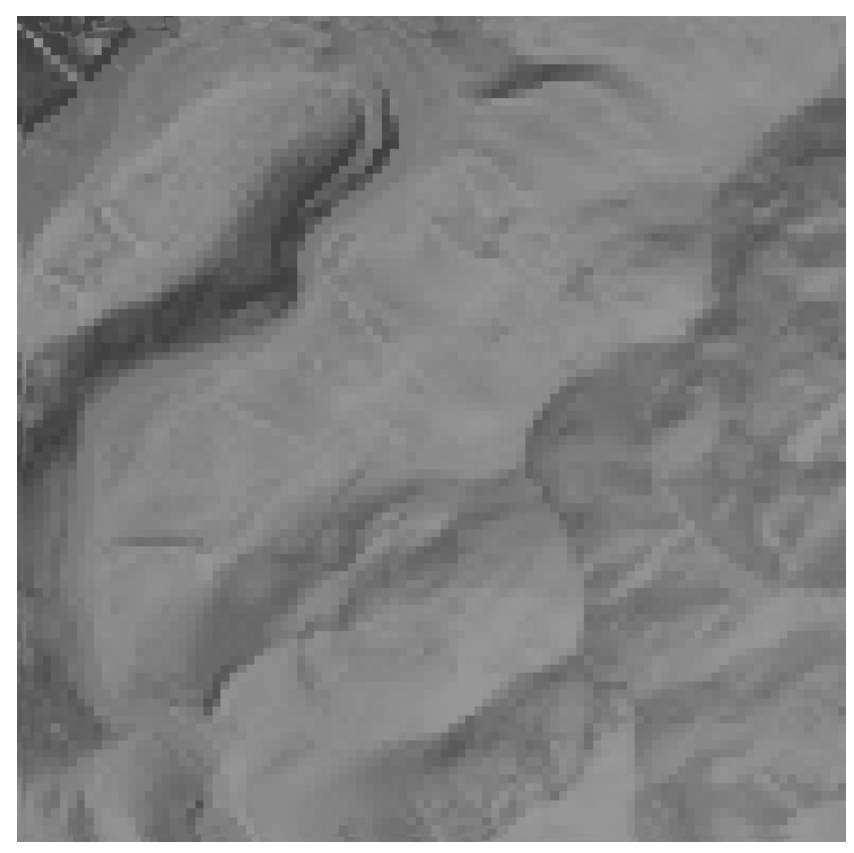

Figura 3.5 - Representação do MDE por mapas sombreados.

Onde se pode eleger a posição de um ponto de iluminação e verificar a influência no sombreamento da região estudada. Bastante útil em estudos de insolação.

- Mapas hipsométricos coloridos. 


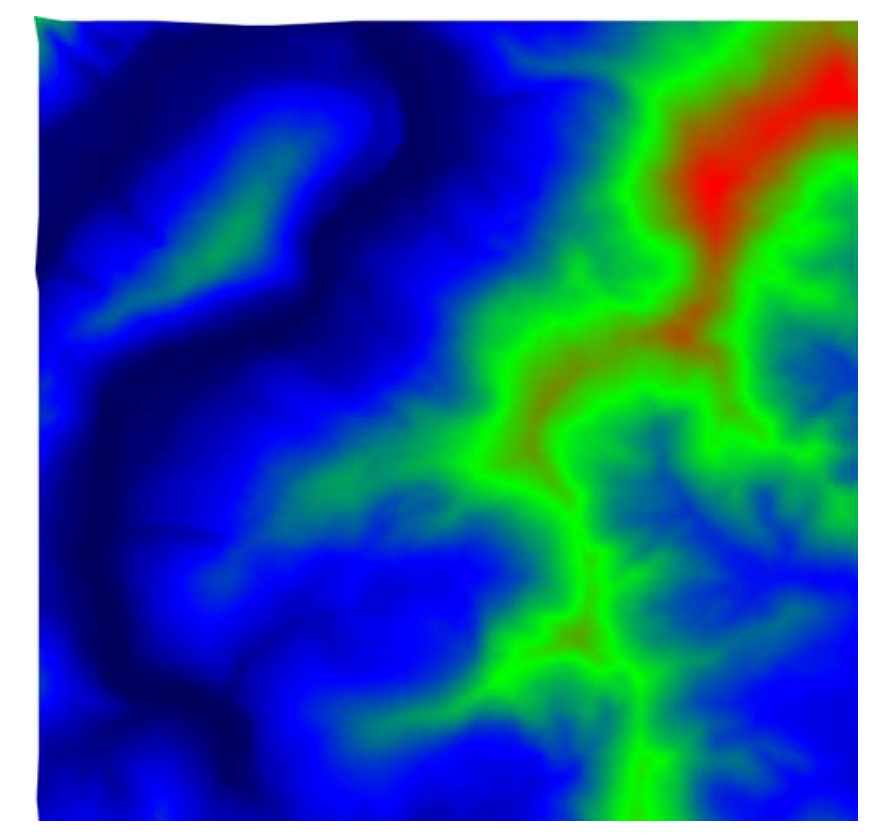

Figura 3.6 - Mapa hipsométricos em cores.

Nos mapas hipsométricos em cores estas usualmente variam do azul ao vermelho, segundo a variação cromática do arco-íris, de maneira que a cada cor corresponda uma altitude.

- Representações híbridas

Por muitas vezes, para o projetista, é interessante a visualização do MDE combinando-se duas ou mais, das diversas possibilidades de sua representação, são denominadas nesses casos de representações híbridas. 


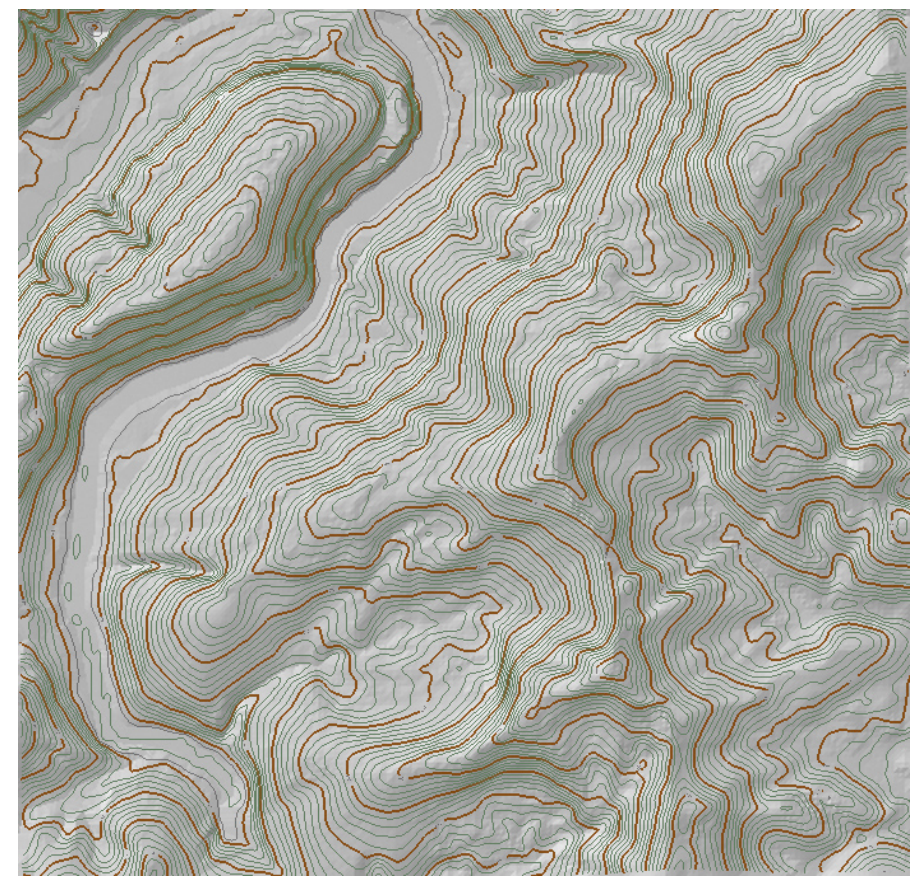

Figura 3.7 - Mapa de curvas de nível sobre representação sombreada.

- Mapas clinográficos.

São mapas onde se representam, não as altitudes, mas sim as inclinações da superfície amostrada, obtidas por operadores que apontam a primeira derivada desta. São bastante úteis para estudos agronômicos, ambientais e de risco.

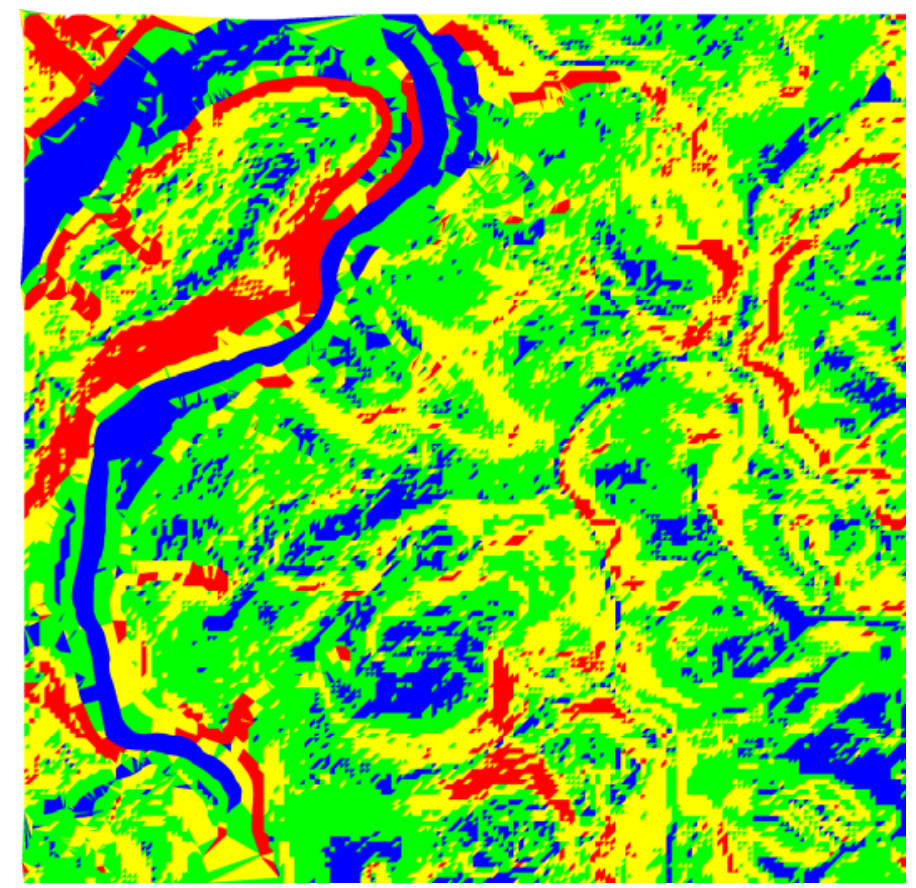

Figura 3.8 - Mapa clinográfico. 
- Mapas de exposição de vertentes.

São mapas onde se vêem as orientações da superfície amostrada. Bastante úteis em planejamento urbano e estudos agronômicos.

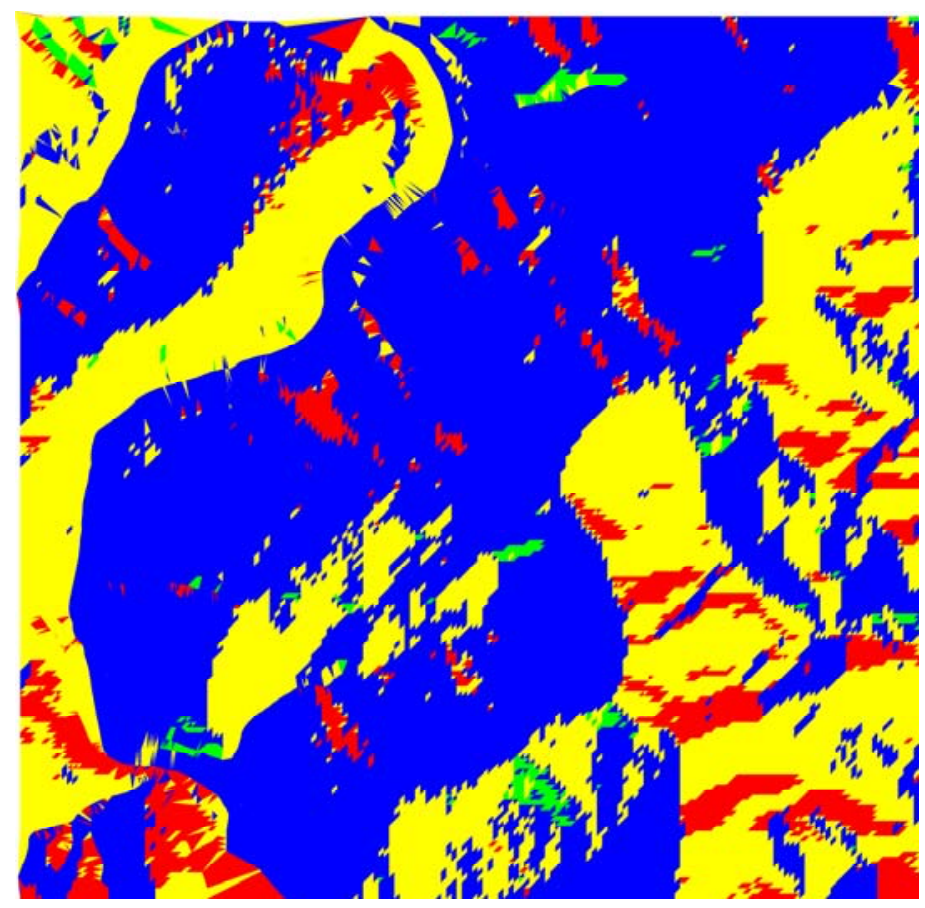

Figura 3.9 - Mapa de exposição de vertentes.

\subsection{Aplicações.}

São diversas as aplicações de modelos digitais de elevação. Algumas podem ser citadas aqui:

Geração de mapas de declividades.

Geração de ortofotocartas.

Geração de mapas de exposição de vertentes.

Modelagens diversas para estudos geomorfológicos, hidrodinâmicos, prevenção de desastres, ondas de impacto e inundação, mapas irradiação de antenas, mapas de visibilidade, projetos de engenharia, cálculos de volumes, identificação automática de decorrelação temporal, cálculo de insolação, vistas em perspectiva, realidade virtual, simulações, entre outros. 


\section{Capítulo 4}

\section{Fotogrametria.}

\subsection{Sistemas de referência em Fotogrametria.}

Os principais sistemas de referência utilizados em Fotogrametria são:

- Sistema do espaço objeto (ou de terreno).

- Sistema fiducial (ou do fotograma).

- O sistema fotogramétrico (ou do sensor).

- O sistema de imagem digital.

\subsubsection{Sistema do espaço objeto.}

O sistema do espaço objeto é o referencial do espaço de interesse, o terreno. Tem sua importância para especificar não só as posições relativas (sistemas locais) como também as absolutas (sistemas globais) das feições a serem levantadas quando se utilizam medidas fotogramétricas, topográficas ou outras. Mais recentemente tem crescido o reconhecimento de sua importância devido ao aumento do emprego das geotecnologias, com maior ênfase nos SIG, sistemas de informações geográficas, nos quais existe uma correspondência importante entre os dados e suas posições para análises e estudos.

No caso da Fotogrametria pode-se definir o sistema objeto como um referencial tridimensional da região que engloba as feições imageadas nas fotografias. No âmbito deste trabalho, este sistema referencial deve estar relacionado com a porção do terreno a ser medido. No entanto, outros sistemas locais podem ser definidos para o imageamento de peças mecânicas, arqueológicos, espeliológicos, de perícias, entre outros.

Para o mapeamento de porções do terreno é importante que todas as feições sejam criteriosamente posicionadas em relação a um referencial. Isto é 
particularmente importante para que dados espaciais obtidos por diversas fontes possam ser integrados de maneira a evitar sobreposições, lacunas e incompatibilidades.

Neste sentido, vários referenciais podem teoricamente ser utilizados tais como Planos Topográficos Locais, Projeções Cartográficas. Em geral opta-se por um sistema local (X, Y, Z), ou o UTM (sistema adotado pelo SGB). Em qualquer caso, é importante que esteja referido a um sistema geodésico definido e materializado, de maneira a posicionar adequadamente as feições a serem mapeadas.

\subsubsection{Sistema fiducial (ou do fotograma).}

As marcas fiduciais situadas no plano focal das câmaras métricas constituem um referencial materializado do sistema de coordenadas fiduciais (ou sistema de coordenadas do fotograma), ilustrado na figura 4.1.

O ponto de interseção das linhas retas formadas pela união das marcas fiduciais opostas é denominado de centro fiducial (FC - fiducial center). O sistema fiducial, também denominado de sistema do fotograma, é definido como tendo sua origem no FC, com eixo $X$ tendo sua direção definida como a bissetriz das retas que unem as fiduciais de cantos opostos e aproximadamente coincidente com a direção do vôo. $\mathrm{O}$ eixo $Y$ perpendicular ao eixo $X$ com origem também no $\mathrm{FC}$, de forma a formarem ambos um par dextrogiro. 


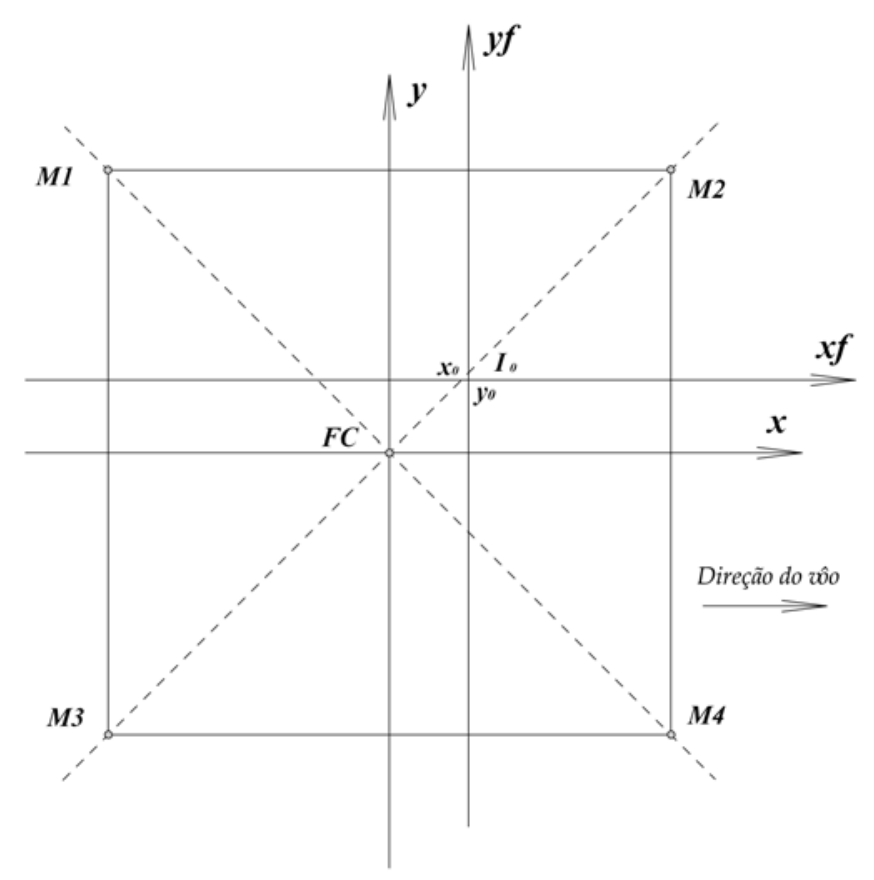

Figura 4.1 - Sistema de coordenadas fiduciais ou do fotograma.

\subsubsection{O sistema fotogramétrico (ou do sensor).}

Com referência à figura 4.2, o eixo óptico de uma câmara aérea métrica passa através do centro de projeção, e intercepta o plano focal da imagem num ponto denominado de ponto principal ou de ponto principal de autocolimação (PPA principal point of autocolimation). A distância do centro de projeção ao plano focal da imagem medida ao longo do eixo óptico é denominada de distância principal. No caso de câmaras aéreas métricas de foco fixo a distância principal é igual à distância focal. Como esquematizado nessa figura, pode-se ver que o raio óptico entra no conjunto de lentes formando um ângulo de incidência em relação ao eixo, $\alpha$, passa pelo ponto nodal anterior (ou de entrada), e sai, num sistema ideal, com um ângulo $\alpha$ igual ao de entrada, passando pelo ponto nodal posterior, para daí atingir o plano focal. Por comodidade, imagina-se a lente sem dimensões, considerando-se a coincidência do ponto nodal anterior e posterior. A este ponto passa-se a denominar CP (centro de projeção). A distância focal será então a distância do ponto nodal posterior ao plano focal. 


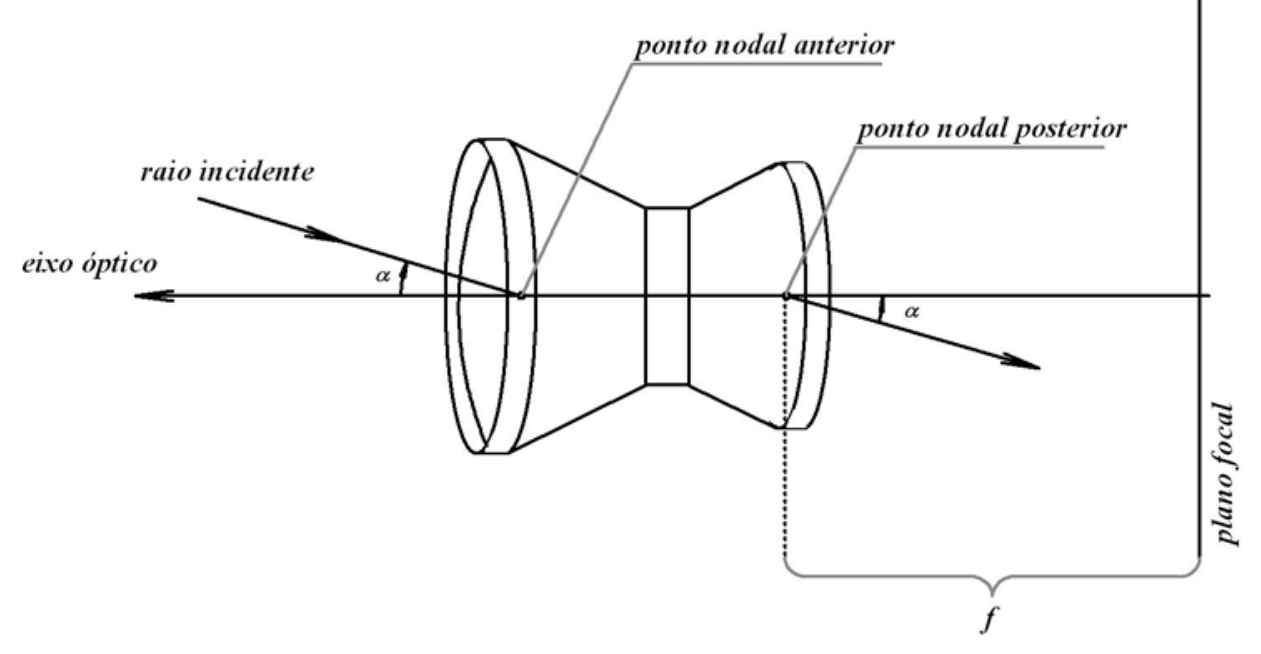

Figura 4.2 - Desenho esquemático da incidência do raio óptico no conjunto de lentes de uma câmara aerofotogramétrica.

O Centro Fiducial FC é próximo, porém raramente coincide com o PPA. Essa distância entre o FC e o PPA é determinada no processo de calibração das câmaras, sendo normalmente expresso pelo par de coordenadas $\left(x_{0}, y_{0}\right)$.

Define-se o sistema fotogramétrico, que se pode visualizar na figura 4.3, como um sistema tri ortogonal cuja origem é o centro de projeção. O eixo zf é coincidente com o eixo óptico da câmara orientado no sentido do ponto nodal posterior para o ponto principal de auto colimação. Os eixos $x_{f}$ e $y_{f}$ são respectivamente paralelos aos eixos $\mathrm{x}$ e y do sistema fiducial ou do fotograma.

Como se pode notar pela definição deste sistema, as coordenadas $z_{f}$ do plano focal (ou do negativo) são iguais à distância principal.

Nota-se que nos certificados de calibração das câmaras aéreas métricas, notadamente nos da RMK TOP 15 da ZEISS, são apresentadas as coordenadas $x_{f}$ e $y_{f}$ das marcas fiduciais já no sistema fotogramétrico e não no fiducial 


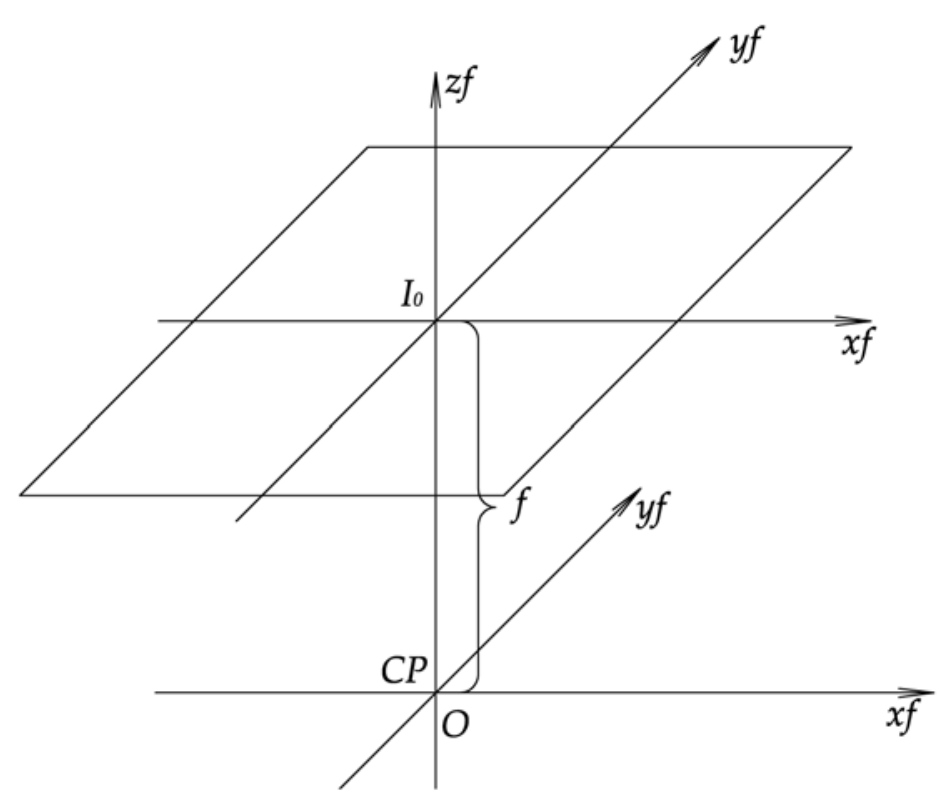

Figura 4.3 - Representação do sistema fotogramétrico.

\subsubsection{Sistema de imagem digital.}

O sistema da imagem digital (figura 4.4) é estabelecido no momento da digitalização do fotograma, seja por meio de escâner fotogramétrico seja por meio da captura por câmaras digitais. É um sistema bidimensional e tem como origem o canto superior esquerdo da imagem. Apresenta como eixo das ordenadas $l$ a reta coincidente com aquela formada pelo canto esquerdo da primeira coluna da imagem e tendo seu sentido crescente como o aumento das linhas. Como eixo das abscissas $c$ a reta coincidente com aquela formada pelo canto superior esquerdo da imagem e tendo o seu sentido crescente como o aumento das colunas.

Em fotogrametria digital é sobre este sistema que são efetuadas as medições de coordenadas dos pontos. Pode-se dizer que este é equivalente ao sistema de máquina da fotogrametria analítica. 


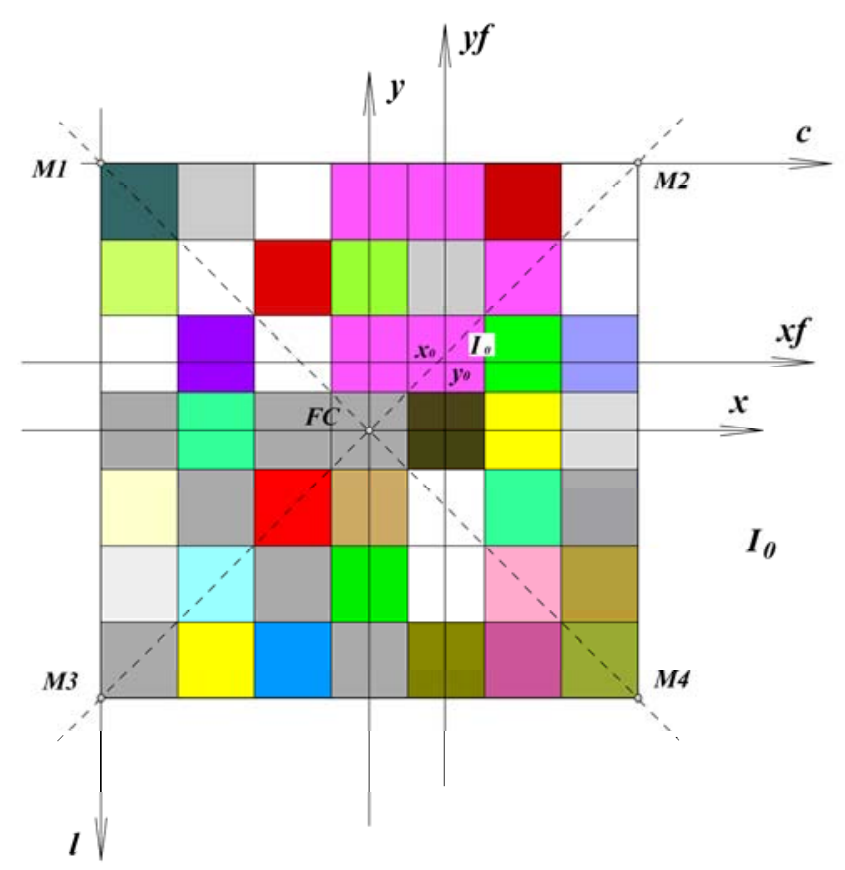

Figura 4.4 - Representação dos sistemas de imagem digital e fotogramétrico.

\subsection{Transformação do sistema da imagem digital para o fotogramétrico (Orientação Interior).}

A orientação interior relaciona as coordenadas da câmara (a partir de suas marcas fiduciais) com as coordenadas da imagem digital (pixel) definindo os elementos geométricos requeridos para a reconstrução dos feixes dos raios no espaço objeto com os correspondentes nos pontos da imagem.

Necessita-se efetuar as leituras no sistema da imagem digital das marcas fiduciais. De posse de seus respectivos valores, ajustar os parâmetros de transformação do sistema de imagem digital para o sistema fotogramétrico, e vice versa, estabelecendo a correspondência entre esses dois sistemas.

Para tanto se pode optar por diferentes transformações sendo que as mais comuns são as de Helmert e Afim.

\subsubsection{Transformação de Helmert.}

Na transformação de Helmert tem-se: 


$$
X=S \times R \times I_{D}+T_{0}
$$

ou

$$
\left[\begin{array}{l}
x_{f} \\
y_{f}
\end{array}\right]=S \cdot\left[\begin{array}{cc}
\cos \theta & \operatorname{sen} \theta \\
-\operatorname{sen} \theta & \cos \theta
\end{array}\right] \cdot\left[\begin{array}{l}
c \\
l
\end{array}\right]+\left[\begin{array}{l}
T_{x} \\
T_{y}
\end{array}\right]
$$

Onde as incógnitas são $S, \theta, T_{x} e T_{y}$.

$S$, o fator de escala;

$\theta$, o ângulo de rotação do plano da imagem em torno do eixo $Z_{f}$ do sistema fotogramétrico;

$T_{x}$ e $T_{y}$, os parâmetros de translação entre os dois sistemas.

$x, y$ são as coordenadas no sistema fiducial.

$x_{0}, y_{0}$, são as coordenadas do ponto principal de autocolimação.

$x_{f,} y_{f,}$ são as coordenadas no sistema fotogramétrico.

le c são a linha e a coluna do pixel no sistema de coordenada digital.

Isso nos dá um modelo de transformação com quatro incógnitas.

\subsubsection{Transformação Afim.}

Lembrando que as leituras fotogramétricas são feitas em relação ao PPA, temse:

$$
\begin{aligned}
& x_{f}=x-x_{0} \\
& y_{f}=y-y_{0}
\end{aligned}
$$

Na transformação afim tem-se que:

$$
I_{D}=M_{O} X_{f}+T
$$

ou

$$
\left[\begin{array}{l}
c \\
l
\end{array}\right]=\left[\begin{array}{ll}
a_{11} & a_{12} \\
a_{21} & a_{22}
\end{array}\right] \cdot\left[\begin{array}{l}
x_{f} \\
y_{f}
\end{array}\right]+\left[\begin{array}{l}
T_{x} \\
T_{y}
\end{array}\right]
$$


Neste caso tem-se seis incógnitas $a_{11}, a_{12}, a_{21}, a_{21}, T_{x}, T_{y}$ que são os parâmetros de orientação. Note-se que a transformação de Helmert é um caso particular da transformação Afim, quando $a_{11}=S \cos \theta, a_{12}=S \operatorname{sen} \theta, a_{21}=-S \operatorname{sen} \theta$ e $a_{22}=S \cos \theta$. Então bastaria a leitura de três marcas fiduciais formando seis equações. Na realidade, as câmaras fotogramétricas são fabricadas com quatro e mais recentemente com oito marcas fiduciais, e assim é possível fazer um ajuste com até dezesseis equações, aplicando o método dos mínimos quadrados e obtendo assim uma solução mais consistente.

Para resolver o problema pelo MMQ pode-se seguir, de acordo com Wolf e Ghilani (1996), a notação clássica, montando um sistema de equações de observações com as matrizes:

$$
A X+V=L
$$

Onde:

$A$ é a matriz das coordenadas fiduciais, acrescidos do deslocamento do Ponto Principal, ou seja, no sistema fotogramétrico, $L$ a matriz das leituras das fiduciais no sistema da imagem digital, $X$ a matriz dos seis parâmetros a serem determinados e $V$ a matriz dos resíduos.

A solução vem dada por:

$$
X=\left(A^{T} \cdot A\right)^{-1} \cdot A^{T} \cdot L=N^{-1} \cdot A^{T} \cdot L
$$

No caso da orientação interior com oito marcas fiduciais, como se utiliza na parte prática do presente trabalho, essas matrizes ficam sendo: 


$$
X=\left[\begin{array}{c}
c_{1} \\
l_{1} \\
c_{2} \\
l_{2} \\
c_{3} \\
l_{3} \\
c_{4} \\
l_{4} \\
c_{5} \\
l_{5} \\
c_{6} \\
l_{6} \\
c_{7} \\
l_{7} \\
c_{8} \\
a_{22} \\
T_{x} \\
T_{y}
\end{array}\right] \quad L\left[\begin{array}{c}
a_{11} \\
l_{8}
\end{array}\right] \quad\left[\begin{array}{l}
v_{1} \\
v_{2} \\
v_{3} \\
v_{4} \\
v_{5} \\
v_{6} \\
v_{7} \\
v_{8} \\
v_{9} \\
v_{10} \\
v_{11} \\
v_{12} \\
v_{13} \\
v_{14} \\
v_{15} \\
v_{16}
\end{array}\right] \quad A=\left[\begin{array}{cccccc}
x_{f_{1}} & y_{f_{1}} & 0 & 0 & 1 & 0 \\
0 & 0 & x_{f_{1}} & y_{f_{1}} & 0 & 1 \\
x_{f_{2}} & y_{f_{2}} & 0 & 0 & 1 & 0 \\
0 & 0 & x_{f_{2}} & y_{f_{2}} & 0 & 1 \\
x_{f_{3}} & y_{f_{3}} & 0 & 0 & 1 & 0 \\
0 & 0 & x_{f_{3}} & y_{f_{3}} & 0 & 1 \\
x_{f_{4}} & y_{f_{4}} & 0 & 0 & 1 & 0 \\
0 & 0 & x_{f_{4}} & y_{f_{4}} & 0 & 1 \\
x_{f_{5}} & y_{f_{5}} & 0 & 0 & 1 & 0 \\
0 & 0 & x_{f_{6}} & y_{f_{5}} & 0 & 1 \\
x_{f_{6}} & y_{f_{6}} & 0 & 0 & 1 & 0 \\
0 & 0 & x_{f_{6}} & y_{f_{6}} & 0 & 1 \\
x_{f_{7}} & y_{f_{7}} & 0 & 0 & 1 & 0 \\
0 & 0 & x_{f_{7}} & y_{f_{7}} & 0 & 1 \\
x_{f_{8}} & y_{f_{8}} & 0 & 0 & 1 & 0 \\
0 & 0 & x_{f_{8}} & y_{f_{8}} & 0 & 1
\end{array}\right]
$$

Onde:

A matriz $A$ é formada por $\left(x_{n}, y_{n}\right)$ que são as posições das 8 fiduciais no sistema fiducial,

A matriz $L$ é formada por $l_{n}, c_{n}$ que são leituras, no sistema da imagem digital, das 8 marcas fiduciais

A matriz $V$ é formada pelos $v_{n}$ que são os resíduos.

A Matriz X é a das incógnitas $a_{11}, a_{12}, a_{21}, a_{22}, T_{x}, T_{y}$, que são os parâmetros da orientação interior a serem obtidos.

Determinados os seis parâmetros da orientação interior, pode-se também escrever que:

$$
\left[\begin{array}{l}
x_{f} \\
y_{f}
\end{array}\right]=\left[\begin{array}{ll}
a_{11} & a_{12} \\
a_{21} & a_{22}
\end{array}\right]^{-1} \cdot\left[\begin{array}{l}
c-T_{x} \\
l-T_{y}
\end{array}\right]
$$

O conjunto de equações $4.3,4.5$ e 4.8, dão as transformações entre os sistemas fotogramétrico e o de imagem digital. 


\subsection{Princípio da colinearidade.}

A característica fundamental de um quadro de imagem fotográfica, num esquema ideal, é que um ponto na imagem, o centro de projeção e o seu respectivo homólogo no terreno pertençam a uma mesma reta (figura 4.5). Em termos reais isso não acontece de forma rigorosa mas aproximada. Isto se deve a diversos fatores, entre eles a refração atmosférica e as distorções das lentes. Na prática o que se faz é admitir que esta linha seja uma reta e modelar, os efeitos da refração e das distorções do sistema óptico.

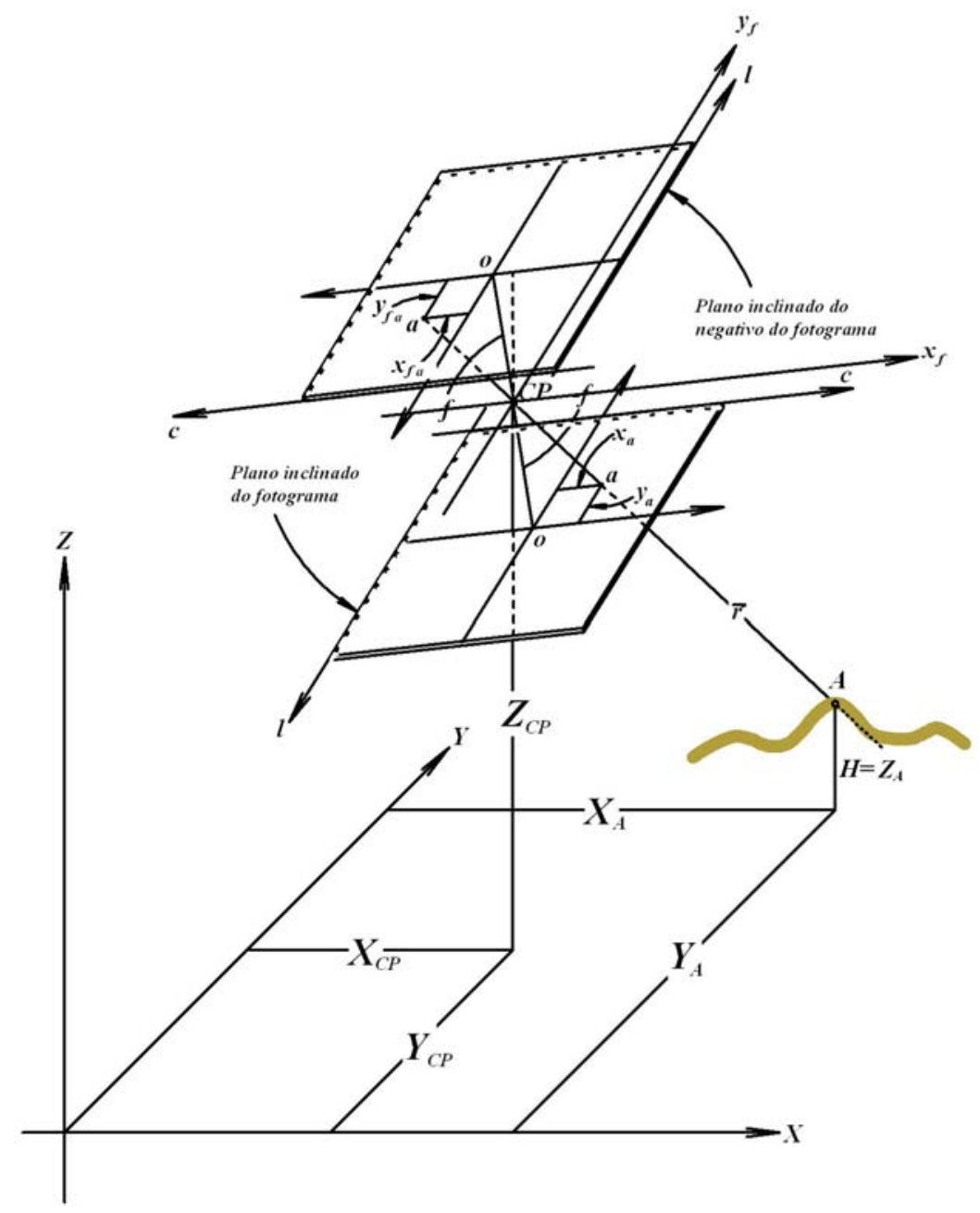

Figura 4.5 - Desenho esquemático do princípio da colinearidade.

A figura 4.5 mostra a reta que passa por A, no terreno, pelo seu homólogo (a) no plano do fotograma orientado no espaço, e pelo centro de projeção CP. Para 
melhor ilustrar, as próximas figuras serão representadas somente no plano do fotograma e não no plano do negativo.

Nessas condições pode-se dizer que a reta que passa por um ponto no terreno e alcança seu respectivo homólogo na plano da imagem orientada no espaço passando pelo centro de projeção pode ser expressa pela seguinte equação paramétrica da reta no espaço:

$$
\vec{r}=\left\{\begin{array}{l}
X=\left(X_{C P}+a s\right) \vec{i} \\
Y=\left(Y_{C P}+b s\right) \vec{j} \\
Z=\left(Z_{C P}+c s\right) \vec{k}
\end{array}\right.
$$

Onde:

$C P=\left(X_{C P}, Y_{C P}, Z_{C P}\right)$ é o ponto no espaço objeto definido como o centro de projeção da imagem;

$A=\left(X_{A}, Y_{A}, Z_{A}\right) \quad$ é o ponto $A$ qualquer no terreno cujo homólogo pertence à imagem;

$\vec{v}=(a, b, c)$ é o vetor diretor da reta no espaço objeto.

s é o parâmetro da reta ou fator de escala;.

$X, Y$ e Z são as coordenadas, no sistema objeto, de um ponto qualquer da reta.

O vetor diretor da reta, para um ponto $A$ será:

$$
\begin{aligned}
& a=X_{A}-X_{C P} \\
& b=Y_{A}-Y_{C P} \\
& c=Z_{A}-Z_{C P}
\end{aligned}
$$

Na forma matricial, se aplicado ao ponto $A$, a equação da reta espacial pode ser escrita como:

$$
\left[\begin{array}{l}
X \\
Y \\
Z
\end{array}\right]=s\left[\begin{array}{c}
X_{A}-X_{C P} \\
Y_{A}-Y_{C P} \\
Z_{A}-Z_{C P}
\end{array}\right]+\left[\begin{array}{c}
X_{C P} \\
Y_{C P} \\
Z_{C P}
\end{array}\right]
$$




\subsection{Orientação exterior.}

A orientação exterior define a posição do centro de projeção e a atitude do sensor no instante da tomada do fotograma, de maneira a posicionar o sistema no espaço objeto.

Para que isto ocorra é necessária a determinação dos parâmetros de orientação exterior $\omega, \varphi, k, X_{C P,} Y_{C P}, Z_{C P .}$, conforme a figura 4.6. Onde $\omega$ é a rotação primária representada pelo ângulo de rolagem em torno do eixo longitudinal da aeronave, ou seja a rotação em torno do eixo $X$ (direção do vôo), com origem em $Y$ em direção a $Z$, com sentido positivo sendo o trigonométrico. $O$ ângulo $\varphi$ é a rotação secundária representada pelo ângulo de arfagem em torno do eixo transversal da aeronave, ou também a rotação em torno do eixo $Y$ com origem em $Z$ em direção a $X$ com sentido positivo sendo o trigonométrico. O ângulo $\kappa$ é a rotação terciária representada pelo ângulo de deriva em torno do eixo vertical da aeronave, ou também a rotação em torno do eixo $Z$ com origem em $X$ em direção a $Y$ com sentido positivo sendo o trigonométrico. $X_{C P}, Y_{C P}, Z_{C P}$ é o terno de coordenadas, no espaço objeto, do centro de projeção do sensor. 

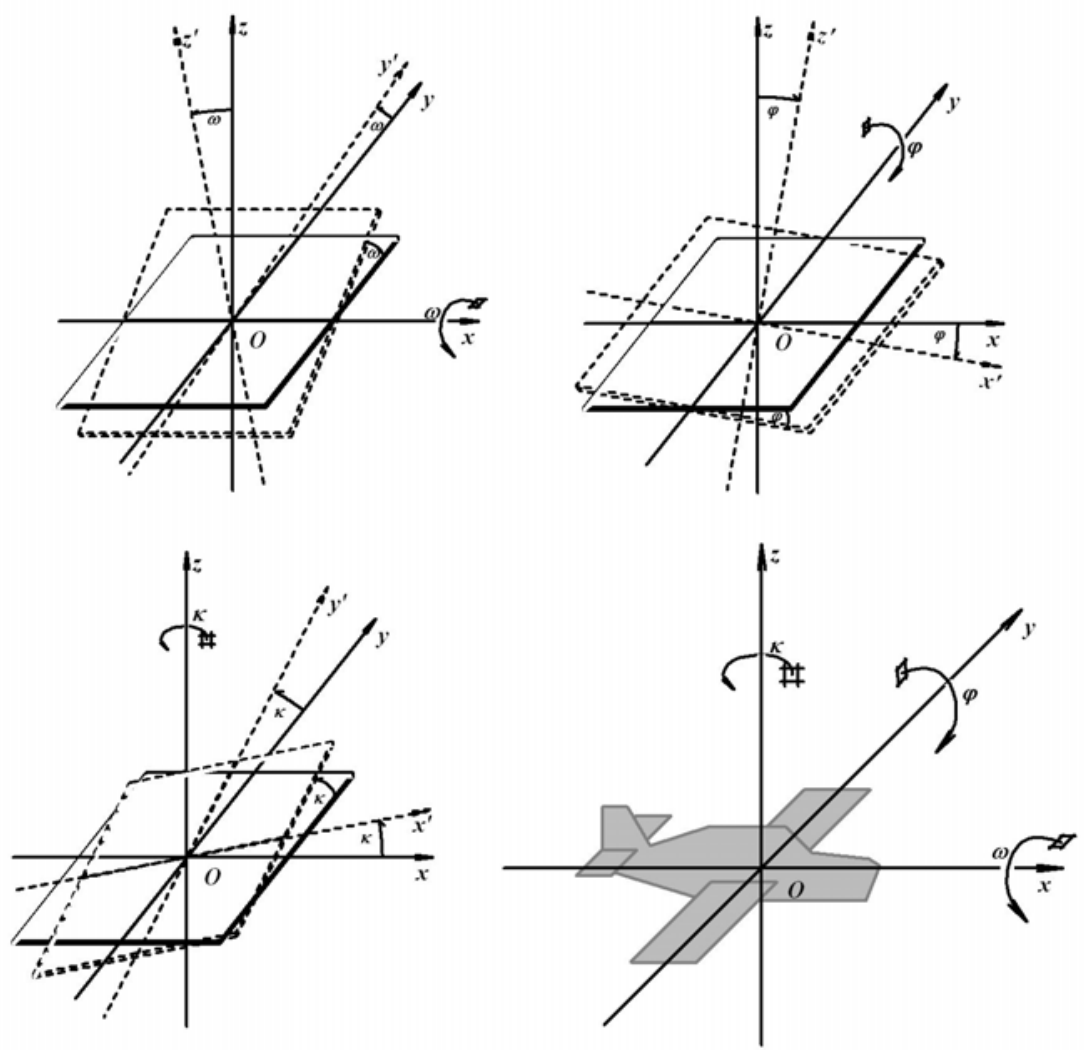

Figura 4.6 - Sistema de orientação do sensor

Este conjunto de parâmetros permite estabelecer a relação entre o sistema objeto e o sistema do sensor, conforme as expressões clássicas mostradas a seguir.

As matrizes de rotação: primária $M_{\omega}$; secundária $M_{\varphi}$; terciária $M_{\kappa}$; podem ser representadas como:

$$
\left.\begin{array}{rl}
M_{\omega} & =\left[\begin{array}{ccc}
1 & 0 & 0 \\
0 & \cos \omega & \operatorname{sen} \omega \\
0 & -\operatorname{sen} \omega & \cos \omega
\end{array}\right] \\
M_{\varphi} & =\left[\begin{array}{ccc}
\cos \varphi & 0 & -\operatorname{sen} \varphi \\
0 & 1 & 0 \\
\operatorname{sen} \varphi & 0 & \cos \varphi
\end{array}\right] \\
M \kappa & =\left[\begin{array}{ccc}
\cos \kappa & \operatorname{sen} \kappa & 0 \\
-\operatorname{sen} \kappa & \cos \kappa & 0 \\
0 & 0 & 1
\end{array}\right]
\end{array}\right\}
$$


A matriz de rotação entre os sistemas fica então:

$M=M_{\kappa} M_{\varphi} M_{\omega}$

$\mathrm{Ou}$,

$M=\left[\begin{array}{lll}m_{11} & m_{12} & m_{13} \\ m_{21} & m_{22} & m_{23} \\ m_{31} & m_{32} & m_{33}\end{array}\right]$

Onde:

$$
\begin{aligned}
& m_{11}=\cos \varphi \cdot \cos \kappa \\
& m_{12}=\cos \omega \cdot \operatorname{sen} \kappa+\operatorname{sen} \omega \cdot \operatorname{sen} \varphi \cdot \cos \kappa \\
& m_{13}=\operatorname{sen} \omega \cdot \operatorname{sen} \kappa-\cos \omega \cdot \operatorname{sen} \varphi \cdot \cos \kappa \\
& m_{21}=-\cos \varphi \cdot \operatorname{sen} \kappa \\
& m_{22}=\cos \omega \cdot \cos \kappa-\operatorname{sen} \omega \cdot \operatorname{sen} \varphi \cdot \operatorname{sen} \kappa \\
& m_{23}=\operatorname{sen} \omega \cdot \cos \kappa+\cos \omega \cdot \operatorname{sen} \varphi \cdot \operatorname{sen} \kappa \\
& m_{31}=\operatorname{sen} \varphi \\
& m_{32}=-\operatorname{sen} \omega \cdot \cos \varphi \\
& m_{33}=\cos \omega \cdot \cos \varphi
\end{aligned}
$$

Sendo assim, os pontos contidos no plano da imagem tem suas coordenadas no sistema objeto determinadas a partir daquelas no sistema fotogramétrico, segundo a seguinte equação:

$$
\left[\begin{array}{c}
x_{f} \\
y_{f} \\
f
\end{array}\right]=\left[\begin{array}{lll}
m_{11} & m_{12} & m_{13} \\
m_{21} & m_{22} & m_{23} \\
m_{31} & m_{32} & m_{33}
\end{array}\right] \cdot\left[\begin{array}{c}
X_{t}-X_{C P} \\
Y_{t}-Y_{C P} \\
Z_{t}-Z_{C P}
\end{array}\right]
$$

Onde:

$x_{f}$ e $y_{f}$ são as coordenadas no sistema fotogramétrico, de um ponto contido no fotograma;

fé a distância focal;

$X_{t}, Y_{t}$ e $Z_{t}$ são as coordenadas do ponto homólogo, no espaço objeto.

Na forma matricial, a mesma equação pode ser escrita como: 


$$
X_{f}=M\left(X_{T}-C P\right)
$$

Sendo a matriz $M$ ortogonal, pode-se dizer que sua inversa é igual à sua transposta. Logo $M^{-1}=M^{T}$.

A equação do plano da imagem no espaço objeto pode ser, então, escrita como:

$$
M^{T} X_{f}=X_{t}-C P \quad \text { ou } \quad X_{T}=M^{T} X_{f}+C P
$$

Ou ainda,

$$
\left[\begin{array}{l}
X_{t} \\
Y_{t} \\
Z_{t}
\end{array}\right]=\left[\begin{array}{lll}
m_{11} & m_{21} & m_{31} \\
m_{12} & m_{22} & m_{32} \\
m_{13} & m_{23} & m_{33}
\end{array}\right] \cdot\left[\begin{array}{c}
x_{f} \\
y_{f} \\
f
\end{array}\right]+\left[\begin{array}{c}
X_{C P} \\
Y_{C P} \\
Z_{C P}
\end{array}\right]
$$

Estes parâmetros podem ser determinados de forma direta ou indireta. Pelo método indireto, através de apoio fotogramétrico "par a par", ou por meio de apoio fotogramétrico obtido por meio de aerotriangulação. Pelo método direto, realizando a medição dessas grandezas no instante da tomada do fotograma com utilização de unidades de medidas inerciais - UMI, ou IMU (inertial mesurity unity), para as

medições dos ângulos de atitude do sensor, e rastreadores GPS para o posicionamento do mesmo.

\subsection{Interseção espacial de reta com plano - equações da colinearidade.}

O plano do fotograma é definido pela equação 4.19 de orientação exterior do fotograma.

De um ponto A no terreno, pode-se obter o seu respectivo homólogo no fotograma utilizando o princípio da colinearidade, aplicando-se então uma interseção da reta $r$, que passa por ele, $\mathrm{A}$, e o centro de projeção $\mathrm{CP}$, com o plano do fotograma no espaço objeto. 
A reta espacial que une $A$ ao centro de projeção $C P$, intercepta o plano da imagem em a, seu homólogo.

Na equação 4.11 que representa a reta de colinearidade tem-se que $X, Y, Z$ são pontos contidos na reta que passa pelo $\mathrm{CP}$ e por um ponto qualquer no terreno. $\mathrm{Na}$ equação 4.19 que define o plano do fotograma, tem-se que $X_{t}, Y_{t}, Z_{t}$, são pontos contidos no plano da imagem. Logo se pode escrever para o ponto $a$, contido no fotograma e homólogo de $A$, no terreno, que:

$$
\left[\begin{array}{l}
X \\
Y \\
Z
\end{array}\right]=\left[\begin{array}{c}
X_{t} \\
Y_{t} \\
Z_{t}
\end{array}\right]
$$

Igualando-se esses termos, das equações 4.11 e 4.19 tem-se que:

$$
\left[\begin{array}{lll}
m_{11} & m_{21} & m_{31} \\
m_{12} & m_{22} & m_{32} \\
m_{13} & m_{23} & m_{33}
\end{array}\right] \cdot\left[\begin{array}{c}
x_{f} \\
y_{f} \\
f
\end{array}\right]+\left[\begin{array}{c}
X_{C P} \\
Y_{C P} \\
Z_{C P}
\end{array}\right]=s\left[\begin{array}{c}
X_{A}-X_{C P} \\
Y_{A}-Y_{C P} \\
Z_{A}-Z_{C P}
\end{array}\right]+\left[\begin{array}{c}
X_{C P} \\
Y_{C P} \\
Z_{C P}
\end{array}\right]
$$

De onde,

$$
\left[\begin{array}{c}
x_{f} \\
y_{f} \\
f
\end{array}\right]=s\left[\begin{array}{lll}
m_{11} & m_{12} & m_{13} \\
m_{21} & m_{22} & m_{23} \\
m_{31} & m_{32} & m_{33}
\end{array}\right] \cdot\left[\begin{array}{c}
X_{A}-X_{C P} \\
Y_{A}-Y_{C P} \\
Z_{A}-Z_{C P}
\end{array}\right]
$$

Que gera as seguintes equações escalares:

$$
\left.\begin{array}{l}
x_{f}=s\left[m_{11}\left(X_{A}-X_{C P}\right)+m_{12}\left(Y_{A}-Y_{C P}\right)+m_{13}\left(Y_{A}-Y_{C P}\right)\right] \\
y_{f}=s\left[m_{21}\left(X_{A}-X_{C P}\right)+m_{22}\left(Y_{A}-Y_{C P}\right)+m_{23}\left(Y_{A}-Y_{C P}\right)\right] \\
f=s\left[m_{31}\left(X_{A}-X_{C P}\right)+m_{32}\left(Y_{A}-Y_{C P}\right)+m_{33}\left(Y_{A}-Y_{C P}\right)\right]
\end{array}\right\}
$$

Dividindo-se as duas primeiras equações pela terceira, elimina-se o parâmetro escalar $s$ da reta espacial de colinearidade e tem-se as equações da colinearidade em sua forma clássica: 


$$
\left.\begin{array}{c}
x_{f}=f \frac{\left[m_{11}\left(X_{A}-X_{C P}\right)+m_{12}\left(Y_{A}-Y_{C P}\right)+m_{13}\left(Z_{A}-Z_{C P}\right)\right]}{\left[m_{31}\left(X_{A}-X_{C P}\right)+m_{32}\left(Y_{A}-Y_{C P}\right)+m_{33}\left(Z_{A}-Z_{C P}\right)\right]} \\
y_{f}=f \frac{\left[m_{21}\left(X_{A}-X_{C P}\right)+m_{22}\left(Y_{A}-Y_{C P}\right)+m_{23}\left(Z_{A}-Z_{C P}\right)\right]}{\left[m_{31}\left(X_{A}-X_{C P}\right)+m_{32}\left(Y_{A}-Y_{C P}\right)+m_{33}\left(Z_{A}-Z_{C P}\right)\right]}
\end{array}\right\}
$$

A partir das coordenadas de um ponto $A$, no terreno, e daquelas do centro de projeção, $C P$, ambas no sistema objeto, as equações clássicas da colinearidade, 4.24 determinam os valores, no sistema fotogramétrico, das coordenadas de seu homólogo $a$, contido na imagem.

Fazendo-se desenvolvimento análogo pode-se escrever :

$$
\left.\begin{array}{l}
\left(X_{A}-X_{C P}\right)=\left(Z_{A}-Z_{C P}\right) \frac{m_{11} x_{f}+m_{21} y_{f}+m_{31} f}{m_{31} x_{f}+m_{32} y_{f}+m_{33} f} \\
\left(Y_{A}-Y_{C P}\right)=\left(Z_{A}-Z_{C P}\right) \frac{m_{21} x_{f}+m_{22} y_{f}+m_{32} f}{m_{31} x_{f}+m_{32} y_{f}+m_{33} f}
\end{array}\right\}
$$

\subsection{Correções ao resultado fornecido pela equação da colinearidade.}

Como ficou dito é necessário aplicar algumas correções das quais se pode destacar a refração atmosférica, a curvatura terrestre e as distorções das lentes, que são analisadas a seguir.

\subsubsection{Refração atmosférica.}

O raio de luz que passa por um ponto $A$ no terreno, pelo centro de projeção $C P$, e atinge o plano do fotograma no seu homólogo $a$, se dá na atmosfera e tem sua trajetória aproximando-se de uma reta (figura 4.6).

Pela reta tracejada que vai de $A$, passa pelo centro de projeção $C P$, chega-se ao ponto ideal $a^{\prime}$ a uma distância $r^{\prime}$, na direção radial. O caminhamento real do raio que passa por $A$ e pelo $C P$ (curvo), atinge a imagem no ponto $a$, a uma distância radial $r$ 
do centro da imagem, maior do que a distância $r^{\prime}$, obtida pela equação da colinearidade.

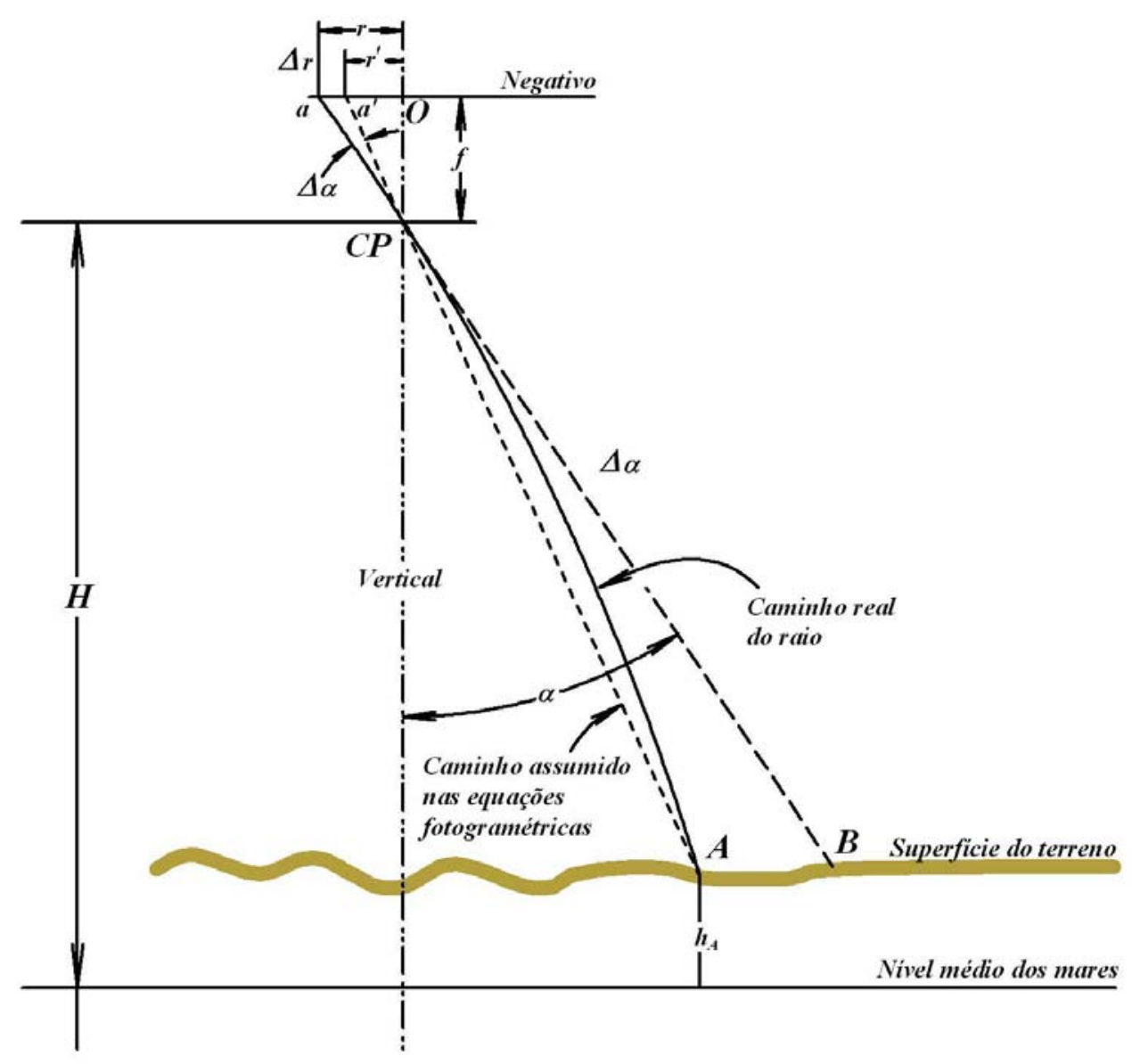

Figura 4.7 - Desenho esquemático do efeito da refração atmosférica.

A utilização da posição $a$ na equação paramétrica da reta de colinearidade (por $a$ e $C P$ ), leva à posição do ponto $B$, e não aquela de $A$, acarretando assim um erro. Aplicando-se a correção da influência da refração no raio homólogo, ou seja, utilizando $a^{\prime}$ esse erro é minimizado. Pode-se usar uma correção para as coordenadas de $a$ ou para o ângulo de incidência $\alpha$, levando a uma posição mais próxima da real.

Para a correção no ângulo $\alpha$, deve-se ter em conta que numa imagem aérea vertical, o efeito do deslocamento devido à refração atmosférica, é modelado como radial, tendo como centro o ponto principal da mesma. Sendo $\vec{v}$ o vetor da reta que une um ponto $A$, no terreno, com seu homólogo $a$, na fotografia, define-se como $\alpha \mathrm{o}$ 
ângulo que $\vec{v}$ forma com a vertical (figura 4.6). O incremento angular provocado por este efeito será $\Delta \alpha$ e pode-se expressá-lo como:

$$
\Delta \alpha=K \tan \alpha
$$

Onde $K$ é o fator de correção do ângulo de incidência, devido à refração. $O$ valor de $K$ depende da altitude da tomada da foto e da altitude do terreno. Existem diversos modelos que determinam o valor de $K$, sempre tomando em conta uma atmosfera padrão. A seguir são apresentados, conforme extraído e adaptado de MIKHAIL (2001) e WOLF (2000), os dois mais utilizados.

\subsubsection{Modelo de correção da refração do ARDC/USAF.}

O modelo do Comando de Pesquisas e Desenvolvimento do Ar da Força Aérea Americana USAF - ARDC (United States Air Force - Air Research and Development Comand):

$$
K=\left[\frac{2410 H}{H^{2}-6 H+250}-\frac{2410 h}{h^{2}-6 h+250} \cdot\left(\frac{h}{H}\right)\right] x 10^{-6}
$$

Onde:

$H$ é a altitude do vôo em km;

$h$ é a altitude do terreno em $\mathrm{km}$

$K$ é o fator de correção do ângulo de incidência em radianos.

Para que se tenha uma idéia da ordem de grandeza dessa correção, exemplifica-se, calculando a posição $(x, y)$ do homólogo de um ponto do terreno no fotograma para a seguinte situação:

Posição no fotograma de $x^{\prime}=97 \mathrm{~mm}$ e $y^{\prime}=103 \mathrm{~mm}$; altitude de vôo $H=4.350 \mathrm{~m}$; altitude de terreno $h=600 \mathrm{~m}$; distância focal da câmara de $152 \mathrm{~mm}$.

$K=0.0000424 \mathrm{rad} ; x=97.008 \mathrm{~mm}$ e $y=103.008 \mathrm{~mm}$. Ou seja, a correção de deslocamento é de $8 \mu \mathrm{m}$ em $x$ e $y$. 


\subsubsection{Modelo de correção da refração do Manual de Fotogrametria da Sociedade Americana de Fotogrametria.}

Segundo o Manual de Fotogrametria da Sociedade Americana de Fotogrametria, o fator $K$ é modelado pela a seguinte expressão:

$$
K=\left(\frac{\pi}{180}\right)\left(7.4 \times 10^{-4}\right)(H-h)[1-0,02(2 H-h)]
$$

Onde:

$H$ é a altitude do vôo em $\mathrm{km}$;

$h$ é a altitude do terreno em $\mathrm{km}$

K é o fator de correção do ângulo de incidência em radianos.

Para a mesma situação anterior tem-se:

$K=0.0000476 \mathrm{rad} ; x=97.009 \mathrm{~mm}$ e $y=103.009 \mathrm{~mm}$. Ou seja a correção de deslocamento de $9 \mu \mathrm{m}$ em $x$ e $y$, valor próximo da anterior, sendo a fórmula mais simples.

\subsubsection{Curvatura terrestre}

A curvatura terrestre tem o efeito de reduzir a escala dos objetos quanto mais o ponto se afasta do centro do fotograma, como mostrado na figura 4.7. Isso causa uma distorção radial que faz com que, ao utilizar a reta calculada pela equação da colinearidade, atinja-se um ponto mais afastado do centro do fotograma, que não o homólogo do ponto buscado. 


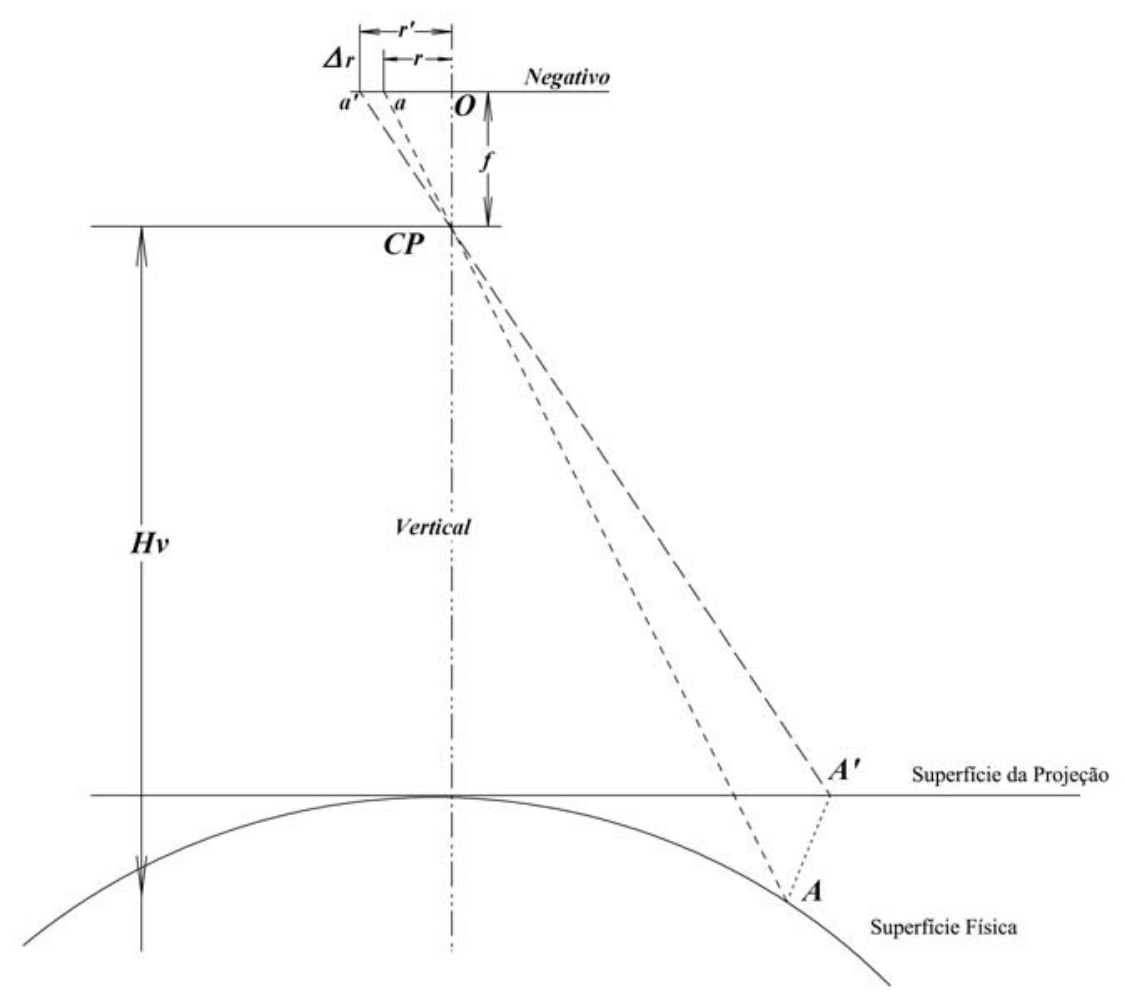

Figura 4.8 - Desenho esquemático do efeito da curvatura terrestre.

Segundo MIKHAIL (2001), a correção da curvatura pode ser obtida pela seguinte expressão:

$$
\Delta r=\frac{r^{3} H}{2 f^{2}(R+h)}
$$

Onde:

$\Delta r$ é a correção da distância radial devido à curvatura;

r' é a distância radial para a' (o pseudo homólogo de A);

$H$ é a altitude do vôo;

$h$ é a altitude do terreno;

fé a distância focal da câmara;

$R$ é o raio médio da terra na região. 
Para que se tenha idéia do valor dessa correção, avalia-se aqui para as mesmas condições onde foi avaliada a correção da refração em 4.6.1, tomando-se como raio médio terrestre o valor de $6.376 \mathrm{~km}$.

$x=96.971 \mathrm{~mm}$ e $y=102.970 \mathrm{~mm}$. Pode-se perceber uma correção de deslocamento de $30 \mu \mathrm{m}$ em $x$ e $y$.

A maioria dos programas de aerotriangulação trabalham em sistemas de coordenadas retangulares para a representação da superfície curva da Terra, usando coordenadas geocêntricas ou referenciais cartesianos locais. No caso de se utilizar um sistema desses, a correção da curvatura não deve ser aplicada uma vez que a transformação para coordenadas na projeção desejada leva em conta esse efeito. (MIKHAIL, 2001)

Quando as coordenadas desse sistema forem de uma projeção cartográfica, que já levam em conta a curvatura, a correção desta poderá melhorar nas duas dimensões, ou degradar uma dimensão ou ambas do seu plano horizontal. Por exemplo, quando se utiliza a projeção UTM, a aplicação da correção da curvatura irá melhorar a exatidão da componente $\mathrm{Y}$ (ou $\mathrm{N}$ ), porém irá degradar a posição em $\mathrm{X}$ (ou E). (WOLF, 2000)

Uma das maneiras de corrigir esse efeito, quando o sistema objeto é o de uma projeção cartográfica, é o de criar um plano cartesiano referido à normal local, e, para cada modelo, efetuar todas as medidas neste sistema objeto não corrigindo a curvatura, retornando-se, em seguida para o sistema topocêntrico e daí, para o sistema de coordenadas objeto.

No caso da utilização de planos topográficos locais, onde as dimensões são representadas num plano, em grandeza natural, a correção da curvatura, como apresentada na equação 4.29, melhorará o posicionamento do homólogo. 


\subsubsection{Distorções das lentes}

Todos os conjuntos ópticos de lentes esféricas apresentam aberrações, que correspondem a desvios da geometria teórica de imageamento.

Segundo Mikhail (2001) das cinco principais, aberração esférica, coma, astigmatismo, curvatura de campo e distorção, nos casos de utilização de câmaras métricas, somente a última não pode ser desprezada, e deve ser corrigida em processos fotogramétricos.

A descentrada também referida na literatura como tangencial é conseqüência de erros na montagem dos componentes do conjunto, e apresenta componentes afetando a simetria rotacional da imagem.

A distorção radial simétrica é o deslocamento na direção radial de um ponto na imagem em relação à sua posição numa geometria ideal. É determinada no processo de calibração da câmara, e tem seus valores positivos quando o deslocamento se dá do ponto principal para fora da imagem e negativo em caso contrário. No anexo 4 encontra-se um certificado de calibração de uma Câmara RMK TOP 15 da Zeiss, onde se pode verificar a determinação dessa distorção. Para exemplificar, apresenta-se a seguir o trecho deste documento onde se observa as determinações da distorção radial, partindo do centro no sentido das marcas fiduciais de canto, 5, 6, 7 e 8 e a sua respectiva média. Nota-se que neste conjunto óptico esses valores são, na prática, irrelevantes por se tratarem de valores bastante pequenos, o que pode não ocorrer em outras câmaras. 
Quadro 4.1 - Detalhe de certificado de calibração onde se observa no item 2 os valores da distorção radial em função da distância do Ponto Principal.

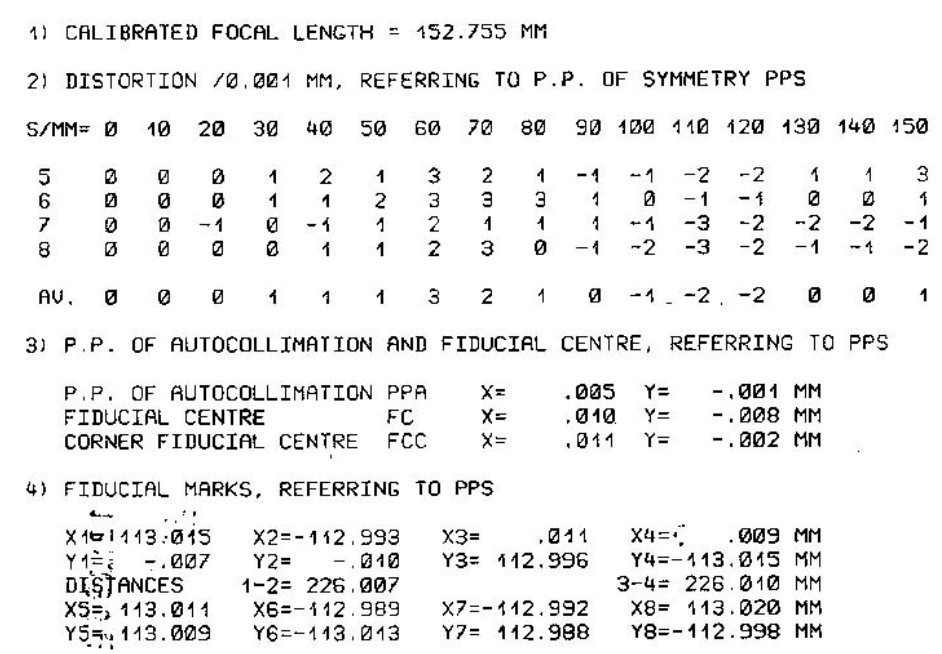

Outra maneira de representar esses valores é o polinomial, onde a distorção radial, $d_{r}$, é representada por uma série de potências da distância radial, $r$. Esses valores podem ser vistos no anexo 4 no certificado de calibração de câmara de onde se extrai o quadro a seguir para exemplificar os valores da distorção radial e a descentrada.

Quadro 4.2 - Detalhe do certificado de calibração de câmara apresentando os valores dos parâmetros de distorção radial e descentrada.

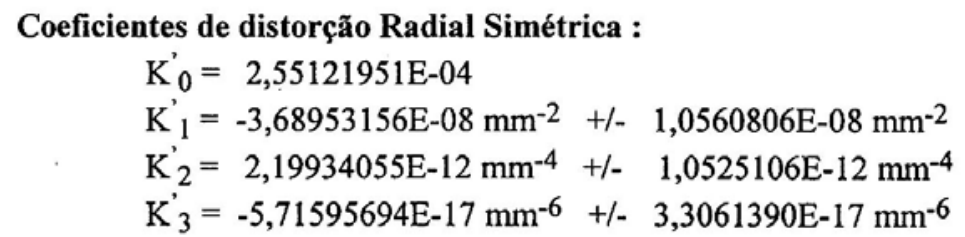

Coeficientes de Distorção Descentrada :

$$
\begin{aligned}
& \mathrm{P}_{1}=1,47767361 \mathrm{E}-07 \mathrm{~mm}^{-2} \quad+/-8,0585057 \mathrm{E}-08 \mathrm{~mm}^{-2} \\
& \mathrm{P}_{2}=4,41053931 \mathrm{E}-07 \mathrm{~mm}^{-2} \quad+/-9,8398437 \mathrm{E}-08 \mathrm{~mm}^{-2}
\end{aligned}
$$

As equações polinomiais assumem formas do tipo (MITISHITA, 2003): 


$$
\begin{aligned}
& r=\sqrt{x^{2}+y^{2}} \\
& \delta x=\left(K_{0}+K_{1} r^{2}+K_{2} r^{4}+K_{3} r^{6}\right) x \\
& \delta y=\left(K_{0}+K_{1} r^{2}+K_{2} r^{4}+K_{3} r^{6}\right) y \\
& \delta^{\prime} x=P_{1}\left(r^{2}+2 x^{2}\right)+2 P_{2} x y \\
& \delta^{\prime} y=P_{1} x y+P_{2}\left(r^{2}+2 y^{2}\right) \\
& x^{\prime}=x-\delta x-\delta^{\prime} x \\
& y^{\prime}=y-\delta y-\delta^{\prime} y
\end{aligned}
$$

Onde:

r é a distância radial de um ponto qualquer do fotograma ao ponto principal;

$\delta x$ e $\delta y$ são as componentes da distorção radial em $x$ e $y$, respectivamente;

$\delta^{\prime} x$ e $\delta^{\prime} y$ são as componentes da distorção descentrada em $x$ e $y$, respectivamente;

$x^{\prime}$ e $y^{\prime}$ são as coordenadas fotogramétricas corrigidas da distorção radial e da descentrada.

Para que se tenha a ordem de grandeza desta correção, determinou-se a seguir seus valores, nesta câmara, para o mesmo ponto utilizado no item 4.6.2. , ou seja, $x=96.971 \mathrm{~mm}$ e $y=102.970 \mathrm{~mm}$.

Aplicando-se as equações acima se tem: $\delta x=-0.0059 \mathrm{~mm}, \delta y=-0.0062 \mathrm{~mm}$, $\delta^{\prime} x=0.0145 \mathrm{~mm}, \delta^{\prime} y=0.0211 \mathrm{~mm}, x^{\prime}=96.962 \mathrm{~mm}$ e $y^{\prime}=102.955 \mathrm{~mm}$, apresentando um deslocamento devido às distorções de $-9 \mu \mathrm{m}$ em $x$ e $-15 \mu \mathrm{m}$ em $y$. O que em se trabalhando com resolução geométrica de 15 a $28 \mu \mathrm{m}$ se mostra relevante.

\subsection{Ortofoto digital}

Os conceitos aqui apresentados foram extraídos e adaptados de Wolf e Dewitt (2000) e Mikhail et al (2001).

Uma ortofoto é uma fotografia mostrando imagens de objetos na sua verdadeira posição ortográfica, ou seja, em planta. Ortofotos então, são geometricamente equivalentes aos mapas convencionais de linhas e símbolos que 
também mostram as posições ortográficas dos objetos. A maior diferença entre ortofoto e um mapa convencional é que, na primeira as feições são representadas por suas imagens, enquanto na segunda, são representadas por linhas e símbolos. Devido à sua correção planimétrica, as ortofotos podem ser utilizadas como mapas, para que nela se façam diretamente medidas de ângulos, distâncias, posições e áreas, dispensando correções devido ao deslocamento da imagem em função do relevo e da inclinação da tomada. São geralmente utilizadas como complementação, ou mesmo referência, para feições planimétricas de bases cartográficas, permitindo sobre si a realização de análises e estudos, bem como a extração de feições.

Ortofotomapas elaborados a partir de mosaicagem de ortofotos oferecem uma vantagem significativa sobre aerofotos e mapas vetoriais, pois possuem as vantagens de ambos: por um lado apresentam a qualidade pictórica das fotos aéreas, permitindo a identificação de uma infinidade de objetos e por outro, devido a sua qualidade em planimetria, permite que sejam efetuadas medidas como num mapa vetorial.

No caso de ortofotos digitais, a matriz contendo os elementos de sua imagem é gravada em arquivo digital, nos seus mais diversos formatos, e seu posicionamento em arquivo, também digital, denominado de world files. No caso do formato Tiff, o arquivo de posição usualmente o TFW (tiff world file). Por vezes esses arquivos são incluídos no cabeçalho do arquivo da imagem, como no caso do GeoTIFF.

Para a correção planimétrica da fotografia, de maneira a transformá-la numa ortofoto, é utilizada a técnica da retificação diferencial. Esta, em poucas palavras, pode ser entendida como a retificação em pequenas porções da imagem.

Os efeitos do relevo na imagem podem ser entendidos com o auxílio da figura 4.9 , onde se vêem quatro segmentos $S, R, T$ e $U$, de mesma dimensão dispostos no terreno em diferentes altitudes. Seus homólogos são representados num plano focal de uma imagem de projeção cônica, por $s, r, t$ e $u$, e, num plano de projeção ortogonal, por $S^{\prime}, R^{\prime}, T^{\prime}$ e $U^{\prime}$. 


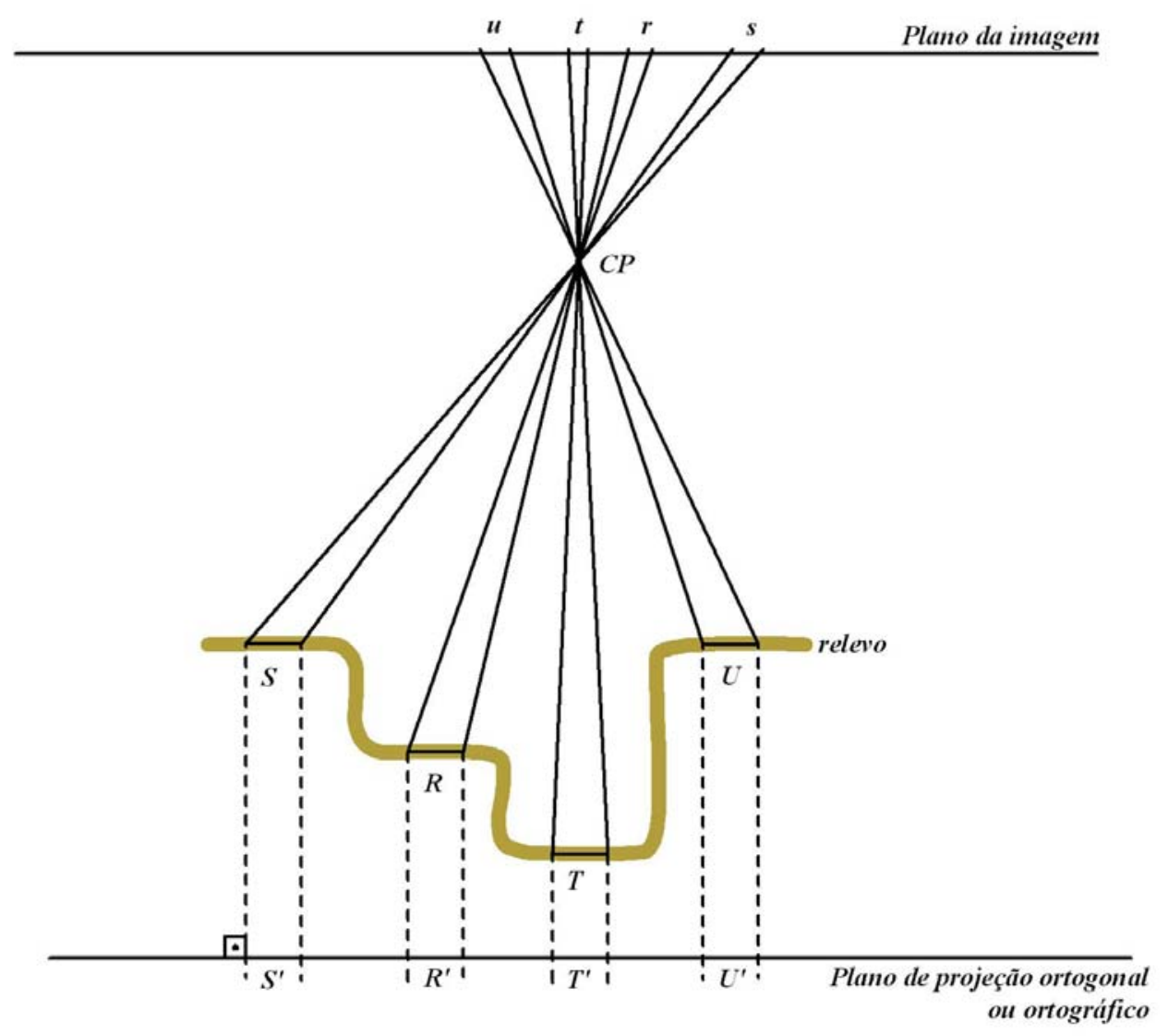

Figura 4.9 - Deslocamentos na fotografia devido à altitude.

Note-se que: $S=R=T=U$, na imagem percebe-se que $s=u>r>t$, e no plano ortogonal, $S^{\prime}=R^{\prime}=T^{\prime}=U^{\prime}$. Verifica-se então que quanto mais afastada do sensor estiver a feição, menor sua escala de representação, e seu posicionamento dentro da imagem, uma vez que esta é contínua, apresenta-se deslocado com relação a uma mesma feição, na mesma posição, que tivesse diferente altitude. Já na projeção ortográfica, os elementos se apresentam com a mesma proporção que no terreno, mesmo que em diferentes altitudes.

Quanto à inclinação, os deslocamentos podem ser avaliados de maneira análoga, utilizando-se da figura 4.10. Onde quatro segmentos de mesma dimensão na mesma altitude tem seus homólogos de dimensões diferentes quando projetados num plano inclinado. Já na projeção ortográfica, os homólogos das feições permanecem semelhantes aos originais. 


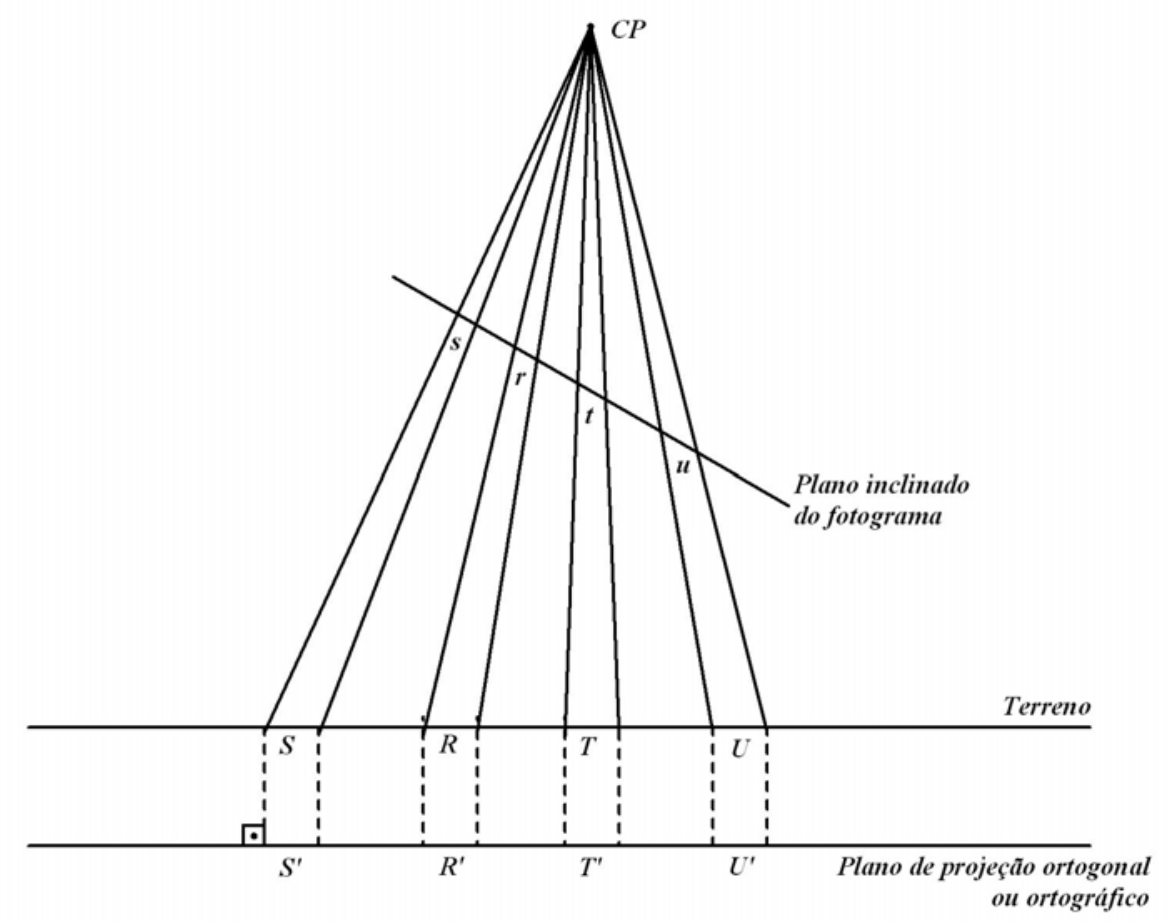

Figura 4.10 - Deslocamentos na fotografia devidos a sua inclinação

Nota-se aqui que $S=R=T=U=S^{\prime}=R^{\prime}=T^{\prime}=U^{\prime}$, porém, $\mathrm{s} \neq \mathrm{r} \neq \mathrm{t} \neq \mathrm{u}$.

O problema então é de transformar essa imagem de projeção cônica inclinada numa de projeção ortogonal. Os deslocamentos na imagem aerofotogramétrica são devidos à posição de sua tomada, da inclinação do plano focal no instante da captura, da distância focal do sensor e do relevo. Sendo assim esses são os fatores a se levar em conta para a ortorretificação.

Segundo Ferreira (1993) e Queiroz Filho (1997), existem duas abordagens a direta e a indireta.

A direta, que parte das coordenadas, no sistema fotogramétrico orientado no espaço e, pelas equações da colinearidade (a reta interceptando a superfície do terreno), determina a posição do ponto em questão. Utilizam-se as fórmulas da equação 4.25. Neste método não se conhecem todos os termos do lado direito da equação, exigindo-se então iterações com aproximações sucessivas para localizar o ponto no terreno. 
A inversa, parte de coordenadas de terreno de um ponto, e localiza-se seu homólogo no sistema fotogramétrico. Uma vez que o fotograma encontra-se orientado pode-se lançar mão das equações da colinearidade. Neste caso são as da equação 4.24. Note-se que neste método, conhecido o modelo numérico do terreno, a partir de uma determinada posição planimétrica, determina-se a altitude, e, por conseguinte, são conhecidos todos os elementos do lado direito da equação, permitindo, assim a determinação dos elementos do lado esquerdo, que são as coordenadas fotogramétricas, do homólogo do ponto.

No caso do presente trabalho, foi utilizado o segundo método. Associa-se uma malha quadrada, regular e equiespaciada planimetricamente no solo, a uma matriz bidimensional. Para cada elemento de solo desta matriz, cujas coordenadas planimétricas são conhecidas, determina-se, a altitude por meio do modelo numérico de elevações. Conhecidas as três dimensões do ponto no solo, utilizando-se das equações 4.24, determina-se a posição de seu homólogo no fotograma. Esta posição é usualmente fracional, logo, deve-se interpolar entre os valores vizinhos para determinar o valor da cor, ou da tonalidade, da célula. Procedendo-se assim para cada uma das células da malha, forma-se uma imagem digital em que, os efeitos do relevo e da inclinação do fotograma estão corrigidos em uma projeção ortográfica. 
Parte II - Metodologia 


\section{Capítulo 5}

\section{Metodologia para geração automática de MDE e ortoimagem em médias e pequenas escalas, utilizando correlação de imagens.}

Como já se apontou, o objetivo deste trabalho é criar uma metodologia para produzir de maneira automática, e, por conseguinte, com custo reduzido, modelos digitais de elevação (MDE) e ortoimagens em escalas compatíveis com as necessidades de gestão, planejamento e projetos básicos e funcionais, ou seja, em escalas médias e pequenas, aqui consideradas 1:5.000 ou menores. Tudo isso se utilizando de imagens aerofotogramétricas em escala 1:25.000 ou menores, munidas de seus parâmetros de orientação exterior.

O motivo foi o fato de haver, no Brasil, uma carência de informações espaciais confiáveis e atuais, produzidas com custo acessível e presteza.

Apresenta-se neste capítulo a metodologia empregada, lançando mão dos conceitos básicos de Fotogrametria e de processamento de imagens digitais apresentados nos capítulos precedentes.

Em seguida mostra-se a aplicação dessa metodologia em uma área teste (Capítulo 6), seguido de sua validação (Capítulo 7), de modo a comprovar e conferir a confiabilidade dos resultados obtidos quanto à exatidão posicional planimétrica e altimétrica, como também de qualidade visual das imagens obtidas. Ou seja uma garantia do produto ao usuário.

\subsection{Materiais necessários}

Para elaborar uma ortoimagem e seu respectivo MDE, de maneira automatizada, utilizando-se a metodologia proposta, são necessários:

- Imagens aerofotogramétricas de projeção cônica; 
- Parâmetros de orientação exterior, $\omega, \varphi, \kappa, C P\left(X_{C P}, Y_{C P}, Z_{C P}\right)$, e distância focal, dessas imagens.

\subsection{Metodologia}

Esta metodologia que visa elaborar, de maneira automática, o modelo digital de elevação e sua correspondente imagem ortorretificada, toma como premissa que exista a cobertura aerofotogramétrica e que se tenha conhecimento dos parâmetros de orientação das imagens.

Tomam-se coberturas em escalas 1:25.000 ou menores, para que haja pouca influência da paralaxe em função da altura de objetos tais como árvores isoladas, edifícios, entre outros, gerando áreas de oclusão, onde não são possíveis as leituras fotogramétricas.

Os parâmetros de orientação exterior devem ser fornecidos, seja por medida direta ou indireta. No caso da medição direta, os ângulos de rolamento $(\omega)$, arfagem $(\varphi)$ e deriva $(\kappa)$ podem ser medidos, em tempo real, por meio de unidades de medidas inerciais (IMU), e a posição do centro de projeção do sensor CP por meio de GPS. No caso de medição indireta, esses parâmetros são obtidos, usualmente, por meio de apoio de campo e ajuste de aerotriangulação em blocos de imagens.

Para o caso prático na área teste, como se verá adiante, foi utilizada a determinação dos parâmetros de orientação exterior pelo método indireto.

\subsubsection{Digitalização das imagens}

Para construir o MDE e a ortoimagem, é necessário contar-se com o respectivo conjunto de imagens digitais fotogramétricas.

Essas podem ser obtidas com a utilização de câmaras aerofotogramétricas digitais de projeção cônica, ou a filme, também conhecidas como analógicas. 
No caso de obtenção de imagens com câmara aerofotogramétrica analógica, é preciso digitalizar o original negativo em escâneres métricos de precisão, para que se tenha a imagem em formato digital.

Usualmente esses equipamentos apresentam:

- Exatidão posicional da ordem de 2 a $3 \mu \mathrm{m}$,

- Resolução radiométrica de 8 bits por banda de cor.

- Resolução espacial variável.

As digitalizações são executadas, usualmente, nas três bandas de cores com resolução espacial variando de $14 \mu \mathrm{m}$ a $28 \mu \mathrm{m}$.

O aumento da resolução espacial provoca um aumento quadrático do tamanho do arquivo em que se armazena a imagem digital.

Para que se tenha uma idéia, uma imagem colorida de um negativo de quadro focal de $23 \mathrm{~cm}$ por $23 \mathrm{~cm}$ digitalizada com uma resolução espacial de $28 \mu \mathrm{m}$ gera um arquivo com cerca de 200 MB; já uma mesma imagem digitalizada a uma resolução de $21 \mu \mathrm{m}$ gera outro de $360 \mathrm{MB}$. Sendo assim, ao utilizar a imagem deve-se procurar reduzir o tamanho do arquivo, sem prejudicar a definição necessária aos serviços.

\subsubsection{Fluxograma das etapas.}

Para que se tenha uma idéia do encadeamento das etapas e tarefas a serem executadas, apresenta-se na figura 5.1 um fluxograma esquemático da metodologia. Cada uma das etapas do processo será apresentada nos itens subseqüentes. 

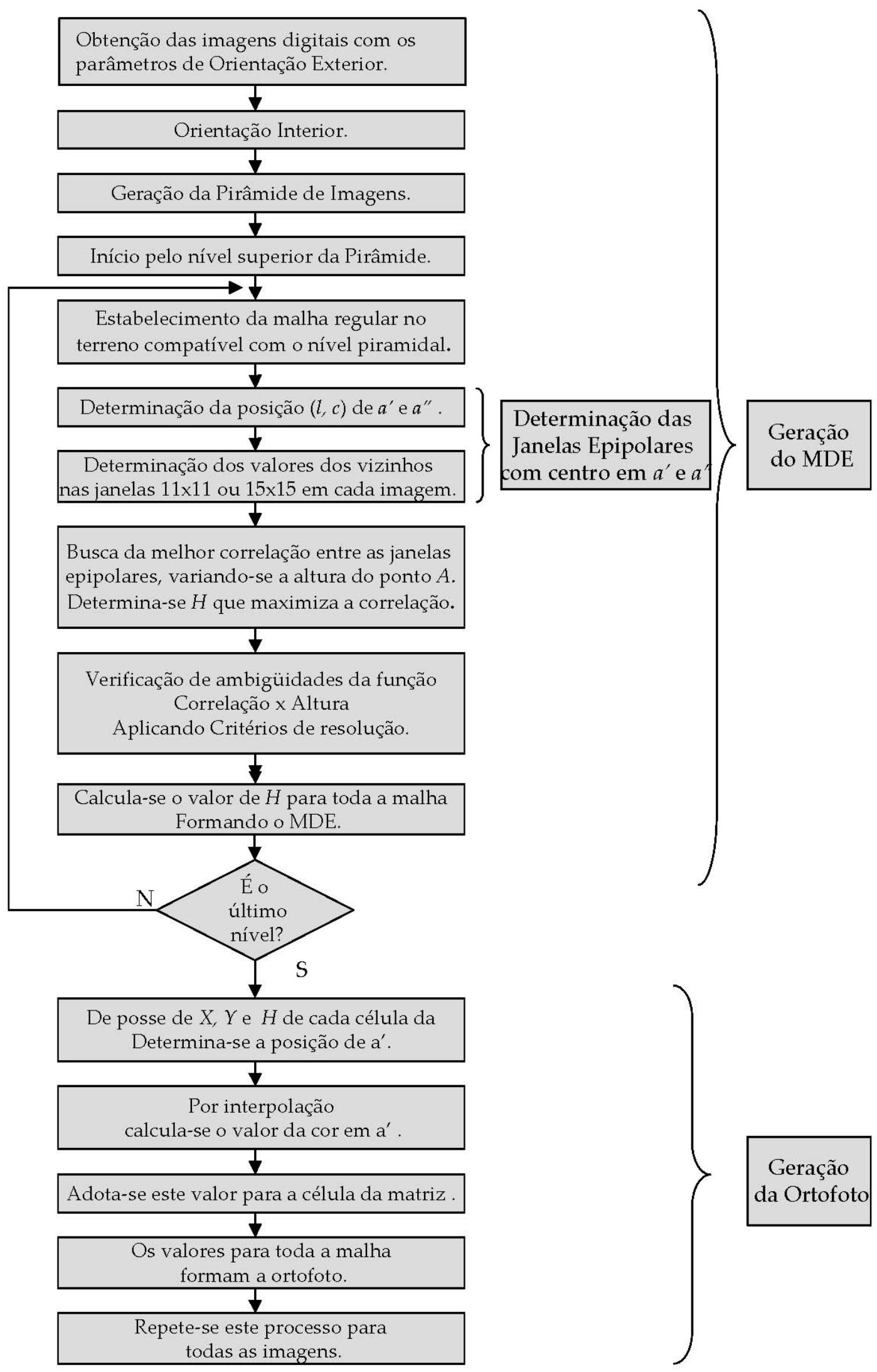

Figura 5.1 - Fluxograma das etapas do processo da metodologia apresentada. 


\subsubsection{Orientação interior}

Todas as leituras em fotogrametria digital são feitas sobre o sistema de coordenadas da imagem digital. Sendo assim, o primeiro passo é o da orientação interior que possibilita a conversão, do sistema de coordenadas de imagem digital para o fotogramétrico, e vice versa, como se mostrou anteriormente.

O método aqui empregado é o de ajuste das leituras de linhas e colunas das posições das marcas fiduciais na imagem digital, pelo método dos mínimos quadrados, de maneira a obter os parâmetros da transformação Afim.

Essa operação permite a transformação entre os dois sistemas de coordenadas (imagem digital e fotogramétrico) através da equação 4.5 aqui transcrita:

$$
\left[\begin{array}{l}
c \\
l
\end{array}\right]=\left[\begin{array}{ll}
a_{11} & a_{12} \\
a_{21} & a_{22}
\end{array}\right] \cdot\left[\begin{array}{l}
x_{f} \\
y_{f}
\end{array}\right]+\left[\begin{array}{l}
T_{x} \\
T_{y}
\end{array}\right]
$$

Essa equação transforma coordenadas do sistema de fotogramétrico $\left(x_{f}, y_{f}\right)$ em imagem digital $(l, c)$. Quando necessária a operação inversa, de transformação de coordenadas do sistema de imagem digital para o sistema fotogramétrico, utiliza-se a equação 5.2.

$$
\left[\begin{array}{l}
x_{f} \\
y_{f}
\end{array}\right]=\left[\begin{array}{ll}
a_{11} & a_{12} \\
a_{21} & a_{22}
\end{array}\right]^{-1} \cdot\left[\begin{array}{l}
c-T x \\
l-T y
\end{array}\right]
$$

No caso de câmaras digitais, como a Vexcel UltraCamD, por exemplo, os parâmetros da orientação interior aparecem no cabeçalho (ou header) da imagem, bastando assim sua leitura para que se tenham os dados para estabelecer as equações da orientação interior.

\subsubsection{Orientação exterior}

Conhecidos a distância focal $(f)$ e os parâmetros de orientação exterior, deriva $(\kappa)$, arfagem $(\varphi)$, rolagem $(\omega)$ e posição do centro de projeção do sensor CP $\left(X_{C P}, Y_{C P}, Z_{C P}\right)$, podem-se estabelecer as equações da orientação exterior e as equações 
da intersecção da reta de colinearidade com o plano do fotograma, conforme as equações 4.24 , aqui transcritas por comodidade:

$$
\begin{aligned}
& x_{f}=f \frac{\left[m_{11}\left(X_{A}-X_{C P}\right)+m_{12}\left(Y_{A}-Y_{C P}\right)+m_{13}\left(Z_{A}-Z_{C P}\right)\right]}{\left[m_{31}\left(X_{A}-X_{C P}\right)+m_{32}\left(Y_{A}-Y_{C P}\right)+m_{33}\left(Z_{A}-Z_{C P}\right)\right]} \\
& y_{f}=f \frac{\left[m_{21}\left(X_{A}-X_{C P}\right)+m_{22}\left(Y_{A}-Y_{C P}\right)+m_{23}\left(Z_{A}-Z_{C P}\right)\right]}{\left[m_{31}\left(X_{A}-X_{C P}\right)+m_{32}\left(Y_{A}-Y_{C P}\right)+m_{33}\left(Z_{A}-Z_{C P}\right)\right]}
\end{aligned}
$$

Onde os elementos da matriz de rotação podem ser vistos no conjunto de equações 4.15

Por meio dessas equações, a partir das coordenadas, no sistema objeto, de um ponto $A$ qualquer no terreno, e do conjunto de parâmetros de orientação exterior, pode-se localizar a posição, no sistema fotogramétrico, dos homólogos $a^{\prime}$ e $a^{\prime \prime}$.

\subsection{Geração do MDE.}

Esta é a parte central da metodologia apresentada, em que o conceito das janelas epipolares é mostrado.

Determinam-se as altitudes de uma malha pré estabelecida no solo a partir da correlação, pelo método baseado em área, entre pequenos intervalos de imagens epipolares de duas, ou mais, imagens que cobrem a parcela do terreno.

\subsubsection{Estabelecimento de uma malha regular no terreno}

O primeiro passo é o do estabelecimento de uma malha quadrada equiespaciada no terreno. Esta deve abarcar a área coberta pelas imagens, ou seja, a área de abrangência do modelo. Sua resolução será equivalente ao tamanho do pixel da imagem da cobertura em unidades do sistema objeto.

\subsubsection{Geração das janelas epipolares em imagens digitais.}

Conhecido um ponto $A$ no terreno e suas coordenadas $X_{A}, Y_{A}, Z_{A}$, determinase sua respectiva intersecção com o plano de cada imagem, utilizando-se as equações da colinearidade (equação 4.24) na forma inversa, ou seja, determinam-se as 
coordenadas, no sistema fotogramétrico, de seus homólogos nas imagens da esquerda e da direita, $a^{\prime}$ e $a^{\prime \prime}$ respectivamente. Essas posições aqui obtidas devem ser corrigidas dos efeitos da refração, das distorções da lente e, quando for o caso, da curvatura terrestre.

A partir das equações da colinearidade, de posse das coordenadas no sistema objeto de um ponto $A$ com homólogo na imagem e do centro de projeção, determinam-se aquelas do sistema fotogramétrico. Obtém-se desta maneira as coordenadas fotogramétricas dos homólogos de $A$ ( $\mathrm{a}^{\prime}$ e $\left.a^{\prime \prime}\right)$ em ambos os fotogramas.

Essas posições obtidas devem ser, agora, corrigidas do efeito da refração e das distorções da objetiva, de maneira que sejam levados em conta seus efeitos, e se tenham as coordenadas de fotograma dos homólogos de $A, a^{\prime}$ e $a^{\prime \prime}$.

A correção da curvatura terrestre, só deve ser aplicada se o sistema objeto for um plano topográfico local, ou outra projeção cartográfica. Caso este seja um cartesiano local ou topocêntrico, esta não é recomendada.

De posse das equações de orientação interior dos fotogramas, e das coordenadas fotogramétricas dos homólogos de $A$, determinam-se as posições destes nos sistemas de imagem digital, tanto da esquerda como da direita.

Essas posições $\left(l a^{\prime}, c a^{\prime}\right)$ são as coordenadas no sistema de imagem digital do homólogo de $A$ na imagem esquerda, e, analogamente, $\left(l a^{\prime \prime}, c a^{\prime \prime}\right)$ são as da imagem direita.

Esses valores de linhas e colunas que se calculam não são inteiros, e assim, para que se conheçam os valores das diferentes bandas, é necessário interpolar os valores de cada célula com sua vizinhança. Para tanto, utilizou-se, a interpolação bicúbica, uma vez que é a que melhor restaura um sinal.

Conhecem-se então os valores do ponto central da janela epipolar, ou seja o valor para a posição $\left(l a^{\prime}, c a^{\prime}\right)$, que não cai no centro de um pixel das imagens. Este ponto central de cada janela epipolar, juntamente com os valores de seus vizinhos 
serão utilizados como as amostras para a determinação da correlação entre as imagens naquele ponto.

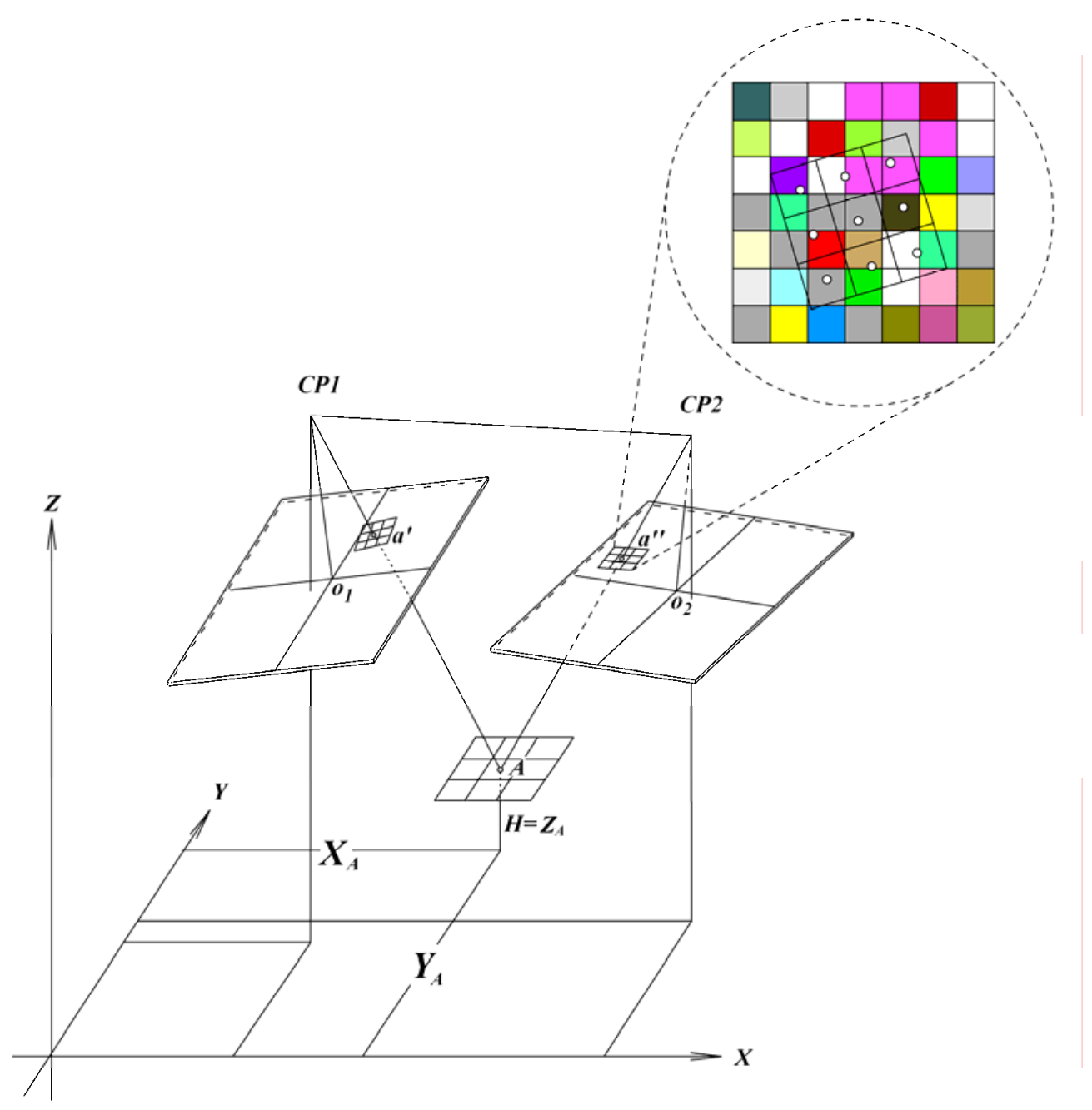

Figura 5.2 - Ilustração das janelas epipolares de comparação.

Para verificar a correlação entre as imagens digitais correspondentes à posição $A$, de terreno, deve-se analisar o entorno do ponto central de cada janela..

Não se pode simplesmente avaliar a correlação entre as imagens tomando-se os vizinhos de $\left(l a^{\prime}, c a^{\prime}\right)$ na imagem esquerda e de $\left(l a^{\prime \prime}, c a^{\prime \prime}\right)$ na imagem direita, pois como se sabe, as imagens apresentam rotações nos três eixos dimensionais, e sofrem, ainda, o efeito da paralaxe em função das altitudes do terreno.

Para construir essas janelas epipolares, parte-se de uma malha regular no terreno, com um espaçamento constante e ao redor de $A$. Na figura 5.3 tem-se o 
ponto central $\mathrm{A}=\mathrm{A}_{22}$ com seus 8 vizinhos, numa janela $3 \times 3$. Na aplicação prática foram utilizadas janelas de 11×11 e de 15x15, a simplificação da figura é por simples praticidade para visualização e raciocínio. Para cada posição desta malha no terreno, calculam-se, analogamente ao que foi feito para o ponto $A$, as posições de seus homólogos nas imagens digitais, e, de posse desses, por interpolação Bi-cúbica, os valores das três bandas para as posições obtidas.

\begin{tabular}{|l|l|l|}
\hline $\mathrm{A}_{11}$ & $\mathrm{~A}_{12}$ & $\mathrm{~A}_{13}$ \\
\hline $\mathrm{A}_{21}$ & $\mathrm{~A}_{22}$ & $\mathrm{~A}_{23}$ \\
\hline $\mathrm{A}_{31}$ & $\mathrm{~A}_{32}$ & $\mathrm{~A}_{33}$ \\
\hline
\end{tabular}

Figura 5.3-Malha de busca no solo, simplificada. Na implementação da metodologia foram usadas malhas de $11 \times 11$ e $15 \times 15$.

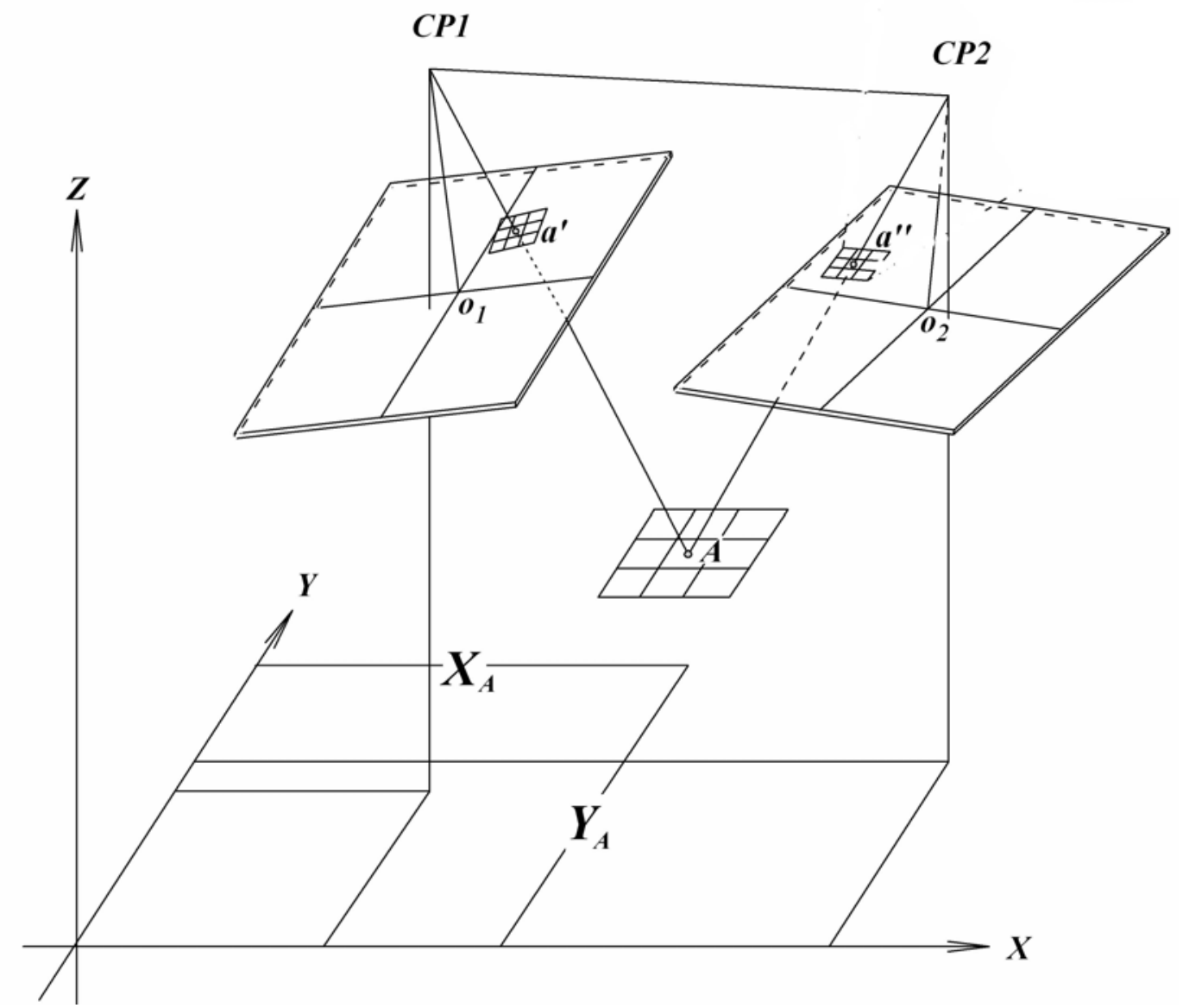

Figura 5.4 - Janela de busca no solo e suas respectivas janelas epipolares nas imagens 
Localizando os homólogos dos oito vizinhos mais próximos de $A$, nas duas imagens digitais, ter-se-ão as janelas epipolares nas duas imagens digitais que representam os homólogos dos pontos da janela de observação no terreno.

De posse das imagens dessas janelas epipolares passa-se a determinar a correlação entre elas.

Note-se que, como se pode visualizar nas figuras 5.2 e 5.3, estas janelas epipolares permitem que se possa efetuar a busca não somente em duas, mas em múltiplas imagens que cobrem a mesma região e que possuam sobreposição..

\subsubsection{Método de correlação.}

A razão da utilização de correlação de imagens é que esta permite, de uma maneira automatizável, determinar os pontos homólogos em diferentes imagens digitais.

Determinam-se as duas, ou mais, janelas de comparação, no caso aqui, como intervalos de epipolares. Estas, obrigatoriamente, deverão ter dimensões em colunas $c$ e em linhas $l$ ímpares, para que o ponto de interesse situe-se no seu centro. A correlação é feita pelo método baseado em área, onde os valores das janelas são confrontados pelo método da correlação cruzada. Conforme visto em 2.10.1.

O valor da correlação $C$ obtido, na equação 2.25 , ou a sua equivalente 2.27 , varia de 0 a 1 . Entende-se como melhor correlação, o valor de $C=1$, e nenhuma correlação o valor de $C=0$. A correlação será maior quanto mais próximo da unidade for o valor de $\mathrm{C}$, significando que as disparidades normalizadas entre as duas janelas são mais semelhantes.

Esse método mostrou-se bastante robusto, como se pôde comprovar na validação dos produtos obtidos. Isso se deve ao fato de, ao se normalizar a amostra, minimizarem-se os efeitos de diferenças de brilho e contraste entre as imagens digitais, restando ainda, neste caso, o ruído. 
No caso de imagens coloridas, utiliza-se a correlação entre as três bandas de cores. Verificou-se, na implementação, que as melhores correlações são obtidas pela banda $\mathrm{G}$ (verde). Sendo assim atribuiu-se a esta um peso maior. Seguida da banda $\mathrm{R}$ (vermelho) e da B (azul), às quais se atribuíram pesos menores. O índice de correlação aqui adotado foi:

$$
C=C_{R} \cdot 0.3+C_{G} \cdot 0.5+C_{B} \cdot 0.2
$$

Essa ponderação das correlações obtidas nas distintas bandas de cores foi obtida por comunicação verbal dos senhores José Angel Martinez e Manuel Quirós, sócios proprietários e desenvolvedores da Digi21, empresa espanhola produtora de softwares de Fotogrametria. Embora neste trabalho tenham sido verificados bons resultados com sua aplicação, recomenda-se que se estude mais a fundo essa atribuição de pesos.

\subsubsection{Espaço de busca.}

Em outras técnicas, o espaço de busca ocorre deslocando-se a janela de 15x15 nas 4 direções por ela definida. O presente trabalho, no entanto, adota outra técnica: o espaço de busca se dará variando-se a altitude do ponto $A$, o que fará com que as imagens sejam varridas por linhas epipolares, como mostra a figura 5.5. Para cada valor incremental da altitude, são geradas novas janelas epipolares nas duas, ou mais, imagens. Serão, então, medidos os valores de correlação entre as novas janelas de imagens epipolares. 


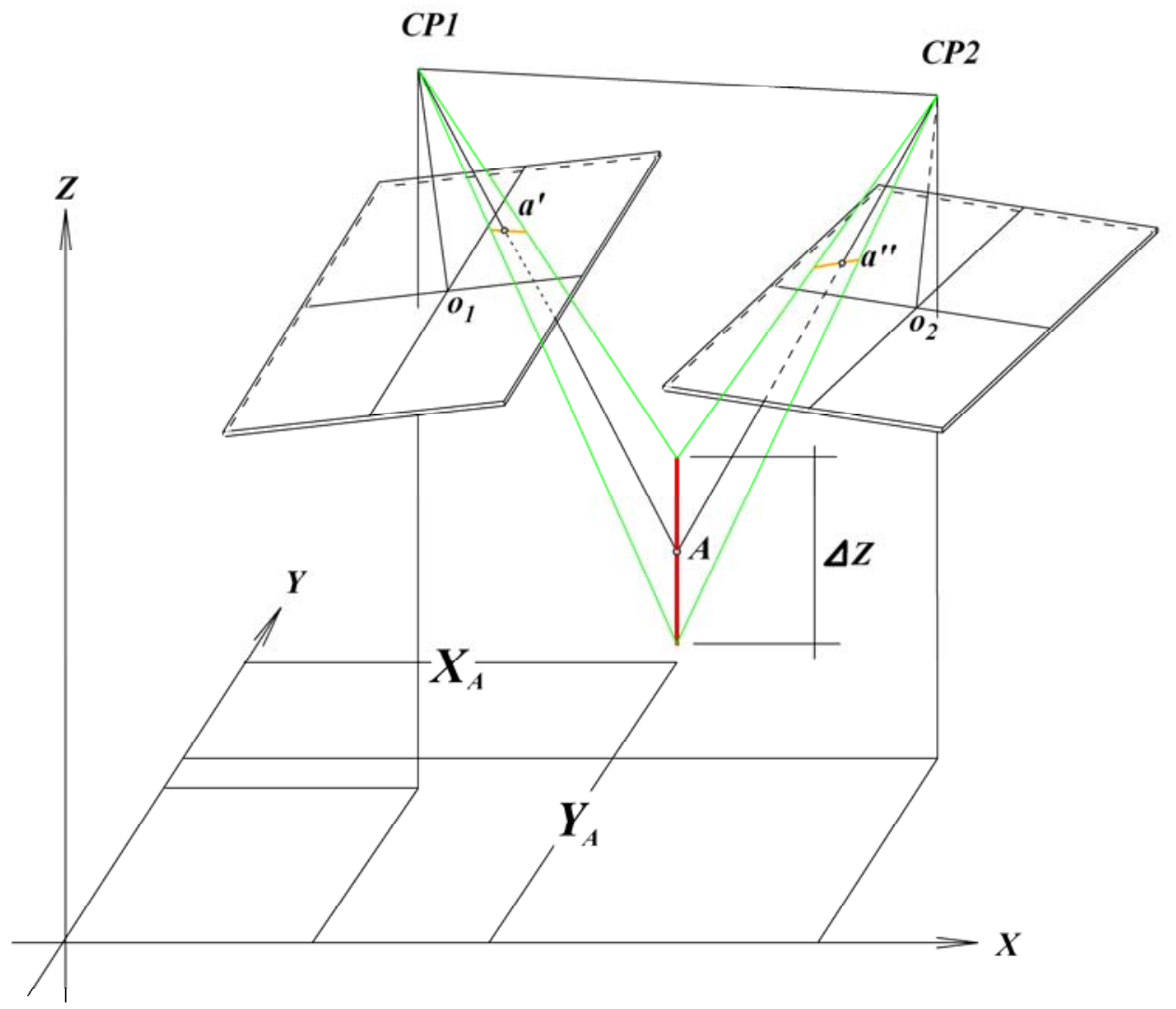

Figura 5.5 - Espaço de busca, ao longo da vertical.

Para que se determine a altitude do ponto $A$ (com coordenadas planimétricas fixas), varia-se incrementalmente a altitude de $A$, o que altera a janela de busca, como se pode ver em detalhe na figura 5.5. Os pequenos trechos de reta vermelhos em cada imagem correspondem à variação de coordenada do ponto central da janela epipolar (3×3 ou 15x15) de cada imagem, em função da variação da altura do ponto central da janela de busca no solo $A$.

Parte-se então de uma altitude mínima, incrementando-a de valores que variam de um valor correspondente a um quarto a meio pixel, até uma altitude máxima, calculando-se a correlação para cada uma dessas altitudes. Adota-se a altitude da posição do ponto $A$ como aquela que apresentou a melhor correlação entre as imagens das janelas epipolares como pode ser visto no esquema da figura 5.6. 


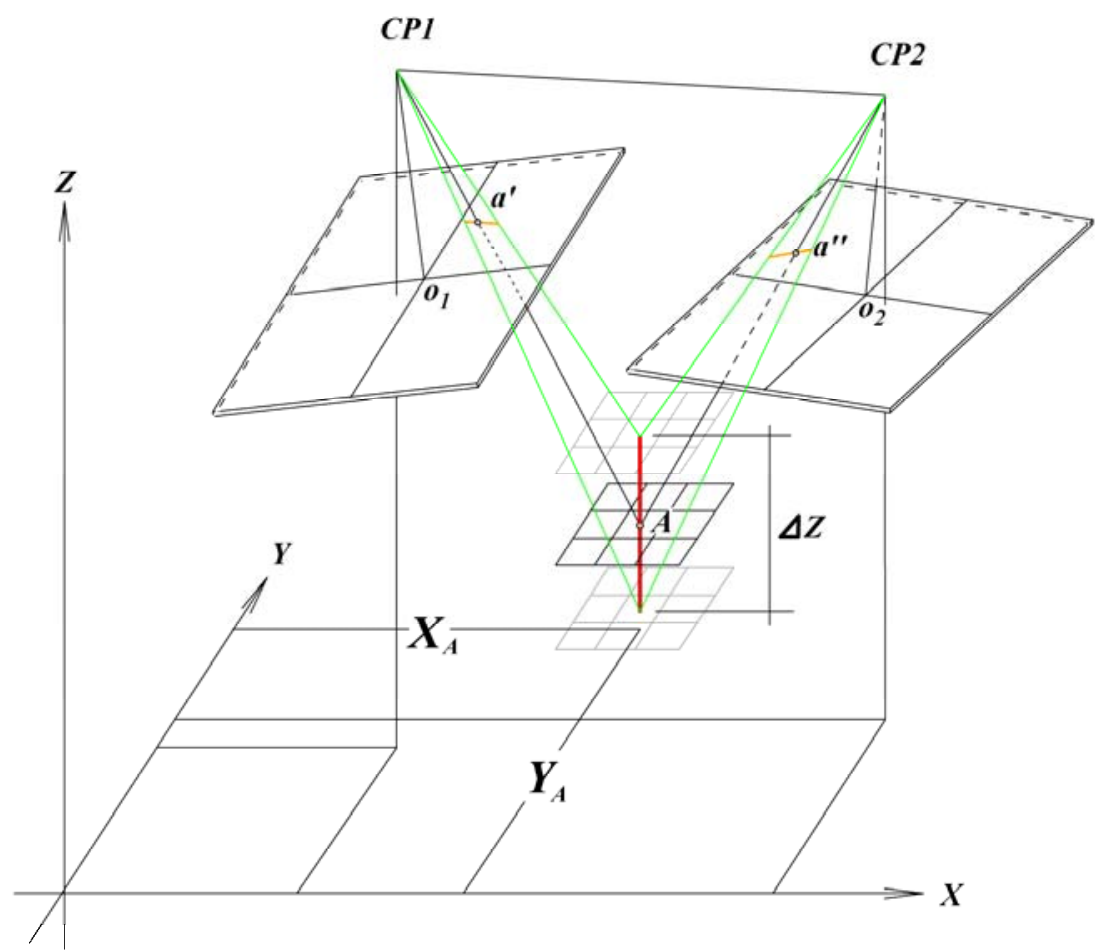

Figura 5.6 - Variação da altitude de $A$, e respectiva variação ao longo da linha epipolar, do centro das janelas epipolares.

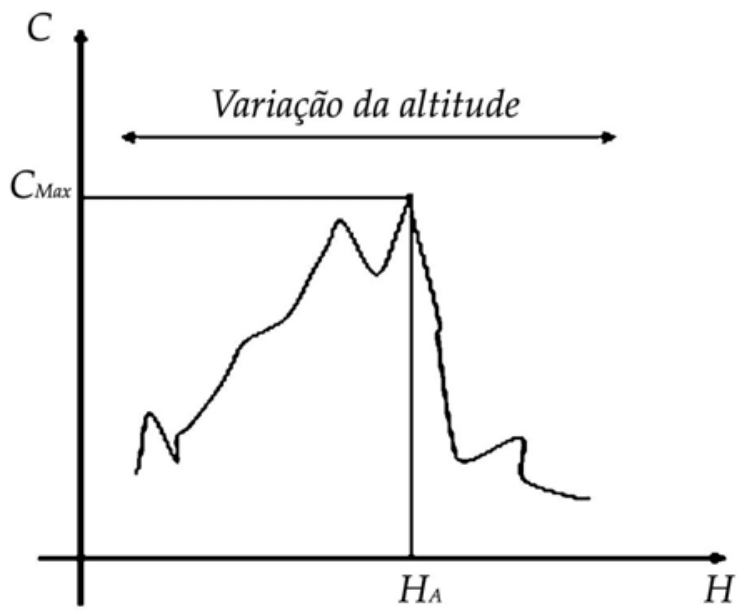

Figura 5.7 - Variação do índice de correlação em função da variação de altitude da posição planimétrica de $A$, indicando, onde é adotada a altitude $H_{A}$ em que ocorre o maior índice de correlação 
Ao obter a altitude do primeiro ponto, já se tem um parâmetro para os próximos pontos: esse valor pode ser considerado como o ponto médio de um intervalo de busca. A amplitude desse intervalo também pode ser diminuída.

Isto se faz ao longo de todas as posições da malha estabelecida no solo, para o espaço de validade das imagens, ou seja, todo o espaço do terreno cujos homólogos pertençam às imagens.

Terminada a varredura ficam determinados os valores de altitude para toda a malha quadrada estabelecida no solo. Está criado o MDE - modelo digital de elevação elaborado por correlação automática de imagens aerofotogramétricas digitais.

Na prática, o processo é melhorado já que na forma aqui proposta, para efeitos didáticos, demandaria um tempo muito grande de computação, inviabilizando o método. Para melhorar o desempenho, lança-se mão de diversas técnicas. Uma delas é a criação da pirâmide de imagens.

Para isso são criadas imagens piramidais 1:2, 1:4, 1:8, 1:16, 1:32, 1:64 e 1:128, como se mostra na figura 5.8. Os valores adotados para cada pixel do novo nível piramidal é o da média dos valores dos quatro pixels da imagem anterior.

Estabelece-se juntamente a isto uma malha no terreno compatível com cada um dos níveis piramidais, ou seja, para a imagem 1:2 a malha no terreno terá um espaçamento duas vezes maior que o original e assim sucessivamente.

Inicia-se então a determinação das altitudes pela imagem de nível 1:128. No exemplo de aplicação as imagens originais possuem aproximadamente 8200 por 8200 pixels, logo neste nível piramidal elas apresentam algo em torno de 64 por 64 pixels. Varre-se essa malha em sua totalidade, respeitando-se os limites das imagens, determinando as altitudes aproximadas de suas células.

De posse dessa primeira aproximação do MDE, parte-se para o nível seguinte, tomando-se como referência a altitude média determinada no nível anterior. Varre- 
se assim esta imagem num espaço de busca em altitude, de quatro vezes o tamanho do pixel do nível superior, para mais e para menos, variando a altitude em passos de um décimo de pixel.

A partir dessa segunda amostra do MDE, comparam-se os valores de altitude dele extraídos com os do nível anterior, de maneira a verificar possíveis discrepâncias grosseiras. Detectada alguma discrepância grosseira, refaz-se a determinação no nível em questão, repetindo-se o processo até que não sejam mais detectadas essas discrepâncias grosseiras.

Segue-se então para o nível seguinte, repetindo-se o mesmo processo, e assim sucessivamente até chegar ao nível 1:1 onde se terá um espaço de busca bastante reduzido, diminuindo o tempo de processamento computacional.

Uma vez feita a primeira varredura, restam zonas em que a altitude não pode ser determinada (ver a seguir resoluções de ambigüidades). Nessas zonas onde existem ambigüidades, a varredura é repetida nos dois sentidos das duas direções $(X$ e $Y$ ) do terreno, confirmando-se assim os valores obtidos. Isto se deve ao fato de em havendo uma ambigüidade quando se varre em determinada direção e sentido, geralmente causada por oclusão, o que pode ser minimizado varrendo-se na outra direção ou no outro sentido.

Exemplifica-se esse processo de correlação com o auxílio de pirâmide de imagens a seguir com a figura 5.8. A seqüência de imagens mostra o aumento da resolução do MDE gerado a partir da busca em imagens piramidais.

Verifica-se a primeira aproximação do MDE na imagem que representa as altitudes determinadas no processamento do nível piramidal 1:128. Em seguida é feita a sua segunda aproximação no nível 1:64, em que ainda é difícil perceber os detalhes do terreno. Essa seqüência segue, e vê-se na imagem do processamento do nível 1:16 os primeiros detalhes de relevo começando aparecer. Na imagem do MDE em nível 1:4 já se percebe a várzea do rio e a rodovia. Na imagem representativa do MDE em 
nível 1:1 se visualizam os cantos das edificações, das árvores, das margens dos rios, entre outras feições.
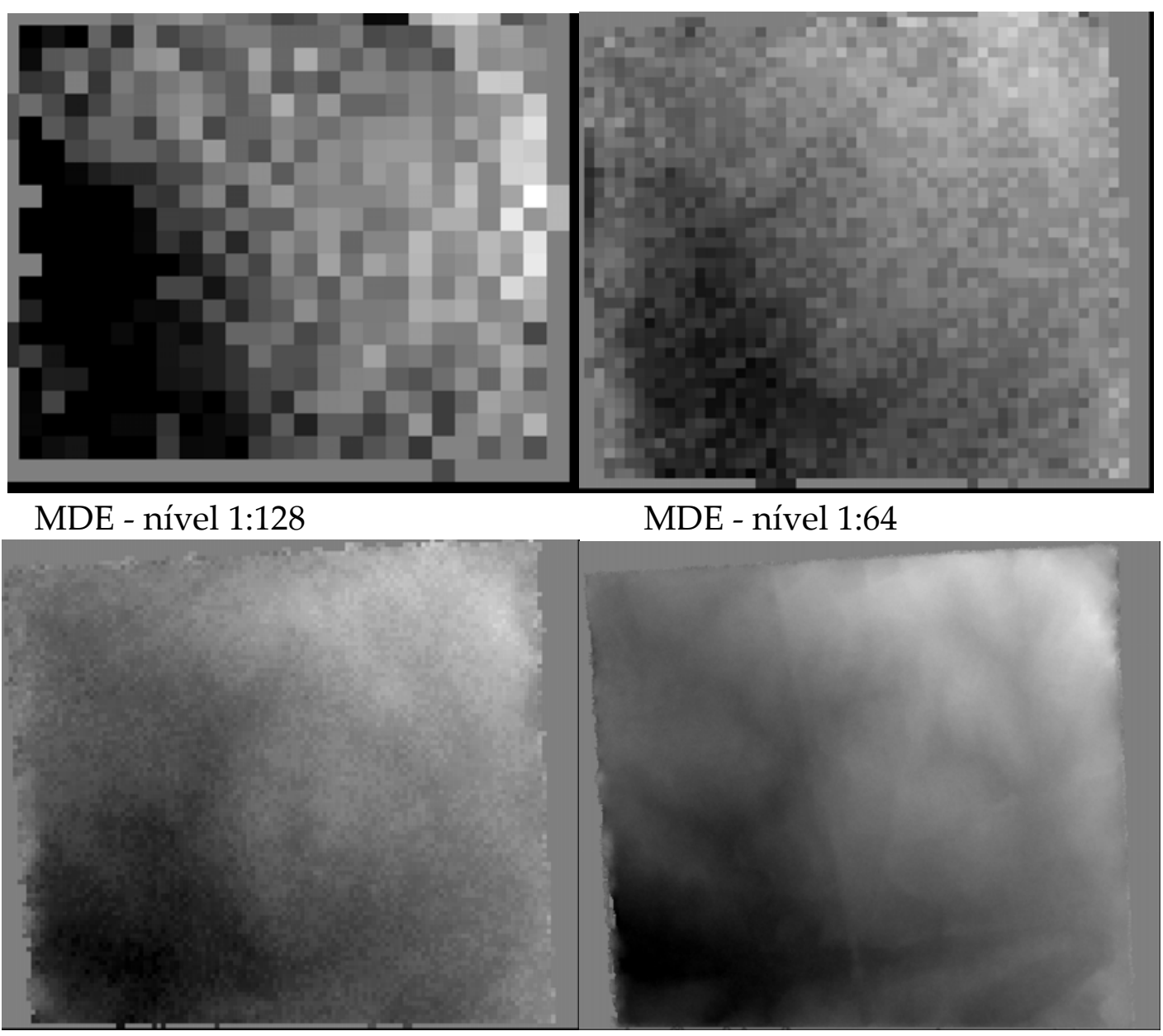

MDE - nível 1:16

MDE - nível 1:4

MDE - nível 1:2

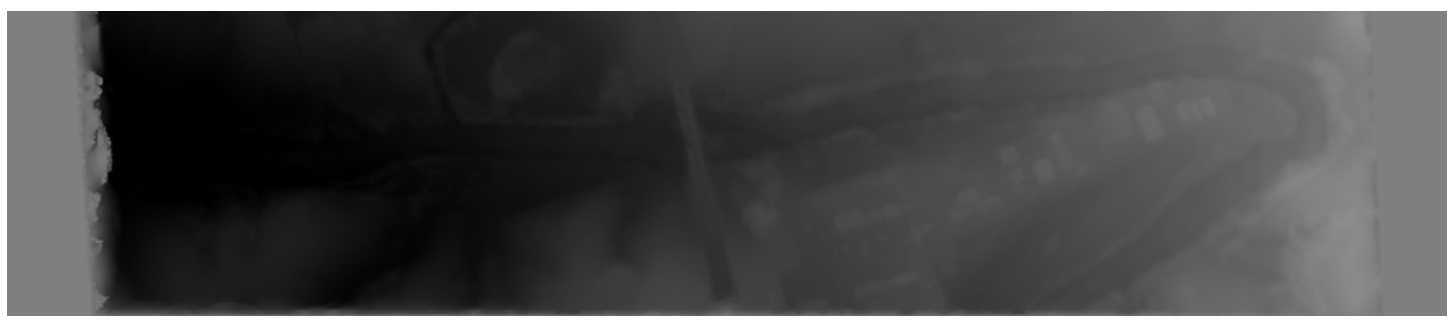

MDE - nível 1:1

Figura 5.8 - MDE gerado a partir da busca em imagens piramidais. 
A exatidão e a precisão deste MDE serão avaliadas mediante um caso prático e respectiva validação.

\subsubsection{Considerações sobre o espaço de busca e correlação.}

Verifica-se, e a prática mostrou isso, que em vários casos dentro do espaço de busca, encontram-se condições que dificultam a análise de qual altitude de terreno proporciona a melhor correlação. Por exemplo, quando se está numa região onde a feição é água, todos os valores de correlação serão altos. Já quando se está em regiões de sombras, todas as correlações serão baixas.

Para resolver essas ambigüidades, foi adotado um critério, que na prática mostrou-se eficiente.

1. Não se aceitam os valores calculados quando todas as correlações forem inferiores a 0.5. Esses casos são muito comuns em zonas de sombras e matas.

2. Não se aceitam os valores calculados quando muitas correlações consecutivas forem superiores a 0.8. Esses casos são muito comuns em locais de textura muito homogênea, como por exemplo em água, rodovias e cana.

Nesses dois casos adota-se o valor de altitude como a média de seus vizinhos.

3. Quando se encontram valores de máximos de correlação discretos para diferentes altitudes, adota-se o critério de avaliar qual o máximo de correlação que aponta para um valor de altitude, que melhor se adéqua a seus vizinhos e com os valores da altitude dos níveis piramidais superiores. É adotado o valor de altitude que, dentre os candidatos, apresente o menor afastamento com relação à média de seus vizinhos.

4. Quando a ambigüidade se mantém não se adota valor algum, e posteriormente, a todas as passagens pela malha, adota-se a média dos seus vizinhos. 


\subsubsection{Armazenamento do MDE.}

\subsubsection{O armazenamento das altitudes.}

O armazenamento da altitude de cada célula dessa malha quadrada é feito por meio de um artifício que se demonstrou eficiente e prático: cada célula será associada a um valor de cor, formando uma imagem colorida em formato TIFF com a seguinte codificação que definirá o valor numérico da altitude:

- R é o canal de variação mais significativo, seguido de G e de B.

- O intervalo de variação adotado foi de -1.000 metros até 10.000 metros.

- Assim o valor $(R, G, B)=(0,0,0)$ representa a altitude de -1.000 metros e $(R, G, B)=(255,255,255)$ representa a altitude de 10.000 metros.

- A seguir se estabelece a seguinte regra de transformação do valor armazenado, ou lido, numa imagem, em altitude:

$$
H=11000 \times\left(\frac{R}{2^{8}}+\frac{G}{2^{16}}+\frac{B}{2^{24}}\right)-1000
$$

- Para a transformação de altitudes em valores RGB.

$$
\begin{aligned}
& \Delta R=\frac{11000}{2^{8}}, \quad \Delta G=\frac{11000}{2^{16}}, \quad \Delta B=\frac{11000}{2^{24}} \\
& R^{\prime}=\left[\frac{(H+1000)}{\Delta R}\right], \quad R=\operatorname{int}\left(R^{\prime}\right) \\
& G^{\prime}=\frac{\Delta R\left(R^{\prime}-R\right)}{\Delta G}, \quad G=\operatorname{int}\left(G^{\prime}\right) \\
& B^{\prime}=\frac{\Delta G\left(G^{\prime}-G\right)}{\Delta B}, \quad B=\operatorname{int}\left(B^{\prime}\right)
\end{aligned}
$$




\subsubsection{O posicionamento da imagem do MDE.}

O posicionamento da imagem do MDE se faz por meio de um arquivo ttfw que indica o posicionamento de seu canto superior esquerdo (origem do sistema de imagem digital), o tamanho e o sentido dos pixels nas direções $X$ e $Y$ do sistema objeto.

Exemplos de arquivo do MDE podem ser vistos nas figuras 6.5 à 6.10.

Exemplo de seu arquivo .tfw:

$\begin{array}{cc}0.700000000 \odot & a_{11} \\ 0 . \odot & a_{21} \\ 0 . \odot & a_{12} \\ -0.7000000000 & a_{22} \\ 260374.689 & T_{x} \\ 7435560.214 & T_{y}\end{array}$

O arquivo TFW armazena, em arquivo texto, a seqüência dos parâmetros da Transformação Afim que leva as coordenadas do sistema da imagem digital para as do sistema objeto.

$$
\left[\begin{array}{l}
X \\
Y
\end{array}\right]=\left[\begin{array}{ll}
a_{11} & a_{12} \\
a_{21} & a_{22}
\end{array}\right] \cdot\left[\begin{array}{l}
c \\
l
\end{array}\right]+\left[\begin{array}{l}
T_{X} \\
T_{Y}
\end{array}\right]
$$

Na primeira linha deste arquivo TFW, encontra-se o valor do tamanho do pixel em $X$ (no caso $0.70 \mathrm{~m}$ ), sendo que o valor positivo indica que é crescente nesta direção. Na segunda e terceira linhas estão as inclinações em relação aos eixos $X$ e $Y$, no caso sem rotação. Na quarta linha está a dimensão $Y$ do pixel $(-0.70 \mathrm{~m})$, indicando o sinal negativo, que sua variação é no sentido contrário de $Y$. A quinta e a sexta linha apresentam os valores $X$ e $Y$, respectivamente, do centro do pixel superior esquerdo da imagem digital.

\subsection{Geração da ortoimagem}

De posse do modelo digital de superfície obtido, e das imagens munidas de seus parâmetros de orientação interior e exterior, pode-se gerar a ortoimagem. 
Para isso, estabelece-se uma malha no terreno, no caso igual à do MDE gerado. Para cada uma de suas posições têm-se, então, as coordenadas planimétricas e a altimétrica. Resta gerar uma imagem cujos pixels sejam coincidentes com essa malha, ou seja, calcular o valor de R, G e B de cada célula.

Para cada posição da malha, conhecendo-se sua altitude, ter-se-á um ponto $A$ com as três coordenadas $(X, Y, Z)$, e, pelas equações da colinearidade (equação 4.24), pode-se determinar seu homólogo $a^{\prime}$ na imagem digital.

Determinada a posição de $a^{\prime}$ na imagem pelas equações da colinearidade, deve-se proceder as correções de refração, distorções da lente e curvatura (quando for o caso), para localizar, na imagem digital, a posição do homólogo $a$ do ponto $A$.

De maneira análoga àquela anteriormente descrita, conhecendo-se a posição do homólogo de $A$, tem-se uma posição fracionária e não linha e coluna inteiras, determinam-se, então, os valores dos níveis do pixel de $a$, na imagem digital para as três cores, por meio de interpolação bi-cúbica, levando em consideração seus vizinhos na imagem.

No caso de imagens em tons de cinza, esse valor interpolado é o próprio obtido, uma vez que estas trazem apenas o valor da intensidade refletida. Já para as imagens coloridas deve-se ter um cuidado maior, uma vez que o valor interpolado para os canais $R, G$ e $B$, nem sempre representam a cor que um ser humano interpretaria como cor intermediária para esses valores. Ou seja, um valor interpolado dentro do espaço de cores RGB é bastante útil para fazer correlação entre imagens, porém pode não agradar à vista humana.

Para imagens coloridas, é usual, quando da elaboração do produto final para a utilização humana, a utilização de espaço de cor sensitivo e não o espectral. No caso, transformam-se os valores do domínio RGB para o domínio HSV, conforme abordado em 3.5.4, e neste se faz a interpolação bi-cúbica para a determinação do matiz $(H)$, saturação $(S)$ e valor $(V)$. Lembrando-se que sendo este um domínio não 
cartesiano, a interpolação de $V$ é direta, porém de $H$ e $S$ a interpolação será por soma vetorial, por estarem compreendidas em um domínio polar. Determinados os valores de HSV do pixel, retorna-se para o domínio RGB de maneira a gravar o valor do pixel na ortoimagem.

O posicionamento da ortoimagem se faz por meio de um arquivo .tfw que indica o posicionamento de seu canto superior esquerdo (origem do sistema de imagem digital), o tamanho e o sentido dos pixels nas direções $X$ e $Y$ do sistema objeto.

Essa metodologia foi posta em prática e alguns exemplos de produtos são mostrados nas figuras 6.11 a 6.17 , no próximo capítulo. 
Parte III - Aplicação da Metodologia. 


\section{Capítulo 6}

\section{Aplicação da metodologia na região de Salto (SP).}

Para confirmar o funcionamento da metodologia proposta, a mesma foi aplicada a um caso real, para posterior avaliação de seus resultados.

Essa área teste foi escolhida em função dos materiais disponíveis serem, em primeiro lugar, recentes e, portanto contemporâneos ao presente trabalho. Em segundo lugar por terem sido plenamente disponibilizados pela empresa executante, a BASE Aerofotogrametria e Projetos S/A. Em terceiro lugar porque havia ali uma boa variedade de feições, indo de urbano a rural, passando por zonas de matas, reflorestamentos, lavouras, rodovias, ferrovia, viadutos, pontes, rios, córregos, taludes de corte e aterro, que permitiriam visualizar e quantificar a qualidade dos produtos obtidos. Em quarto lugar, porque nesse mesmo local foram executadas simultaneamente duas coberturas aerofotogramétricas coloridas, uma em escala 1:25.000, e outra em 1:5.000, o que permitiu uma avaliação dos produtos obtidos a partir da cobertura mais alta, objeto do presente estudo, por aquela mais baixa. Enfim, estavam presentes todas as condições para a implementação e respectiva avaliação da metodologia aqui proposta.

Esta área teste localiza-se no município de Salto, Estado de São Paulo, no vale do rio Tietê.

\subsection{Materiais disponibilizados.}

Para a implementação foi disponibilizado o seguinte material:

\subsubsection{Referente à cobertura aerofotogramétrica na escala 1:25.000.}

- Arquivo, em formato .dgn, do foto-índice dessa cobertura;

- Imagens digitais coloridas com resolução espacial de $28 \mu \mathrm{m}$, e resolução radiométrica de 24 bits ( 8 bits por banda de cor); 
- Arquivo contendo o relatório da aerotriangulação em bloco, e respectivos parâmetros de orientação exterior das imagens digitais;

- Listagem das coordenadas do apoio de campo;

- Arquivo .dgn do esquema do apoio;

- Relatório de execução dos serviços.

\subsubsection{Referente à cobertura aerofotogramétrica em escala 1:5.000.}

- Arquivo, em formato .dgn, do foto-índice dessa cobertura;

- Imagens digitais coloridas com resolução espacial de $28 \mu \mathrm{m}$, e resolução radiométrica de 24 bits ( 8 bits por banda de cor);

- Arquivo contendo os relatórios da aerotriangulação em bloco, e respectivos parâmetros de orientação exterior das imagens digitais;

- Listagem das coordenadas do apoio de campo;

- Relatório de execução dos serviços.

\subsubsection{Considerações sobre o material recebido.}

A empresa BASE S/A foi contratada em 2005 pela Prefeitura de Salto para executar a atualização de um mapeamento em âmbito municipal, existente na escala 1:10.000 por ela executado no ano de 2002, e, para executar um mapeamento em escala 1:1.000, em âmbito de zona urbana e de expansão urbana.

Foram executadas, então as duas coberturas, uma em escala 1:25.000 da totalidade da área municipal, e outra, em escala 1:5.000 das áreas urbana e de expansão urbana.

\subsubsection{Características da cobertura aerofotogramétrica na escala 1:25.000.}

- Autorização do Ministério da Defesa: 065/05.

- Data de execução: Junho de 2005.

- Recobrimento longitudinal $60 \%$ e lateral $30 \%$. 
- Câmara: RMK TOP 15 - ZEISS , $f=152.749$ mm.

- Filme: Aerocolor III 2444.

- Processamento do original negativo: Colex C41

- Digitalização dos negativos: UltraScan 5000 - Vexcel.

- Tratamento radiométrico: RadComp 3.0 BASE

As fotografias aéreas foram digitalizadas em escâneres aerofotogramétricos diretamente dos originais negativos, com formato de saída TIFF. A resolução geométrica de digitalização foi de $28 \mu \mathrm{m}$ (907 dpi) e a radiométrica de 24 bits.

As fotografias digitalizadas receberam um tratamento radiométrico a partir do software RadComp, que foi desenvolvido pela BASE S/A.

- Como apoio de campo, foram utilizados os mesmos pontos de apoio medidos em 2002.

Os pontos foram medidos com receptores GPS de dupla freqüência, marca Topcon modelo Legacy, no modo estático, e ajustados tomando-se como injunção os pontos da Rede GPS de Campinas, vértices Bandeirantes e Mercedes.

As precisões do transporte de coordenadas, de Campinas para Salto, fornecidas pelo programa de ajuste, foram de 2, 3 e $4 \mathrm{~cm}$, respectivamente para latitude, longitude e altitude geométrica. O fechamento da rede de pontos de apoio fotogramétrico apresentou erros da ordem de 7; 7 e $10 \mathrm{~mm}$ em latitude, longitude e altitude geométrica.

As altitudes ortométricas foram obtidas mediante um modelo de ondulação geoidal local, elaborado para a região pois se dispunha das altitudes geométricas $(h)$, obtidas por rastreamento GPS, e das altitudes ortométricas $(H)$ dos marcos integrantes da Rede de Referência Cadastral do Município. Esse modelo geoidal local apresenta uma precisão nominal de $10 \mathrm{~cm}$. 


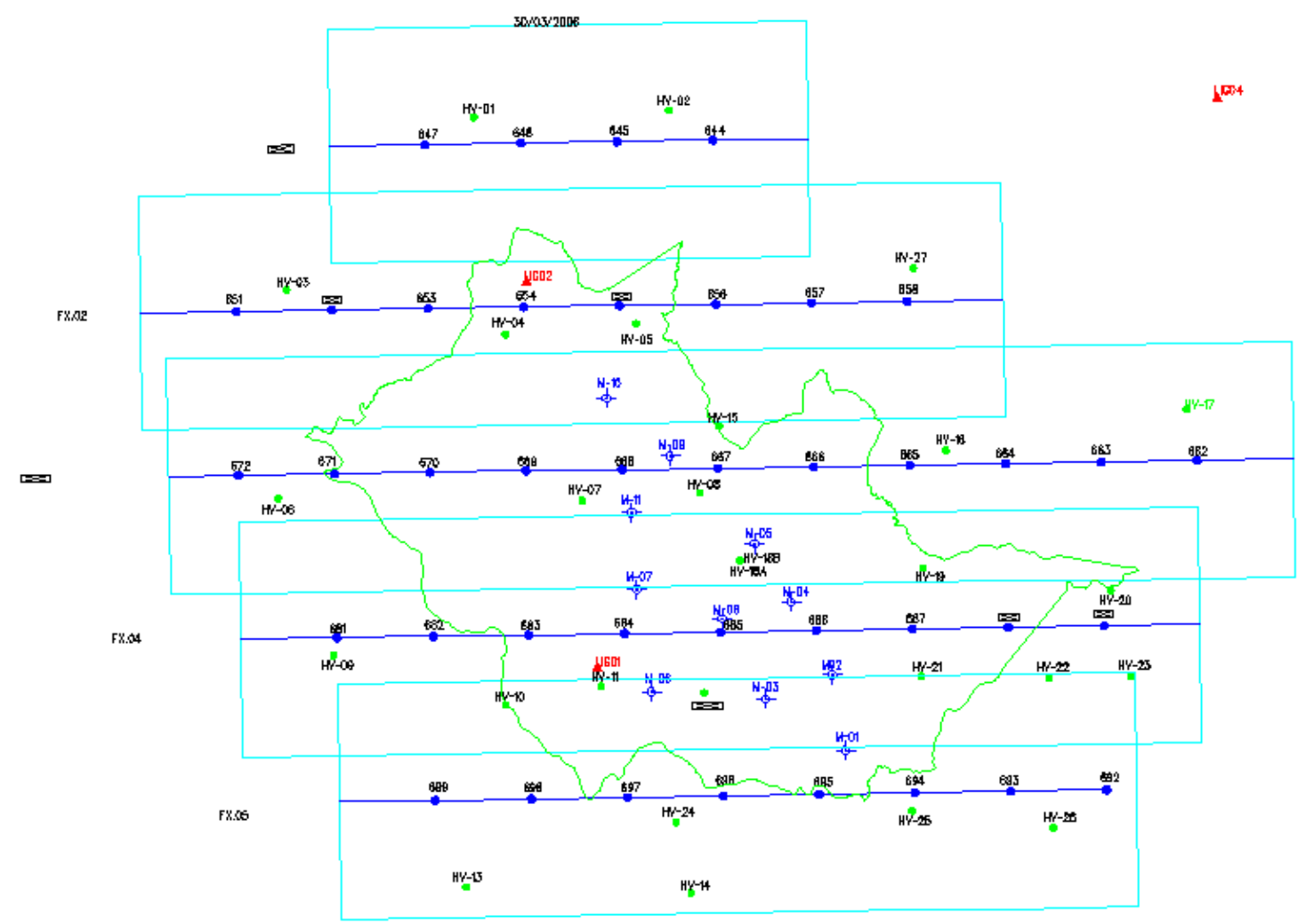

Figura 6.1 - Esquema do apoio para a cobertura 1:25.000

A figura 6.1 mostra o esquema da cobertura 1:25.000, onde se vêem os marcos já existentes em azul, o limite municipal e os pontos de apoio fotogramétrico em verde, e os pontos de ligação com as injunções Band e Merc em vermelho.

- A figura 6.2 mostra o foto índice da cobertura 1:25.000 


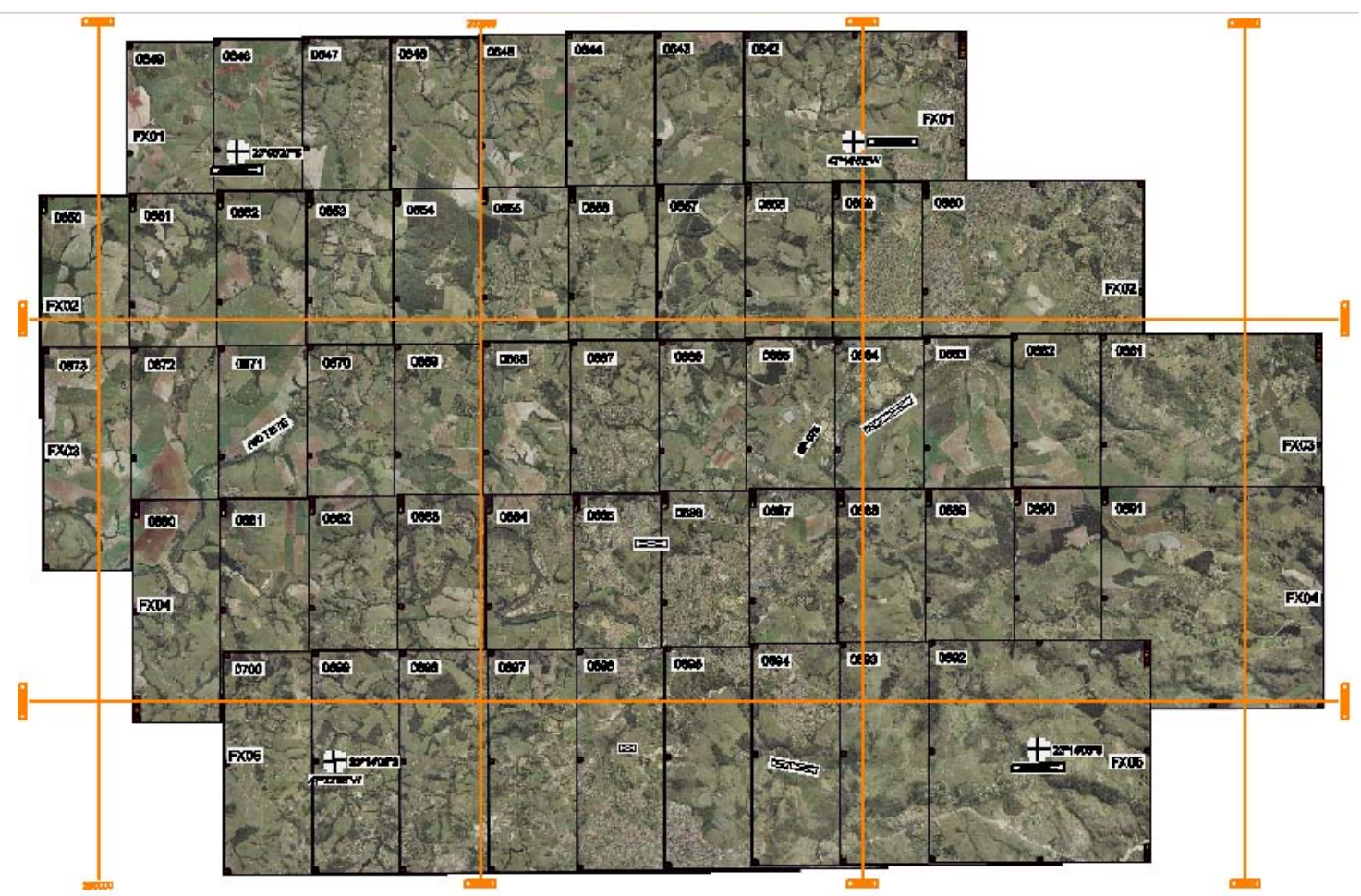

Figura 6.2 - Foto índice da cobertura 1:25.000 com malha aproximada em UTM.

- Relatório da aerotriangulação

As leituras da aerotriangulação foram efetuadas em estações analítico digitais DIAP - ISM, e o ajuste foi calculado através do programa PAT B.

Neste relatório estão contidos todos os parâmetros de orientação exterior das imagens, bem como as precisões obtidas no ajuste. Encontra-se no anexo digital do presente trabalho.

\subsubsection{Características da cobertura aerofotogramétrica na escala 1:5.000.}

- Autorização do Ministério da Defesa: 065/05.

- Data de execução: Junho de 2005.

- Câmara: $\quad$ RMK TOP 15 - ZEISS , $f=152.749 \mathrm{~mm}$.

- Filme: $\quad$ Aerocolor III 2444.

- Processamento do original negativo: Colex C41 
- Digitalização dos negativos: UltraScan 5000 - Vexcel.

- Tratamento radiométrico: RadComp 3.0 BASE

- Apoio de campo

O apoio de campo foi executado em junho de 2006.

Foram utilizados rastreadores GPS de dupla freqüência modelo Hyper marca Topcon.

O transporte de coordenadas foi executado partindo-se de quatro estações da rede Brasileira de Monitoramento Contínuo, NEIA, PARA, UBAT, VARG. O erro médio padrão deste transporte foi inferior a $10 \mathrm{~mm}$ nas três coordenadas.

O fechamento da rede de pontos de apoio fotogramétrico apresentou desvios padrão de $17 \mathrm{~mm}$ em latitude e longitude e $25 \mathrm{~mm}$ em altitude geométrica.

As altitudes ortométricas foram obtidas como já mencionado.

\subsubsection{Sobreposição das coberturas em 1:25.000 e 1:5.000.}

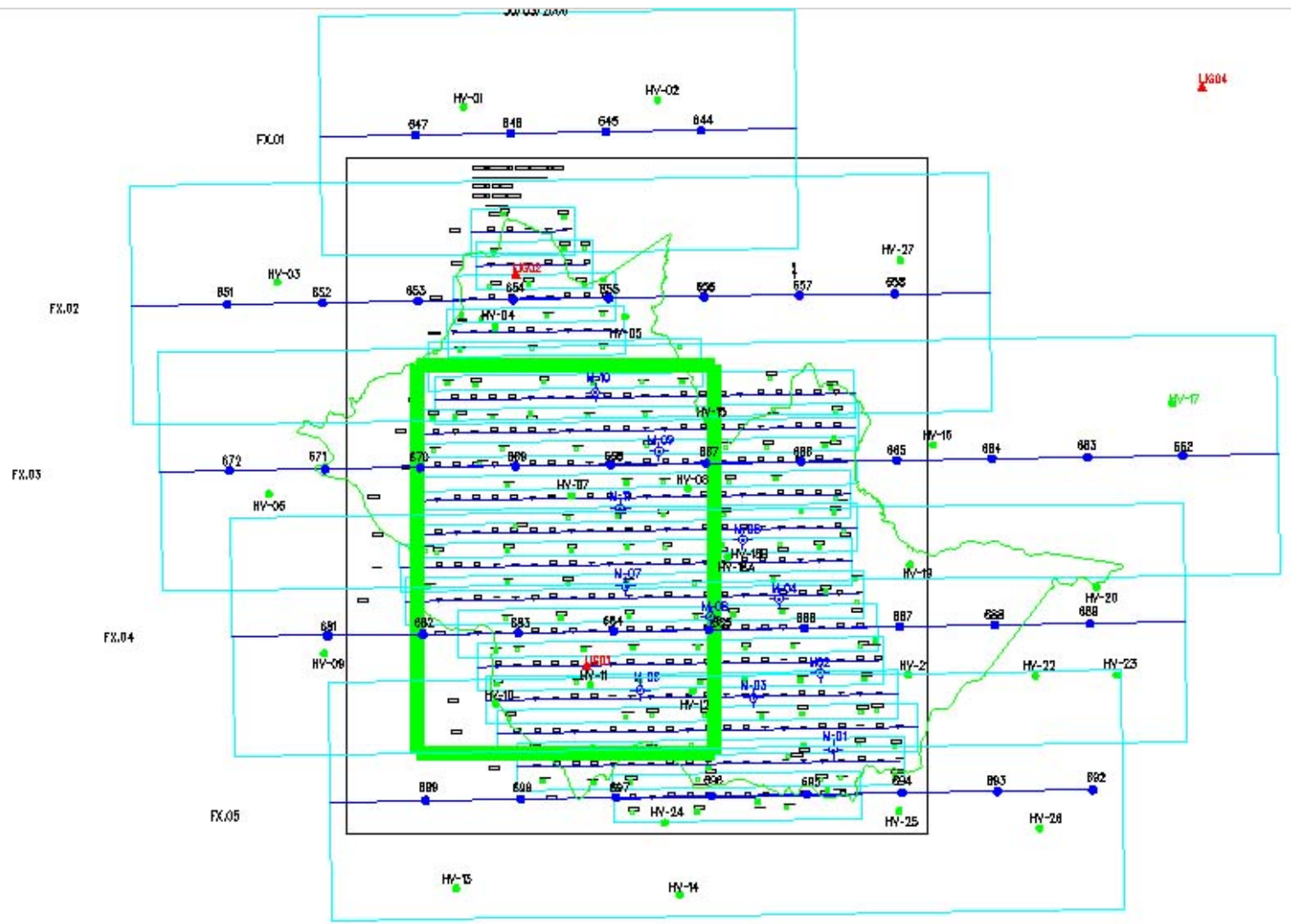


Figura 6.3 - Sobreposição das coberturas 1:25.000 e 1:5.000 e delimitação da área teste

Na figura 6.3 observa-se a área de sobreposição das duas coberturas e vê-se em verde a delimitação da área teste.

\subsection{A escolha da área teste}

A escolha da área teste foi feita observando-se as seguintes características:

- Estar contida em área aerotriangulada nas duas coberturas.

- Conter a maior variedade de feições em áreas urbanas e rurais.

Estas características visaram não só a elaboração dos produtos mas também sua posterior validação.

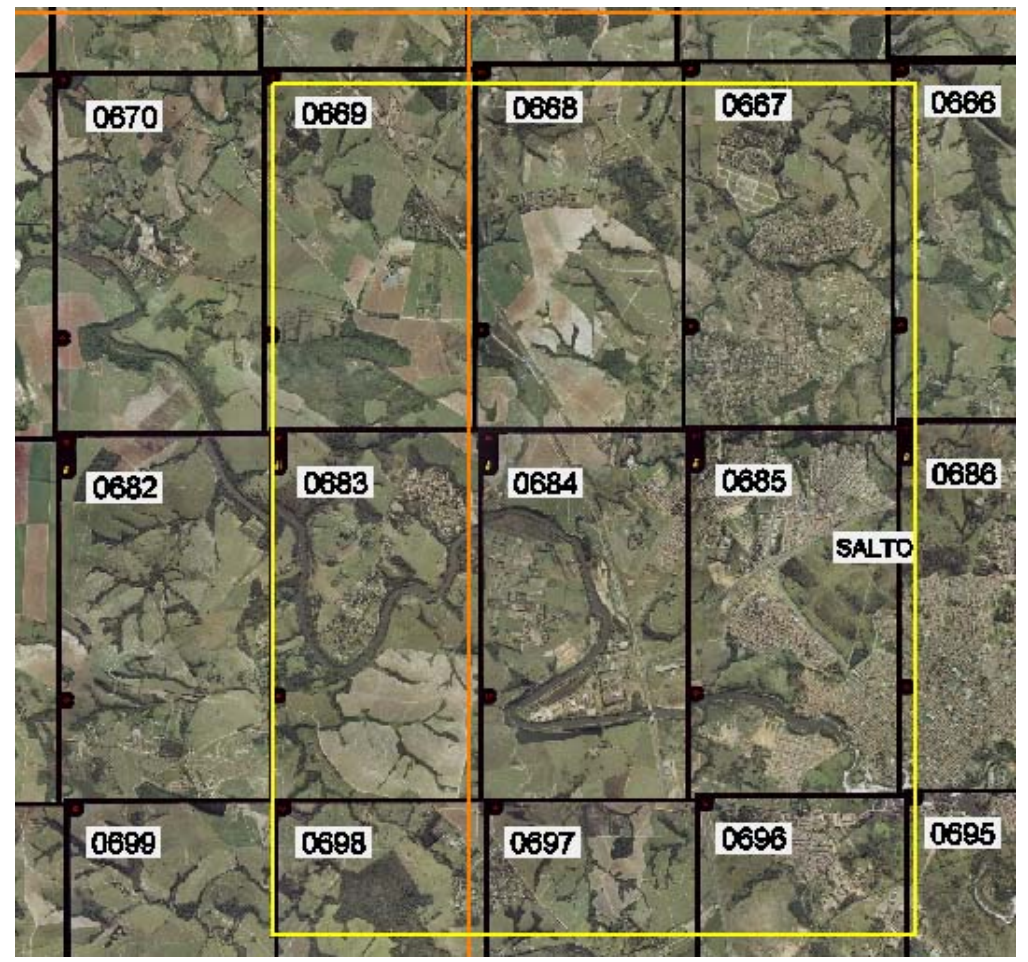

Figura 6.4 - Área teste e respectivas imagens em escala 1:25.000

Como se pode visualizar na figura 6.4 delimitada pela linha amarela, a área teste está na área de cobertura estereoscópica das imagens 667, 668, 669, 670, 682, 683, 684, 685. Possui seis modelos que formarão duas sobreposições longitudinais por faixa e três sobreposições entre faixas. Isto permitiu avaliar eventuais 
discrepâncias entre os modelos digitais de superfície e ortofotos, gerados a partir da metodologia proposta, para os diferentes modelos estereoscópicos dentro de uma mesma faixa de vôo, e de faixas contíguas.

\subsection{Elaboração das rotinas computacionais.}

Como ficou dito, o presente trabalho tem como objetivo a proposta de metodologia de elaboração automatizada de ortoimagens e modelos digitais de superfície. Para que se pusesse em prática esta metodologia, gerando produtos que se possam validar, foi necessário elaborar rotinas computacionais. Para isso contouse com a colaboração de um profissional da área de Ciências da Computação, que, sob a orientação permanente do autor do presente trabalho implementou-as.

\subsection{Produtos obtidos.}

Como se possuíam as imagens digitais com os respectivos parâmetros de orientação exterior, foram produzidos, seguindo a metodologia proposta, os modelos digitais de superfície e as respectivas ortofotos.

Dessa forma foram gerados seis MDE e seis ortofotos dos modelos 0670_0669, 0669_0668,0668_0667,0682_0683,0683_0684 e 0684_0685. Estes posteriormente foram mosaicados e unidos em dois arquivos que abarcam toda a área, um referente ao MDE e outro à ortofoto. A resolução espacial de ambos é de $70 \mathrm{~cm}$, uma vez que as imagens em escala 1:25.000 foram digitalizadas com resolução espacial de $28 \mu \mathrm{m}$.

Esses produtos são apresentados nas figuras seguintes. As ortofotos apresentadas são as das imagens da esquerda do modelo. Embora produzida em todos os casos, é apresentada também, apenas para visualização, uma ortofoto gerada a partir da imagem da direita

As figuras dos MDE são a representação em cores, conforme codificação apresentada em 5.3.6, da malha quadrada contendo as altitudes de terreno.

A seguir serão feitos comentários e análises. 


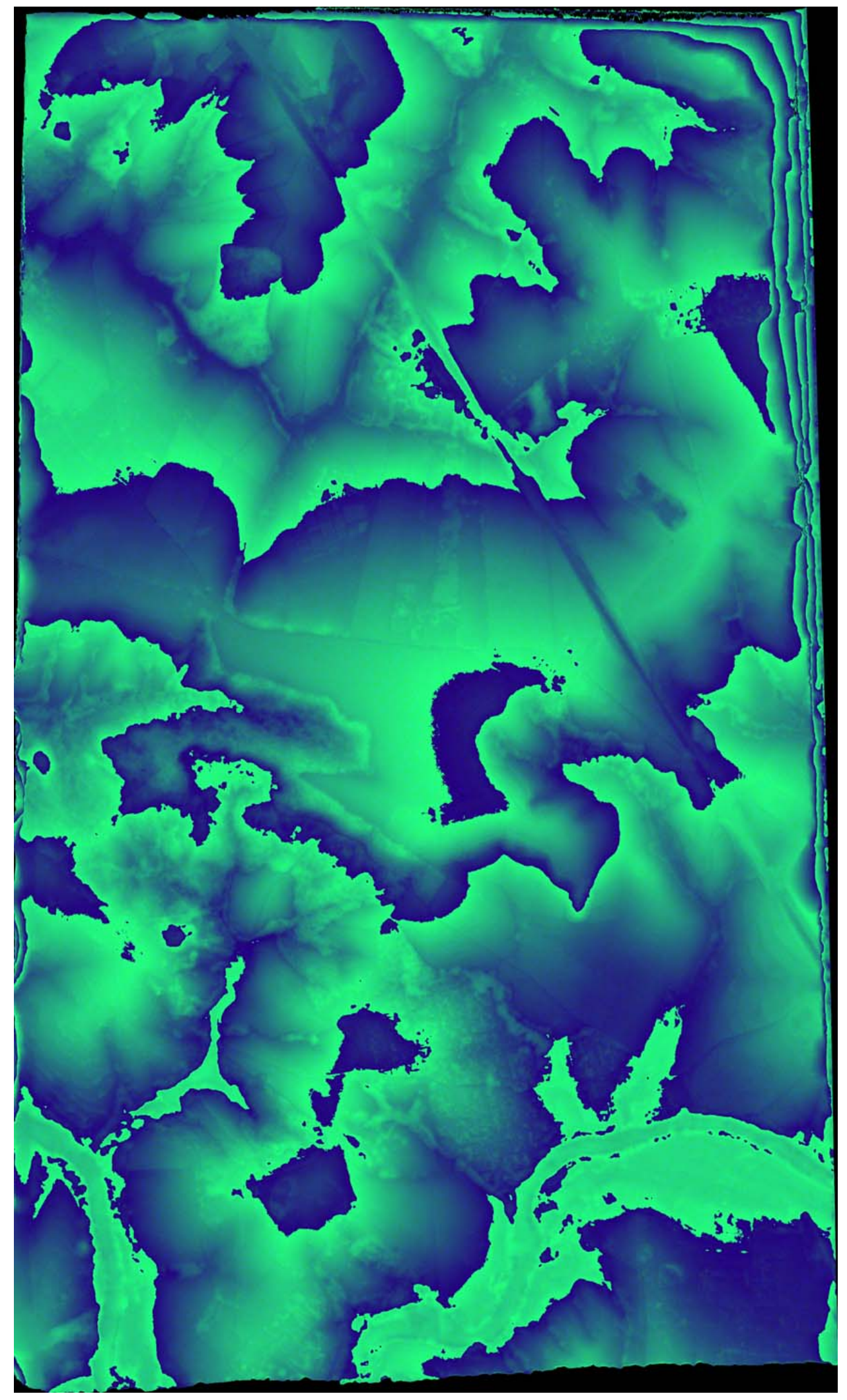

Figura 6.5 - Modelo Digital de Elevação do modelo 0670_0669 


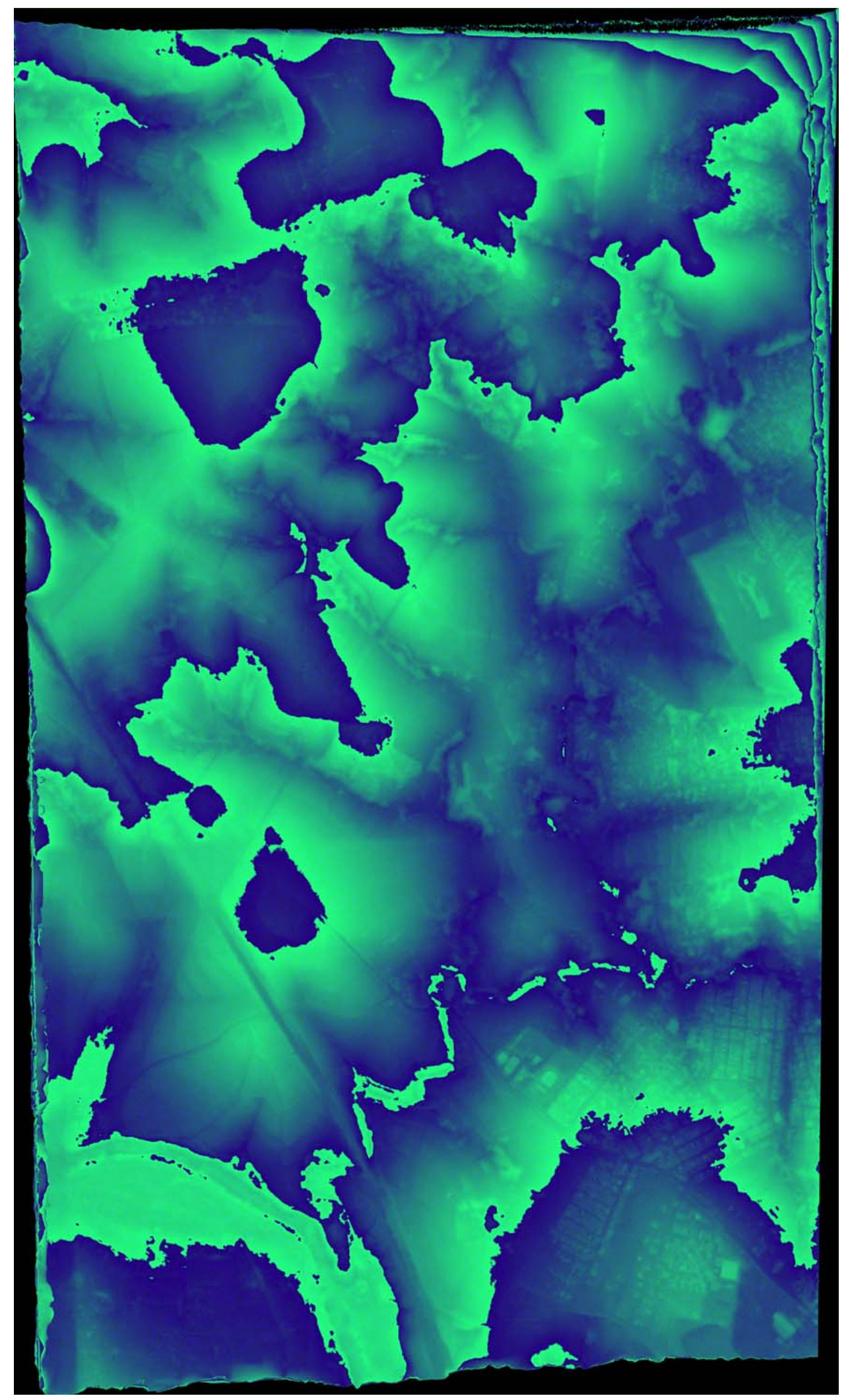

Figura 6.6 - Modelo Digital de Elevação do modelo 0669_0668 


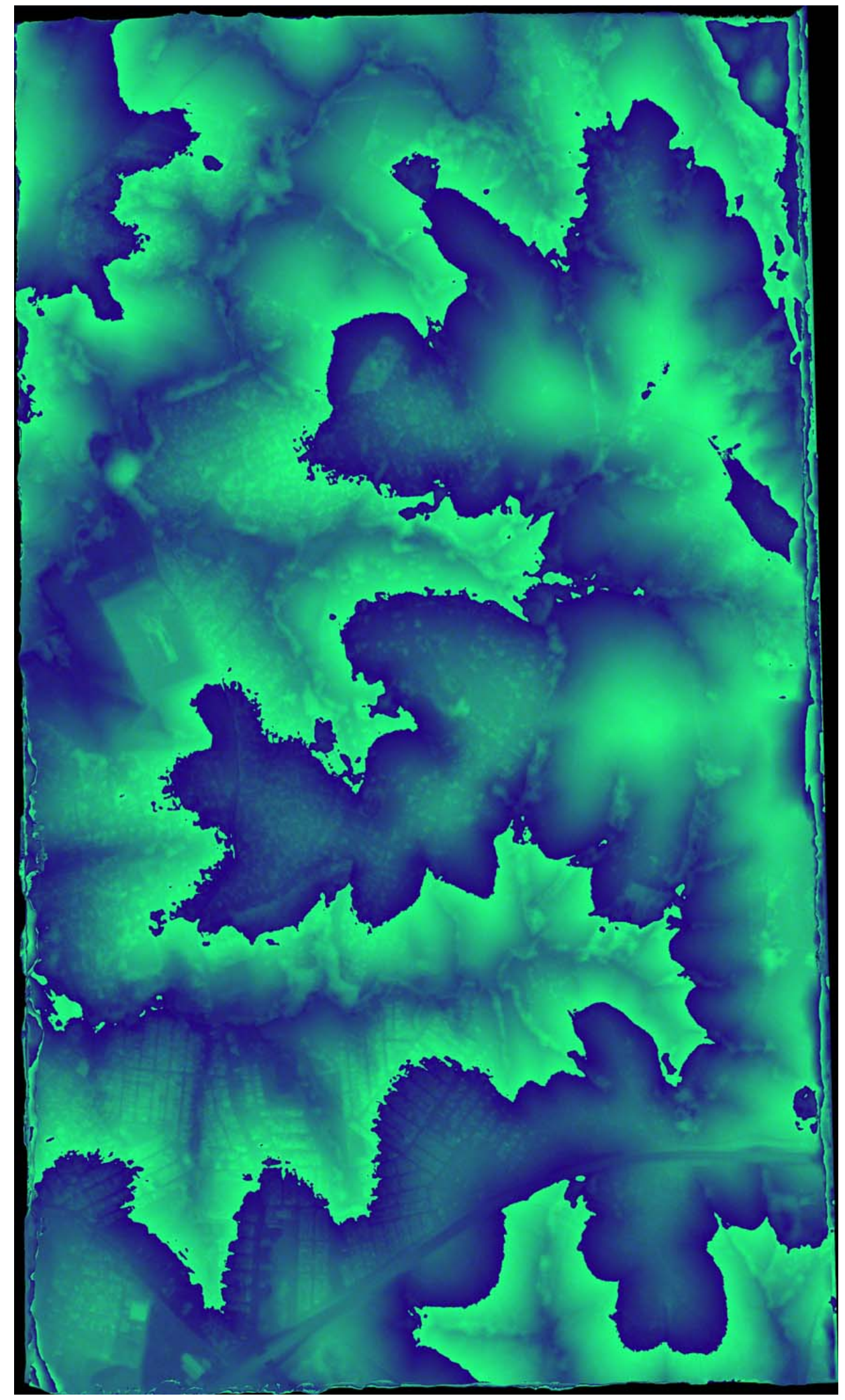

Figura 6.7 - Modelo Digital de Elevação do modelo 0668_0667 


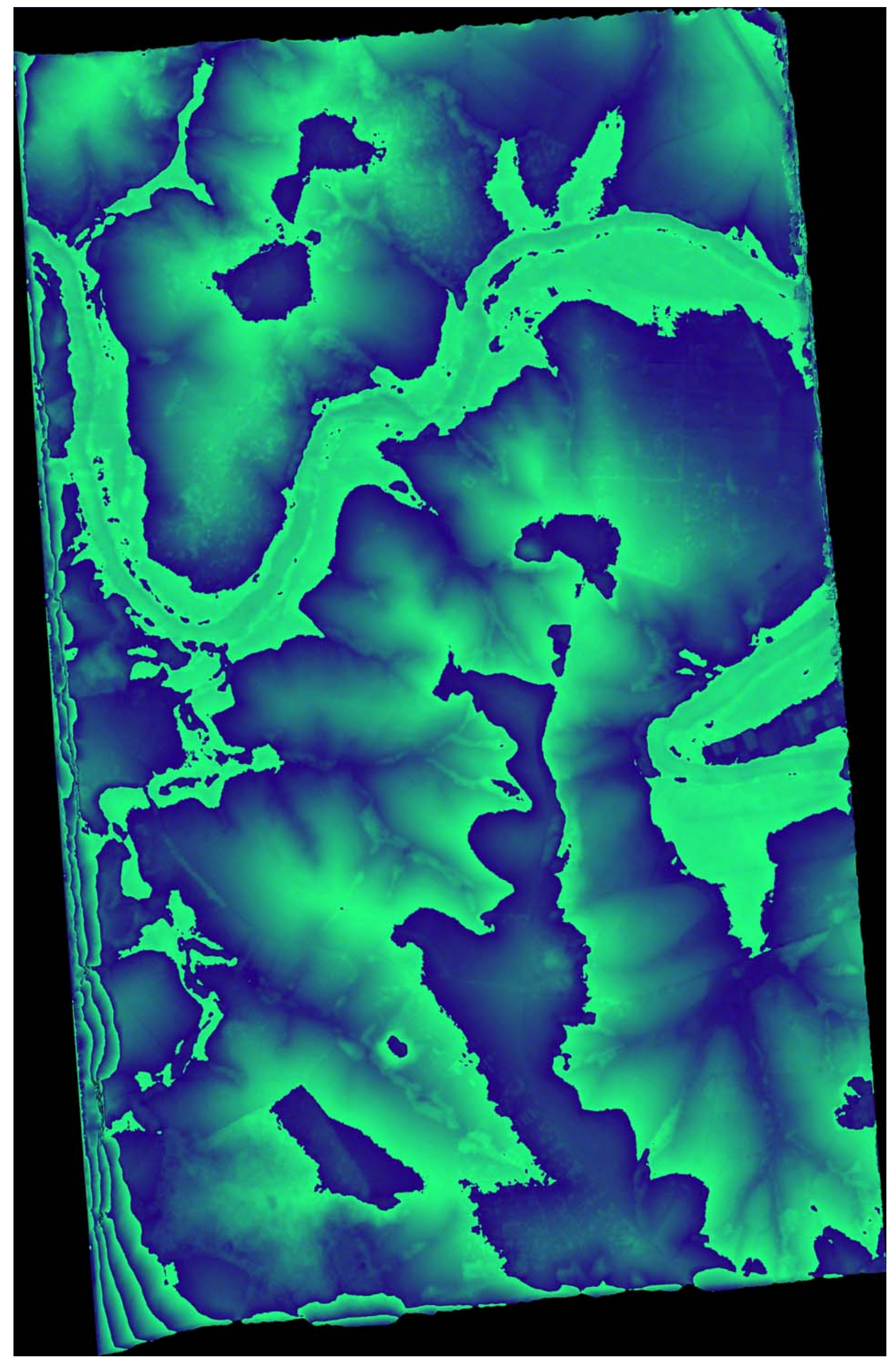

Figura 6.8 - Modelo Digital de Elevação do modelo 0682_0683 


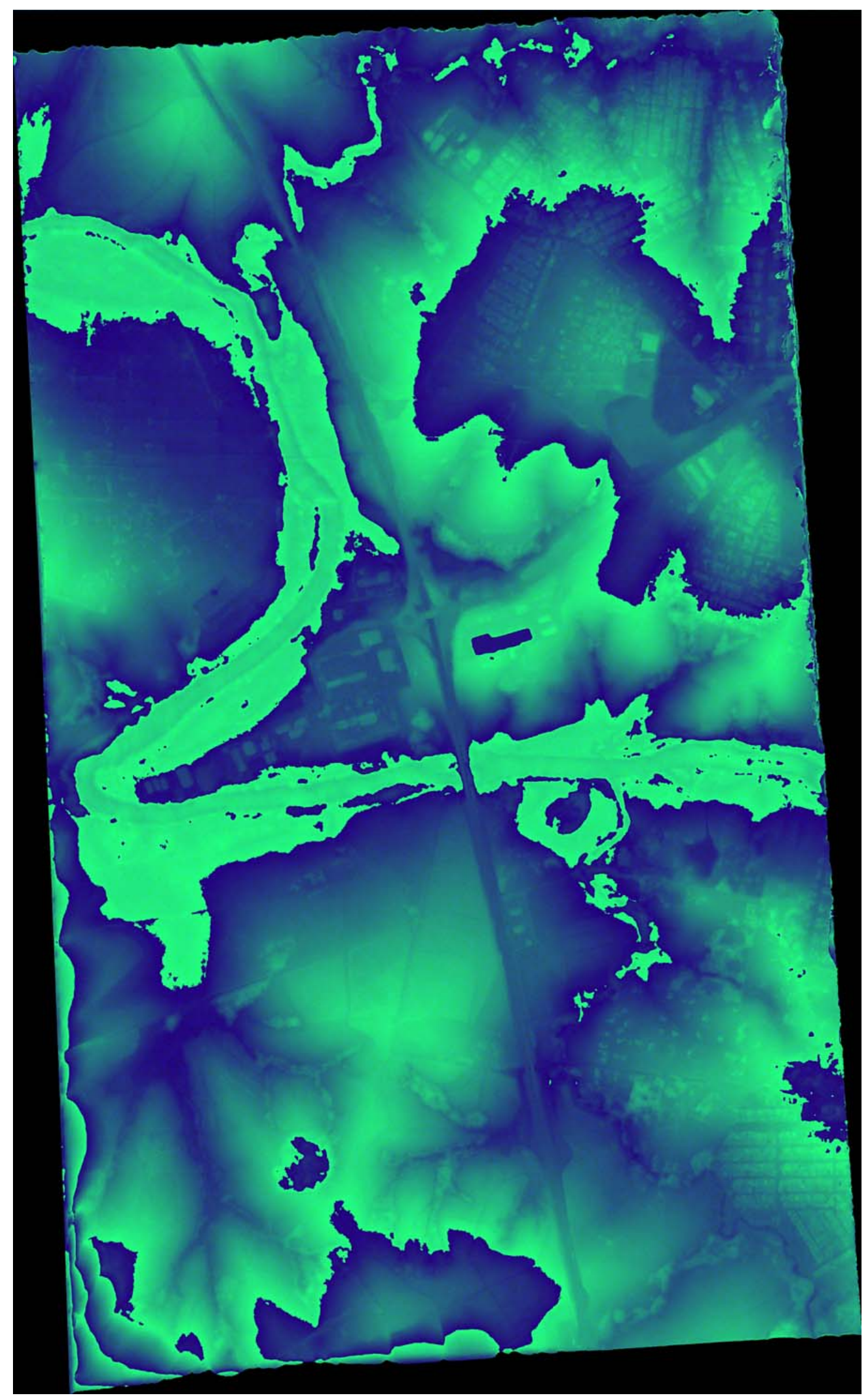

Figura 6.9- Modelo Digital de Elevação do modelo 0683_0684 


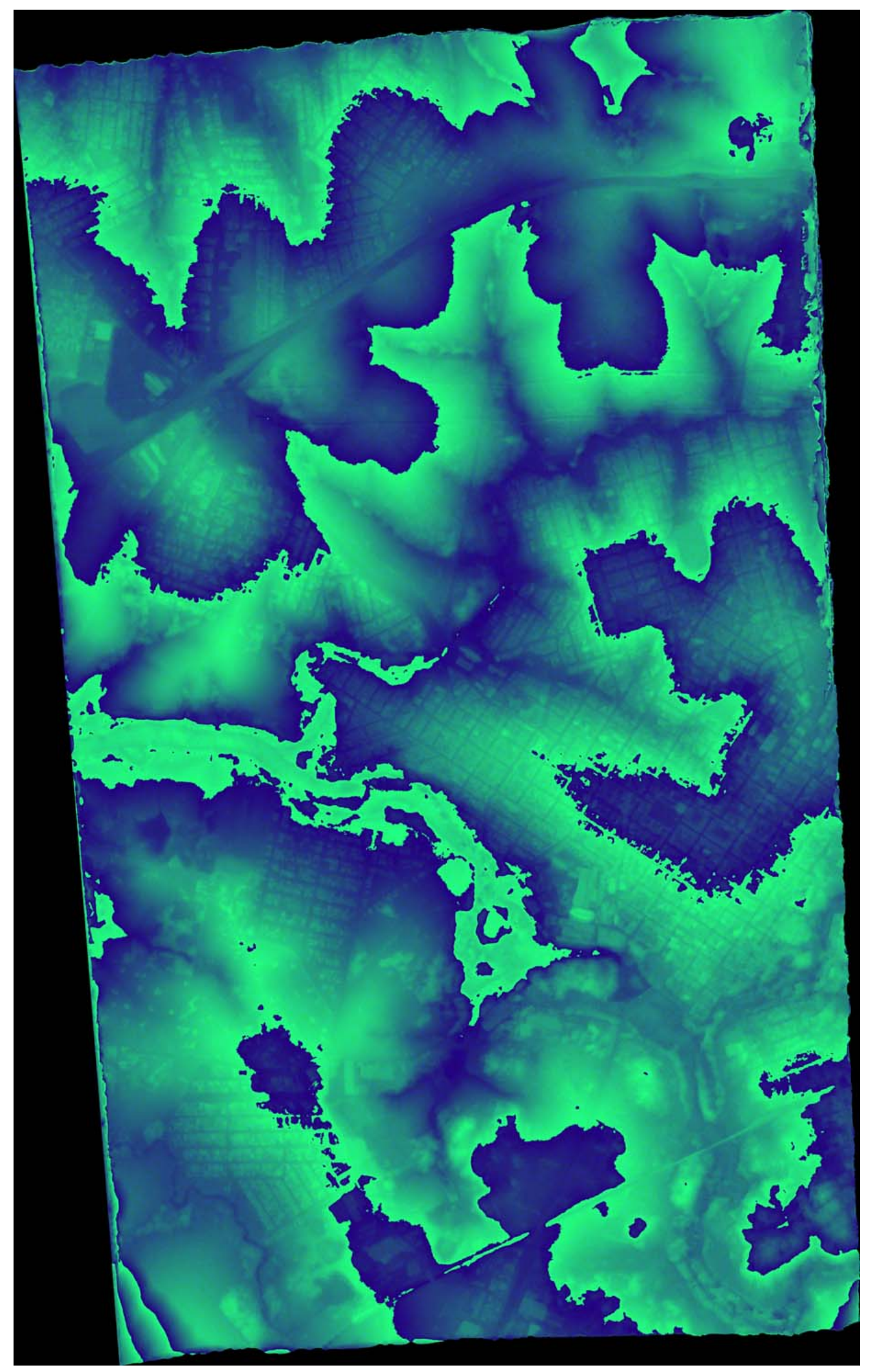

Figura 6.10 - Modelo Digital de Elevação do modelo 0684_0685 


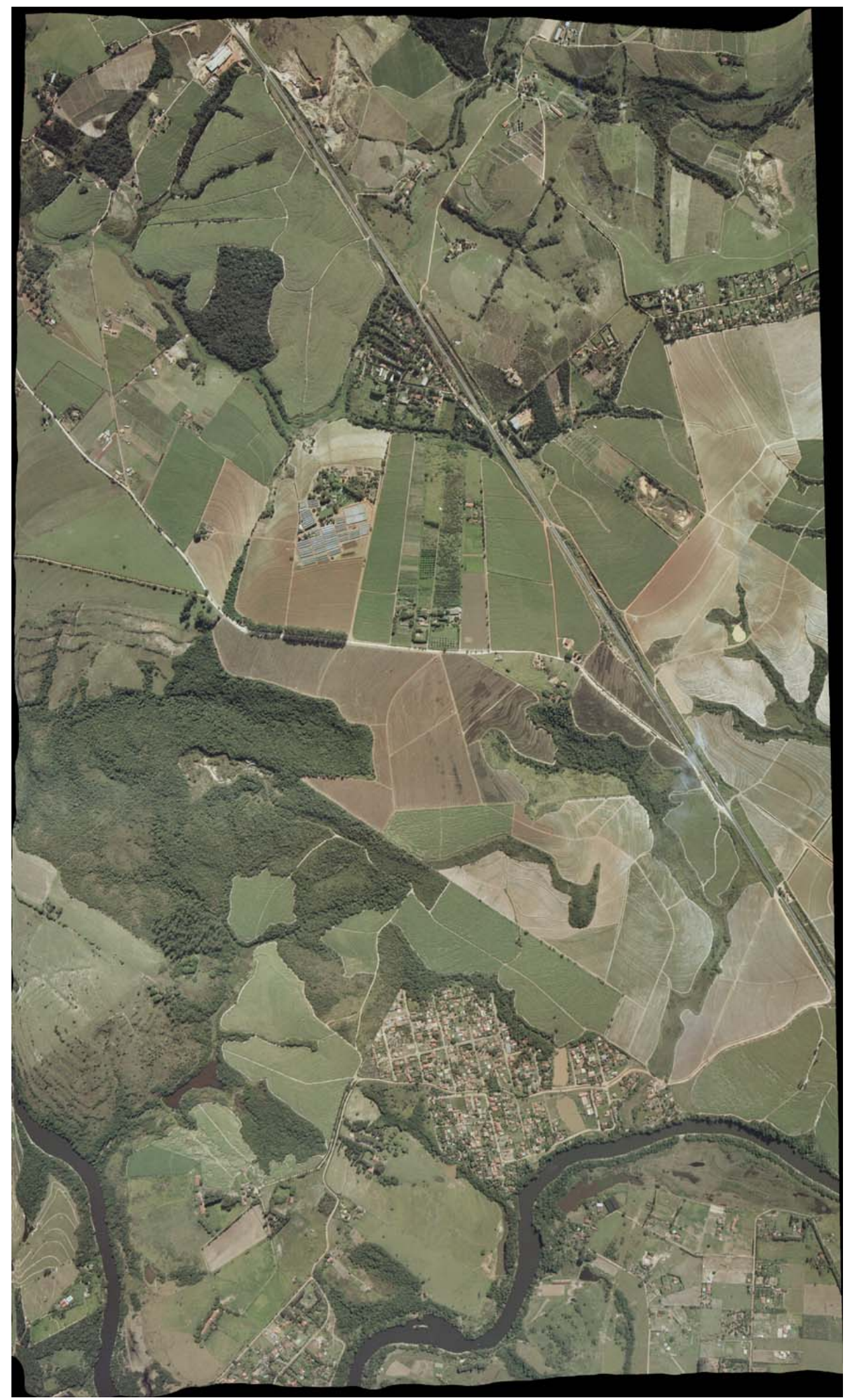

Figura 6.11 - Ortofoto da imagem esquerda do modelo 0670_0669 


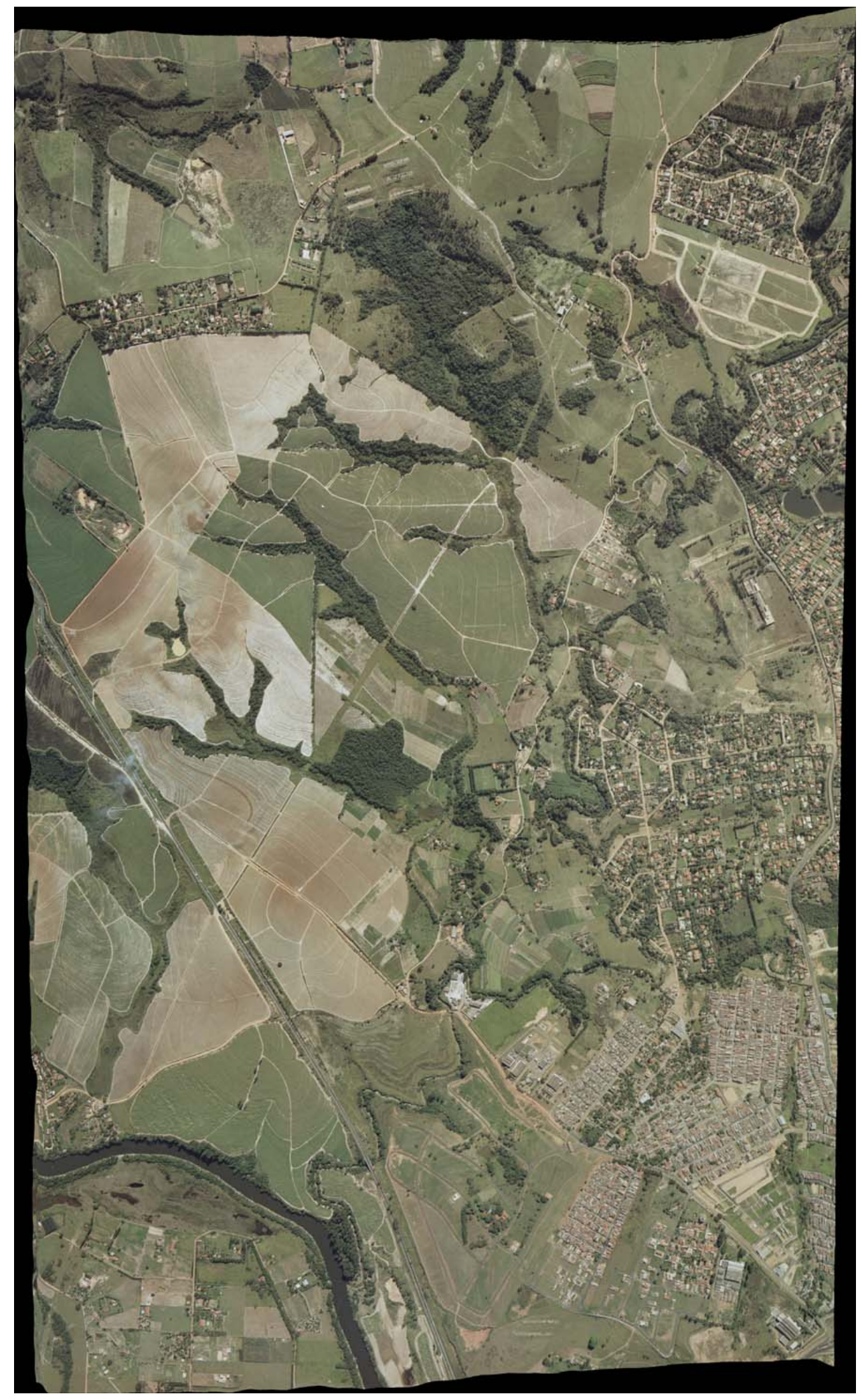

Figura 6.12 - Ortofoto da imagem esquerda do modelo 0669_0668 


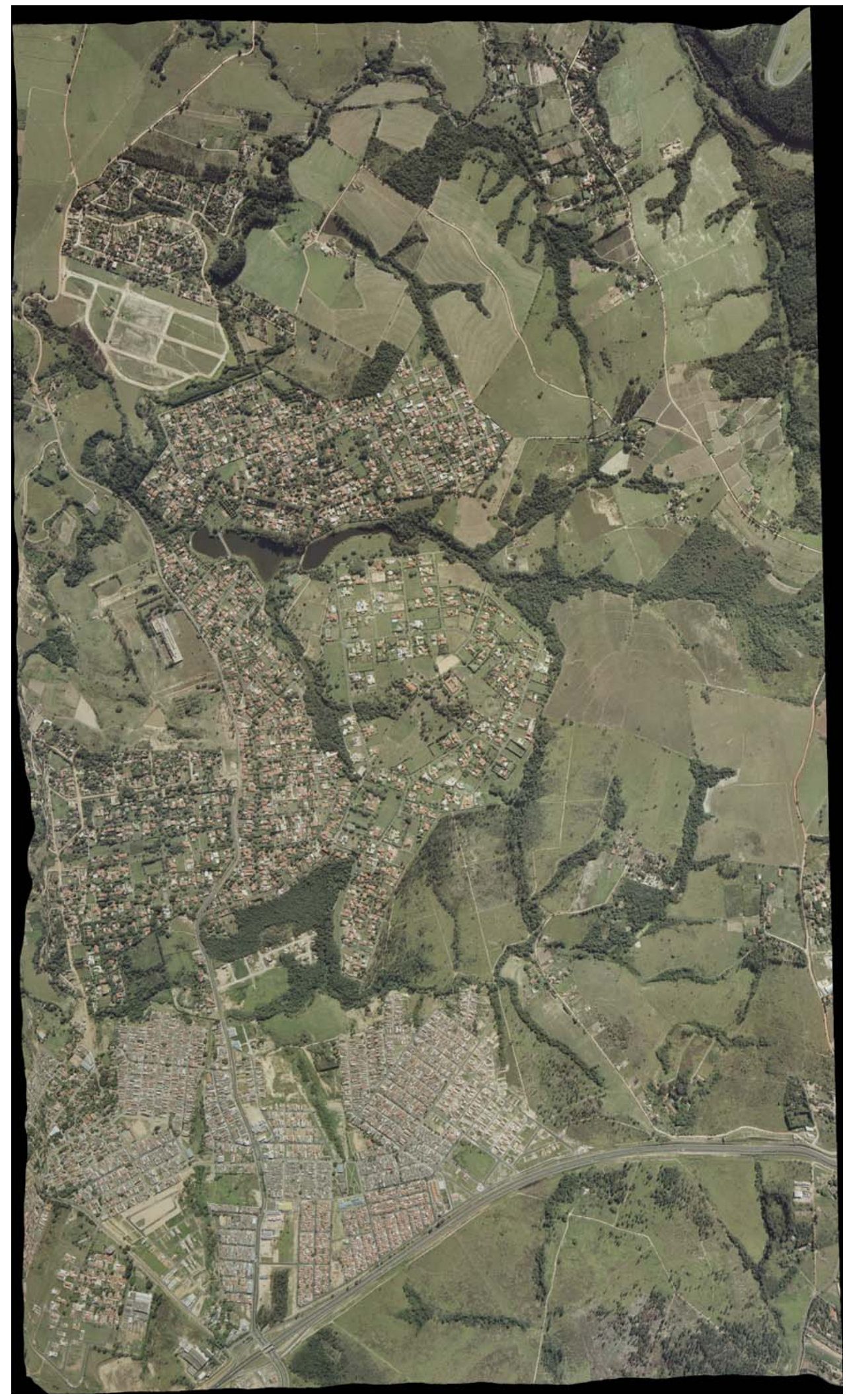

Figura 6.13 - Ortofoto da imagem esquerda do modelo 0668_0667 


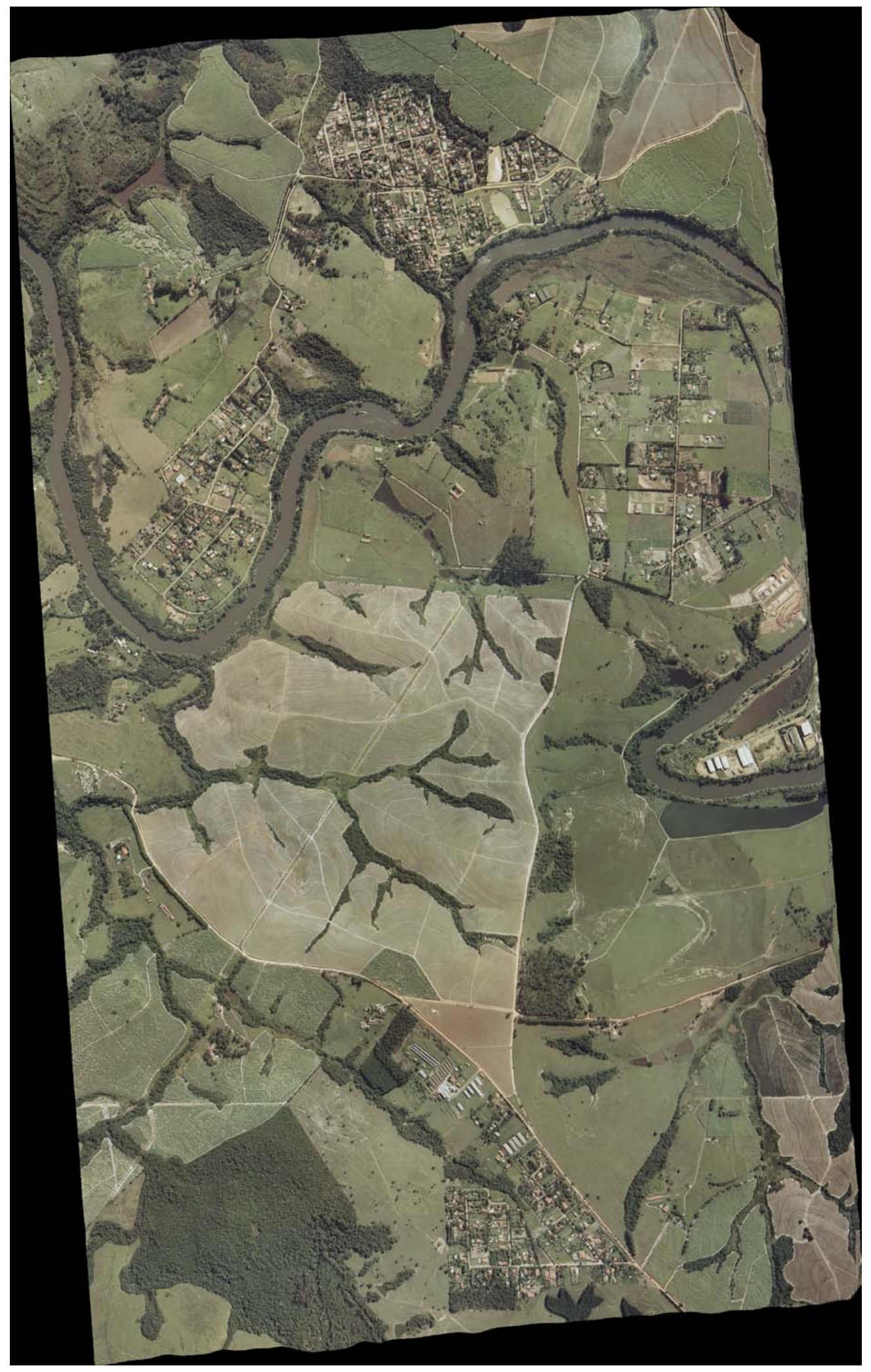

Figura 6.14 - Ortofoto da imagem esquerda do modelo 0682_0683 


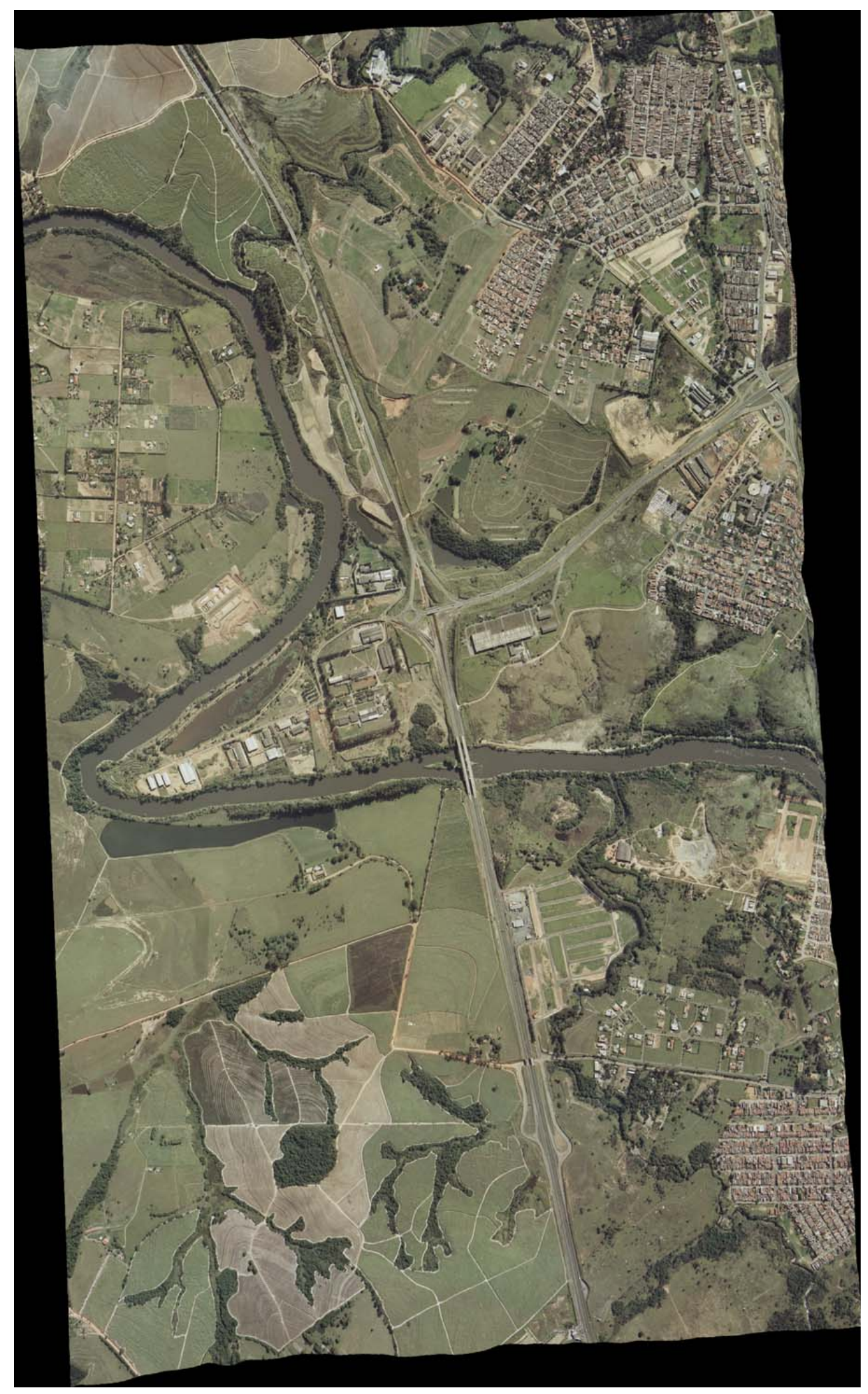

Figura 6.15 - Ortofoto da imagem esquerda do modelo 0683_0684 


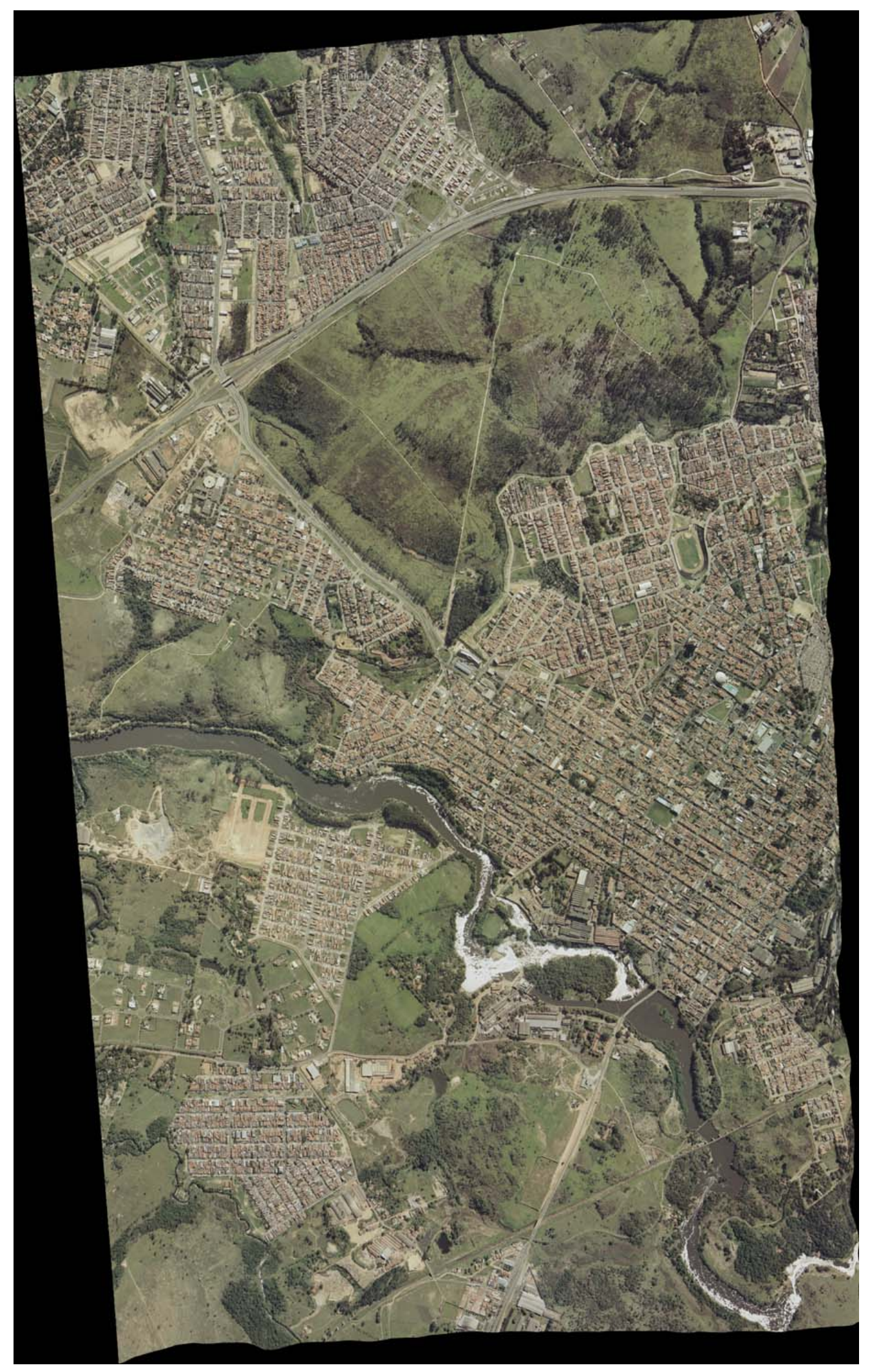

Figura 6.16 - Ortofoto da imagem esquerda do modelo 0684 _0685 


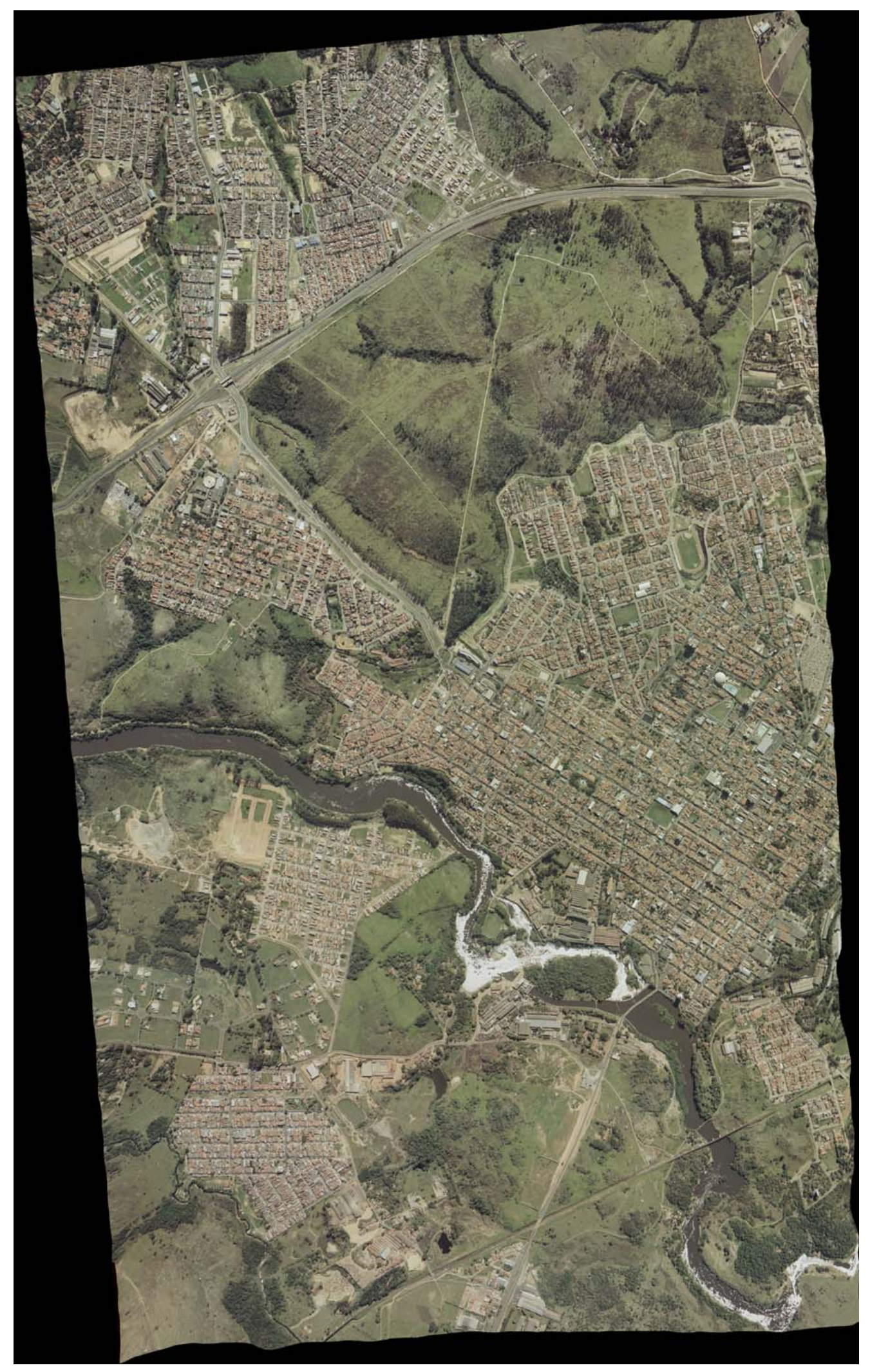

Figura 6.17 - Ortofoto da imagem direita do modelo 0684_0685 


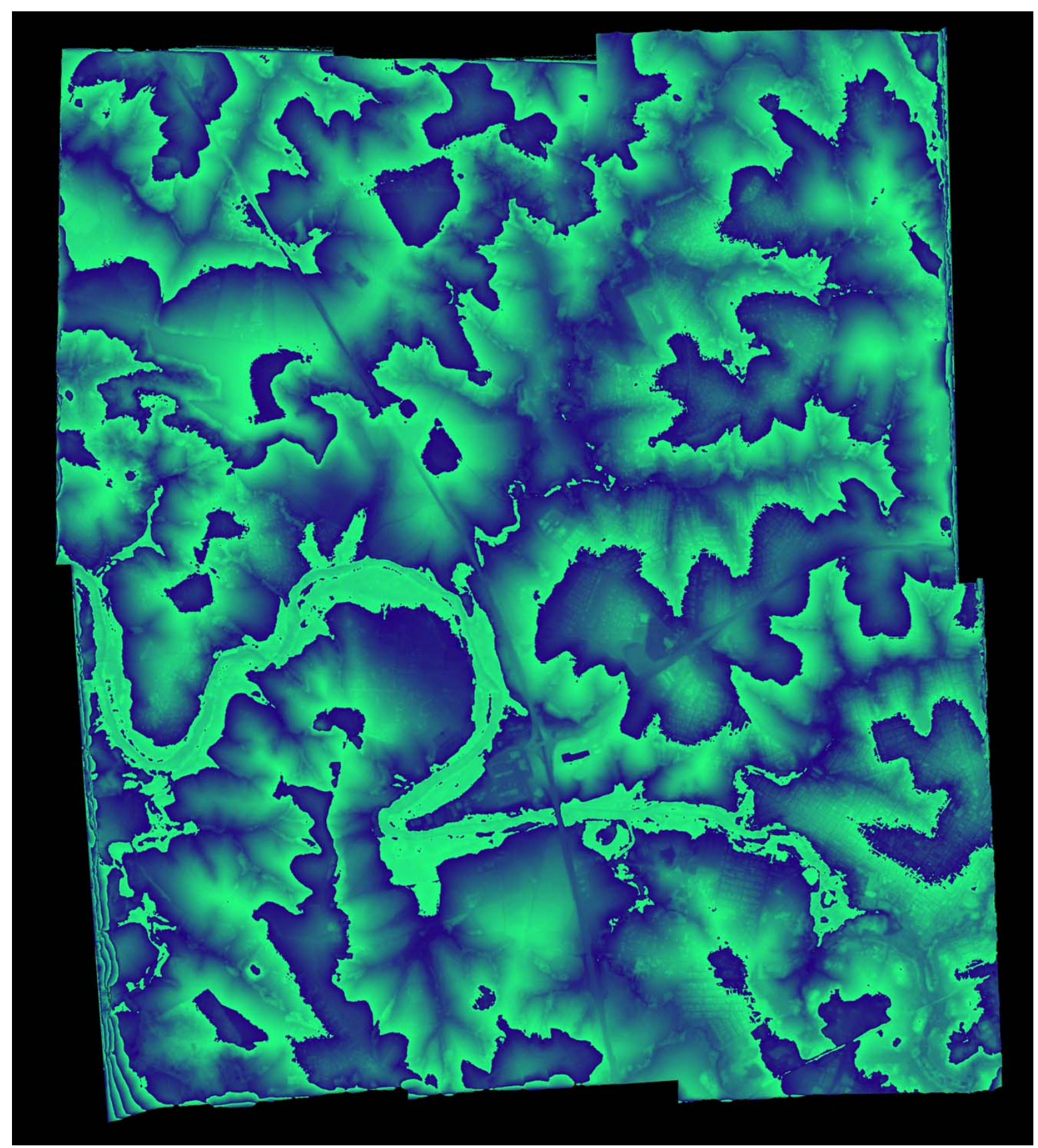

Figura 6.18 - Mosaico geral do MDE produzido.

A variação do vermelho se dá a cada 42.96m sendo que o verde varia, por 256 níveis, de mais escuro até mais claro dentro desse limite. Assim sendo, pode-se visualizar as zonas mais altas e mais baixas, e as pequenas variações, identificandose até feições de rodovias, hidrografia, vegetação, edificações, viadutos, ruas, entre outros como pode-se notar comparando o MDE obtido com as respectivas ortoimagens. 


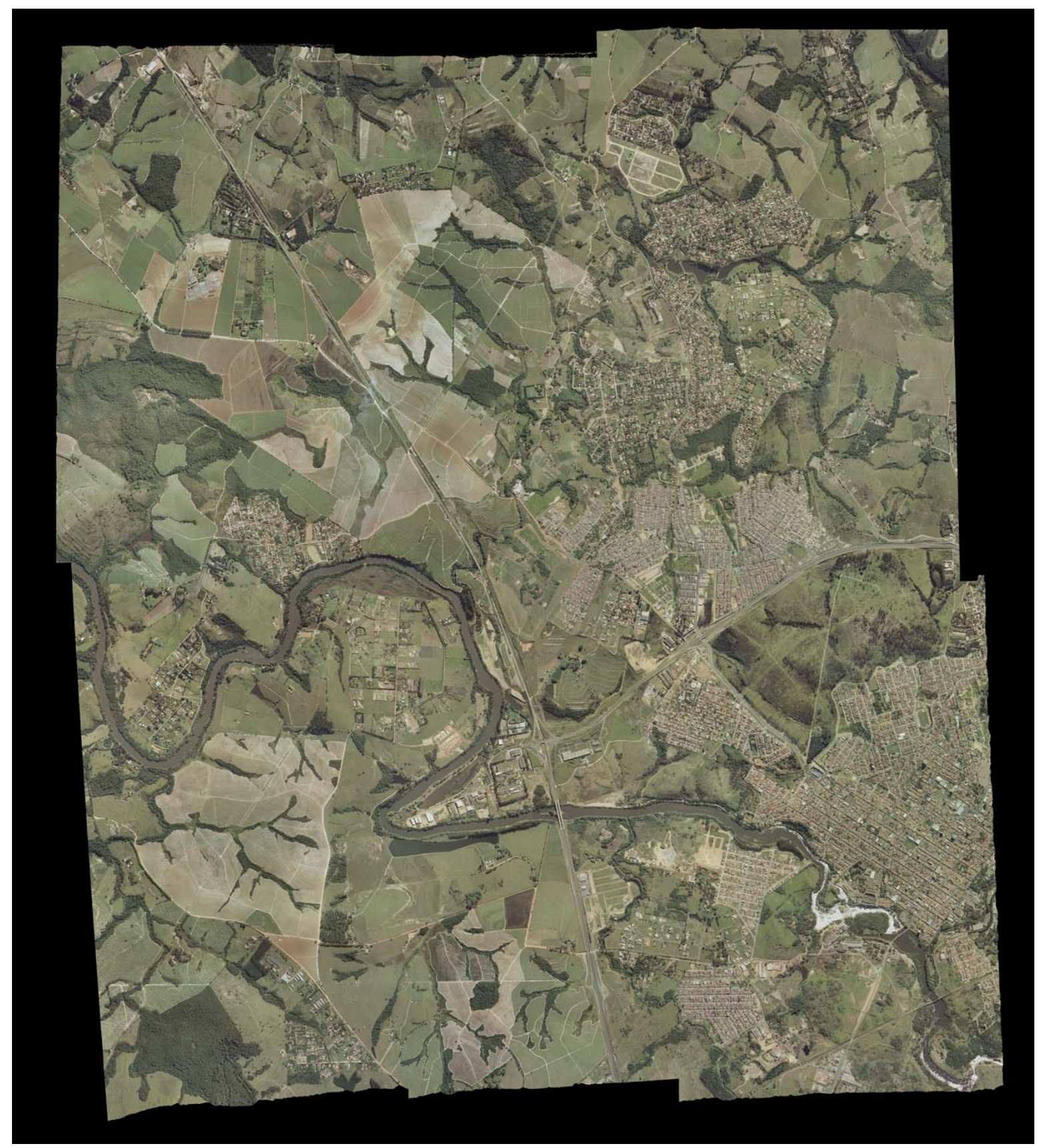

Figura 6.19 - Mosaico geral das ortofotos produzidas.

\subsubsection{Mosaicagem.}

Para a mosaicagem, tanto das ortofotos, como do MDE, foi utilizado o software DIAP USER. Foram feitas, manualmente, linhas de corte nas ortoimagens, de maneira a unir os seis modelos gerados. Isso é feito para avaliar as descontinuidades entre ortofotos contíguas. As mesmas linhas de corte foram utilizadas para mosaicar o MDE, em uma única imagem. 
Esses mosaicos podem ser vistos nas figuras 6.18 e 6.19 .

\subsection{Análises preliminares}

- Erros grosseiros em bordas

Como se pode notar nas figuras ilustrativas dos MDE gerados a partir da metodologia proposta, as bordas dos modelos apresentam erros grosseiros que se manifestam por ondulações e franjas, correspondentes a variações anômalas de $z$. A existência desses erros grosseiros no MDE, acarreta, por conseguinte, deformações importantes na ortofoto na mesma região, pois esta se utiliza dele para ser gerada.

Isso já era esperado uma vez que nessas regiões o processo de correlação automática de imagens se torna ineficaz. Assim sendo, devem ser desprezadas todas as regiões próximas às bordas. Como a cobertura realizada na área possui um recobrimento longitudinal de $60 \%$ e lateral de $30 \%$, o que é o mínimo usual para coberturas aerofotogramétricas, existe uma boa sobreposição, o que permite restringir a área de elaboração do MDE e da ortofoto, eliminando assim as áreas de bordas.

O fato positivo que aqui se verifica é a possibilidade de utilização de coberturas aerofotogramétricas com recobrimentos convencionais para a elaboração dos produtos.

- Comparação visual entre MDEs vizinhos e pertencentes à mesma faixa.

Foi extraída uma amostra em malha quadrada regular com eqüidistância de 28 metros, dos MDE gerados, aplicando-se um exagero de cinco vezes na dimensão $Z$ de maneira a visualizar a sobreposição de modelos vizinhos em uma mesma faixa. Pode-se ver na figura 6.20 o MDE do modelo 0670_0669 em verde, o do 0669_0668 em vermelho e o 0668_0667 em azul. 


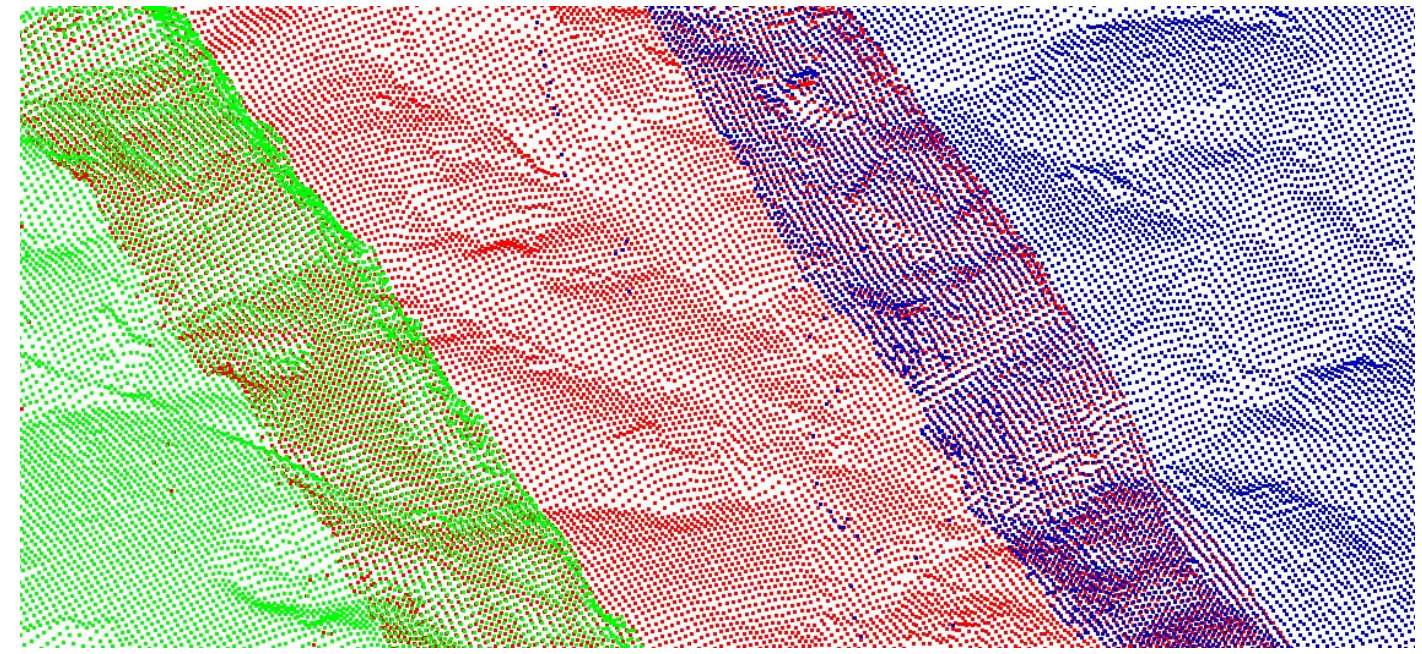

Figura 6.20 - Visualização de amostra dos DSM de 3 modelos vizinhos pertencentes a uma mesma faixa de vôo, com exagero de cinco vezes na dimensão Z.

Para que se tenha uma noção melhor são representadas na figura 6.21 , as curvas de nível interpoladas partir dos valores do MDE, onde se pode observar a compatibilidade das curvas geradas a partir de três modelos, sendo dois de uma mesma faixa e outro de faixa vizinha.

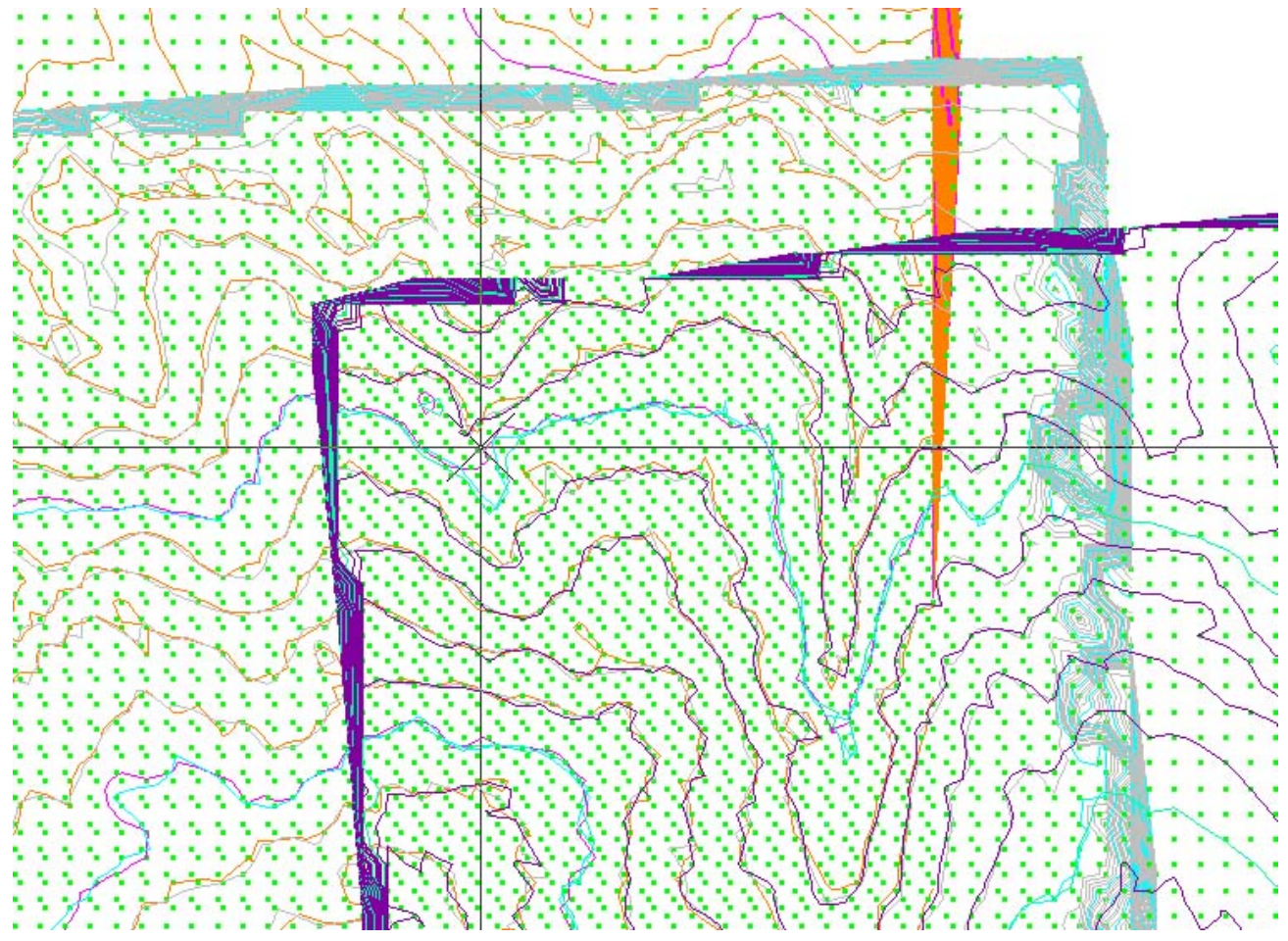

Figura 6.21 - Curvas interpoladas a partir de MDE reamostrados de três modelos adjacentes. 
- Comparação visual entre Modelos digitais de superfície vizinhos e pertencentes faixas contíguas.

De maneira análoga verifica-se na figura 6.22 o MDE de modelos vizinhos pertencentes a faixas contíguas de vôo.

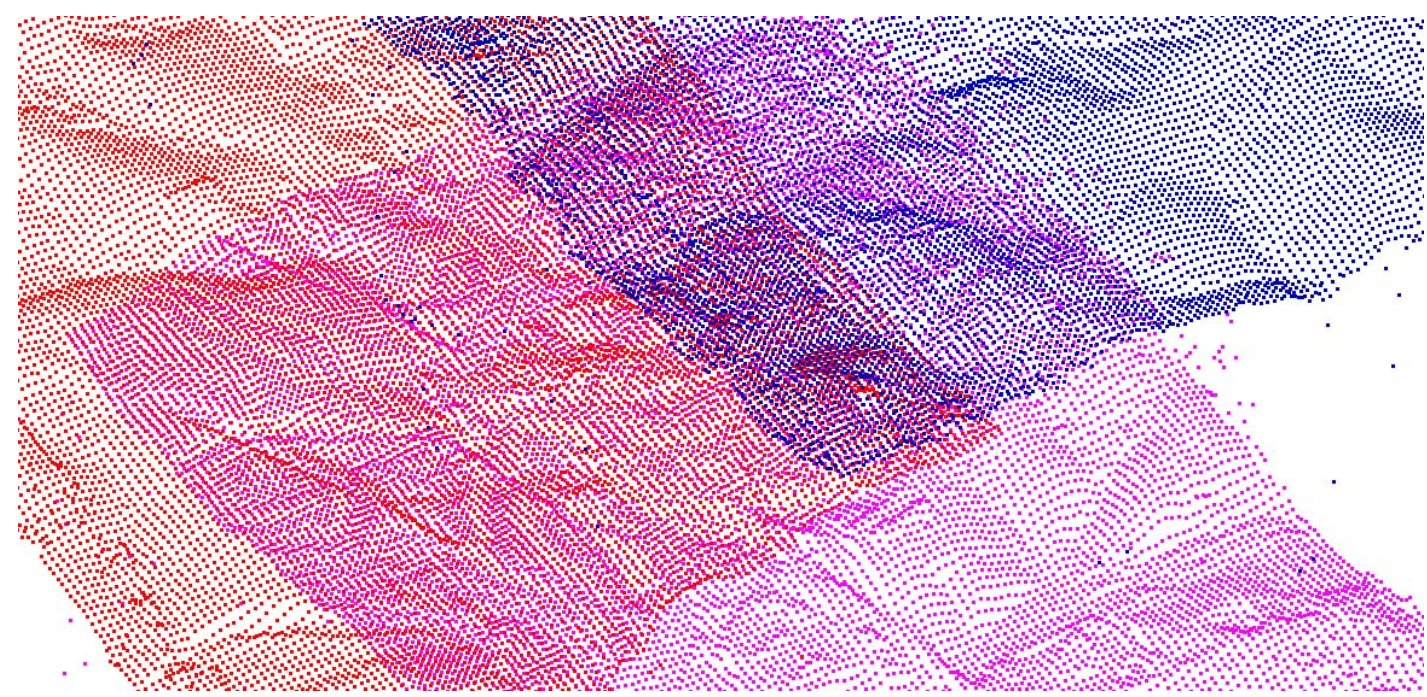

Figura 6.22 - Visualização do DSM de modelos de faixas contíguas com exagero de cinco vezes na dimensão $Z$.

Analogamente pode-se verificar visualmente a compatibilidade entre os MDE de modelos vizinhos pertencentes a faixas contíguas de vôo.

- Visualização de nuvem de pontos gerados a partir do MDE

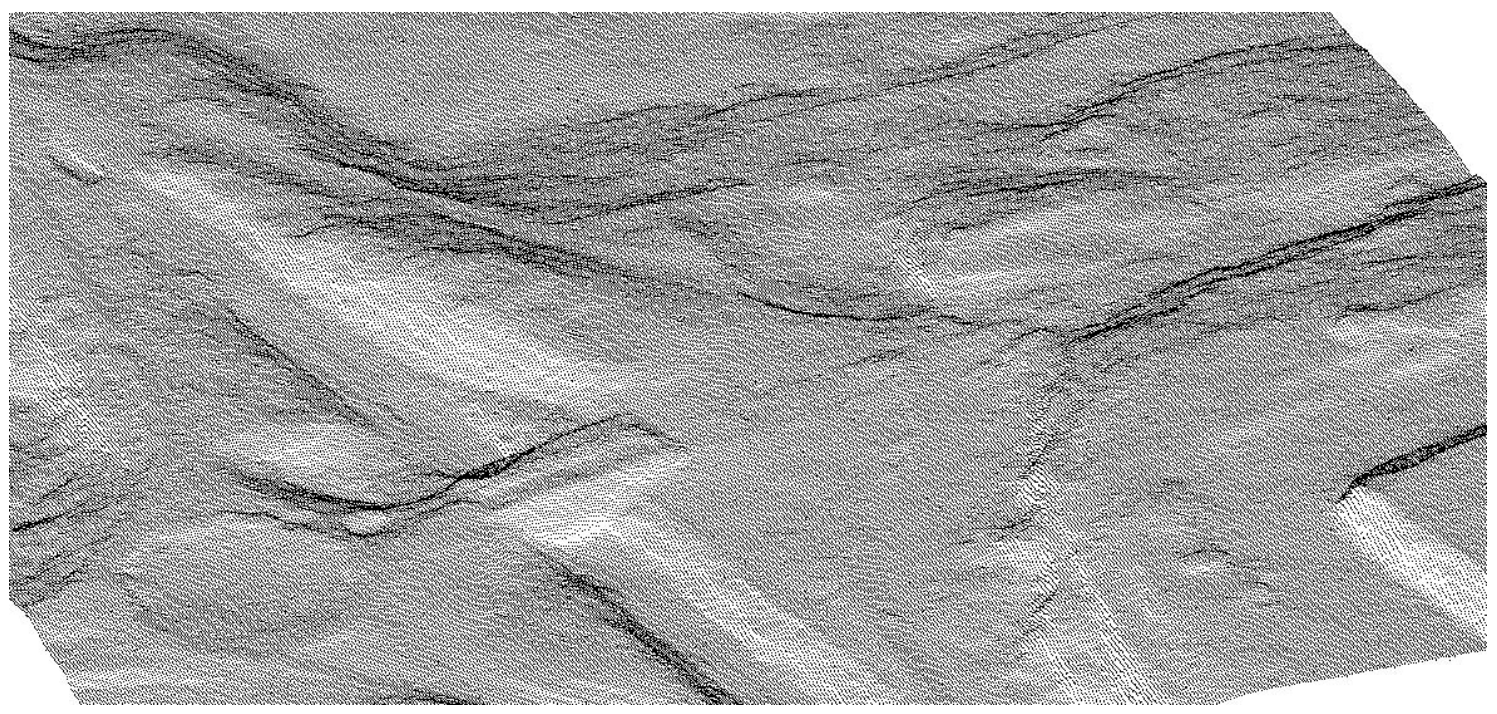

Figura 6.23 - Visualização da nuvem de pontos em uma amostra do MDE sendo que cada um de seus pixels é representado por um ponto no espaço. 
Na figura 6.23, mostra-se a nuvem de pontos da malha quadrada nos solo, em perspectiva isométrica, cuja eqüidistância planimétrica dos elementos é de 0.70 metros (o mesmo tamanho do pixel da imagem). Verifica-se que é um modelo digital de elevações bastante denso cujas precisão e exatidão serão determinadas mais adiante no processo de validação.

- Detalhes de continuidade em feições como viadutos e pontes

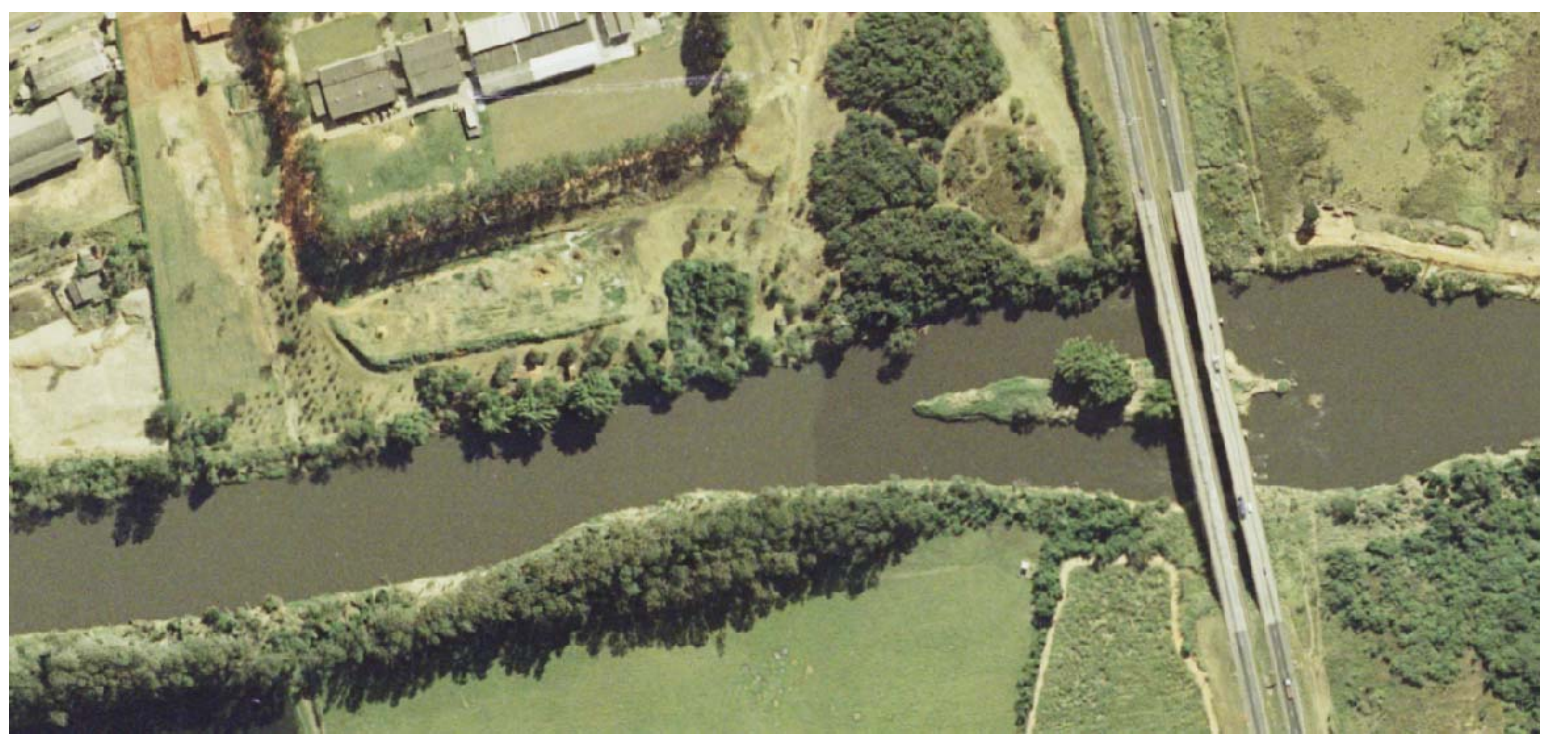

Figura 6.24 - Detalhe da ortofoto em região de emenda de mosaicagem e ponte.

Pode-se verificar na figura 6.24 a existência de mosaicagem, por diferença de tonalidade na água do rio, à esquerda da ponte mas se percebe também a boa continuidade das feições. Nota-se também a continuidade no posicionamento do viaduto, feição bastante crítica no processo de ortorretificação, e que costuma aparecer de forma ondulada quando o processo apresenta algum problema. 
Parte IV - Validação da metodologia e dos produtos. 


\section{Capítulo 7}

\section{Processo de validação.}

\subsection{Introdução.}

O objetivo deste capítulo é a descrição do processo de validação da metodologia de geração dos MDE e das ortofotos a partir de um vôo na escala 1:25.000 com base no princípio de correlação automática de imagens. Para tanto, foi aplicado o método de controle de qualidade posicional de bases cartográficas proposto por Nero (2005) para mapeamentos sistemáticos. Entretanto, para o caso de ortofotos devem ser levados em conta fatores adicionais, por exemplo na escolha dos pontos de controle que devem ser bem definidos e confiáveis nesse produto. Outra consideração refere-se ao tipo de usuário, coisa que foi considerada.

Foi então realizado um estudo comparativo para a avaliação dos produtos obtidos com a aplicação da metodologia proposta, ou seja, MDE e ortofoto na escala 1:5.000 elaborada a partir de cobertura aerofotogramétrica colorida em escala nominal de 1:25.000. Nesse estudo foram tomadas como referência as medidas, de pontos homólogos àqueles das ortofotos, feitas sobre modelos estereoscópicos apoiados da cobertura aerofotogramétrica na escala nominal de 1:5.000 executado na mesma época daquela 1:25.000.

A seguir são apresentadas as peculiaridades e as recomendações para o caso do controle de qualidade para MDE e ortofotos e a descrição detalhada de todo o processo de validação.

\subsection{Peculiaridades dos produtos gerados e a Norma Brasileira de controle de qualidade posicional.}

No que se refere ao MDE e à ortofoto, comparativamente ao produto vetorial gerado para o mapeamento tradicional, existe uma maior quantidade de pontos de controle bem identificados e confiáveis. No entanto, deve-se levar em conta alguns 
conceitos na escolha desse pontos de controle tais como, sua altura sobre uma base de referência (devem ser projetados no chão) e qual a incerteza das medidas de campo de um ponto considerado como bem definido e identificável (por exemplo de colocação do bastão do prisma entre outras).

Dessa maneira, o primeiro requisito é que o ponto esteja no "chão", pois aqueles que apresentam grande variação de altura (caso de edificações, postes, árvores, etc.) possuem uma distorção radial, sendo projetados lateralmente na imagem. Isso acontece devido ao fato de que o modelo digital do terreno (e não MDE) ser criado apenas com dados de altimetria filtrados e estarem também no "chão". Esse problema poderia ser resolvido com o processo de criação da True Ortofoto (Sato, 2003), porém é um processo com custo de produção elevado devido à necessidade de um maior número de fotos (por exigir maior superposição, tanto lateral como longitudinal) e maior tempo de processamento, não se aplicando ao caso do presente trabalho.

O segundo requisito é que o ponto de controle tenha uma incerteza compatível à qualidade esperada. Assim, a incerteza do ponto no campo deve ser equivalente a um terço do erro padrão (EP) esperado (Merchant, 1982), de acordo com o padrão de exatidão cartográfica (PEC), segundo a escala. Ou seja, os pontos de referência devem ter uma precisão três vezes melhor que a da documentação em avaliação. Nesse sentido, o quadro 7.1, apresentado por Kraus (1993) apud Sato (2003), serve como base para a definição dos pontos de controle adequados.

Quadro 7.1 - Incertezas na definição de pontos de controle naturais.

\begin{tabular}{|c|c|c|}
\hline Tipo de Pontos & $\begin{array}{c}\text { Planimetria } \\
(\mathrm{cm})\end{array}$ & $\begin{array}{c}\text { Altimetria } \\
(\mathrm{cm})\end{array}$ \\
\hline Cantos de edificações e de muros e cercas & 7 a 12 & 8 a 15 \\
\hline Tampos de caixas de inspeção & 4 a 6 & 1 a 3 \\
\hline Cantos de canteiros & 20 a 100 & 10 a 20 \\
\hline Arbustos e árvores & 20 a 100 & 20 a 100 \\
\hline
\end{tabular}


Paralelamente, deve-se ter em conta a legislação vigente no Brasil, no que se refere à qualidade posicional em Cartografia. Isso é estabelecido pelo Decreto Lei $\mathrm{n}^{\circ}$ 89.817 de 20 de junho de 1984 (Brasil, 1984). No Capítulo II desse decreto o tema tratado é o controle de qualidade do produto final, abrangendo os seguintes tópicos:

a) Classificação de uma carta quanto à exatidão: os documentos cartográficos devem obedecer ao PEC (Padrão de Exatidão Cartográfica), que se refere a um indicador estatístico de dispersão, relativo a $90 \%$ de probabilidade, ou seja, $\mathrm{PEC}=1,6449^{*} \mathrm{EP}$, onde o EP corresponde ao Erro-padrão (equivalente ao termo desvio-padrão). Assim, o EP num trabalho cartográfico não ultrapassará $60,8 \%$ do PEC. Esse valor foi definido mediante a inversão da fórmula anterior, obtendo-se $\mathrm{EP}=\mathrm{PEC} / 1,6449=0,608^{*} \mathrm{PEC}$. Como norma em planimetria é estabelecido que $90 \%$ dos pontos bem definidos num documento cartográfico e testados no terreno, ou fonte mais precisa, não deverão apresentar erro superior ao PEC planimétrico estabelecido. Já em termos de altimetria $90 \%$ dos pontos interpolados e testados no terreno não deverão resultar em erro superior ao PEC altimétrico estabelecido.

b) No que se refere às classes estabelecidas apresenta-se no quadro 7.2 um resumo dos parâmetros do PEC e respectivos EP para planimetria e altimetria.

Quadro 7.2 - Resumo dos parâmetros estabelecidos pela norma de controle de qualidade geométrica de documentos cartográficos.

\begin{tabular}{|c|c|c|c|c|}
\hline & \multicolumn{2}{|c|}{ Planimetria } & \multicolumn{2}{c|}{ Altimetria } \\
\hline & PEC & EP & PEC & EP \\
\hline A & $0.5 \mathrm{~mm}$ & $0.3 \mathrm{~mm}$ & $1 / 2 \mathrm{Eq}$ & $1 / 3 \mathrm{Eq}$ \\
\hline $\mathrm{B}$ & $0.8 \mathrm{~mm}$ & $0.5 \mathrm{~mm}$ & $3 / 5 \mathrm{Eq}$ & $2 / 5 \mathrm{Eq}$ \\
\hline $\mathrm{C}$ & $1.0 \mathrm{~mm}$ & $0.6 \mathrm{~mm}$ & $3 / 4 \mathrm{Eq}$ & $1 / 2 \mathrm{Eq}$ \\
\hline
\end{tabular}

Fonte: Nero (2000) adaptado de Brasil (1984).

Onde:

EP=Erro padrão;

Eq=eqüidistância das curvas de nível. 
Nessa tabela, a primeira coluna, com as letras A, B e C, indica as possíveis classes segundo o decreto $\mathrm{n}^{\mathrm{o}}$ 89.817/84, e as demais apresentam os parâmetros quantitativos de PEC e EP estabelecidos em termos de planimetria e altimetria. Para calcular o valor em termos reais deve-se multiplicar o valor da tabela pelo módulo da escala do mapa; e no caso da altimetria pela eqüidistância das curvas de nível.

Com respeito à escala de mapeamento do presente trabalho, ou seja, 1:5.000, os parâmetros de qualidade do PEC são os apresentados no quadro 7.3, que são a aplicação concreta dos valores apresentados no quadro 7.2.

Quadro 7.3 - Valor do PEC e EP sugeridos para a escala 1:5.000 para as respectivas classes.

\begin{tabular}{|c|c|c|c|c|c|c|c|}
\hline \multirow[b]{2}{*}{ Escala } & \multicolumn{3}{|c|}{ Planimetria } & \multicolumn{4}{|c|}{ Altimetria } \\
\hline & Classe & $\operatorname{PEC}(\mathrm{m})$ & $\mathrm{EP}(\mathrm{m})$ & $\begin{array}{c}\text { Eq. CN } \\
(\mathrm{m})\end{array}$ & Classe & $\operatorname{PEC}(\mathrm{m})$ & $\mathrm{EP}(\mathrm{m})$ \\
\hline \multirow{3}{*}{$1: 5.000$} & A & 2.50 & 1.50 & \multirow{3}{*}{5} & $\mathrm{~A}$ & 2.50 & 1.5 \\
\hline & B & 4.00 & 2.50 & & B & 3.00 & 1,8 \\
\hline & C & 5.00 & 3.00 & & C & 3.75 & 2,3 \\
\hline
\end{tabular}

Onde Eq. $\mathrm{CN}$ = eqüidistância das curvas de nível, que para um mapeamento na escala 1:5.000 é, usualmente em engenharia, de $5 \mathrm{~m}$.

Fazendo uma analogia do quadro com o quadro de incertezas de campo previstas por Kraus (1993) apud Sato (2003) e considerando a classe A tem-se que as incertezas em campo devem ser de $0,50 \mathrm{~m}(50 \mathrm{~cm})$, correspondentes a um terço do EP para planimetria e altimetria. Assim, quase todos os tipos de ponto poderiam ser coletados como pontos bem definidos, com exceção das árvores e arbustos, além de alguns cantos de canteiros e de edificações (devido ao problema de projeção radial destas).

No caso da ortofoto 1:5.000 produzida neste trabalho alguns pontos mostraram-se totalmente viáveis e considerados como pontos bem definidos para compor a população $(\mathrm{N})$ de pontos de controle, tal como cantos de piscina, cantos de canteiros bem definidos, faixas de sinalização de vias, cantos de quadras esportivas, 
etc. Exemplos desses pontos de controle bem definidos na ortofoto 1:5.000 podem ser visualizados na figura 7.1, sendo estes representados com uma cruzeta em vermelho.

Considerando que o material disponível para a avaliação deve ser três vezes mais acurado que o material a ser avaliado, os pontos de controle homólogos foram identificados e coletados diretamente sobre modelos estereoscópicos provenientes de uma cobertura aerofotogramétrica colorida na escala 1:5.000, executada na mesma época. Supondo-se que a precisão é a mesma, o fato de uma escala ser cinco vezes maior que a outra conduz à presunção de que o material é cinco vezes mais preciso.

A seguir será detalhado todo o processo de controle de qualidade empregado para a avaliação posicional, em N, E e H. As duas primeiras coordenadas avaliam a precisão planimétrica da ortofoto e a terceira avalia o MDE.

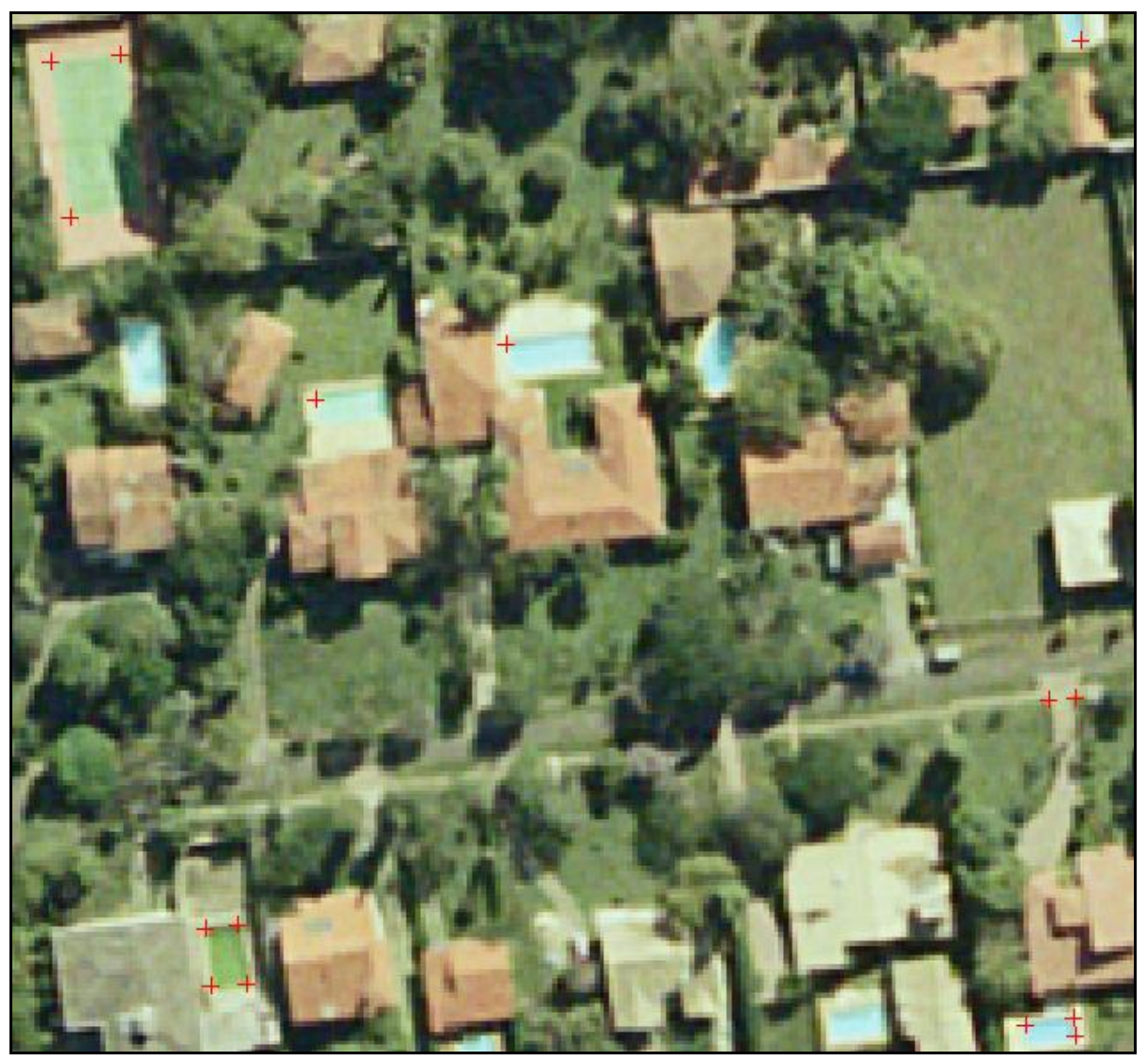

Figura 7.1 - Exemplos de pontos de controle bem definidos e extraídos da ortofoto 1:5.000 (visão em escala ampliada). 


\subsection{Processo de controle de qualidade posicional.}

\subsubsection{Determinação da População.}

Da ortofoto na escala de 1:5.000 foram extraídos 3445 pontos (só em coordenadas planimétricas $\mathrm{N}, \mathrm{E}$ ), sendo estes de uma maneira geral, pontos bem definidos correspondentes a cantos de piscina, cantos de quadras esportivas, cantos de jardins bem definidos, entre outros. Uma parcela de tais pontos pode ser observada na figura 7.2.

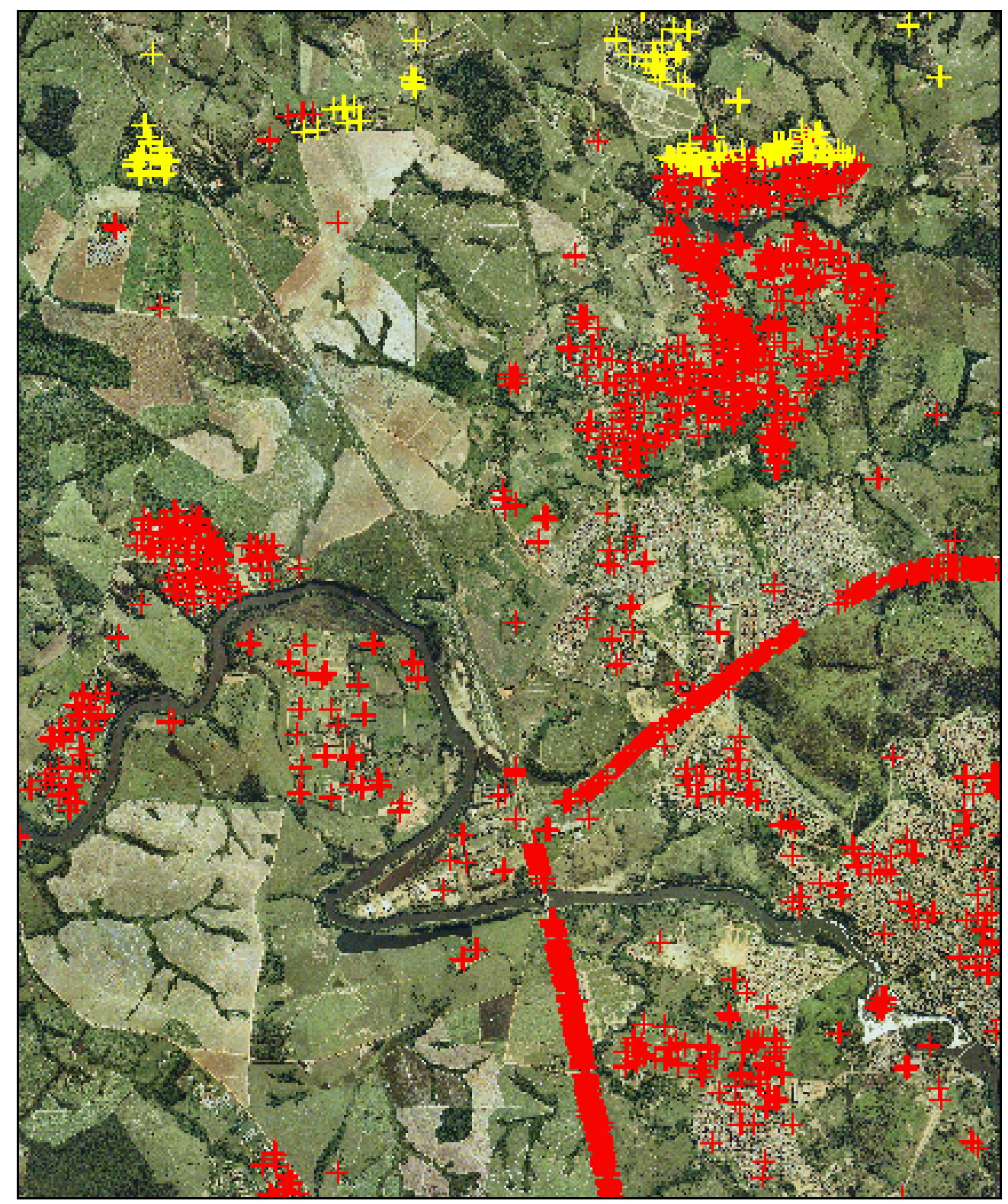

Figura 7.2 - Pontos de controle bem definidos extraídos da ortofoto 1:5.000. 
Essa quantidade de pontos levaria a um trabalho de controle muito grande e por isso impõe-se a escolha de pontos amostrais. Para isso procede-se a um sorteio dirigido que determina previamente áreas de maior ou menor criticidade, onde se esperam erros maiores ou menores.

\subsubsection{Amostragem dirigida.}

Para a realização da amostragem dirigida foram criados, inicialmente, os mapas temáticos, a partir dos quais se elaborarão os mapas de criticidade, ou seja, mapas de declividade (figura 7.3) e de distância dos possíveis pontos amostra ao ponto de apoio mais próximo (figura 7.4).

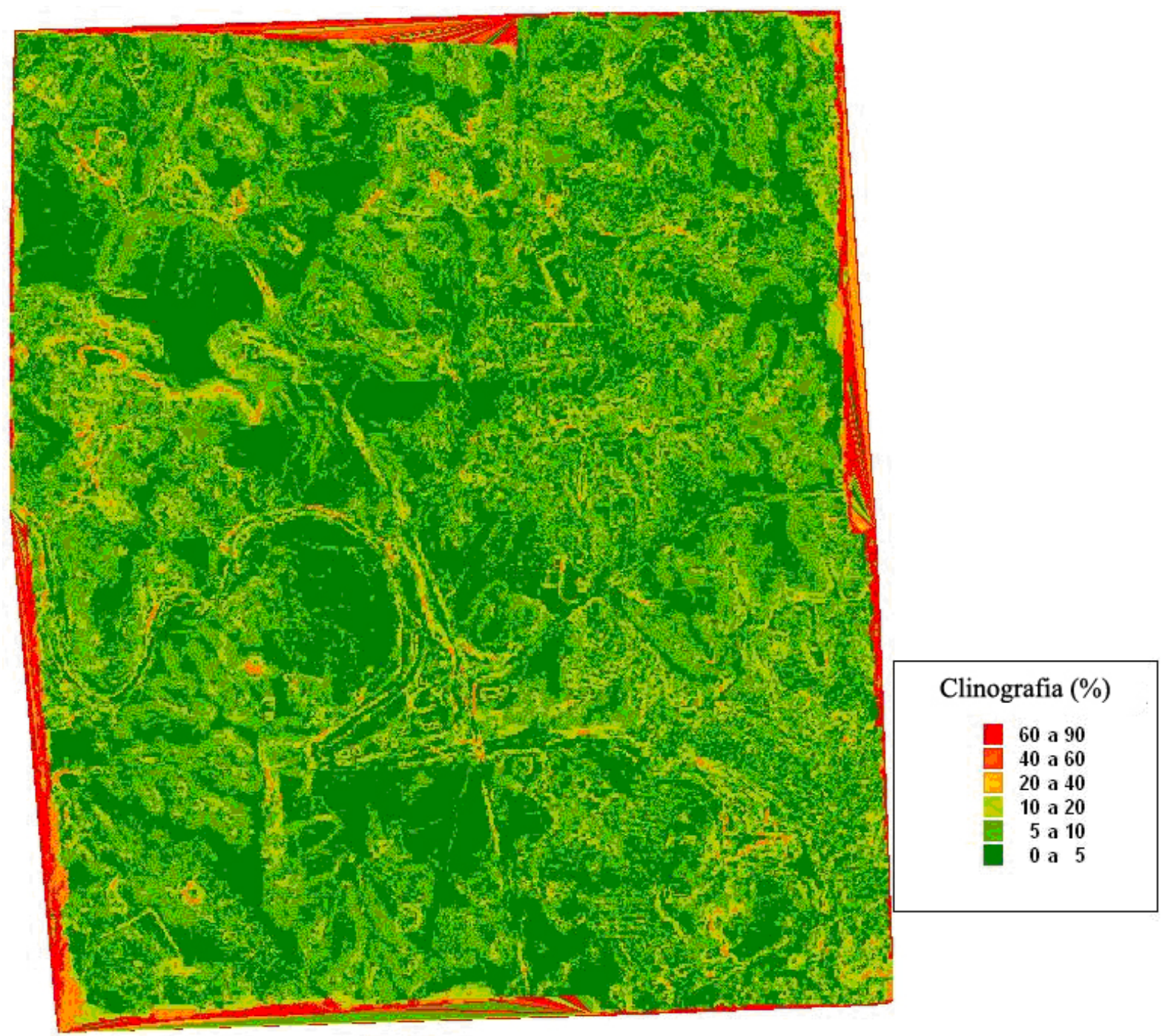

Figura 7.3 - Mapa clinográfico, dividido em seis classes. 
O pressuposto é que quanto maior a declividade mais sujeito a erro estará a determinação das coordenadas planimétricas, e o mesmo acontece com a distância dos pontos de apoio: quanto mais longe, mais crítico.

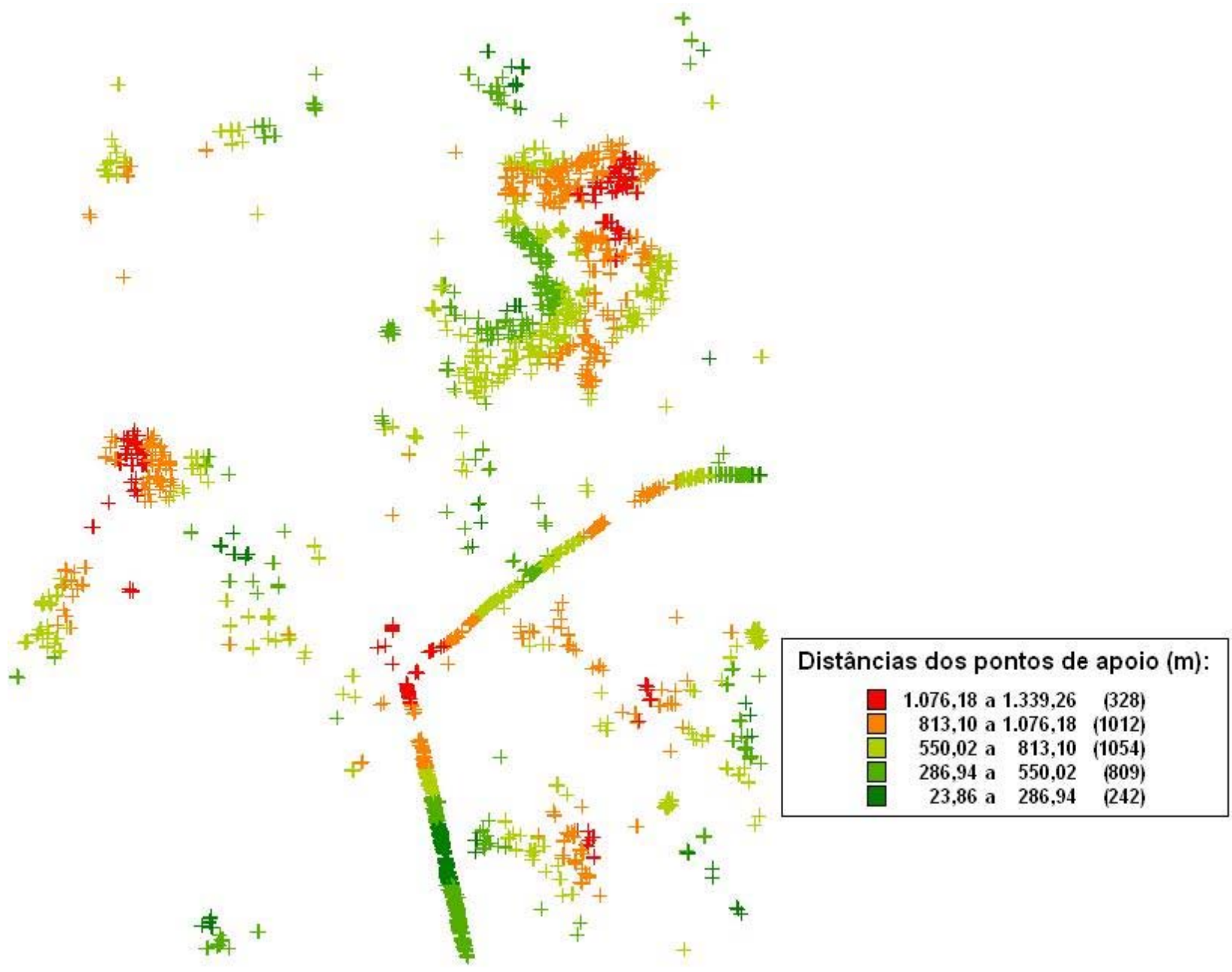

Figura 7.4 - Distâncias dos pontos de controle ao ponto de apoio mais próximo, em cinco classes.

Por combinação de tais mapas de classes foi criado um mapa temático de três classes de criticidade, com a indicação dos locais mais críticos segundo um índice, criado a partir dos valores das dos mapas temáticos anteriores (clinográfico e de distância dos pontos de apoio), sendo gerado o mapa temático da figura 7.5. Esse critério de combinação pode ser visto com maiores detalhes em Nero (2005). 
Considerando a norma MIL-STD-105E, a qual foi editada na norma ISO-28591, tem-se que para um produto novo (MDE e ortofoto gerado por processo automatizado) é recomendável a aplicação do Nível de Inspeção II.

Para que se tenha uma idéia mais clara dos níveis de inspeção, apresenta-se as finalidades de cada um deles:

- Nível III - aplicável a produtos com processo de produção que apresenta grande possibilidade de rejeição. Exige uma amostra grande.

- Nível II - aplicável a produtos novos cujo processo de produção pode implicar, por exemplo, em inovação tecnológica. Exige amostras médias.

- Nível I - aplicável a produtos com processo de produção consagrados. Exige amostras mais reduzidas.

Detalhes maiores, consultar as normas MIL-STD-105E e ISO 2859-1, e Nero (2005).

Com a aplicação da norma MIL-STD-105E, que trata de procedimentos de amostragem e tabelamento para inspeção por atributos, para um nível de inspeção normal I e com o valor da população fornecida chega-se a um valor mínimo de tamanho de amostra de 200 pontos de controle bem definidos.

A norma brasileira indica um número de 20 pontos, mas embora não indique explicitamente, esse valor se aplica a uma única carta executada com metodologia convencional, e aqui se trata de um mapeamento contínuo utilizando-se de nova metodologia. Em sendo omissa a norma brasileira no trato de uma nova metodologia, adotou-se aqui a norma MIL-STD-105E, para que, uma vez validada a metodologia, possa-se utilizar esta amostra reduzida para uma carta.

A escolha de uma amostra maior, justifica-se em termos de avaliação mais rigorosa deste protótipo e da teoria de amostragem. Para uma população de 3445 pontos, consultada a tabela ISSO, chega-se a uma amostra de 200 pontos. 


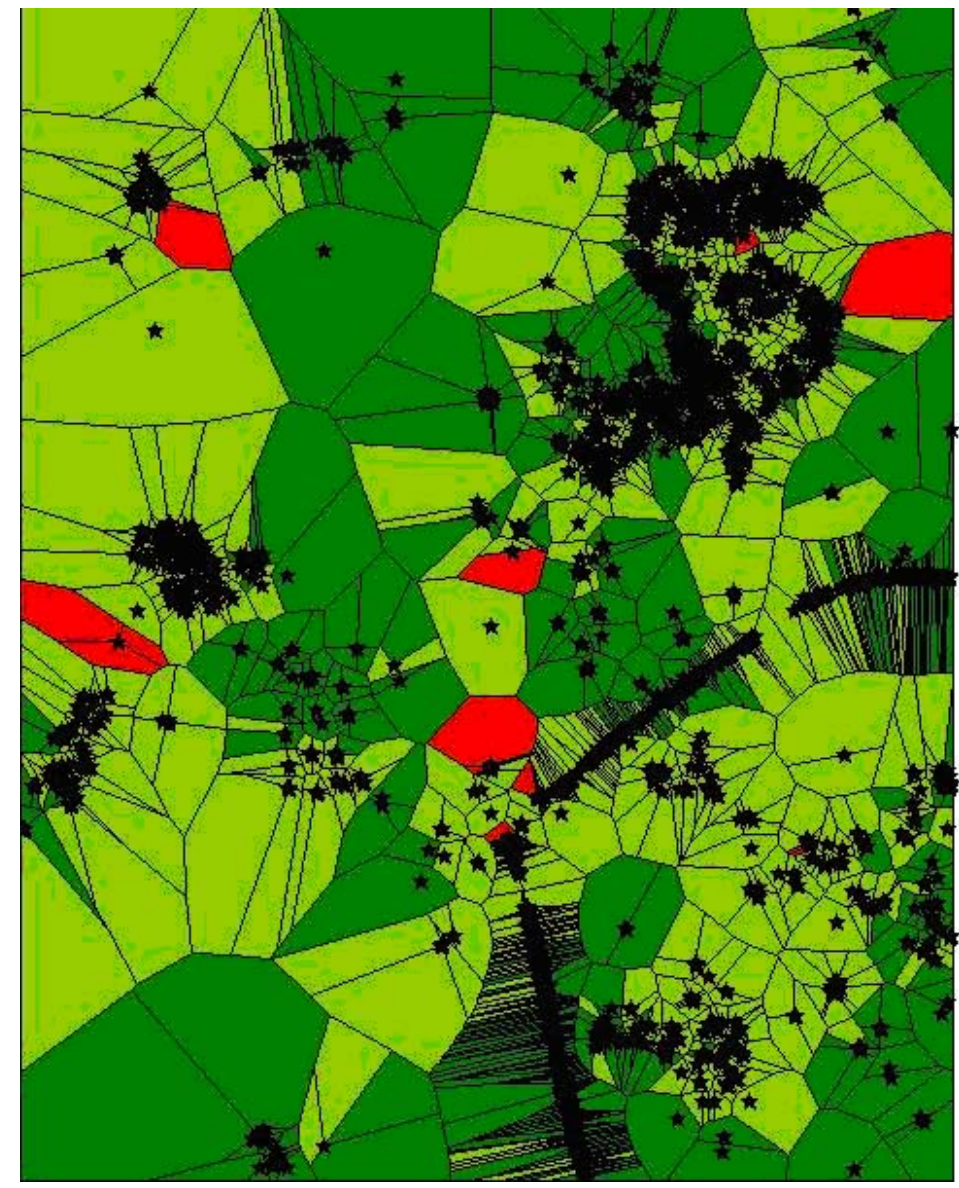

\section{Classes de Criticidade}

$\begin{array}{lr}\text { Classe } 1 & \text { (84) } \\ \text { Classe } 2 & (2074)\end{array}$

Classe 3 (1286)

Figura 7.5 - Mapa de Classes de Criticidade segundo o índice calculado.

Os duzentos pontos foram escolhidos segundo as classes de amostragem, conforme descrito em NERO (2005). Para tanto, foram realizados os seguintes cálculos:

$n_{1}=N_{1}=84$ pontos de controle na classe $1, \mathrm{o}$ total da população da classe 1 , mais crítica, equivalente a $42 \%$ da amostra total para este caso prático;

$n_{2}=(2 / 3)^{*}\left(n-n_{1}\right)=78$ pontos de controle na classe 2, equivalente a dois terços dos pontos restantes e 39\% da amostra total para este caso prático;

$n_{3}=(1 / 3)^{*}\left(n-n_{1}\right)=38$ pontos de controle na classe 3 , menos crítica, equivalente a $19 \%$ da amostra total.

Isso, e mais o critério de se tomar pontos no maior número de modelos distintos da cobertura em escala 1:5000 utilizada como referência, configurou a distribuição de pontos de controle mostrada na figura 7.6. 


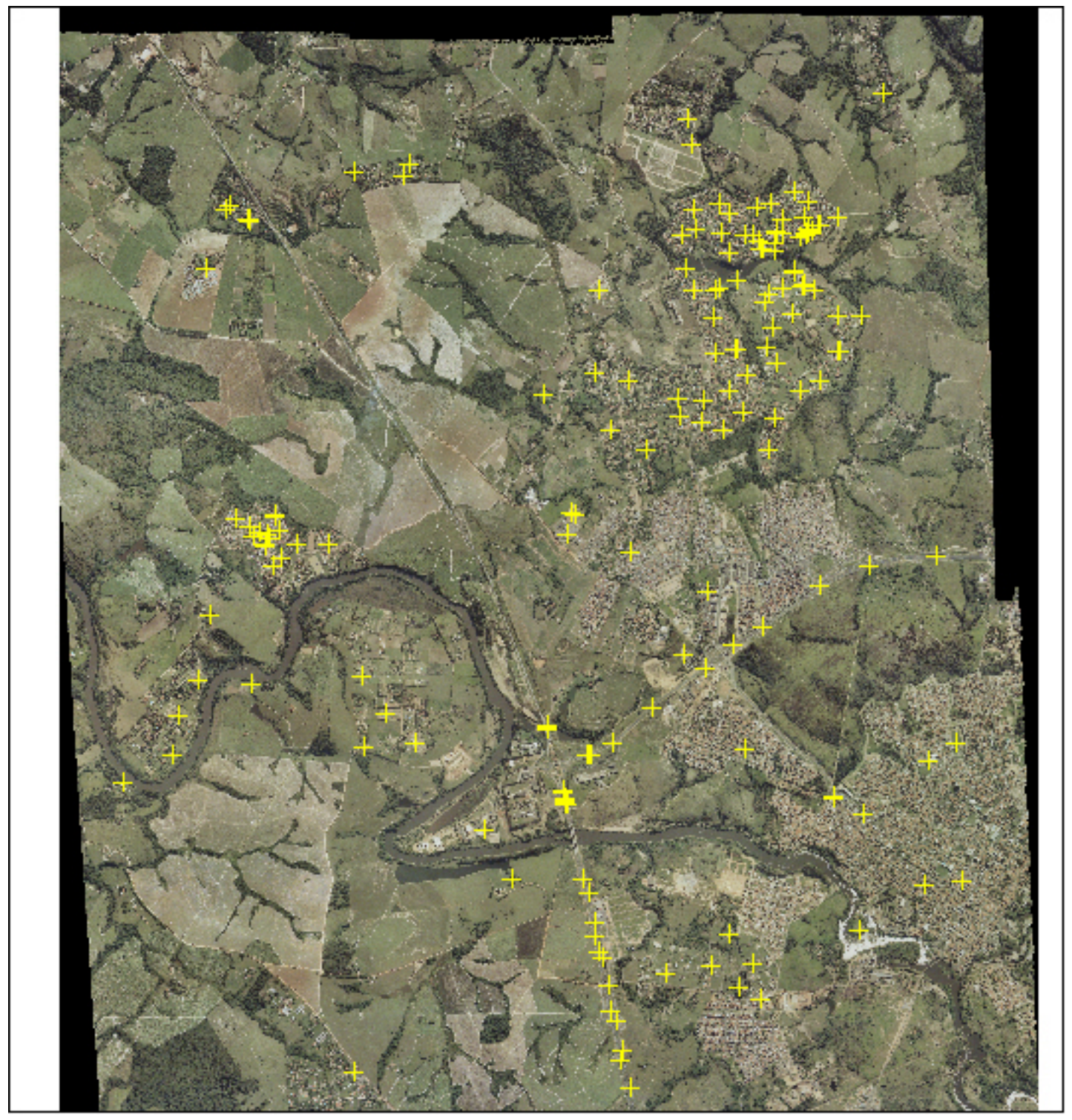

Figura 7.6 - Distribuição da amostra de 200 pontos de controle.

\subsubsection{Testes estatísticos e classificação.}

Com as coordenadas da ortofoto 1:5.000 e da fonte mais acurada (vôo 1:5.000), podendo produzir mapas em escala 1:1.000, foi possível fazer os testes e análises comparativas como descrito a seguir.

\subsubsection{Erros grosseiros.}

Ao primeiro momento, corresponde detectar erros grosseiros, ou seja, verificar em que pontos o erro é superior à média mais ou menos $3 \sigma$. Antes de notificar tais erros e descartar os pontos, deve-se fazer uma análise caso a caso, de 
modo a verificar, por exemplo, se são problemas de correspondência entre os pontos homólogos (erro de identificação entre uma fonte e outra), ou os pontos não são bem identificados (zonas de oclusão, regiões arbustivas,...) como pede a norma brasileira. Tais pontos, no caso de motivos justificados, podem ser retirados da amostra, antes de serem feitos os testes de tendência e precisão.

\subsubsection{Teste de normalidade.}

Eliminados os erros grosseiros pode-se realizar o teste de normalidade, ou seja, verificar se a amostra obedece a uma distribuição normal. A partir da estatística descritiva, pode-se criar o histograma para a análise visual da distribuição e, em seguida, aplicar o teste numérico, ao nível de confiança de 90\%. Uma descrição pode ser encontrada em RAMOS (1999). A partir dos dados da estatística descritiva avaliam-se os valores de curtose $(K)$ e da assimetria $(S a)$. Para tanto, segundo a Estatística, esses valores devem estar na faixa de limites considerados abaixo:

$$
\begin{aligned}
& -0.5 \leq S a \leq 0.5 ; \\
& 2.5 \leq K \leq 3.5
\end{aligned}
$$

No caso concreto os valores encontrados foram $S a=0.23$ e $K=2.69$, o que indica que a distribuição é normal e não há especiais precauções a serem tomadas.

\subsubsection{Teste de média e desvio padrão}

Para realizar os testes de Tendência e de Precisão faz-se necessário, previamente, os cálculos da média dos erros e do desvio padrão para cada uma das coordenadas (E, N e H) isoladamente, de acordo com a formulação apresentada a seguir:

Cálculo da média dos erros $(\mu)$, numa dada direção $X(N, E, H)$ : soma dos erros pelo número dos pontos de controle.

$$
\mu=\sum_{i=1}^{N} \frac{\Delta X_{i}}{n}=\frac{\left[\sum_{i=1}^{n}\left(x_{c_{i}}-x_{d_{i}}\right)\right]}{n}
$$


Onde:

$\mu=$ média dos erros numa direção $X ;$

$n$ = número de pontos de controle;

$x_{c i}=$ coordenadas dos pontos de controle de referência obtidos numa dada direção, neste caso dos modelos da cobertura 1:5.000;

$x_{d i}=$ coordenadas dos pontos correspondentes no produto a ser avaliado (base).

Cálculo do desvio padrão $\left(\mathrm{S}_{\mathrm{x}}\right)$ numa dada direção $X(\mathrm{~N}, \mathrm{E}$ ou $\mathrm{H})$ : corresponde à raiz quadrada da soma dos erros menos a média $(\mu)$ elevado ao quadrado e dividido pelo número de pontos de controle menos 1, conforme a equação 7.2.

$$
S_{x}=\left[\frac{\sum_{i=1}^{n}\left(\Delta X_{i}-\mu\right)^{2}}{(n-1)}\right]^{\frac{1}{2}}
$$

Onde:

$S_{X}=$ desvio padrão numa direção $X$;

$\Delta \mathrm{X} i=\left(x_{c i}-x_{d i}\right)$, que neste caso sai diretamente da tabela criada;

$\mu=$ Média dos erros;

$n=$ número de pontos de controle.

\subsubsection{Teste de tendência (Avaliação do erro sistemático).}

Este teste tem por objetivo a detecção de erro sistemático numa dada coordenada.

Para Tanto, aplica-se o seguinte teste de hipóteses:

$\mathrm{H}_{0}$ : Se $\mu=0$, então não existe tendência numa dada coordenada.

$\mathrm{H}_{1}$ : Se $\mu \neq 0$, então existe tendência numa dada coordenada. 
Ou seja, é realizado inicialmente o chamado "Teste de Tendências", para um nível de confiança (1- $\alpha)$, e, como habitualmente, adota-se $\alpha=0.9$ ou $90 \%$. Permite concluir se a coordenada em questão, possui ou não tendência.

Pela Função Distribuição Normal Unidimensional " $Z$ " chega-se ao valor de 1,645 para o nível de $90 \%$. Assim, se $\left|Z_{x}\right|<Z_{(1-\alpha / 2)}$ o documento cartográfico pode ser aceito como livre de efeito sistemático numa dada coordenada $\mathrm{X}$ qualquer.

A equação a seguir, 7.3, é utilizada para o cálculo de Z×:

$$
Z_{x}=\left(\frac{1}{E P}\right) \mu \sqrt{n}
$$

Ocorrendo erro sistemático, ou seja, existindo tendência, deve-se avaliar se o valor encontrado é significativo, na escala avaliada. Caso seja significativo, pode-se eliminá-lo, subtraindo a média de cada valor, o que equivale a uma simples translação na direção em que se constata tal ocorrência.

\subsubsection{Teste do Qui-quadrado (Avaliação da precisão):}

O segundo teste, denominado "Teste de Precisão" avalia as seguintes hipóteses numa dada coordenada qualquer $X$ :

$\mathrm{H}_{0}:$ Se $S x^{2} \leq \sigma x^{2}$ o documento cartográfico atende à precisão desejada numa dada coordenada, para um valor de Sx pré-fixado, que pode ser compatível com os valores do EP da norma brasileira,

$\mathrm{H}_{1}$ : Se $S x^{2}>\sigma x^{2}$ o documento cartográfico não atende à precisão desejada numa dada coordenada.

Considerando o erro padrão (EP), tem-se:

$\sigma x=\mathrm{EP}$

Se $\chi_{(x, n-1)}^{2} \leq \chi_{(n-1, \alpha)}^{2}$, então o documento cartográfico atende à precisão numa dada direção qualquer $X$.

A equação 7.4, utilizada para o cálculo de $\chi_{(x, n-1)}^{2}$, é apresentada a seguir: 


$$
\chi_{(x, n-1)}^{2}=(n-1)\left(\frac{S_{x}^{2}}{\sigma_{x}^{2}}\right)
$$

\subsubsection{Classificação do documento cartográfico de acordo com a Norma Brasileira}

O teste do item anterior (Qui-quadrado) é o da Norma Americana, sendo que a Norma Brasileira utiliza um teste estatístico equivalente, mas com diferente comparação.

Em vez de fixar $\sigma$, e portanto $68 \%$ dos pontos numa distribuição normal deveriam estar no intervalo $\mu \pm \sigma$, utiliza outro ponto da distribuição, para exigir que $90 \%$ dos pontos esteja no intervalo $\mu \pm 1.645 \sigma$.

O produto $1.645 \sigma$ corresponde ao valor do PEC (igual a 1.645 EP) e então basta examinar o intervalo $\mu \pm$ PEC e verificar se, no máximo, $10 \%$ dos pontos está fora dela.

A imposição de diferentes valores de PEC conforme os quadros 7.2 e 7.3 é o que permite que o produto possa ser classificado em $\mathrm{A}, \mathrm{B}$ ou $\mathrm{C}$, de acordo com o Decreto Federal n‥ 89.817/84.

\subsection{Aplicação e classificação dos produtos cartográficos.}

Num primeiro momento os dados utilizados, em termos de planimetria e altimetria foram os 200 pontos de controle escolhidos de acordo com o critério de criticidade (item 7.3.2) e apresentados na figura 7.6. para poder descartar algum valor, na prática tomaram-se 205 pontos.

No que se refere aos dados de altimetria, além disso, foi criada uma malha regular de espaçamento de 150 metros, o que resultou em cerca de 1250 pontos de controle em altimetria. Estes, que serão as referências, foram coletados nos estereomodelos na escala 1:5.000. Para as mesmas posições planimétricas foram extraídas as altitudes do MDE gerado. Estas últimas (que devem ser controladas) foram confrontadas com aquelas altitudes de referência. 
Os conjuntos de dados, planimétricos e altimétricos, foram levantados por diferentes operadores com as seguintes características pessoais:

- Dados planimétricos extraídos das ortofotos:

a) Operador AD: experiência de 35 anos em aerofotogrametria, sendo 10 com imagens digitais;

b) Operador A: experiência de 35 anos em aerofotogrametria, sendo 4 com imagens digitais;

c) Operador F: experiência de 7 anos em aerofotogrametria digital;

- Dados de referência extraídos dos estereomodelos da cobertura aerofotogramétrica na escala 1:5.000:

d) Operadores V e D: experiência de 5 anos em aerofotogrametria digital.

Para a avaliação planimétrica, os 200 pontos de controle são resultantes de leituras feitas nos modelos estereoscópicos de cobertura em escala 1:5.000, com pixel de $0.14 \mathrm{~m}$. Foi montada uma tabela em que figuram as leituras dessas coordenadas de referência (anexo 5), assim como o conjunto de leituras de seus homólogos feitas por três operadores (A, AD e F) na ortoimagem em escala 1:5.000, com pixel de $0.70 \mathrm{~m}$.

Para a avaliação altimétrica, além das altitudes dos 200 pontos de controle, foram efetuadas leituras nos modelos estereoscópicos em escala 1:5.000 (que poderia gerar mapa em 1:1.000), em uma malha espaçada de 150 metros, que na área teste gerou aproximadamente 1250 pontos de controle. Do MDE gerado a partir das aerofotos em escala 1:25.000 seguindo a metodologia proposta foram extraídas as altitudes nas mesmas coordenadas dos pontos de controle, ou seja na mesma malha. A avaliação se fez analisando as diferenças entre as altitudes de controle (mais precisas) e aquelas extraídas do MDE.

As tabelas de avaliação, tanto para a planimetria como para a altimetria, são apresentadas a seguir. 


\subsubsection{Avaliação dos dados de planimetria.}

Os dados planimétricos foram tabulados em 3 quadros, um para cada operador. Calculados seus desvios e suas tendências observa-se o seguinte resultado para os diferentes operadores e escalas avaliadas:

Quadro 7.4 - Confrontação das observações feitas pelo operador AD nas ortofotos geradas com medidas de referência.

Quadro referente ao operador AD

\begin{tabular}{|c|r|l|}
\hline \multicolumn{3}{|c|}{ Tabela 1: Dados gerais } \\
\hline & $\mathrm{X}$ & \multicolumn{1}{c|}{$\mathrm{Y}$} \\
\hline$\mu$ & -0.140 & -0.350 \\
\hline$\sigma$ & 0.408578 & 0.44222 \\
\hline & $\mathrm{n}=$ & 205 \\
\hline \multirow{2}{*}{ Classe A } & $\mathrm{EP}(\mathrm{mm})=$ & 0.3 \\
\cline { 2 - 3 } & $\mathrm{PEC}(\mathrm{mm})=$ & 0.5 \\
\hline \multirow{4}{*}{$\mathrm{Z} \mathrm{tab}=$} & 1.645 \\
\cline { 2 - 3 } & $\mathrm{X} \mathrm{tab}=$ & 230.276 \\
\cline { 2 - 3 }
\end{tabular}

\begin{tabular}{|c|c|c|c|c|r|r|r|r|r|c|}
\hline \multicolumn{4}{|c|}{ Tabela 2: Testes } & \multicolumn{5}{|c|}{ X } & \multicolumn{3}{|c|}{ Y } \\
\hline Escala 1: & EP(m) & PEC $(\mathrm{m})$ & Zcalc & A / R & X calc & A / R & Zcalc & A / R & X calc & A / R \\
\hline 25,000 & 7.5 & 12.50 & 0.2673 & A & 0.6054 & A & 0.6682 & $\mathrm{~A}$ & 0.7092 & $\mathrm{~A}$ \\
\hline 10,000 & 3.0 & 5.00 & 0.6682 & $\mathrm{~A}$ & 3.7839 & $\mathrm{~A}$ & 1.6704 & $\mathrm{R}$ & 4.4327 & $\mathrm{~A}$ \\
\hline 5,000 & 1.5 & 2.50 & 1.3363 & $\mathrm{~A}$ & 15.1355 & $\mathrm{~A}$ & 3.3408 & $\mathrm{R}$ & 17.7306 & $\mathrm{~A}$ \\
\hline 3,000 & 0.9 & 1.50 & 2.2272 & $\mathrm{R}$ & 42.0431 & $\mathrm{~A}$ & 5.5680 & $\mathrm{R}$ & 49.2518 & $\mathrm{~A}$ \\
\hline 2,500 & 0.8 & 1.25 & 2.6727 & $\mathrm{R}$ & 60.5421 & $\mathrm{~A}$ & 6.6816 & $\mathrm{R}$ & 70.9226 & $\mathrm{~A}$ \\
\hline 2,000 & 0.6 & 1.00 & 3.3408 & $\mathrm{R}$ & 94.5971 & $\mathrm{~A}$ & 8.3521 & $\mathrm{R}$ & 110.8165 & $\mathrm{~A}$ \\
\hline
\end{tabular}


Quadro 7.5 - Confrontação das observações feitas pelo operador A nas ortofotos geradas com medidas de referência.

* Quadro referente ao operador A

\begin{tabular}{|c|r|l|}
\hline \multicolumn{3}{|c|}{ Tabela 1: Dados gerais } \\
\hline & $\mathrm{X}$ & \multicolumn{1}{c|}{$\mathrm{Y}$} \\
\hline$\mu$ & -0.165 & -0.122 \\
\hline$\sigma$ & 0.773 & 0.636 \\
\hline & $\mathrm{n}=$ & 205 \\
\hline \multirow{2}{*}{ Classe A } & $\mathrm{EP}(\mathrm{mm})=$ & 0.3 \\
\cline { 2 - 3 } & $\mathrm{PEC}(\mathrm{mm})=$ & 0.5 \\
\cline { 2 - 2 } & $\mathrm{Z} \mathrm{tab}=$ & 1.645 \\
\cline { 2 - 3 } $\mathrm{X} \mathrm{tab}=$ & 230.276 \\
\cline { 2 - 3 }
\end{tabular}

\begin{tabular}{|c|c|c|c|c|r|r|r|r|r|c|}
\hline \multicolumn{4}{|c|}{ Tabela 2: Testes } & \multicolumn{4}{|c|}{ X } & \multicolumn{3}{|c|}{ Y } \\
\hline Escala 1: & EP(m) & PEC $(\mathrm{m})$ & Zcalc & A / R & X calc & A / R & Zcalc & A / R & X calc & A / R \\
\hline 25,000 & 7.5 & 12.50 & 0.3143 & A & 2.1698 & A & 0.2335 & $\mathrm{~A}$ & 1.4656 & $\mathrm{~A}$ \\
\hline 10,000 & 3.0 & 5.00 & 0.7859 & $\mathrm{~A}$ & 13.5610 & $\mathrm{~A}$ & 0.5837 & $\mathrm{~A}$ & 9.1599 & $\mathrm{~A}$ \\
\hline 5,000 & 1.5 & 2.50 & 1.5717 & $\mathrm{~A}$ & 54.2440 & $\mathrm{~A}$ & 1.1674 & $\mathrm{~A}$ & 36.6395 & $\mathrm{~A}$ \\
\hline 3,000 & 0.9 & 1.50 & 2.6195 & $\mathrm{R}$ & 150.6777 & $\mathrm{~A}$ & 1.9456 & $\mathrm{R}$ & 101.7763 & $\mathrm{~A}$ \\
\hline 2,500 & 0.8 & 1.25 & 3.1434 & $\mathrm{R}$ & 216.9759 & $\mathrm{~A}$ & 2.3348 & $\mathrm{R}$ & 146.5579 & $\mathrm{~A}$ \\
\hline 2,000 & 0.6 & 1.00 & 3.9293 & $\mathrm{R}$ & 339.0248 & $\mathrm{R}$ & 2.9184 & $\mathrm{R}$ & 228.9968 & $\mathrm{~A}$ \\
\hline
\end{tabular}

Onde A é aprovado e R é reprovado. 
Quadro 7.6 - Confrontação das observações feitas pelo operador F nas ortofotos geradas com medidas de referência.

* Quadro referente ao operador $F$

\begin{tabular}{|c|c|l|}
\hline \multicolumn{3}{|c|}{ Tabela 1: Dados gerais } \\
\hline & $\mathrm{X}$ & \multicolumn{1}{c|}{$\mathrm{Y}$} \\
\hline$\mu$ & 0.02 & -0.54 \\
\hline$\sigma$ & 0.54 & 0.56 \\
\hline & $\mathrm{n}=$ & 205 \\
\hline \multirow{2}{*}{ Classe A } & $\mathrm{EP}(\mathrm{mm})=$ & 0.3 \\
\cline { 2 - 3 } & $\mathrm{PEC}(\mathrm{mm})=$ & 0.5 \\
\hline \multirow{4}{*}{$\mathrm{Z} \mathrm{tab}=$} & 1.645 \\
\cline { 2 - 3 } & $\mathrm{X} \mathrm{tab}=$ & 230.276 \\
\cline { 2 - 3 }
\end{tabular}

\begin{tabular}{|c|c|c|c|c|r|r|r|r|r|c|}
\hline \multicolumn{4}{|c|}{ Tabela 2: Testes } & \multicolumn{9}{|c|}{ X } & \multicolumn{3}{|c|}{ Y } \\
\hline Escala 1: & EP(m) & PEC $(\mathrm{m})$ & Zcalc & A / R & X calc & A / R & Zcalc & A / R & X calc & A / R \\
\hline 25,000 & 7.5 & 12.50 & 0.0311 & A & 1.0693 & A & 1.0309 & A & 1.1333 & A \\
\hline 10,000 & 3.0 & 5.00 & 0.0776 & A & 6.6832 & $\mathrm{~A}$ & 2.5772 & $\mathrm{R}$ & 7.0829 & $\mathrm{~A}$ \\
\hline 5,000 & 1.5 & 2.50 & 0.1553 & $\mathrm{~A}$ & 26.7330 & $\mathrm{~A}$ & 5.1544 & $\mathrm{R}$ & 28.3316 & $\mathrm{~A}$ \\
\hline 3,000 & 0.9 & 1.50 & 0.2588 & $\mathrm{~A}$ & 74.2583 & $\mathrm{~A}$ & 8.5907 & $\mathrm{R}$ & 78.6989 & $\mathrm{~A}$ \\
\hline 2,500 & 0.8 & 1.25 & 0.3106 & $\mathrm{~A}$ & 106.9319 & $\mathrm{~A}$ & 10.3088 & $\mathrm{R}$ & 113.3264 & $\mathrm{~A}$ \\
\hline 2,000 & 0.6 & 1.00 & 0.3882 & $\mathrm{~A}$ & 167.0811 & $\mathrm{~A}$ & 12.8860 & $\mathrm{R}$ & 177.0726 & $\mathrm{~A}$ \\
\hline
\end{tabular}

Onde A é aprovado e $\mathrm{R}$ é reprovado.

Observa-se que, para os operadores $\mathrm{F}$ e $\mathrm{AD}$, já na escala 1:10.000 é perceptível a existência de uma tendência (valor da média), apontados como reprovado (R) em vermelho na tabela. Note-se porém que ela é de $2 \mathrm{~cm}$ e $14 \mathrm{~cm}$ em X, e $54 \mathrm{~cm}$ e $35 \mathrm{~cm}$ em Y. Já para o outro operador (A) a tendência das medidas foram significativas a partir de 1:3.000. Isso significa que existe erro sistemático, seja de leitura, seja de processo, porém este é de valor inferior à dimensão do pixel da imagem digital.

Quanto à precisão verifica-se que para todos os operadores chega-se ao PEC Classe A em escala 1:2.500, chegando mesmo, em um casos (operador A) a ter PEC Classe A para a Escala 1:2.000.

Analisando-se a dispersão sem a retirada da tendência, ou seja, do erro sistemático, tem-se os quadros 7.7 a 7.9, a seguir: 
Quadro 7.7 - Confrontação das observações feitas pelo operador AD nas ortofotos geradas com medidas de referência, sem a retirada do erro sistemático.

Quadro referente ao operador AD

\begin{tabular}{|c|r|l|}
\hline \multicolumn{3}{|c|}{ Tabela 1: Dados gerais } \\
\hline & $\mathrm{X}$ & $\mathrm{Y}$ \\
\hline$\sigma$ & 0.432 & 0.564 \\
\hline & $\mathrm{n}=$ & 205 \\
\hline \multirow{2}{*}{ Classe A } & $\mathrm{EP}(\mathrm{mm})=$ & 0.3 \\
\cline { 2 - 3 } & $\mathrm{PEC}(\mathrm{mm})=$ & 0.5 \\
\hline & $\mathrm{Z} \mathrm{tab}=$ & 1.645 \\
\cline { 2 - 3 } & $\mathrm{X} \mathrm{tab}=$ & 230.276 \\
\cline { 2 - 3 }
\end{tabular}

\begin{tabular}{|c|c|c|r|r|r|c|}
\hline \multicolumn{3}{|c|}{ Tabela 2: Testes } & & & \\
\hline Escala 1: & EP(m) & PEC $(\mathrm{m})$ & \multicolumn{1}{|c|}{ X calc } & A / R & X calc & A / R \\
\hline 25,000 & 7.5 & 12.50 & 0.6768 & $\mathrm{~A}$ & 1.1536 & $\mathrm{~A}$ \\
\hline 10,000 & 3.0 & 5.00 & 4.2301 & $\mathrm{~A}$ & 7.2102 & $\mathrm{~A}$ \\
\hline 5,000 & 1.5 & 2.50 & 16.9206 & $\mathrm{~A}$ & 28.8407 & $\mathrm{~A}$ \\
\hline 3,000 & 0.9 & 1.50 & 47.0016 & $\mathrm{~A}$ & 80.1131 & $\mathrm{~A}$ \\
\hline 2,500 & 0.8 & 1.25 & 67.6823 & $\mathrm{~A}$ & 115.3628 & $\mathrm{~A}$ \\
\hline 2,000 & 0.6 & 1.00 & 105.7536 & $\mathrm{~A}$ & 180.2544 & $\mathrm{~A}$ \\
\hline
\end{tabular}

Onde A é aprovado e $\mathrm{R}$ é reprovado.

Quadro 7.8 - Confrontação das observações feitas pelo operador A nas ortofotos geradas com medidas de referência, sem a retirada do erro sistemático.

* Quadro referente ao operador $\mathbf{A}$

\begin{tabular}{|c|r|l|}
\hline \multicolumn{3}{|c|}{ Tabela 1: Dados gerais } \\
\hline & $\mathrm{X}$ & \multicolumn{1}{c|}{$\mathrm{Y}$} \\
\hline$\sigma$ & 0.789 & 0.646 \\
\hline & $\mathrm{n}=$ & 205 \\
\hline \multirow{2}{*}{ Classe A } & $\mathrm{EP}(\mathrm{mm})=$ & 0.3 \\
\cline { 2 - 3 } & $\mathrm{PEC}(\mathrm{mm})=$ & 0.5 \\
\hline & $\mathrm{Z} \mathrm{tab}=$ & 1.645 \\
\cline { 2 - 3 } & $\mathrm{X}$ tab $=$ & 230.276 \\
\hline
\end{tabular}

\begin{tabular}{|c|c|c|r|r|r|c|}
\hline \multicolumn{3}{|c|}{ Tabela 2: Testes } & & & \\
\hline Escala 1: & EP(m) & PEC(m) & \multicolumn{1}{|c|}{ X calc } & A / R & X calc & A / R \\
\hline 25,000 & 7.5 & 12.50 & 2.2577 & $\mathrm{~A}$ & 1.5135 & $\mathrm{~A}$ \\
\hline 10,000 & 3.0 & 5.00 & 14.1105 & $\mathrm{~A}$ & 9.4592 & $\mathrm{~A}$ \\
\hline 5,000 & 1.5 & 2.50 & 56.4419 & $\mathrm{~A}$ & 37.8367 & $\mathrm{~A}$ \\
\hline 3,000 & 0.9 & 1.50 & 156.7831 & $\mathrm{~A}$ & 105.1018 & $\mathrm{~A}$ \\
\hline 2,500 & 0.8 & 1.25 & 225.7676 & $\mathrm{~A}$ & 151.3466 & $\mathrm{~A}$ \\
\hline 2,000 & 0.6 & 1.00 & 352.7619 & $\mathrm{R}$ & 236.4791 & $\mathrm{R}$ \\
\hline
\end{tabular}


Quadro 7.9 - Confrontação das observações feitas pelo operador F nas ortofotos geradas com medidas de referência, sem a retirada do erro sistemático.

\begin{tabular}{|c|c|c|c|c|c|c|}
\hline \multicolumn{3}{|c|}{ Tabela 1: Dados gerais } & & & & \\
\hline & $X$ & $\mathrm{Y}$ & & & & \\
\hline \multirow[t]{2}{*}{$\sigma$} & 0.54 & 0.78 & & & & \\
\hline & $\mathrm{n}=$ & 205 & & & & \\
\hline \multirow{4}{*}{ Classe A } & $\mathrm{EP}(\mathrm{mm})=$ & 0.3 & & & & \\
\hline & $\operatorname{PEC}(\mathrm{mm})=$ & 0.5 & & & & \\
\hline & $\mathrm{Z}$ tab $=$ & 1.645 & & & & \\
\hline & $X$ tab $=$ & 230.276 & & & & \\
\hline \multicolumn{7}{|c|}{ Tabela 2: Testes } \\
\hline Escala 1: & $\mathrm{EP}(\mathrm{m})$ & $\mathrm{PEC}(\mathrm{m})$ & $\mathrm{X}$ calc & $\begin{array}{c}\mathrm{A} / \\
\mathrm{R}\end{array}$ & $\mathrm{X}$ calc & $\begin{array}{c}\mathrm{A} / \\
\mathrm{R}\end{array}$ \\
\hline 25,000 & 7.5 & 12.50 & 1.0654 & $\mathrm{~A}$ & 2.1895 & $\mathrm{~A}$ \\
\hline 10,000 & 3.0 & 5.00 & 6.6587 & A & 13.6845 & A \\
\hline 5,000 & 1.5 & 2.50 & 26.6346 & A & 54.7381 & $\mathrm{~A}$ \\
\hline 3,000 & 0.9 & 1.50 & 73.9850 & A & 152.0503 & $\mathrm{~A}$ \\
\hline 2,500 & 0.8 & 1.25 & 106.5384 & A & 218.9524 & $\mathrm{~A}$ \\
\hline 2,000 & 0.6 & 1.00 & 166.4663 & $\mathrm{~A}$ & 342.1131 & $\mathrm{R}$ \\
\hline
\end{tabular}

Onde A é aprovado e $\mathrm{R}$ é reprovado.

Uma vez que o erro sistemático apresentado era da ordem de grandeza do pixel, era de se pensar que para diversas escalas de representação não se verificaria sua influência. Pode-se observar nos quadros 7.7, 7.8 e 7.9 que todos os operadores tiveram suas leituras planimétricas, sem a retirada do erro sistemático, avaliadas como PEC Classe A até a escala 1:2.500 em termos de planimetria.

\subsubsection{Avaliação dos dados de altimetria.}

\subsubsection{Avaliação da amostra de 205 pontos bem definidos.}

Primeiramente analisa-se aqui os pontos bem definidos utilizados para o controle planimétrico. Estes tiveram suas altitudes confrontadas com aquelas extraídas do MDE gerado. Num total de 205 pontos, verificou-se os resultados apresentados a seguir nos quadros 7.10 e 7.11: 
Quadro 7.10 - Altitudes retiradas do MDE nas posições dos 205 pontos de controle planimétrico, confrontadas com medidas altimétricas de referência.

\section{${ }^{*}$ Quadro referente às altitudes extraídas do MDE}

\begin{tabular}{|r|r|l|}
\hline \multicolumn{2}{|c|}{ Tabela 1: Dados gerais } \\
\cline { 2 - 3 } & & \multicolumn{1}{c|}{$\mathrm{H}$} \\
\cline { 2 - 3 } & $\mu$ & 1.104 \\
\cline { 2 - 3 } & $\sigma$ & 0.794 \\
\hline \multirow{4}{*}{ Classe A } & $\mathrm{n}=$ & 205 \\
\cline { 2 - 3 } & $\mathrm{EEC}=$ & $1 / 3 \mathrm{Eq}$ \\
\cline { 2 - 3 } & $\mathrm{Ptab}=$ & 1.645 \\
\hline & $\mathrm{X} \mathrm{tab}=$ & 230.276 \\
\hline
\end{tabular}

\begin{tabular}{|c|c|c|r|c|r|c|}
\hline \multicolumn{3}{|c|}{ Tabela 2: Testes } & \multicolumn{4}{c|}{$\mathrm{H}$} \\
\hline Eqüidist. & $\mathrm{EP}(\mathrm{m})$ & $\mathrm{PEC}(\mathrm{m})$ & \multicolumn{1}{c|}{ Zcalc } & $\mathrm{A} / \mathrm{R}$ & $\mathrm{X}$ calc & $\mathrm{A} / \mathrm{R}$ \\
\hline 20 & 6.0 & 10.00 & 2.6440 & $\mathrm{R}$ & 3.6176 & $\mathrm{~A}$ \\
\hline 10 & 3.0 & 5.0 & 5.2880 & $\mathrm{R}$ & 14.4704 & $\mathrm{~A}$ \\
\hline 5 & 1.5 & 2.5 & 10.5761 & $\mathrm{R}$ & 57.8817 & $\mathrm{~A}$ \\
\hline 3 & 0.9 & 1.5 & 17.6268 & $\mathrm{R}$ & 160.7825 & $\mathrm{~A}$ \\
\hline 2 & 0.6 & 1.0 & 26.4402 & $\mathrm{R}$ & 361.7606 & $\mathrm{R}$ \\
\hline
\end{tabular}

Onde A é aprovado e $\mathrm{R}$ é reprovado.

Quadro 7.11 - Altitudes retiradas do MDE nas posições dos 205 pontos de controle planimétrico, sem a retirada do erro sistemático, confrontadas com medidas altimétricas de referência.

* Quadro referente às altitudes extraídas do MDE sem a retirada do erro sistemático

\begin{tabular}{|r|r|l|}
\hline \multicolumn{3}{|c|}{ Tabela 1: Dados gerais } \\
\cline { 2 - 3 } & $\sigma$ & \multicolumn{1}{|c|}{$\mathrm{H}$} \\
\cline { 2 - 3 } & $\mathrm{n}=$ & 205 \\
\hline \multirow{2}{*}{ Classe A } & $\mathrm{EP}=$ & $1 / 3 \mathrm{Eq}$ \\
\cline { 2 - 3 } & $\mathrm{PEC}=$ & $1 / 2 \mathrm{Eq}$ \\
\hline & $\mathrm{X}$ tab $=$ & 230.276 \\
\hline
\end{tabular}

\begin{tabular}{|c|c|c|r|c|}
\hline \multicolumn{3}{|c|}{ Tabela 2: Testes } & \multicolumn{2}{c|}{$\mathrm{H}$} \\
\hline Eqüidist. & $\mathrm{EP}(\mathrm{m})$ & $\mathrm{PEC}(\mathrm{m})$ & $\mathrm{X}$ calc & $\mathrm{A} / \mathrm{R}$ \\
\hline 20 & 6.0 & 10.00 & 10.5738 & $\mathrm{~A}$ \\
\hline 10 & 3.0 & 5.00 & 42.2950 & $\mathrm{~A}$ \\
\hline 5 & 1.5 & 2.50 & 169.1800 & $\mathrm{~A}$ \\
\hline 3 & 0.9 & 1.50 & 469.9445 & $\mathrm{R}$ \\
\hline 2 & 0.6 & 1.00 & 1057.3751 & $\mathrm{R}$ \\
\hline
\end{tabular}

Onde A é aprovado e $\mathrm{R}$ é reprovado. 
Como se observa no quadro 7.10, a amostra apresenta uma tendência que se mostra significativa desde a representação de curvas de nível de 20 em 20 metros. Porém seu desvio padrão mostra que, para pontos bem definidos, o MDE apresenta resultados compatíveis com a representação de curvas de nível de 3 metros de eqüidistância.

Indo-se além, mesmo que não se retire o erro sistemático da amostra, verificase, que os resultados são compatíveis com a representação de curvas de nível de 5 metros de eqüidistância.

\subsubsection{Avaliação da altimetria em uma amostra em malha regular equiespaciada de 150 metros.}

Foram executadas leituras, nos modelos estereoscópicos em escala 1:5.000, de pontos planialtimétricos em uma malha regular de 150 metros, totalizando 1248 pontos, adotados como referência. Para estas posições as altitudes foram extraídas do MDE. As análises dessa amostra encontram-se tabeladas nos quadros 7.12 e 7.13.

Quadro 7.12 - Altitudes retiradas do MDE em posições de uma malha regular de 150 metros.

\begin{tabular}{|r|r|l|}
\hline \multicolumn{2}{|c|}{ Tabela 1: Dados gerais } \\
\cline { 2 - 3 } & & \multicolumn{1}{|c|}{$\mathrm{H}$} \\
\cline { 2 - 3 } & $\mu$ & 0.773 \\
& $\sigma$ & 0.930 \\
\cline { 2 - 3 } Classe A & $\mathrm{n}=$ & 1248 \\
\cline { 2 - 3 } & $\mathrm{EP}=$ & $1 / 3 \mathrm{Eq}$ \\
\hline \multirow{4}{*}{$\mathrm{PEC}=$} & $1 / 2 \mathrm{Eq}$ \\
\hline $\mathrm{Z} \mathrm{tab}=$ & 1.645 \\
\hline $\mathrm{X} \mathrm{tab}=$ & 1313 \\
\hline
\end{tabular}

\begin{tabular}{|c|c|c|r|r|r|c|}
\hline \multicolumn{3}{|c|}{ Tabela 2: Testes } & \multicolumn{4}{|c|}{$\mathrm{H}$} \\
\hline Eqüidist. & $\mathrm{EP}(\mathrm{m})$ & $\mathrm{PEC}(\mathrm{m})$ & Zcalc & $\begin{array}{c}\mathrm{A} / \\
\mathrm{R}\end{array}$ & X calc & $\mathrm{A} / \mathrm{R}$ \\
\hline 20 & 6.0 & 10.00 & 4.5503 & $\mathrm{R}$ & 29.9552 & $\mathrm{~A}$ \\
\hline 10 & 3.0 & 5.0 & 9.1005 & $\mathrm{R}$ & 119.8207 & $\mathrm{~A}$ \\
\hline 5 & 1.5 & 2.5 & 18.2010 & $\mathrm{R}$ & 479.2829 & $\mathrm{~A}$ \\
\hline 3 & 0.9 & 1.5 & 30.3351 & $\mathrm{R}$ & 1331.34 & $\mathrm{R}$ \\
\hline 2 & 0.6 & 1.0 & 45.5026 & $\mathrm{R}$ & 2995.52 & $\mathrm{R}$ \\
\hline
\end{tabular}


Quadro 7.13 - Altitudes retiradas do MDE em posições de uma malha regular de 150 metros, sem a retirada do erro sistemático

\begin{tabular}{|r|r|l|}
\hline \multicolumn{3}{|c|}{ Tabela 1: Dados gerais } \\
\cline { 2 - 3 } & & \multicolumn{1}{c|}{$\mathrm{H}$} \\
\cline { 2 - 3 } & $\sigma$ & 1.366 \\
\hline \multirow{4}{*}{ Classe A } & $\mathrm{n}=$ & 1248 \\
\cline { 2 - 3 } & $\mathrm{EPC}=$ & $1 / 3 \mathrm{Eq}$ \\
\hline & $\mathrm{Ptab}=$ & $1 / 2 \mathrm{Eq}$ \\
\cline { 2 - 3 } & 1313 \\
\hline
\end{tabular}

\begin{tabular}{|c|c|c|r|c|}
\hline \multicolumn{3}{|c|}{ Tabela 2: Testes } & \multicolumn{2}{c|}{$\mathrm{H}$} \\
\hline Eqüidist. & $\mathrm{EP}(\mathrm{m})$ & $\mathrm{PEC}(\mathrm{m})$ & \multicolumn{1}{c|}{ X calc } & $\begin{array}{c}\mathrm{A} / \\
\mathrm{R}\end{array}$ \\
\hline 20 & 6.0 & 10.00 & 64.6346 & $\mathrm{~A}$ \\
\hline 10 & 3.0 & 5.00 & 258.5386 & $\mathrm{~A}$ \\
\hline 5 & 1.5 & 2.50 & 1034.1543 & $\mathrm{~A}$ \\
\hline 3 & 0.9 & 1.50 & 2872.6508 & $\mathrm{R}$ \\
\hline 2 & 0.6 & 1.00 & 6463.4643 & $\mathrm{R}$ \\
\hline
\end{tabular}

\subsubsection{Análises e considerações quanto à altimetria}

Fazendo-se uma análise nesta amostra, verifica-se que a totalidade dos pontos que apresentam erros superiores a 10 metros, e aqueles entre 5 e 10 metros, encontram-se em zonas de matas e de sombras. Pode-se verificar um exemplo disso na figura 7.7, onde os pontos em vermelho são aqueles com erros superiores a 10 metros, e os lilás são com erros entre 5 e 10 metros. No conjunto de 1248 pontos da amostra total estes são 91. A rigor esses pontos não devem figurar na amostra pois a Norma Brasileira fala muito claramente de pontos bem definidos na imagem e no terreno, o que não ocorre com esses. 


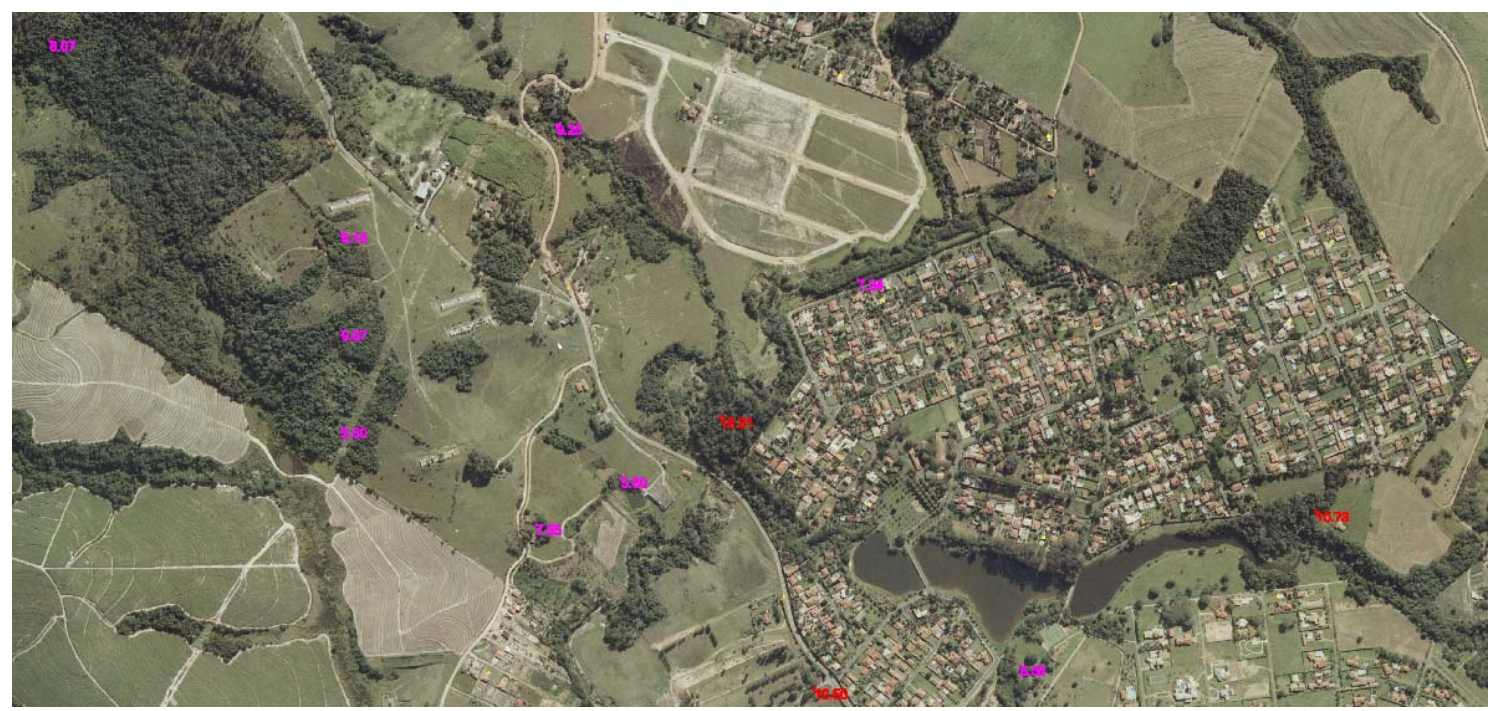

Figura 7.7 -Pontos do MDE com erros superiores a 5 metros.

Nesta mesma análise verifica-se que a totalidade de erros superiores a 3 metros encontram-se em zonas arbustivas ou em telhados urbanos como se exemplifica na figura 7.8 com os pontos marcados em cor amarela.

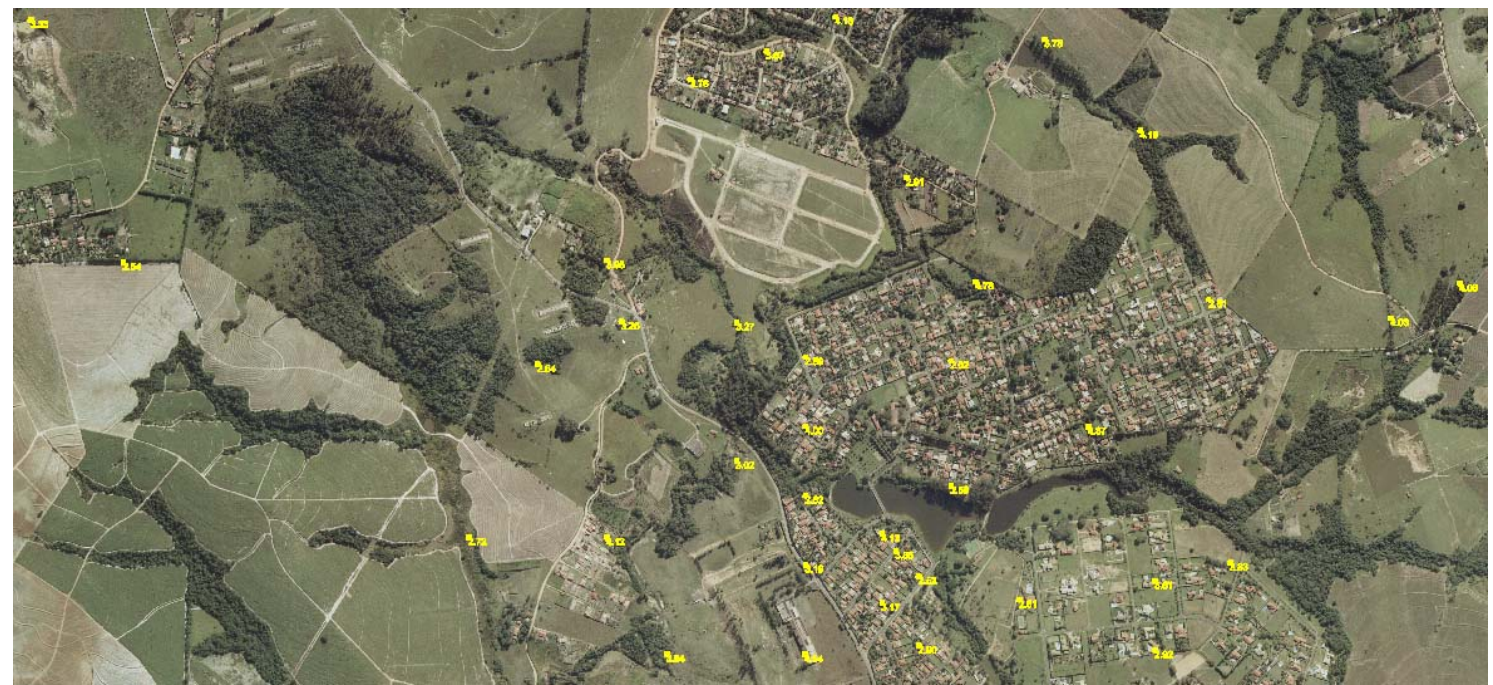

Figura 7.8 -Pontos do MDE que apresentam erro entre 3 e 5 metros.

O restante dos pontos da amostra, localizados no "chão" tanto em zona rural como urbana e em estradas, que no teste totalizam 1073 pontos, apresentam erro inferior a 2.5 metros. Pode-se avaliar sua distribuição na figura 7.9. Deve-se pensar também que dados e medições a partir desses produtos vão ocorrer baseados sobre esses pontos e não sobre os mal definidos (árvores, matas, etc.) 


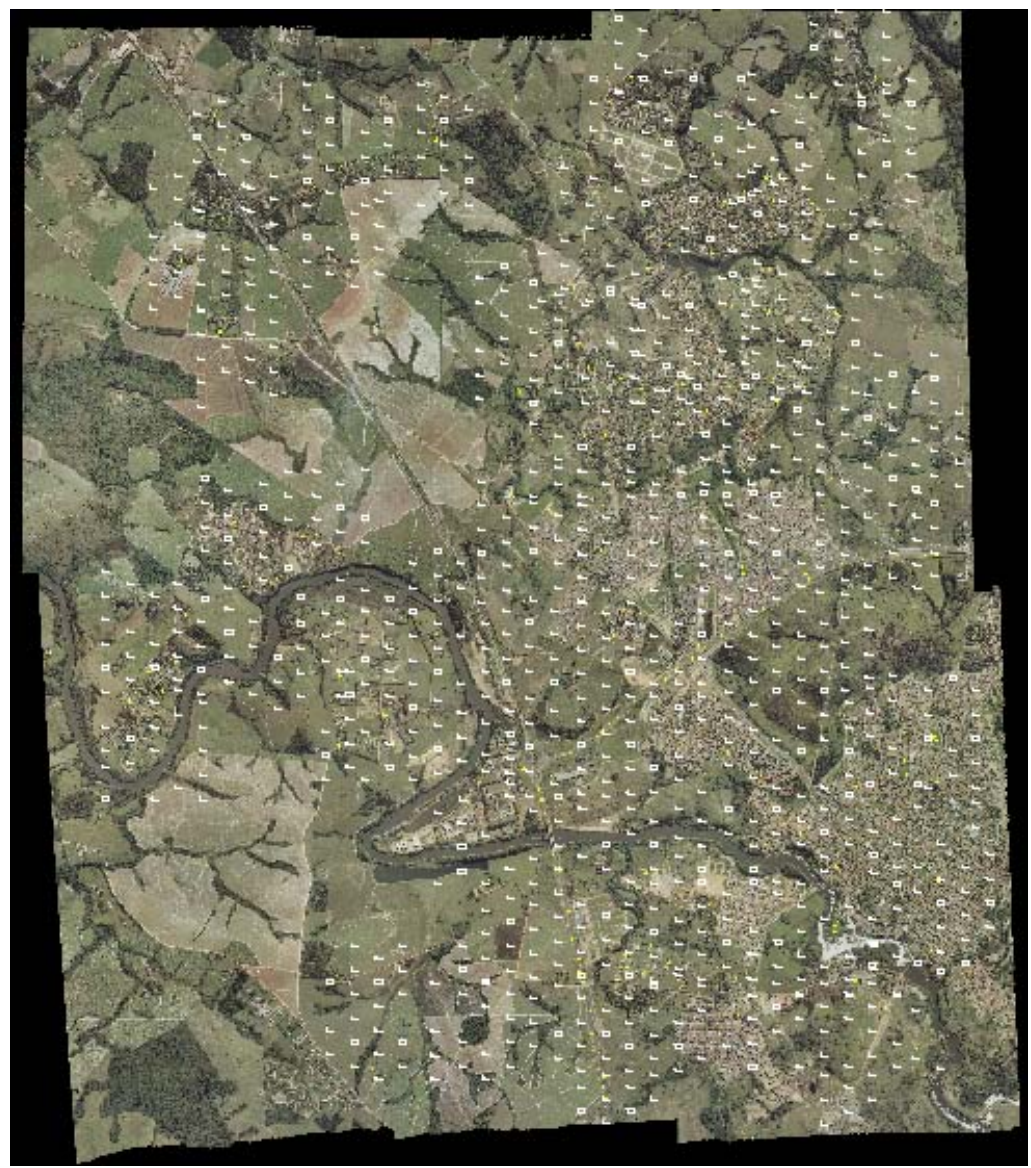

Figura 7.9 - Vista geral de pontos da amostra que apresentam erro inferior a 2.5 metros.

Para que se tenha uma visualização do que ocorre em zonas urbanas e em rurais apresentam-se a seguir as figuras 7.10 e 7.11.

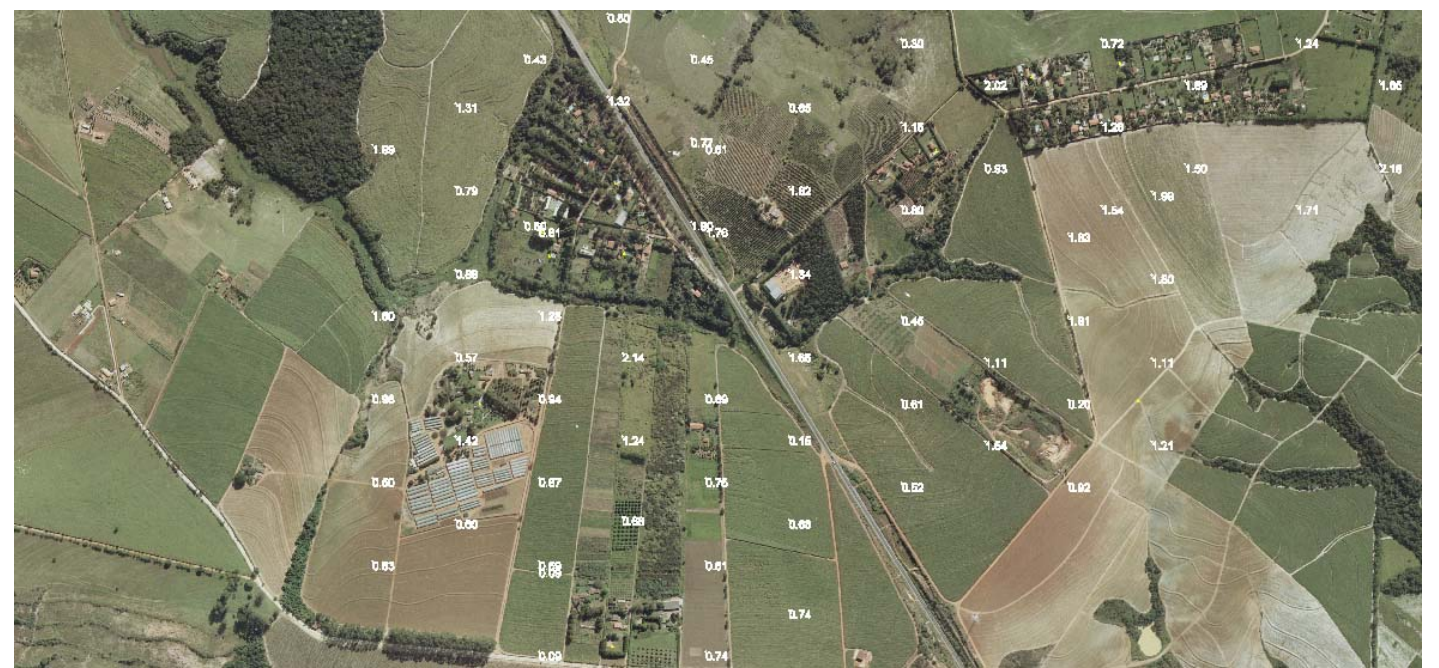

Figura 7.10 - Detalhe da amostra com erros inferiores a 2.5 metros em zona rural 


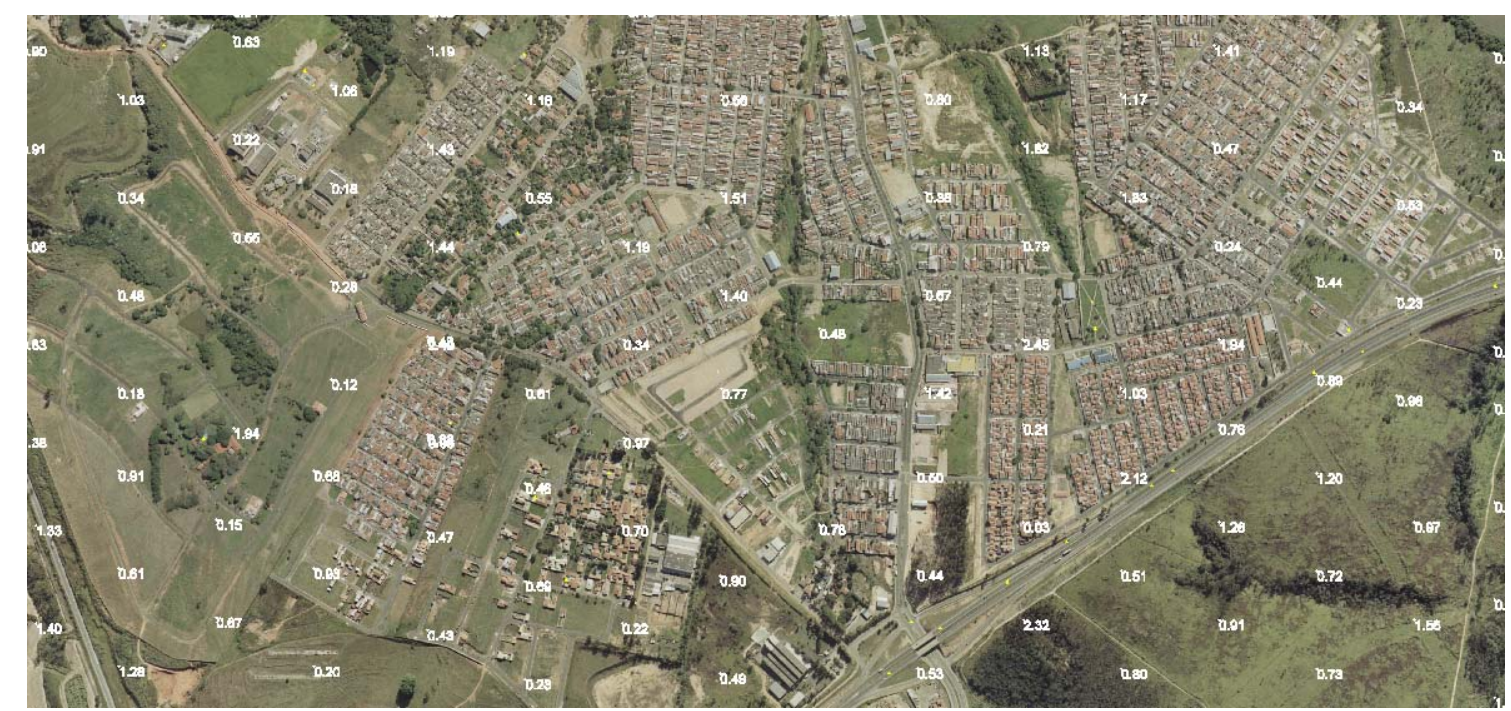

Figura 7.11 - Detalhe da amostra com erros inferiores a 2.5 metros em zona urbana

\subsection{Teste da Norma Brasileira.}

Na norma Brasileira tem-se que $90 \%$ dos pontos bem definidos devem ter erro inferior ao PEC. Esta análise é feita, tanto para planimetria como para altimetria.

\subsubsection{Teste na planimetria.}

O quadro 7.14 apresenta o erro máximo de $90 \%$ das leituras dos operadores $\mathrm{AD}, \mathrm{A}$ e F.

Quadro 7.14 - Erro máximo de 90\% das leituras em planimetria.

\begin{tabular}{|l|r|r|}
\hline \multicolumn{3}{|c|}{ 90\% dos pontos com erro inferior a } \\
\hline Operador & Erro X $(\mathrm{m})$ & Erro $\mathrm{Y}(\mathrm{m})$ \\
\hline $\mathrm{AD}$ & 0.64 & 0.93 \\
\hline $\mathrm{A}$ & 1.19 & 1.10 \\
\hline $\mathrm{F}$ & 0.84 & 1.20 \\
\hline
\end{tabular}


Quadro 7.15 - Avaliação da precisão da ortofoto, levando-se em conta PEC Classe A.

\begin{tabular}{|c|c|c|c|r|c|}
\hline \multicolumn{2}{|l|}{ Operador AD } & \multicolumn{4}{|c|}{$90 \%$ dos pontos com erro inferior a } \\
\hline Escala 1: & PEC $(\mathrm{m})$ & $\mathrm{X}$ & $\mathrm{A} / \mathrm{R}$ & $\mathrm{Y}$ & $\mathrm{A} / \mathrm{R}$ \\
\hline 25,000 & 12.50 & 0.64 & $\mathrm{~A}$ & 0.93 & $\mathrm{~A}$ \\
\hline 10,000 & 5.00 & 0.64 & $\mathrm{~A}$ & 0.93 & $\mathrm{~A}$ \\
\hline 5,000 & 2.50 & 0.64 & $\mathrm{~A}$ & 0.93 & $\mathrm{~A}$ \\
\hline 3,000 & 1.50 & 0.64 & $\mathrm{~A}$ & 0.93 & $\mathrm{~A}$ \\
\hline 2,500 & 1.25 & 0.64 & $\mathrm{~A}$ & 0.93 & $\mathrm{~A}$ \\
\hline 2,000 & 1.00 & 0.64 & $\mathrm{~A}$ & 0.93 & $\mathrm{~A}$ \\
\hline
\end{tabular}

\begin{tabular}{|c|c|c|c|r|c|}
\hline \multicolumn{2}{|l|}{ Operador A } & \multicolumn{5}{|c|}{$90 \%$ dos pontos com erro inferior a } \\
\hline Escala 1: & PEC(m) & X & A / R & Y & A / R \\
\hline 25,000 & 12.50 & 1.19 & $\mathrm{~A}$ & 1.10 & $\mathrm{~A}$ \\
\hline 10,000 & 5.00 & 1.19 & $\mathrm{~A}$ & 1.10 & $\mathrm{~A}$ \\
\hline 5,000 & 2.50 & 1.19 & $\mathrm{~A}$ & 1.10 & $\mathrm{~A}$ \\
\hline 3,000 & 1.50 & 1.19 & $\mathrm{~A}$ & 1.10 & $\mathrm{~A}$ \\
\hline 2,500 & 1.25 & 1.19 & $\mathrm{~A}$ & 1.10 & $\mathrm{~A}$ \\
\hline 2,000 & 1.00 & 1.19 & $\mathrm{R}$ & 1.10 & $\mathrm{R}$ \\
\hline
\end{tabular}

\begin{tabular}{|c|c|c|c|r|c|}
\hline \multicolumn{2}{|l|}{ Operador F } & \multicolumn{5}{|c|}{$90 \%$ dos pontos com erro inferior a } \\
\hline Escala 1: & PEC $(\mathrm{m})$ & $\mathrm{X}$ & $\mathrm{A} / \mathrm{R}$ & $\mathrm{Y}$ & $\mathrm{A} / \mathrm{R}$ \\
\hline 25,000 & 12.50 & 0.84 & $\mathrm{~A}$ & 1.20 & $\mathrm{~A}$ \\
\hline 10,000 & 5.00 & 0.84 & $\mathrm{~A}$ & 1.20 & $\mathrm{~A}$ \\
\hline 5,000 & 2.50 & 0.84 & $\mathrm{~A}$ & 1.20 & $\mathrm{~A}$ \\
\hline 3,000 & 1.50 & 0.84 & $\mathrm{~A}$ & 1.20 & $\mathrm{~A}$ \\
\hline 2,500 & 1.25 & 0.84 & $\mathrm{~A}$ & 1.20 & $\mathrm{~A}$ \\
\hline 2,000 & 1.00 & 0.84 & $\mathrm{~A}$ & 1.20 & $\mathrm{R}$ \\
\hline
\end{tabular}

Analisando o quadro 7.15, pode-se concluir que, levando-se em conta as leituras de todos os operadores, a ortofoto gerada apresenta PEC Classe A para a escala 1:2.500. Nota-se também que para um deles (operador AD) atinge-se PEC Classe A na escala de 1:2000. Vê-se que os resultados obtidos são compatíveis com aqueles obtidos anteriormente no item 7.4.1.

\subsubsection{Teste na altimetria.}

\subsubsection{Teste na altimetria para a amostra dirigida.}


Analogamente se faz o teste na altimetria na amostra dirigida, verificando qual o erro máximo do MDE para 90\% dos pontos. Verifica-se nas leituras extraídas do MDE que esse valor é de 1.11 metros. No quadro 7.16 é feita a análise de classificação da eqüidistância das curvas de nível em acordo com PEC Classe A.

Quadro 7.16 - Classificação da altimetria da amostra dirigida em acordo com PEC Classe A.

\begin{tabular}{|c|c|r|c|}
\hline \multicolumn{4}{|c|}{$90 \%$ dos pontos com erro inferior a } \\
\hline $\begin{array}{c}\text { Eqüidistância } \\
(\mathrm{m})\end{array}$ & $\mathrm{PEC}(\mathrm{m})$ & $\Delta \mathrm{H}(\mathrm{m})$ & $\mathrm{A} / \mathrm{R}$ \\
\hline 20 & 10.00 & 1.11 & $\mathrm{~A}$ \\
\hline 10 & 5.00 & 1.11 & $\mathrm{~A}$ \\
\hline 5 & 2.50 & 1.11 & $\mathrm{~A}$ \\
\hline 3 & 1.50 & 1.11 & $\mathrm{~A}$ \\
\hline 2 & 1.00 & 1.11 & $\mathrm{R}$ \\
\hline
\end{tabular}

Verifica-se que o MDE apresenta PEC Classe A para uma representação de curvas de nível de 3 metros de eqüidistância para os pontos bem definidos utilizados na amostra dirigida para a validação da planimetria.

\subsubsection{Avaliação da altimetria em uma amostra em malha regular equiespaciada de 150 metros.}

O teste da altimetria em uma amostra em malha regular equiespaciada de 150 metros é feito de maneira análoga àquela do item 7.5.2.1. Nessa amostra de 1248 pontos o erro máximo do MDE para 90\% dos pontos é de 3.84 para a totalidade da amostra. O quadro 7.17 mostra a análise de classificação da eqüidistância das curvas de nível em acordo com PEC Classe A. 
Quadro 7.17 - Classificação da altimetria em uma amostra em malha regular equiespaciada de 150 metros.

\begin{tabular}{|c|c|r|c|}
\hline \multicolumn{4}{|c|}{$90 \%$ dos pontos com erro inferior a } \\
\hline $\begin{array}{c}\text { Eqüidistância } \\
(\mathrm{m})\end{array}$ & $\mathrm{PEC}(\mathrm{m})$ & $\Delta \mathrm{H}(\mathrm{m})$ & $\mathrm{A} / \mathrm{R}$ \\
\hline 20 & 10.00 & 3.84 & $\mathrm{~A}$ \\
\hline 10 & 5.00 & 3.84 & $\mathrm{~A}$ \\
\hline 5 & 2.50 & 3.84 & $\mathrm{R}$ \\
\hline 3 & 1.50 & 3.84 & $\mathrm{R}$ \\
\hline 2 & 1.00 & 3.84 & $\mathrm{R}$ \\
\hline
\end{tabular}

Verifica-se que o MDE apresenta PEC Classe A para uma representação de curvas de nível de 10 metros de eqüidistância. Deve-se levar em conta o discutido em 7.4.2.3, pois as considerações feitas ali são as cabíveis aqui.

\subsection{Considerações finais da validação}

\subsubsection{Precisão planimétrica.}

Verifica-se que as ortofotos obtidas com o emprego da metodologia proposta, apresentaram, para uma cobertura aerofotogramétrica em escala 1:25.000, PEC classe A para uma escala de 1:2.500 ou menores. Essa precisão e exatidão alcançadas superaram as expectativas, pois o usual para esta escala de vôo é a produção de restituição em escala 1:5.000. Como os produtos aqui gerados estão pensados e recomendados para a escala 1:5.000, pode-se dizer que atendem, com larga margem, os requisitos de precisão e exatidão planimétrica.

\subsubsection{Precisão altimétrica}

Pode-se dizer que o MDE gerado apresenta distintas exatidões, variando em função do tipo de feição em que foi construído. O usuário, sabedor dessas características dos produtos, poderá servir-se deles contando com uma exatidão altimétrica melhor que 1.5 metros para pontos no "chão". Já em locais de mata, arbustivo ou sombras esta acurácia não é atingida, como também não acontece com os produtos tradicionais nesses locais. 
Pode-se dizer que foi gerado um produto compatível com um espaçamento de curvas de nível de 5 em 5 metros pois a precisão de 1.5 metros é melhor que um terço desse espaçamento. Por sua vez, este espaçamento é o costumeiro em utilizações na área de Engenharia para a escala 1:5.000. 


\section{Capítulo 8}

\section{Considerações finais.}

A metodologia proposta foi implementada e testada para um caso prático em área teste. Os produtos ali obtidos foram modelos digitais de elevação e ortofotos, gerados a partir de cobertura aerofotogramétrica em escala 1:25.000 com recobrimento longitudinal de $60 \%$ e lateral de $30 \%$.

Esses produtos após terem sido testados pelos processos convencionais de controle de qualidade, e até com maior rigor, apresentaram PEC classe A para a escala 1:2.500 em planimetria e intervalo de curva de nível de 5 metros de eqüidistância.

Embora apresente PEC Classe A em planimetria para a escala de 1:2.500, o material não permite a foto-interpretação para diversas feições usuais desta escala. Isso se deve ao fato de ter sido produzido de uma cobertura em 1:25.000, que permite boa interpretação para a escala 1:5.000, que é recomendada para esses produtos.

Esse material (MDE e ortofoto) é bastante útil como base cartográfica em aplicações usuais à escala 1:5.000 ou menores, tais como gestão, planejamento, e projetos básicos e funcionais de engenharia, bem como manejo agro-silvo-pastoril, estudos de bacias e simulações hidrodinâmicas, estudos ambientais e todos os demais que partem de bases cartográficas nessa escala.

Esses dois produtos permitem a elaboração de uma série de derivados, podendo-se aqui exemplificar alguns:

- Planta de curvas de nível;

- Ortofotos com curvas de nível;

- Anaglifos e orto-anaglifos; 
- Extração de feições diretamente da ortofoto, com altitudes obtidas do MDE.

- Mapa de declividades e de exposição de vertentes;

- Mapa hipsométrico colorido;

- Estudos de decorrelação temporal, comuns em atualizações e monitoramento, por diferenças de MDE.

Como recomendações para trabalhos futuros, são aqui apresentadas algumas:

- Aplicação de filtros para obter MDT a partir do MDE gerado;

- Desenvolvimento da potencialidade do uso das janelas epipolares para o processamento de imagens em escalas maiores, bem como de múltiplas imagens, incluindo maior sobreposição.

- Utilização de outras técnicas de correspondência em nível sub-pixel para melhorar a precisão.

- Utilização de algoritmos de localização de sombras para otimização do MDE.

- Algoritmos de otimização para diminuir o tempo de processamento, por exemplo: iniciar a correspondência em janelas menores que 15x15; estudar outras pirâmides de imagens,...

- Estudo da possível melhoria da precisão por meio de maior resolução do escaneamento.

- Estudar mais a fundo os problemas de curvatura.

- Utilização de imagens compactadas, estudando o impacto no tempo do processamento e na precisão. 
- Estudo da melhoria de técnicas de correlação em segunda passada utilizando como referência o MDE intermediário.

Concluindo, pode-se dizer que os objetivos foram atingidos já que a metodologia foi capaz de conduzir aos produtos pretendidos, que foram aprovados nos testes de validação, atingindo a mesma ou melhor precisão que os produtos convencionais, sendo portanto uma alternativa tecnicamente viável.

Do ponto de vista econômico, uma primeira avaliação mostrou que esses produtos podem ser produzidos a um custo que é de $40 \%$ do produto convencional. Resta no entanto implementá-lo em escala de produção dentro do esquema empresarial e analisar o impacto que causará na cadeia de produção. 


\section{Referências Bibliográficas}

A Ciência das Cores $-<$ http://www.efg2.com/Lab/Library/Color/Science.htm>. Acesso em 16/06/2007.

ADELSON, E. H. Lightness Perception and Lightness Illusions. Department of Brain and Cognitive Sciences - Massachusetts Institute of Technology Press. 2nd ed. Cambridge, MA. 2000.

ALBERTZ, J; KREILING, W. Photogrammetric Guide. Karlsruhe. Wichmann, Alemanha: 1989.

ANDRADE, J. B;. Fotogrametria. Ed. SBEE. Curitiba, Brasil: 1998.

BOULOS, P.; OLIVEIRA, I. C. Geometria Analítica: um tratamento vetorial. Mc GraW-Hill. São Paulo. 1987.385p.

BRASIL. Decreto n 89.817 de 30 de março de 1983. Normas para o controle de qualidade de documentos cartográficos. Brasília, Diário Oficial da União, 1984. Disponível em: <http://www.concar.ibge.gov.br/FCCA32.HTM>. Acesso em: 20 dez. 2003.

BRITO, J. N.; COELHO, L. Fotogrametria Digital. Instituto Militar de Engenharia. 1a Ed. Rio de Janeiro, Brasil: 2002.

CINTRA, J. P. Modelo Digital de Terreno. Tese (Doutorado). Escola Politécnica da USP. São Paulo, 1985.

COSTA, F. A. L. Geração de Coordenadas Tridimensionais do Terreno a Partir de Imagens Fotogramétricas Digitais - Projeto do PIBIC/1999. Instituto Militar de Engenharia. Rio de Janeiro, Brasil: 2000.

DAL POZ, A. P. Metodologias semi-automáticas para extração de rodovias em imagens digitais usando programação dinâmica, análise de bordas de rodovia e teste ativo. Tese (Livre-Docência). UNESP. Presidente Prudente, SP. 2003. 159p.

Digital Photogrammetry - An Addendum to the Manual of Photogrammetry. The American Society for Photogrammetry and Remote Sensing. Bethesda, MA, Estados Unidos: 1997.

ECW (Wavelet compression for digital imagery and image web server from earth resourse mapping). <http://www.gisdevelopment.net/technology/ic/techip003.htm>. Acesso em 13/9/07.

ELETRICAL ENGINEERING DEPARTMENT OF COOPER UNION. The Tiff Image File Format. <http://www.ee.cooper.edu/courses/course_pages/past_courses/EE458/TIFF/. Acessado em 03/08/2004.

FERNANDES, S. L. Desenvolvimento de um programa protótipo para restituição fotogramétrica. Tese (Doutorado). EPUSP. São Paulo. 2001. 197p.

FERREIRA, C. F. Desenvolvimento de um sistema de mono-restituição auxiliada por computador. EPUSP. São Paulo. 1997. 134p.

FOLEY, J. D., VAN DAM, A. Fundamentals of Interactive Computer Graphics. AddisonWesley. Boston, MA. 1982.

GEMAEL, C. Introdução ao Ajustamento de Observações. Ed. UFPR. Curitiba, Brasil: 1994. 
GHOSH, S. K. Analytical Photogrammetry. Pergamon Press. 2a Ed. New York. 1988. 308p.

ISO - 19.113: Geographic Information - Quality principles. Versão 2.0. Oslo, Norway, 03 mai. 2002. 37pp.

ISO - 19.114: Geographic Information - Quality evaluation procedures. Versão 2.1. Oslo, Norway, 29 jan. 2003. 72pp.

ISO - 2859-1: Sampling procedures for inspection by attributes Part 1 : Sampling plan indexed by acceptable quality level (AQL) for lot-by-lot inspection. Ed. 2.0. 01 nov. 1999. 87pp.

JONES, N. Photogrammetry - Lecture Notes. The University of Melbourne. Melbourne, Austrália: 1998.5.17

KASSER, M.; EGELS, Y. Digital Photogrammetry. Taylor \& Francis. Londres. 2002. 351p.

KLINKENBERG, B. Digital Elevation Models, in NCGIA Core Curriculum in GIS. National Center for Geographic Information and Analysis, University of California. Santa Barbara. 1990. $<$ http://www.geog.ubc.ca/courses/klink/gis.notes/ncgia/u38.html\#UNIT38>. Acesso em 8 mar 2007.

KRAUS, K. Photogrammetry, Fundamentals and Standard Processes. Ed.: Ferd. Dümmler Verlag Bonn, 1993.

KRAUS, K. Photogrammetry - Fundamentals and Processes. Vol 1, 4a Ed. Ferg, Dummler Verlag. Bonn. 1999.

LANDIM, P.M.B. Introdução aos métodos de estimação espacial para confecção de mapas.DGA,IGCE,UNESP/Rio Claro, Lab. Geomatemática,Texto Didático 02, 20 pp. 2000. Disponível em

LEVINE, D. M.; BERENSON, M. L., STEPHAN, D. Estatística: Teoria e Aplicações. LTC Livros Técnicos e Científicos Editora S.A. Rio de Janeiro. 1998. 811p.

LizardTech's MrSID Tecnology Primer. <http://www.lizardtech.com.files/ geo/techinfo/ MrSID_Tech_Primer.pdf $>$. Acesso em 13/09/07.

Manual of Remote Sensing. The American Society for Photogrammetry and Remote Sensing. 2d ed. Bethesda, MA, Estados Unidos: 1993.

MERCHANT, D. C. Spatial Accuracy Standards for Large Scalle Line Maps. In: Techinical Congress on Surveing and Mapping. Proceedings. v. 1, p. 222-231, 1982.

MIKHAIL, E. M.; BETHEL, J. S.; MCGLONE, J. C. Introduction to modern photogrammetry. John Willey \& Sons. Inc. Danvers, MA, EUA: 2001.479p.

MILONE, G. Estatística Geral e Aplicada. Pioneira Thomsom Learning. São Paulo: 2004. 483p.

MIL-STD-105E - SAMPLING PROCEDURES AND TABLES FOR INSPECTION BY AITRIBUTES. 10/05/1989.

MITISHITA, E. A. Certificado de Calibração de Câmara Aerofotogramétrica. Curitiba. 2002.

NBR 5425. Guia para inspeção por amostragem no controle e certificação de qualidade. Ed. ABNT (Brasil), jan. 1985.

NBR 5426. Planos de amostragem e procedimentos na inspeção por atributos. Ed. ABNT 
(Brasil), jan. 1985.

NBR 5427. Guia para utilização da norma NBR 5426 - Planos de amostragem e procedimentos na inspeção por atributos. Ed. ABNT (Brasil), jan. 1985.

NBR 5428. Procedimentos estatísticos para determinação da validade de inspeção por atributos feita pelos fornecedores. Ed. ABNT (Brasil), jan. 1985.

NBR 5429. Planos de amostragem e procedimentos na inspeção por variáveis. Ed. ABNT (Brasil), jan. 1985.

NBR 5430. Guia de utilização da NBR 5429 - Planos de amostragem e procedimentos na inspeção por variáveis. Ed. ABNT (Brasil), jan. 1985.

NERO, M. A. Estudo comparativo de metodologias de digitalização de mapas e seu controle de qualidade geométrica. Dissertação (Mestrado). Escola Politécnica da USP. São Paulo, 2000. 233p.

NERO, M. A. Metodologias avançadas para o controle de qualidade posicional de bases cartográficas. Relatório de Pós-doutorado. Escola Politécnica da USP. São Paulo, 2006. 199p.

NERO, M. A. Propostas para o controle de qualidade de bases cartográficas com ênfase na componente posicional. Tese (Doutorado). Escola Politécnica da USP. São Paulo, 2005. 186p.

OLEARI, C. Colour Spaces, Chromaticity Diagrams and Non-Uniformity of Scale, Department of Physics (INFM), University of Parma, Parma, Italy<http://www.fis.unipr.it/ fermi/PagInternet_English/GCA_Color_Theory.html> último acesso $9 / 9 / 07$

POLIDORIO, A. M., FLORES, F. C., FRANCO, C., IMAI, N. N., TOMMASELLI, A. M. G. Detecção automática de sombras e nuvens em imagens CBERS e Landsat 7 ETM - in Anais XII Simpósio Brasileiro de Sensoriamento Remoto, Goiânia, 16-21 abril 2005, INPE, p.4233-4240.

QUEIROZ FILHO, A. P. Ortofoto digital para atualização cartográfica em um sistema de informações geográficas. Dissertação (Mestrado). EPUSP. São Paulo. 1993.138p.

RAMOS, J. P. L. O uso de índices financeiros: uma analise empírica. Dissertação (Mestrado). Universidade Federal de Santa Catarina. Florianópolis, 1999. 122p. Disponível em: $<$ http://teses.eps.ufsc.br/defesa/pdf/3689.pdf>. Acesso em: 27 abr. 2005.

ROCHA, R. S. Exatidão Cartográfica para as cartas digitais urbanas. Tese (Doutorado). Universidade Federal de Santa Catarina. Florianópolis-SC- Brasil, 2002. 127p.

ROSALEN, D. L. Estudo do processo de captação de imagens aplicado à Fotogrametria Digital. Dissertação (Mestrado). Escola de Engenharia de São Carlos - USP. São Carlos, SP. 1997.

RUIZ, A. Modelos de Terreno, in Curso Teórico- Práctico sobre Técnicas Cartográficas Avanzadas II - Fotogrametría Espacial. ICC- Istitut Cartogràfic de Catalunya. Barcelona. 2003.

RUIZ, A. Nuevas Técnicas de Obtención de DTM, in Curso Teórico- Práctico sobre Técnicas Cartográficas Avanzadas I - Fotogrametría Digital. ICC- Istitut Cartogràfic de Catalunya. Barcelona. 2002.

S.J. Sangwine and R.E.N. Horne, Eds., The Colour Image Processing Handbook, Chapman \& Hall, London, 1998. 
SANGWINE, S.J.; HORNE, R.E.N. The Colour Image Processing Handbook, Chapman \& Hall, London, 1998.

SANTOS, D. R., DALMOLIN, Q., BASSO, M. A. Detecção automática de sombras - in Boletim de Ciências Geodésicas - UFPR, sec. Artigos, Curitiba, v. 12, n. 1, p 87-99, jan-jun 2006.

SATO, S. S. Sistema de Controle de Qualidade dos Processos Fotogramétricos Digitais para Produção de Dados Espaciais. Tese (Doutorado). Escola de Engenharia de São Carlos - USP. São Carlos, 2003. 229p.

SCHENK, T. Digital Photogrammetry - Volume I. TerraScience. 1a Ed. Estados Unidos: 1999.

TOMMASELLI, A. M. G. Correspondência de Imagens, in Fotogrametria Digital. UNESP Presidente Prudente, SP. 2006. <http://www2.prudente.unesp.br/area_doc/foto1 /fotogram_digital/ material_2006/ fotodig_corr_aula_3_4/ foto_dig_corr_lsm_preanalise _3.pdf>. Acesso em 21 mai 2007.

WANDERLEY, J.F.C. Introdução ao processamento de imagens digitais - Formação dimagens e cores. <www.ene.unb.br/juliana/cursos/semana2>. Acesso em 3/08/04.

WOLF, P. R.; DEWITT, B.A. Elements of Photogrammetry with applications in GIS. McGrawHill. 3a Ed. EUA: 2000. 608p.

WOLF, P. R.; GHILANI, C. D. Adjustments computations: statitistics and least squares in surveying and GIS. John Wiley \& Sons Inc. New York. 1996. 564p.

WONG, P. The Fundamentals of Digital Photogrammetry. ISM. Vancouver: 1998. 78p. 
Anexos 


\section{Anexo 1 - Progressão de cores RGB e HSV.}

Partindo-se da cor RGB $(225,108,37)$ são realizadas a seguir duas progressões de cores para se chegar à cor $\operatorname{RGB}(40,94,21)$. No primeiro quadro por interpolação linear dentro do domínio RGB, e no segundo no domínio HSV. Nos quadros, são apresentados os valores numéricos das cores intermediárias em ambos os domínios para que se possa fazer a comparação.

1. Média por interpolação linear dos valores R G B

\begin{tabular}{|l|c|c|c|c|c|c|c|c|c|c|c|}
\hline & Cor 1 & \multicolumn{8}{|c|}{ Progressão por interpolação linear em RGB } & Cor 2 \\
\hline$R$ & 225 & 207 & 188 & 170 & 151 & 133 & 114 & 96 & 77 & 59 & 40 \\
\hline$G$ & 108 & 107 & 105 & 104 & 102 & 101 & 100 & 98 & 97 & 95 & 94 \\
\hline$B$ & 37 & 35 & 34 & 32 & 31 & 29 & 27 & 26 & 24 & 23 & 21 \\
\hline$H$ & 23 & 25 & 28 & 31 & 35 & 42 & 50 & 62 & 76 & 90 & 104 \\
\hline$S$ & 84 & 83 & 82 & 81 & 79 & 78 & 76 & 73 & 75 & 76 & 78 \\
\hline$V$ & 88 & 81 & 74 & 67 & 59 & 52 & 45 & 38 & 38 & 37 & 37 \\
\hline
\end{tabular}

2. Média por interpolação linear vetorial no domínio HSV

\begin{tabular}{|c|c|c|c|c|c|c|c|c|c|c|c|}
\hline & Cor 1 & \multicolumn{9}{|c|}{ Progressão por interpolação linear vetorial em HSV } & Cor 2 \\
\hline$R$ & 225 & 211 & 198 & 185 & 172 & 156 & 129 & 103 & 80 & 58 & 40 \\
\hline$G$ & 108 & 126 & 140 & 151 & 158 & 159 & 146 & 133 & 121 & 107 & 94 \\
\hline$B$ & 37 & 49 & 58 & 63 & 54 & 62 & 56 & 49 & 40 & 30 & 21 \\
\hline$H$ & 23 & 28 & 35 & 43 & 52 & 61 & 71 & 81 & 90 & 97 & 104 \\
\hline$S$ & 84 & 77 & 71 & 66 & 63 & 61 & 61 & 63 & 67 & 72 & 78 \\
\hline$V$ & 88 & 83 & 78 & 73 & 68 & 63 & 57 & 52 & 47 & 42 & 37 \\
\hline
\end{tabular}




\section{Anexo 2 - Exemplos de reamostragem de imagem digita}

Dada uma imagem digital, deseja-se conhecer o valor da intensidade do pixel fracional P(2962.25,3329.43), onde os valores das intensidades da janela indicada são dados ao lado.

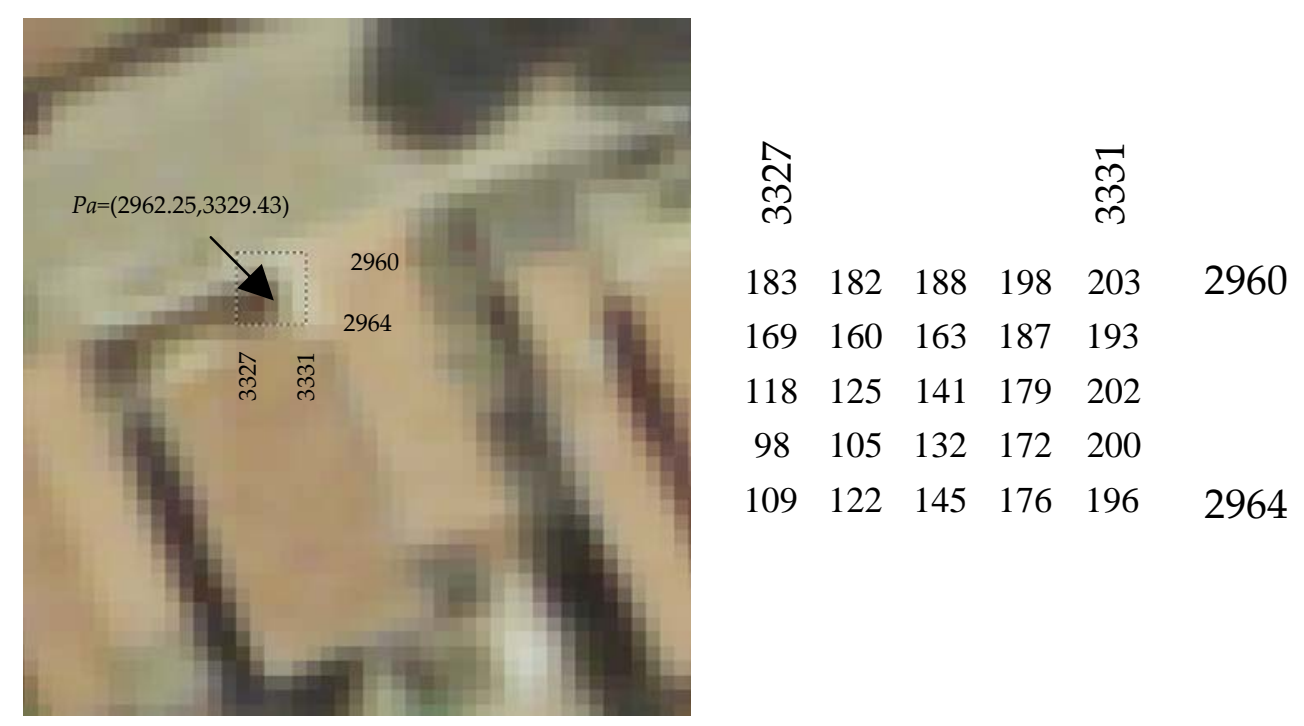

\section{a) Vizinho mais próximo.}

Pelo método do vizinho mais próximo, o valor para o pixel $\mathrm{P}(2962.25,3329.43)$ é o mesmo do valor do pixel $\mathrm{P}(2962,3329)$, ou seja 141.

\section{b) Bi-linear}

Pelo método de interpolação bi-linear, em primeiro lugar deve-se levar em conta o problema de referencial, por exemplo, o centro do pixel 2960 é 2960.5, logo o afastamento $x$ será: $x=a b s[c a-(c n+0.5)]$ para as colunas e $x=a b s[l a-(l m+0.5)]$. Tomam-se então os valores dos 4 vizinhos, onde:

$$
a_{11}=160 ; a_{12}=163 ; a_{21}=125 ; a_{22}=141
$$


A função $f(x)$ do peso para cada um dos elementos em linha será:

$x_{1}=a b s(2962.25-2961.5)=0.75 \quad f\left(x_{1}\right)=1-x_{1}=0.25$

$x_{2}=a b s(2962.25-2962.5)=0.25 \quad f\left(x_{2}\right)=1-x_{2}=0.75$ ou diretamente $f\left(x_{2}\right)=1-f\left(x_{1}\right)$

$\left.y_{1}=a b s(3329.43-3328.5)\right)=0.93 \quad f\left(y_{1}\right)=1-y_{1}=0.07$

$\left.y_{2}=a b s(3329.43-3329.5)\right)=0.93 \quad f\left(y_{2}\right)=1-y_{2}=0.93$ ou diretamente $f\left(y_{2}\right)=1-f\left(y_{1}\right)$

Assim sendo, pode-se escrever:

$I=\left[\begin{array}{ll}0.25 & 0.75\end{array}\right] \cdot\left[\begin{array}{ll}160 & 163 \\ 125 & 141\end{array}\right] \cdot\left[\begin{array}{l}0.07 \\ 0.93\end{array}\right]=145.61$

\section{c) Bi-cúbica}

As funções de peso da interpolação bi-cúbica são

$$
\begin{array}{llr}
f_{1}(x)=(a+2) x^{3}-(a+3) x^{2}+1 & \text { Para } & 0 \leq x \leq 1 \\
f_{2}(x)=a x^{3}-5 a x^{2}+8 a x-4 a & \text { Para } & 1 \leq x \leq 2 \\
f_{3}(x)=0 & \text { Para } & x \geq 2
\end{array}
$$

Lembrando-se do problema do referencial, pode-se então estabelecer as funções de peso para linhas e colunas:

Cálculo dos pesos das linhas colunas para a posição $l_{a}=2962.25$, e $c_{a}=3329.43$.

\begin{tabular}{|c|c|c|c|}
\hline$l$ & Afastamento $(y)$ & Função de Peso & Peso $P_{l n}$ \\
\hline 2960 & 1.75 & $f_{2}(x)$ & -0.2344 \\
\hline 2961 & 0.75 & $f_{1}(x)$ & 0.2266 \\
\hline 2962 & 0.25 & $f_{1}(x)$ & 0.8672 \\
\hline 2963 & 1.25 & $f_{2}(x)$ & -0.0703 \\
\hline 2964 & 2.25 & $f_{3}(x)$ & 0 \\
\hline$c$ & Afastamento $(x)$ & Função de Peso & Peso $P_{c n}$ \\
\hline 3327 & 1.93 & $f_{2}(x)$ & -0.0022785 \\
\hline 3328 & 0.93 & $f_{1}(x)$ & 0.0442855 \\
\hline 3329 & 0.07 & $f_{1}(x)$ & 0.9882645 \\
\hline 3330 & 1.07 & $f_{2}(x)$ & -0.0302715 \\
\hline 3331 & 2.07 & $f_{3}(x)$ & 0 \\
\hline
\end{tabular}


Sabendo-se que :

$$
I=\left[\begin{array}{lllll}
P_{l 1} & P_{12} & P_{l 3} & P_{l 4} & P_{l 5}
\end{array}\right] \cdot\left[\begin{array}{lllll}
v_{11} & v_{12} & v_{13} & v_{14} & v_{15} \\
v_{21} & v_{22} & v_{23} & v_{24} & v_{25} \\
v_{31} & v_{32} & v_{33} & v_{34} & v_{35} \\
v_{41} & v_{42} & v_{43} & v_{44} & v_{45} \\
v_{51} & v_{52} & v_{53} & v_{54} & v_{55}
\end{array}\right] \cdot\left[\begin{array}{l}
P_{c 1} \\
P_{c 2} \\
P_{c 3} \\
P_{c 4} \\
P_{c 5}
\end{array}\right]
$$

Calcula-se o valor da intensidade para esta posição fracional resultando em $I=143.93$.

\section{Resumindo:}

\begin{tabular}{|c|c|}
\hline Método & Valor do pixel \\
\hline Vizinho mais próximo & 141 \\
\hline Bi-linear & 145.61 \\
\hline Bi-cúbico & 143.93 \\
\hline
\end{tabular}




\section{Anexo 3 - O Formato TIFF.}

A apresentação a seguir foi extraída e adaptada de Fernandes (2001) e ELETRICAL ENGINEERING DEPARTAMENT OF COOPER UNION - EEDCU , (1999).

TIFF é a abreviação do termo inglês tagged image file format que pode ser traduzido para o português como formato de arquivo imagem categorizado. $\mathrm{O}$ termo etiqueta ( $\operatorname{tag})$, embora estranho, significa que todas as informações da imagem armazenadas neste formato, são categorizadas e precedidas de uma etiqueta tag, a qual é um código é constituído por um número de 0 a 65535 indicando o tipo de informação da imagem armazenado na seqüência (EEDCU , 1999).

O formato TIFF foi criado pela Aldus Corporation em 1986, após um encontro com vários fabricantes de escâneres e desenvolvedores de softwares. Esta primeira versão foi considerada como uma revisão de outras duas versões anteriores, razão pela qual esta foi denominada Revisão 3.0 do TIFF. Posteriormente houve mais três revisões do formato, respectivamente em 1987 (Revisão 4.0), em 1988 (Revisão 5.0) e em 1992 (Revisão 6.0)

Segundo o EEDCU (1999), o TIFF foi criado para ser o formato padrão de troca de dados de imagens entre computadores, scanners e softwares diferentes.

As especificações descritas a seguir referem-se à Versão 6.0 do formato.

\section{A estrutura do formato TIFF.}

Um arquivo TIFF começa com um cabeçalho de 8 bytes. Nestes 8 bytes contém três informações distintas. A primeira delas é composta por 2 bytes e contém a informação do tipo de processador em que o arquivo foi gerado. Nestes dois bytes iniciais são gravados dois números inteiros que representam caracteres no código ASCII (American Standard Code for Interchange Information ). Existem dois valores possíveis para estes dois bytes. Ou eles assumem os valores "II" ou "MM". Este 
campo de cabeçalho especifica a ordem com que os valores que ocupam mais de um byte no arquivo são armazenados. Assim se o valor do campo for igual à "II", isto significa que o processador utilizado na geração do arquivo é da Intel. Um processador da Intel grava um número que ocupa mais de um byte no arquivo na seguinte ordem: os bytes mais significativos do número são gravados nos endereços finais do registro e os bytes menos significativos nos endereços iniciais do registro (EEDCU, 1999).

Assim, por exemplo, um valor inteiro equivalente a 656 ocupa dois bytes no arquivo. O primeiro byte registrado ou gravado terá valor igual a 144 (byte menos significativo). O segundo byte registrado terá o valor 2 (byte mais significativo). Para obter o valor do número aplica-se o algoritmo:

$$
\begin{aligned}
& \text { Valor_byte_Menos_significativo x } 256^{\circ}=144 \\
& \text { Valor_Byte_Mais_Significativo x } 256^{1}=512 \\
& 144+512=656
\end{aligned}
$$

Se o valor do campo for igual a "MM", isso significa que o arquivo foi gerado por um processador Motorola. Este tipo de processador grava os bytes mais significativos de um número nos menores endereços do arquivo e os bytes menos significativos de um número nos endereços finais de registro. Então, para o exemplo dado anteriormente, o primeiro byte a ser gravado no disco seria o valor 2 . $\mathrm{Na}$ seqüência seria gravado o byte de valor 144 .

Este informação é fundamental para que um programa que leia dados TIFF consiga recuperar corretamente os valores neles contidos independentemente do tipo de processador que o gerou (EEDCU, 1999).

Os dois bytes seguintes do cabeçalho registram o número inteiro " 42 " que serve para indicar que o arquivo é do tipo TIFF. 
Os 4 bytes restantes do cabeçalho correspondem a um valor inteiro que indica o deslocamento em bytes, a partir do início do arquivo, em que se localiza o primeiro diretório do arquivo imagem (EEDCU, 1999).

O diretório do arquivo imagem é uma estrutura de dados que se inicia com um contador que ocupa 2 bytes no disco e que indica o número de entradas de diretório que estão presentes no mesmo.

Cada entrada do diretório por sua vez é uma estrutura de dados que se inicia com um contador, quer ocupa 2 bytes no disco, que indica o número de entradas de diretório que estão presentes no mesmo.

Cada entrada no diretório por sua vez é uma estrutura de dados de 12 bytes que contém uma ou mais informações da imagem que está armazenada no arquivo.

Os 12 bytes de cada entrada de diretório apresentam os seguintes campos:

- Tag ou Etiqueta - correspondem aos 2 bytes iniciais da entrada de diretório. Nestes 2 bytes aparece um número inteiro de 0 a 65355. Este número indica que tipo de informação da imagem está contida na entrada de diretório. Por exemplo o número 256 indica que naquela entrada de diretório está contida a informação da largura da imagem em pixels.

- Os 2 bytes seguintes correspondem ao tipo de dado do parâmetro da imagem que é informado pela tag. Os valores que podem assumir o campo tipo de dado de uma entrada de diretório são mostrados na Tabela 1.

- Os 4 bytes seguintes contêm um número chamado de contador. Ele representa o número de valores do tipo indicado nos 2 bytes anteriores necessários para armazenar o valor total da tag correspondente. Por exemplo, na tag número 256 (largura da imagem), um único valor inteiro é necessário para informar a largura da imagem. Portanto, o valor do contador será igual a 1. 


\begin{tabular}{|l|l|c|c|}
\hline Tipos de dados & Descrição e Escopo & Código do tipo & $\mathbf{N}^{0}$ de bytes \\
\hline Byte & Inteiro absoluto (0..255) & 1 & 1 \\
\hline ASCII & Caractere no código ASCII & 2 & 1 \\
\hline Short & Inteiro curto absoluto (0...65535) & 3 & 2 \\
\hline Long & Inteiro Longo absoluto $\left(0 . .4,29 \times 10^{9}\right)$ & 4 & 4 \\
\hline Rational & $\begin{array}{l}\text { Dois inteiros longos sendo que o } \\
\text { primeiro representa o numerador de } \\
\text { uma fração e o segundo o denominador } \\
\text { da mesma }\end{array}$ & 5 & 8 \\
\hline
\end{tabular}

Tabela 1 - Tipos de dados possíveis e respectivos códigos que aparecem no arquivo.

- Os últimos 4 bytes de uma entrada de diretório podem armazenar diretamente o valor da tag ou o valor do deslocamento em bytes a partir do inicio do arquivo (endereço no arquivo), onde estará localizado o valor ou valores da tag. Se o valor da tag ocupar um espaço em disco menor ou igual a 4 bytes, então o valor da mesma será armazenado no próprio corpo da entrada de diretório. Caso contrario, ele será armazenado em outro endereço do arquivo que por sua vez será informado nos 4 bytes reservados para o seu valor.

Após serem registrados as " $\mathrm{n}$ " entradas de diretório indicadas pelos dois primeiros bytes de um diretório imagem, são gravados os últimos 4 bytes do diretório. Nestes 4 bytes é armazenado um número inteiro que indica o endereço no arquivo onde está posicionado o próximo diretório do arquivo ou o valor zero para indicar que não existe outro diretório de imagem no arquivo

Cada diretório de um arquivo imagem corresponde aos dados de uma nova imagem que consta no arquivo. Portanto, em uma arquivo TIFF é possível armazenar o número de imagens que se quiser.

Na tabela 2 são apresentadas as tags mais importantes de um arquivo TIFF, a característica das imagens que elas definem e os respectivos tipos de dados dos seus valores.

É importante ressaltar que as tags em um arquivo sempre aparecem em ordem crescente de seus respectivos números (EEDCU, 1999) 


\section{Descrição das tags mais importantes}

Algumas tags são perfeitamente compreendidas através da tabela 2. Outras, no entanto, devem ser exploradas com mais profundidade para se tornarem mais claras.

A seguir são discutidas algumas dessas tags.

Tag n⿳o 262 - Interpretação fotométrica: essa tag especifica o tipo de imagem que está contida em um arquivo. O formato TIFF suporta os seguintes tipos de imagem:

a)Imagem preto e branco (binária). Neste tipo de imagem os pixels podem assumir apenas dois valores de cores ou preto ou branco (0 ou 1). Este é o caso de imagens geradas pelas máquinas de FAX. O valor do pixel deste tipo de imagem é armazenada em apenas 1 bit.

b)Imagem em tons de cinza (Grayscale). Neste tipo de imagem os pixels são representado por 256 tons de cinza diferentes. Portanto, o valor de cada pixel é armazenado em 1 byte.

Tabela 2 - Etiquetas ou tags mais importantes de formato TIFF com seus respectivos tipos de dados e a característica da imagem que elas definem. 


\begin{tabular}{|c|c|c|c|}
\hline $\mathrm{N}^{0}$ da tag & Características da Imagem & Tipo do dado & Valores que pode assumir \\
\hline 256 & $\begin{array}{l}\text { Largura da Imagem em } \\
\text { pixel }\end{array}$ & Short ou Long & Qualquer valor positivo \\
\hline 257 & Altura da imagem em pixels & Short ou Long & Qualquer valor positivo \\
\hline 258 & Bits por pixel & Short & 0 até 8 \\
\hline 259 & $\begin{array}{l}\text { Tipo de algoritmo de compressão de } \\
\text { dados raster utilizado }\end{array}$ & Short & $\begin{array}{l}\text { Nenhum tipo de algoritmo de } \\
\text { compressão } \\
\text { CCIT ID } \\
\text { Group } 3 \text { FAX } \\
\text { Group } 4 \text { FAX } \\
\text { LZW } \\
\text { JPGE } \\
\text { 32703 - Packbits }\end{array}$ \\
\hline 262 & Interpretação Fotométrica & Short & $\begin{array}{l}0 \text { e } 1 \text { - Imagem preto e branco ou } \\
\text { tons de cinza } \\
2 \text { - Imagem RGB } \\
3 \text { - Imagem RGB Palette } \\
\end{array}$ \\
\hline 273 & Deslocamento de Faixas & $\begin{array}{l}\text { Matriz de valores } \\
\text { do tipo short ou } \\
\text { Long }\end{array}$ & Qualquer valor inteiro positivo \\
\hline 274 & Orientação & Short & 1 até 8 \\
\hline 277 & Amostras por pixel & Short & $\begin{array}{l}\text { 1-nos casos de imagem preto e } \\
\text { branco, tons de cinza e RGB Palette } \\
\text { 3-No caso de imagem RGB }\end{array}$ \\
\hline 278 & Linhas por faixa & Short ou Long & Qualquer valor inteiro positivo \\
\hline 279 & $\begin{array}{l}\text { Número de bytes que cada faixa } \\
\text { ocupa no arquivo }\end{array}$ & $\begin{array}{l}\text { Matriz de valores } \\
\text { dos tipos short ou } \\
\text { Long }\end{array}$ & Qualquer valor inteiro positivo \\
\hline 282 & Resolução no eixo X da imagem & Rational & Quaisquer valores inteiros positivos \\
\hline 283 & Resolução no eixo Y da imagem & Rational & Quaisquer valores inteiros positivos \\
\hline 284 & Configuração planar & Short & $\begin{array}{l}1 \text { Formato concatenado } \\
2 \text { Formato planar }\end{array}$ \\
\hline 296 & $\begin{array}{l}\text { Unidade de medida da resolução da } \\
\text { imagem }\end{array}$ & Short & $\begin{array}{l}\text { 2- Polegadas } \\
\text { 3- Centímetros }\end{array}$ \\
\hline 322 & Largura da Tile em pixels & Short & 0 até 65535 \\
\hline 323 & Altura da Tile em pixels & Short & 0 até 65535 \\
\hline 324 & $\begin{array}{l}\text { Endereço do arquivo onde estão } \\
\text { posicionados as “n” Tiles do } \\
\text { arquivo imagem }\end{array}$ & $\begin{array}{l}\text { Matriz de valores } \\
\text { dos tipos short ou } \\
\text { long }\end{array}$ & Quaisquer valores inteiros positivos \\
\hline 325 & $\begin{array}{l}\text { Para cada Tile o } \mathrm{n}^{\circ} \text { de bytes que ela } \\
\text { ocupa no arquivo }\end{array}$ & $\begin{array}{l}\text { Matriz de valores } \\
\text { dos tipos short ou } \\
\text { long }\end{array}$ & 0 até 65535 \\
\hline
\end{tabular}

c) Imagem do tipo Palette. Imagem colorida para a qual é gerada uma tabela de 256 entradas. A esta tabela é dado o nome de mapa das cores. Para cada uma das 256 entradas da tabela existem 3 valores individuais das cores principais vermelho, verde e azul. Desta forma o valor da cada pixel da imagem ocupa 1 byte no arquivo . Para exibir uma imagem deste tipo na tela do monitor de vídeo é necessário ler o valor do pixel (de 0 a 255), entrar no mapa de cores e identificar os três valores das 
cores principais . Na tag 320 é que estão contidas as informações do mapa de cores da imagem.

Para os três tipos de imagem citados anteriormente (a, b, c) o valor da tag 277 (amostras por pixel) terá valor igual a 1 .

d) Imagem RGB. Imagem colorida em que, para cada pixel da imagem, existem 3 valores numéricos amostrados. Cada valor individual representa, respectivamente, as amostras de intensidade de luminosidade nas bandas do vermelho, do verde e do azul

Assim, quando o valor da tag 262 for igual a 1 ou a 0 , isso significa que a imagem é do tipo preto e branco ou em tons de cinza. A definição entre os dois tipos se dará na observação do valor da tag 258 (bits por pixel). Se o valor desta última tag for igual a 1 bit, então a imagem será do tipo preto e branco. Caso contrario a imagem será do tipo tons de cinza (grayscale).

Ainda, se o valor da $\operatorname{tag} 262$ for 1, então o pixel que tenha um valor de cor igual a zero será representado como um pixel branco. Um pixel de valor 1 (caso da imagem preto e branco) ou 2 (elevado ao valor da tag 258) - 1 (para o caso da imagem em tons de cinza) será representado como branco.

Se o valor da tag 262 for igual a 2, então a imagem contida no arquivo é do tipo RGB.

Finalmente se o valor da tag 262 for 3, a imagem será do tipo palette.

As tags de números 273, 278, 322, 323, 324 e 325 são importantes pois definem o tipo de armazenamento dos dados raster ou seja, a forma de armazenamento dos valores das cores dos pixels de uma imagem.

Existem duas formas usuais para a organização dos dados raster em um arquivo de imagem. A primeira delas é chamada de organização em faixas. Neste caso os dados de valores de cores dos pixels da imagem são armazenadas em linhas completas da imagem. Ou seja, inicialmente são armazenados os valores dos pixels 
de toda a primeira linha da imagem. E, na seqüência, são armazenadas as linhas seguintes

Este será o caso se a tag 273 estiver presente no arquivo. O valor da tag 273 é composto por uma matriz de valores inteiros que representam os endereços do arquivo (deslocamento em bytes a partir de início do arquivo) a partir de onde são armazenados os dados raster das "n" faixas da imagem.

Uma faixa de dados raster, no entanto, pode ser composta por mais de uma linha da imagem.

O número de linhas contidas em uma faixa é definido pelo valor de tag 278.

A organização em faixas de um arquivo TIFF se complementa com a informação contida na tag 279. O valor desta tag também é uma matriz de números inteiros em que cada elemento armazena o numero total de bytes contido em cada faixa especifica da imagem.

A segunda forma de organização dos dados raster de uma imagem é em pacotes de imagem (tiles). Neste tipo de organização, ao invés de armazenar faixas constituídas de linhas inteiras da imagem, são armazenadas porções retangulares da mesma, chamadas pacotes de imagem ou do termo inglês tiles.

Este será o caso de um arquivo TIFF, em que as tags 322, 323, 324, e 325 estiverem presentes.

As tags 322 e 323 armazenam respectivamente a largura e a altura dos pacotes de imagem.

Pode acontecer que a largura da imagem não seja múltipla da largura dos pacotes, e nesse caso será necessário preencher o último pacote com uma única cor. Qualquer cor de preenchimento pode ser utilizada . O mesmo tipo de procedimento aplica-se para a altura da imagem. 
A tag 324 é aquela que apresenta uma matriz de valores inteiros que definem os deslocamentos em bytes a partir do início do arquivo onde foi posicionado o começo dos dados de cada pacote da imagem.

Por sua vez, a tag 325 contém uma matriz de valores inteiros que definem o número de bytes que cada pacote de imagem ocupa no arquivo.

Outra tag fundamental para que se consiga ler corretamente dados TIFF é a de número 284. Esta tag define o tipo de configuração planar utilizada.

A configuração planar define, para um arquivo TIFF que contém uma imagem do tipo RGB, se os três valores das cores vermelho, verde e azul dos pixels da imagem são armazenadas concatenadamente ou seqüencialmente, isto é, se inicialmente são armazenados todos os valores das demais bandas .

Para o primeiro caso a tag 284 terá valor igual a 1. Para o segundo caso a tag 284 assumirá o valor 2.

É importante ressaltar que as matrizes de valores das tags 273, 279, 324, e 325 podem ser matrizes unidimensionais ou bidimensionais, dependendo do valor da tag 284. Assim, se a configuração planar for igual a 1 as matrizes serão unidimensionais e se a configuração planar for igual a 2 elas serão bidimensionais .

Para um arquivo que apresente configuração planar igual a 2, as matrizes das tags 273, 279, 324 e 325 terão 3 linhas e o número de colunas vai depender do número de faixas ou pacotes da imagem. Assim, os elementos da linha 1 das matrizes de endereçamento conterão os endereços das faixas ou dos pacotes de imagem que contém os valores da banda do vermelho das faixas ou dos pacotes. Os elementos das linhas 2 e 3, conterão respectivamente os endereços das faixas ou dos pacotes que contém os valores das bandas verde e azul.

Finalmente, a tag de número 259 revela que tipo de algoritmo de compressão de dados raster foi utilizado na geração do arquivo. Existem muitos algoritmos de 
compressão de dados que podem ser utilizados para diminuir o espaço físico em disco necessário para armazenar os dados de uma imagem.

No entanto, quando o valor da $\operatorname{tag} 259$ foi igual a 1, significa que nenhum algoritmo de compressão foi usado. Existem inúmeras outras tags que definem características das imagens não essenciais para este trabalho e que não serão citadas aqui. 


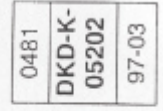

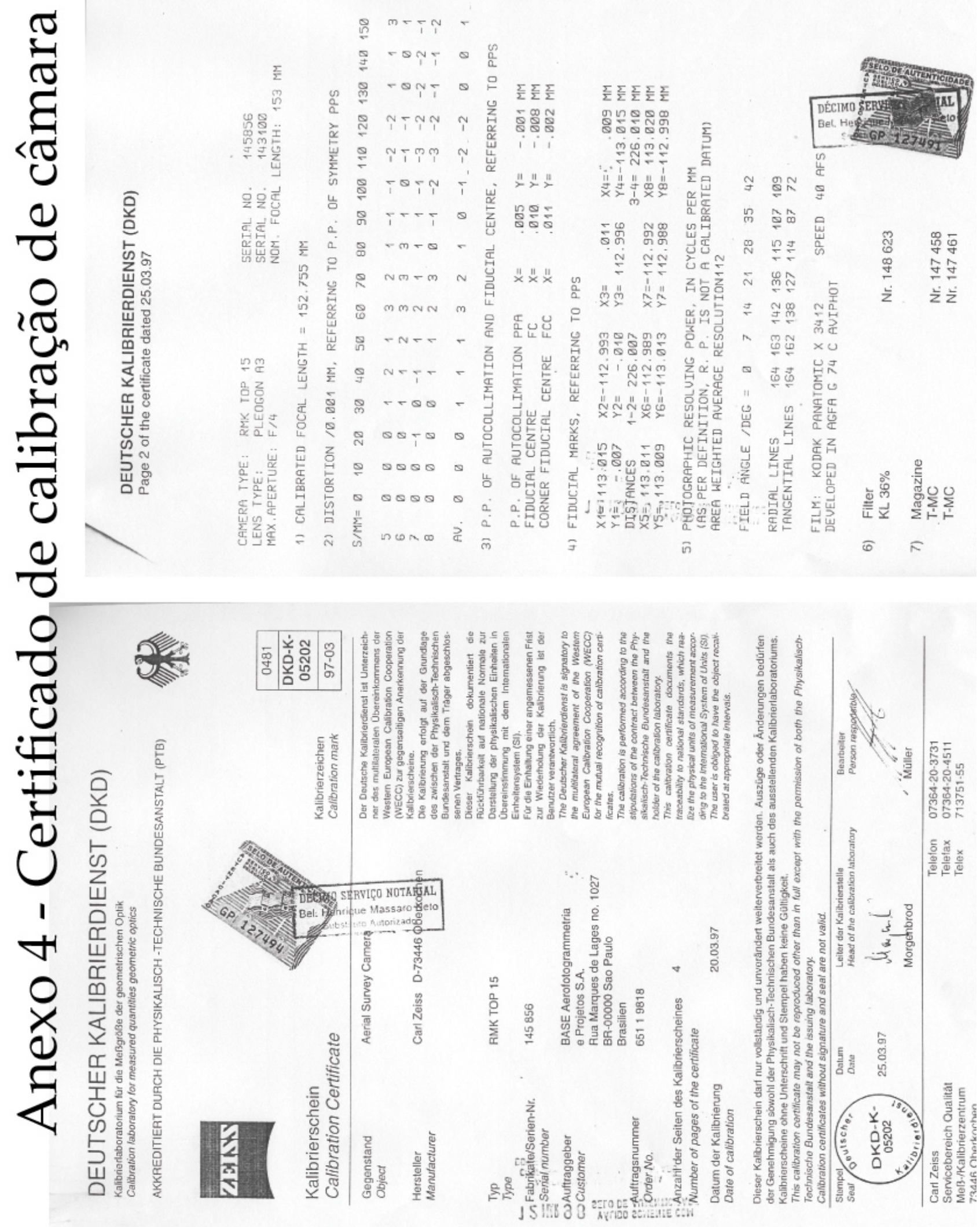




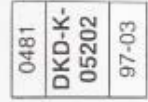
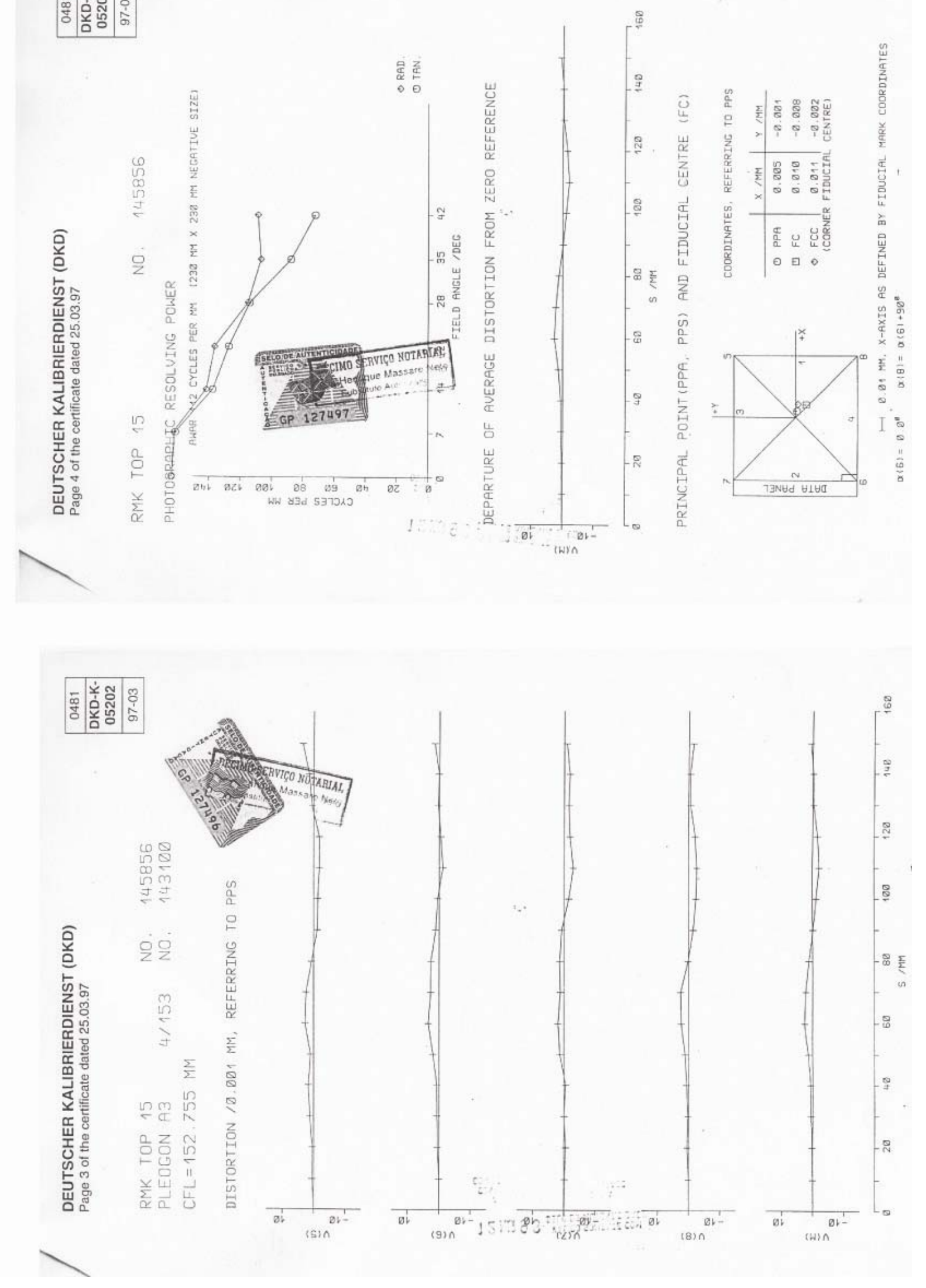

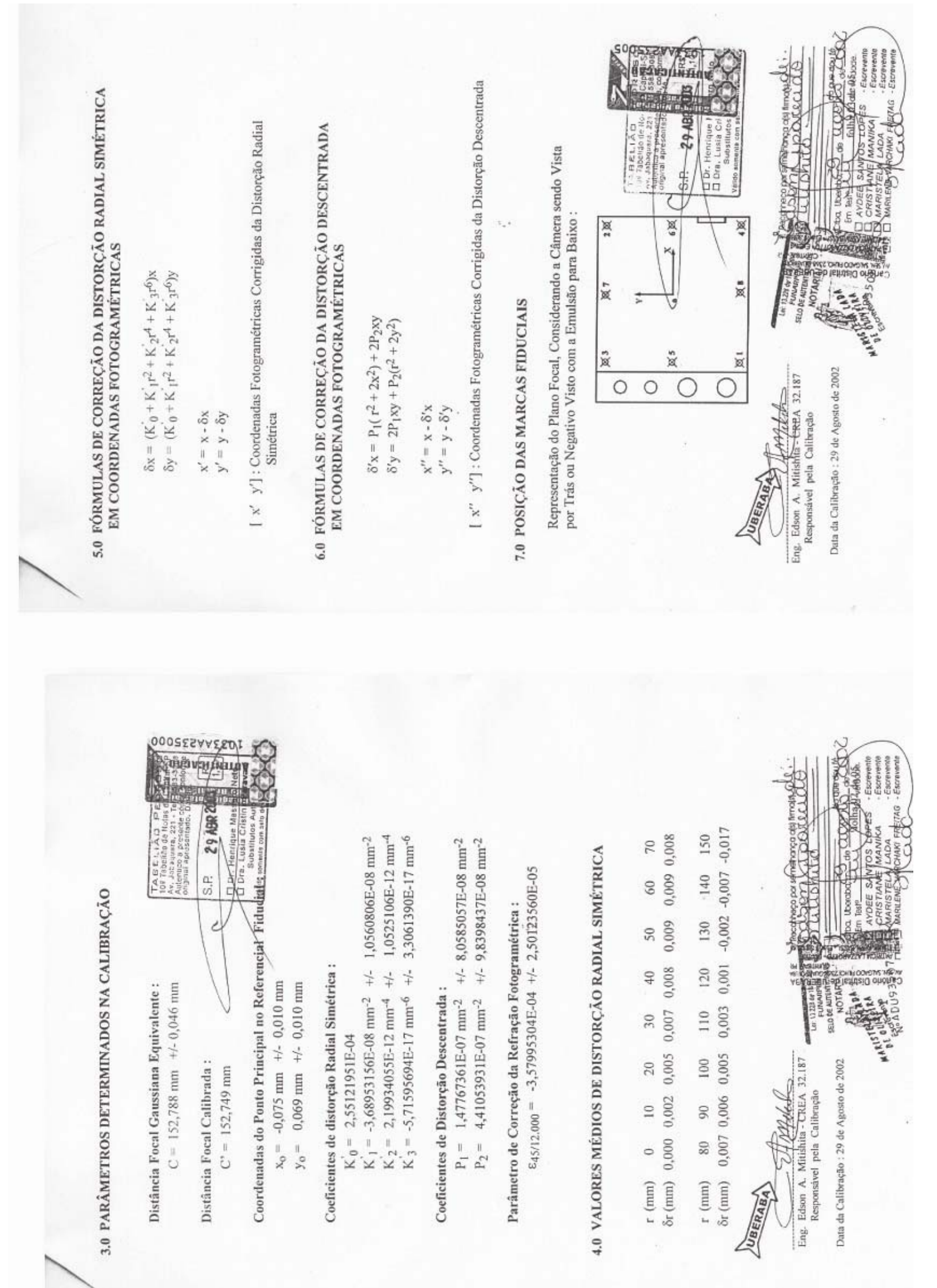


\section{Anexo 5 - Tabulação dos dados de validação.}

Listagem das observações feitas por dois operadores, D e VB, de pontos de controle em modelos estereoscópicos de cobertura aerofotogramétrica em escala 1:5.000. Leituras feitas em estação fotogramétrica analítico-digital marca ISM modelo DIAP. A média dessas leituras gerou a posição de referência (Eref, $\mathrm{N}_{\text {ref, }} \mathrm{H}_{\text {ref }}$ ). Altitudes extraídas do MDE (HMDE).

\begin{tabular}{|c|c|c|c|c|c|c|c|c|c|c|}
\hline \multirow{2}{*}{ Ponto } & \multicolumn{3}{|c|}{ Operador D } & \multicolumn{3}{|c|}{ Operador VB } & \multicolumn{3}{|c|}{ Referência } & \multirow{2}{*}{$\mathrm{H}_{\mathrm{MDE}}$} \\
\hline & $\mathrm{E}$ & $\mathrm{N}$ & $\mathrm{H}$ & $\mathrm{E}$ & $\mathrm{N}$ & $\mathrm{H}$ & $\mathrm{E}_{\mathrm{ref}}$ & $\mathrm{N}_{\text {ref }}$ & $\mathrm{H}_{\text {ref }}$ & \\
\hline 8 & 261245.54 & 7438263.12 & 586.33 & 261245.45 & 7438263.13 & 586.28 & 261245.50 & 7438263.13 & 586.31 & 588.09 \\
\hline 13 & 52866.01 & 7438787.32 & 556.25 & 262866.14 & 7438787.68 & 556.26 & 262866.08 & 7438787.50 & 556.26 & 57.60 \\
\hline 22 & 262690.66 & 7438582.96 & 561.66 & 262690.43 & 7438583.23 & 561.89 & 262690.55 & 7438583.10 & 561.78 & 563.23 \\
\hline 46 & 262897.28 & 7438417.12 & 549.29 & 262897.21 & 7438417.16 & 549.38 & 262897.25 & 7438417.14 & 549.34 & 550.47 \\
\hline 50 & 262945.84 & 7438407.34 & 544.95 & 262945.83 & 7438407.36 & 544.96 & 262945.84 & 7438407.35 & 544.96 & 544.62 \\
\hline 59 & 263120.22 & 7438268.59 & 526.05 & 263120.17 & 7438268.54 & 526.08 & 263120.20 & 7438268.57 & 526.07 & 527.65 \\
\hline 67 & 263548.35 & 7438144.51 & 533.92 & 263548.39 & 7438144.30 & 533.94 & 263548.37 & 7438144.41 & 533.93 & 534.82 \\
\hline 75 & 264754.50 & 7438668.49 & 550.56 & 264754.62 & 7438668.54 & 550.56 & 264754.56 & 7438668.52 & 550.56 & 551.52 \\
\hline 78 & 264889.77 & 7438795.47 & 554.65 & 264889.76 & 7438795.56 & 554.62 & 264889.77 & 7438795.52 & 554.64 & 555.63 \\
\hline 80 & 54963.16 & 7438307.90 & 569.67 & 264963.18 & 7438307.82 & 569.74 & 264963.17 & 7438307.86 & 569.71 & 573.18 \\
\hline 93 & 259458.76 & 7437793.21 & 544.70 & 259458.84 & 7437793.30 & 544.79 & 259458.80 & 7437793.26 & 544.75 & 546.16 \\
\hline 113 & 259282.16 & 7437675.61 & 529.74 & 259282.04 & 7437675.66 & 529.89 & 259282.10 & 7437675.64 & 529.82 & 30.57 \\
\hline 123 & 259300.62 & 7437618.52 & 529.69 & 259300.46 & 7437618.54 & 530.17 & 259300.54 & 7437618.53 & 529.93 & 529.85 \\
\hline 132 & 59481.19 & 7437623.98 & 540.11 & 259481.14 & 437624.04 & 540.47 & 259481.17 & 7437624.01 & 540.29 & 540.96 \\
\hline 133 & 260229.35 & 7437871.89 & 570.42 & 260229.25 & 7437871.56 & 570.37 & 260229.30 & 7437871.73 & 570.40 & 571.27 \\
\hline 141 & 260458.45 & 7438049.10 & 583.89 & 260458.79 & 7438048.76 & 583.85 & 260458.62 & 7438048.93 & 583.87 & 87.15 \\
\hline 152 & 260669.79 & 7438081.74 & 590.24 & 260669.87 & 7438081.85 & 590.30 & 260669.83 & 7438081.80 & 590.27 & 592.18 \\
\hline 165 & 260878.71 & 7437999.37 & 595.85 & 260878.57 & 7437999.53 & 595.92 & 260878.64 & 7437999.45 & 595.89 & 597.51 \\
\hline 170 & 259133.99 & 7437263.43 & 544.42 & 259133.61 & 7437263.67 & 544.53 & 259133.80 & 7437263.55 & 544.48 & 545.50 \\
\hline 174 & 260713.40 & 7437270.89 & 582.40 & 260713.04 & 7437270.75 & 582.53 & 260713.22 & 7437270.82 & 582.47 & 583.13 \\
\hline 175 & 259451.09 & 7436681.75 & 581.71 & 259451.35 & 7436681.79 & 581.53 & 259451.22 & 7436681.77 & 581.62 & 583.11 \\
\hline 177 & 62397.80 & 7437041.03 & 530.34 & 262397.19 & 7437041.15 & 530.89 & 262397.50 & 7437041.09 & 530.62 & 530.50 \\
\hline 193 & 263208.51 & 7437806.56 & 517.47 & 263208.41 & 7437806.54 & 517.44 & 263208.46 & 7437806.55 & 517.46 & 518.79 \\
\hline 271 & 63643.71 & 7437749.46 & 542.17 & 263643.81 & 7437749.54 & 542.30 & 263643.76 & 7437749.50 & 542.24 & 543.14 \\
\hline 321 & 263987.17 & 7437944.50 & 559.49 & 263987.23 & 7437944.68 & 559.60 & 263987.20 & 7437944.59 & 559.55 & 561.25 \\
\hline 330 & 54131.87 & 7437927.67 & 555.57 & 264131.83 & 7437927.70 & 555.56 & 264131.85 & 7437927.69 & 555.57 & 556.59 \\
\hline 347 & 264043.70 & 7437765.73 & 566.41 & 264043.83 & 7437765.74 & 566.46 & 264043.77 & 7437765.74 & 566.44 & 569.04 \\
\hline 396 & 4365.68 & 7437735.80 & 568.32 & 264365.72 & 437736.04 & 568.36 & 264365.70 & 7437735.92 & 568.34 & 571.27 \\
\hline 46 & 264412.73 & 7437682.09 & 568.28 & 264412.88 & 7437682.14 & 568.26 & 264412.81 & 7437682.12 & 568.27 & 569.17 \\
\hline 556 & 3032.37 & 7437457.49 & 519.23 & 263032.05 & 7437457.71 & 519.29 & 263032.21 & 7437457.60 & 519.26 & 521.19 \\
\hline 565 & 263180.48 & 7437387.84 & 518.10 & 263180.39 & 7437388.13 & 518.06 & 263180.44 & 7437387.99 & 518.08 & 520.54 \\
\hline & 3538.78 & 7437319.62 & 528.02 & 263538.75 & 7437319.75 & 527.98 & 263538.77 & 7437319.69 & 528.00 & 528.89 \\
\hline 731 & 263004.49 & 7437197.98 & 514.97 & 263004.09 & 7437198.07 & 515.07 & 263004.29 & 7437198.03 & 515.02 & 516.51 \\
\hline & 264019.98 & 7437197.42 & 530.16 & 264020.02 & 7437197.24 & 530.11 & 264020.00 & 7437197.33 & 530.14 & 531.61 \\
\hline 95 & 263268.53 & 7436877.21 & 537.28 & 263268.49 & 7436877.23 & 537.25 & 263268.51 & 7436877.22 & 537.27 & 540.19 \\
\hline 1001 & 263700.23 & 7436893.14 & 541.32 & 263700.12 & 7436893.36 & 541.11 & 263700.18 & 7436893.25 & 541.22 & 542.51 \\
\hline & 264011.02 & 7436855.32 & 558.42 & 264010.97 & 7436855.36 & 558.39 & 264011.00 & 7436855.34 & 558.41 & 560.04 \\
\hline 1105 & 264573.63 & 7436833.96 & 556.91 & 264573.42 & 7436833.99 & 556.95 & 264573.53 & 7436833.98 & 556.93 & 558.50 \\
\hline & 54513.73 & 7436478.16 & 567.20 & 264513.58 & 7436478.29 & 567.19 & 264513.66 & 7436478.23 & 567.20 & 567.53 \\
\hline 1379 & 264051.08 & 7436290.04 & 565.09 & 264050.87 & 7436290.22 & 565.21 & 264050.98 & 7436290.13 & 565.15 & 567.41 \\
\hline & 63686.79 & 7436224.49 & 557.33 & 263686.75 & 7436224.49 & 557.29 & 263686.77 & 7436224.49 & 557.31 & 558.17 \\
\hline 1424 & 263294.87 & 7436249.19 & 554.25 & 263294.77 & 7436249.19 & 554.05 & 263294.82 & 7436249.19 & 554.15 & 556.09 \\
\hline & 2781.18 & 7436294.06 & 532.55 & 262781.03 & 7436294.09 & 532.49 & 262781.11 & 7436294.08 & 532.52 & 533.69 \\
\hline 1439 & 262951.86 & 7436201.60 & 538.58 & 262951.81 & 7436201.63 & 538.57 & 262951.84 & 7436201.62 & 538.58 & 539.46 \\
\hline
\end{tabular}




\begin{tabular}{|c|c|c|c|c|c|c|c|c|c|c|}
\hline & & & 518.02 & & 7436327.18 & 17.96 & 262562.38 & 7436327.05 & 517.99 & 518.80 \\
\hline 1458 & 264072.85 & 7436110.81 & 565.14 & 264072.77 & 7436110.90 & 564.69 & 264072.81 & 7436110.86 & 564.92 & 565.89 \\
\hline 1475 & 64305.56 & 7436222.25 & 562.90 & 264305.43 & 7436222.16 & 563.19 & 64305.50 & 7436222.21 & 563.05 & 563.82 \\
\hline 1521 & 263498.49 & 7436022.22 & 559.08 & 263498.45 & 7436022.27 & 559.01 & 263498.47 & 7436022.25 & 559.05 & 559.90 \\
\hline 1559 & 262517.90 & 7436389.42 & 510.99 & 262517.61 & 7436389.22 & 510.98 & 262517.76 & 7436389.32 & 510.99 & 513.76 \\
\hline 1574 & 262434.45 & 7436587.40 & 511.91 & 262434.39 & 7436587.52 & 511.88 & 262434.42 & 7436587.46 & 11.90 & 512.44 \\
\hline 1582 & 2346.95 & 7436393.18 & 508.92 & 262346.85 & 7436393.12 & 508.84 & 262346.90 & 7436393.15 & 508.88 & 511.37 \\
\hline 1591 & 261944.70 & 7436177.29 & 521.89 & 261944.60 & 7436177.25 & 521.97 & 261944.65 & 7436177.27 & 221.93 & 524.40 \\
\hline 1601 & 262481.42 & 7436188.46 & 515.83 & 262481.19 & 7436188.54 & 515.84 & 262481.31 & 7436188.50 & 515.84 & 516.99 \\
\hline 1732 & 263947.23 & 7435891.47 & 555.23 & 263947.04 & 7435891.53 & 555.13 & 263947.14 & 7435891.50 & 555.18 & 556.65 \\
\hline 1770 & 263810.39 & 7435536.25 & 527.51 & 263810.32 & 7435536.39 & 527.49 & 263810.36 & 7435536.32 & 27.50 & 527.79 \\
\hline 1778 & 263031.97 & 7435859.33 & 541.99 & 263031.84 & 7435859.35 & 541.76 & 263031.91 & 7435859.34 & 41.88 & 542.97 \\
\hline 1808 & 262648.72 & 7435817.02 & 516.14 & 262648.70 & 7435817.03 & 516.10 & 262648.71 & 7435817.03 & 516.12 & 516.79 \\
\hline 1817 & 262480.99 & 7435814.05 & 507.83 & 262481.02 & 7435814.23 & 507.66 & 262481.01 & 7435814.14 & 07.75 & 508.62 \\
\hline 1842 & 265433.95 & 7435928.40 & 579.49 & 265433.65 & 7435928.55 & 579.54 & 265433.80 & 7435928.48 & 79.52 & 580.28 \\
\hline 1844 & 264951.72 & 7435916.30 & 559.47 & 264951.41 & 7435916.43 & 559.40 & 264951.57 & 7435916.37 & 559.44 & 559.23 \\
\hline 1846 & 264537.67 & 7435465.49 & 533.35 & 264537.61 & 7435465.57 & 533.40 & 264537.64 & 7435465.53 & 533.38 & 534.08 \\
\hline 1848 & 261879.52 & 7435332.07 & 504.92 & 261879.60 & 7435331.84 & 505.00 & 261879.56 & 7435331.96 & 504.96 & 505.86 \\
\hline 1850 & 261893.71 & 7435253.83 & 506.15 & 261893.92 & 7435253.84 & 506.20 & 1893.82 & 7435253.84 & 06.18 & 507.02 \\
\hline 1854 & 262182.92 & 7435201.76 & 515.89 & 262182.88 & 7435201.60 & 515.78 & 262182.90 & 7435201.68 & 15.84 & 515.86 \\
\hline 1878 & 2198.48 & 7435174.73 & 515.84 & 262198.44 & 7435174.92 & 515.76 & 2198.46 & 7435174.83 & 15.80 & 516.72 \\
\hline 1882 & 262631.31 & 7435234.11 & 517.26 & 262631.23 & 7435234.07 & 517.15 & 262631.27 & 7435234.09 & 517.21 & 517.76 \\
\hline 1891 & 62618.49 & 7434868.16 & 542.04 & 2618.29 & 7434868.09 & 541.69 & 2618.39 & 7434868.13 & 11.87 & 43.54 \\
\hline 1902 & 262803.40 & 7434379.84 & 567.78 & 262803.35 & 7434379.81 & 567.68 & 262803.38 & 7434379.83 & 67.73 & 569.60 \\
\hline 1905 & 262653.59 & 7434329.52 & 569.95 & 2653.59 & 7434329.57 & 569.66 & 2653.59 & 4329.55 & 69.81 & 571.06 \\
\hline 1908 & 262479.23 & 7434481.44 & 559.55 & 262478.99 & 7434481.89 & 559.09 & 262479.11 & 7434481.67 & 59.32 & 560.98 \\
\hline 1910 & 261975.93 & 7434449.47 & 540.09 & 261975.70 & 7434450.14 & 540.16 & 261975.82 & 7434449.81 & 10.13 & 540.80 \\
\hline 1912 & 262716.53 & 7434161.25 & 572.84 & 262716.41 & 7434161.19 & 572.86 & 262716.47 & 7434161.22 & 672.85 & 573.75 \\
\hline 1922 & 263799.13 & 7434674.82 & 537.73 & 263798.93 & 7434674.91 & 537.83 & 3799.03 & 7434674.87 & 37.78 & 538.41 \\
\hline 1924 & 263792.21 & 7434729.36 & 535.67 & 263792.15 & 7434729.25 & 535.85 & 263792.18 & 7434729.31 & 535.76 & 536.25 \\
\hline 1925 & 264317.53 & 7434672.04 & 555.68 & 264317.35 & 7434672.15 & 555.43 & 4317.44 & 7434672.10 & 55.56 & 555.68 \\
\hline 1926 & 265079.02 & 7435028.07 & 555.16 & 265078.88 & 7435028.08 & 555.25 & 265078.95 & 7435028.08 & 555.21 & 555.21 \\
\hline 1958 & 259569.54 & 7435104.11 & 535.24 & 9569.59 & 7435104.09 & 535.25 & 9569.57 & 35104.10 & 35.25 & 536.06 \\
\hline 2054 & 259575.40 & 7434789.24 & 533.28 & 259575.25 & 7434789.43 & 533.23 & 259575.33 & 7434789.34 & 33.26 & 534.23 \\
\hline 2079 & 260140.76 & 7434986.59 & 509.74 & 260140.61 & 7434986.65 & 509.76 & 0140.69 & 434986.62 & 9.75 & 509.94 \\
\hline 2082 & 260249.84 & 7434996.70 & 509.84 & 260249.77 & 7434996.65 & 509.90 & 60249.81 & 7434996.68 & 09.87 & 510.07 \\
\hline 2101 & 260447.73 & 7434837.92 & 503.77 & 260447.69 & 7434837.95 & 503.72 & 0447.71 & 434837.94 & 3.75 & 503.96 \\
\hline 2105 & 259919.01 & 7434629.44 & 510.80 & 259919.07 & 7434629.53 & 510.77 & 59919.04 & 7434629.49 & 10.79 & 511.51 \\
\hline 2107 & 259876.25 & 7434596.41 & 513.27 & 259876.05 & 7434596.71 & 513.71 & 9876.15 & 4596.56 & 13.49 & 513.84 \\
\hline 2124 & 259167.15 & 7434335.85 & 546.46 & 259166.87 & 7434335.95 & 546.40 & 259167.01 & 7434335.90 & 46.43 & 546.09 \\
\hline 2127 & 260094.21 & 7434290.46 & 500.95 & 260094.21 & 7434290.48 & 500.95 & 0094.21 & 7434290.47 & & 501.33 \\
\hline 2129 & 260477.29 & 7434291.08 & 506.38 & 260477.28 & 7434291.14 & 506.41 & 260477.29 & 7434291.11 & 06.40 & 506.02 \\
\hline 2149 & 260965.86 & 7434301.52 & 503.82 & 260965.83 & 7434301.66 & 503.83 & 260965.85 & 7434301.59 & 03.83 & 504.74 \\
\hline 2154 & 261247.52 & 7434163.65 & 503.53 & 261247.44 & 7434163.61 & 503.36 & 261247.48 & 7434163.63 & 503.45 & 505.11 \\
\hline 2156 & 261281.45 & 7434053.21 & 504.02 & 261281.64 & 7434053.53 & 504.06 & 261281.55 & 7434053.37 & 04.04 & 504.47 \\
\hline 2161 & 260854.75 & 7434010.61 & 507.51 & 260854.67 & 7434010.54 & 507.39 & 260854.71 & 7434010.58 & 07.45 & 508.53 \\
\hline 2172 & 260450.49 & 7433832.40 & 527.66 & 260450.30 & 7433832.48 & 527.73 & 260450.40 & 7433832.44 & 527.70 & 527.71 \\
\hline 2179 & 260429.26 & 7433648.77 & 536.62 & 260429.24 & 7433649.06 & 536.57 & 260429.25 & 7433648.92 & 536.60 & 536.90 \\
\hline 2195 & 260811.99 & 7433505.56 & 524.06 & 260811.91 & 7433505.58 & 524.10 & 260811.95 & 7433505.57 & 524.08 & 524.81 \\
\hline 2208 & 260885.43 & 7433272.17 & 527.92 & 260885.25 & 7433272.18 & 527.92 & 260885.34 & 7433272.18 & 27.92 & 528.44 \\
\hline 2219 & 260447.02 & 7433249.64 & 547.69 & 260446.95 & 7433249.68 & 547.70 & 260446.99 & 7433249.66 & 547.70 & 549.06 \\
\hline 2222 & 261159.91 & 7433169.12 & 514.64 & 261159.81 & 7433169.30 & 514.66 & 261159.86 & 7433169.21 & 514.65 & 515.56 \\
\hline 2225 & 259513.75 & 7433759.07 & 503.79 & 259513.61 & 7433759.03 & 503.58 & 259513.68 & 7433759.05 & & 504.01 \\
\hline 2230 & 259087.22 & 7433952.17 & 523.80 & 259087.43 & 7433952.65 & 523.92 & 259087.33 & 7433952.41 & 523.86 & 523.78 \\
\hline 2237 & 258864.44 & 7433855.07 & 537.49 & 258864.41 & 7433855.37 & 537.20 & 258864.43 & 7433855.22 & 37.35 & 537.59 \\
\hline 2255 & 258981.45 & 7433697.03 & 528.48 & 258981.43 & 7433697.01 & 528.38 & 258981.44 & 7433697.02 & 528.43 & 528.63 \\
\hline 2262 & 258749.54 & 7433693.64 & 536.14 & 258749.46 & 7433693.72 & 536.18 & 258749.50 & 7433693.68 & 536.16 & 536.27 \\
\hline 2267 & 258693.98 & 7433611.67 & 532.54 & 258693.94 & 7433611.60 & 532.66 & 258693.96 & 7433611.64 & 532.60 & 533.01 \\
\hline 2286 & 258922.69 & 7433393.90 & 519.24 & 258922.53 & 7433393.84 & 519.38 & 258922.61 & 7433393.87 & 519.31 & 519.84 \\
\hline
\end{tabular}




\begin{tabular}{|c|c|c|c|c|c|c|c|c|c|c|}
\hline 357 & & 7433217.00 & 509.19 & 261838.34 & 7433217.03 & 509.15 & 261838.48 & 7433217.02 & 509.17 & 511.19 \\
\hline 2358 & 261971.17 & 7433057.94 & 524.38 & 261970.98 & 7433057.99 & 524.31 & 261971.08 & 7433057.97 & 524.35 & 525.37 \\
\hline 2365 & 262308.02 & 7433173.26 & 524.78 & 262307.81 & 7433173.26 & 524.70 & 262307.92 & 7433173.26 & 524.74 & 26.92 \\
\hline 2367 & 262361.15 & 7433191.32 & 525.71 & 262360.99 & 7433191.34 & 525.74 & 262361.07 & 7433191.33 & 525.73 & 527.32 \\
\hline 2379 & 261594.44 & 7432945.15 & 514.70 & 261594.16 & 7432945.33 & 515.04 & 261594.30 & 7432945.24 & 514.87 & 515.63 \\
\hline 2380 & 261511.27 & 7432774.46 & 504.38 & 261511.26 & 7432774.52 & 504.22 & 261511.27 & 7432774.49 & 504.30 & 07.03 \\
\hline 2384 & 261888.17 & 7432700.59 & 515.07 & 261887.78 & 7432700.68 & 515.10 & 261887.98 & 7432700.64 & 515.09 & 516.38 \\
\hline 2385 & 262105.35 & 7432884.42 & 515.48 & 262105.22 & 7432884.73 & 515.49 & 262105.29 & 7432884.58 & 15.49 & 16.89 \\
\hline 2401 & 262123.90 & 7432798.23 & 515.21 & 262123.87 & 7432798.32 & 515.23 & 262123.89 & 7432798.28 & 515.22 & 516.54 \\
\hline 2414 & 262152.64 & 7432681.29 & 514.62 & 262152.39 & 7432681.64 & 514.61 & 262152.52 & 7432681.47 & 14.62 & 515.59 \\
\hline 2418 & 262187.65 & 7432612.75 & 514.08 & 262187.61 & 7432612.62 & 514.09 & 262187.63 & 7432612.69 & 514.09 & 515.18 \\
\hline 2427 & 262225.99 & 7432340.33 & 512.91 & 262225.93 & 7432340.26 & 512.91 & 2225.96 & 7432340.30 & 12.91 & 13.72 \\
\hline 2438 & 262270.28 & 7432228.67 & 513.13 & 262270.27 & 7432228.86 & 513.15 & 262270.28 & 7432228.77 & 513.14 & 514.27 \\
\hline 2439 & 262275.14 & 7432206.19 & 513.41 & 262275.19 & 7432206.24 & 513.37 & 262275.17 & 7432206.22 & 13.39 & 514.50 \\
\hline 2458 & 262288.17 & 7432051.41 & 515.85 & 262288.15 & 7432051.64 & 515.71 & 262288.16 & 7432051.53 & 15.78 & 516.95 \\
\hline 2481 & 262347.56 & 7431875.39 & 517.13 & 262347.56 & 7431875.59 & 517.12 & 262347.56 & 7431875.49 & 17.13 & 518.20 \\
\hline 2512 & 262376.22 & 7431644.25 & 518.26 & 262376.11 & 7431644.41 & 518.32 & 262376.17 & 7431644.33 & 518.29 & 519.47 \\
\hline 2550 & 262436.46 & 7431481.19 & 516.29 & 262436.35 & 7431481.37 & 516.36 & 262436.41 & 7431481.28 & 516.33 & 517.37 \\
\hline 2557 & 262444.64 & 7431436.51 & 515.83 & 262444.55 & 7431436.67 & 515.80 & 262444.60 & 7431436.59 & 515.82 & 516.63 \\
\hline 2569 & 262434.80 & 7431372.56 & 514.72 & 262434.67 & 7431372.65 & 514.84 & 262434.74 & 7431372.61 & 514.78 & 515.78 \\
\hline 2571 & 262442.78 & 7431334.70 & 513.90 & 262442.83 & 7431334.89 & 514.02 & 262442.81 & 7431334.80 & 513.96 & 514.75 \\
\hline 2577 & 262468.53 & 7431293.08 & 514.03 & 262468.13 & 7431293.37 & 514.10 & 262468.33 & 7431293.23 & 514.07 & 515.23 \\
\hline 2591 & 62473.78 & 7431174.13 & 511.74 & 262473.80 & 7431173.95 & 511.79 & 2473.79 & 7431174.04 & 11.77 & 512.68 \\
\hline 2668 & 262528.22 & 7431053.77 & 512.39 & 262528.04 & 7431053.87 & 512.55 & 262528.13 & 7431053.82 & 512.47 & 513.12 \\
\hline 2714 & 2538.89 & 7430859.78 & 517.56 & 262538.90 & 7430859.73 & 517.75 & 2538.90 & 430859.76 & 17.66 & 518.96 \\
\hline 2757 & 262602.12 & 7430706.23 & 523.79 & 262601.98 & 7430706.41 & 523.81 & 262602.05 & 7430706.32 & 523.80 & 524.72 \\
\hline 2817 & 62604.85 & 7430565.45 & 528.82 & 262604.56 & 7430565.67 & 528.99 & 2604.71 & 7430565.56 & 28.91 & 530.01 \\
\hline 2824 & 262641.88 & 7430503.80 & 530.10 & 262641.86 & 7430503.83 & 530.19 & 262641.87 & 7430503.82 & 530.15 & 531.14 \\
\hline 2838 & 262639.29 & 7430421.62 & 531.57 & 262639.20 & 7430421.62 & 531.46 & 62639.25 & 7430421.62 & 31.52 & 532.32 \\
\hline 2844 & 262660.91 & 7430320.72 & 531.76 & 262660.98 & 7430320.66 & 531.66 & 262660.95 & 7430320.69 & 31.71 & 532.70 \\
\hline 2846 & 262683.64 & 7430310.15 & 531.40 & 262683.56 & 7430310.24 & 531.36 & 262683.60 & 7430310.20 & 31.38 & 532.21 \\
\hline 2858 & 260270.79 & 7430685.27 & 554.81 & 260270.98 & 7430685.44 & 554.85 & 260270.89 & 7430685.36 & 654.83 & 556.65 \\
\hline 2955 & 260712.90 & 7430560.53 & 549.18 & 260712.86 & 7430560.60 & 549.25 & 260712.88 & 7430560.57 & 49.22 & 549.78 \\
\hline 2958 & 261609.55 & 7432077.85 & 512.35 & 261609.48 & 7432077.86 & 512.44 & 261609.52 & 7432077.86 & 512.40 & 514.00 \\
\hline 2962 & 261682.65 & 7432136.19 & 506.89 & 261682.60 & 7432136.34 & 506.90 & 1682.63 & 7432136.27 & 06.90 & 506.87 \\
\hline 2965 & 262449.71 & 7433235.46 & 528.08 & 262449.73 & 7433235.48 & 528.04 & 262449.72 & 7433235.47 & 528.06 & 529.46 \\
\hline 2967 & 265403.09 & 7434835.27 & 571.19 & 65402.98 & 7434835.22 & 571.27 & 5403.04 & 434835.25 & 71.23 & 571.53 \\
\hline $2967_{\mathrm{A}}$ & 265390.21 & 7434839.29 & 571.21 & 265389.92 & 7434839.14 & 571.09 & 265390.07 & 7434839.22 & 571.15 & 570.81 \\
\hline 2976 & 265303.69 & 7434822.00 & 570.21 & 265303.62 & 7434822.14 & 570.27 & 5303.66 & 434822.07 & 70.24 & 570.94 \\
\hline 2997 & 265079.97 & 7434824.06 & 565.91 & 265079.78 & 7434824.10 & 565.87 & 55079.88 & 7434824.08 & 365.89 & 567.01 \\
\hline 3017 & 4796.79 & 7434791.80 & 554.39 & 264796.51 & 7434791.81 & 554.37 & 64796.65 & 7434791.81 & 554.38 & 554.67 \\
\hline 3034 & 54618.26 & 7434761.39 & 549.38 & 264617.97 & 7434761.39 & 549.47 & 4618.12 & 7434761.39 & 549.43 & 549.79 \\
\hline 3047 & 4345.81 & 7434627.33 & 552.91 & 264345.29 & 7434626.97 & 552.77 & 64345.55 & 7434627.15 & 552.84 & 553.29 \\
\hline 3050 & 264246.06 & 7434584.46 & 555.68 & 264245.99 & 7434584.67 & 555.47 & 264246.03 & 7434584.57 & 555.58 & 555.78 \\
\hline 3051 & 263956.98 & 7434384.13 & 562.68 & 263956.88 & 7434384.07 & 562.80 & 63956.93 & 7434384.10 & 562.74 & 562.72 \\
\hline 3055 & 263914.01 & 7434354.31 & 563.61 & 263913.72 & 7434354.17 & 563.76 & 263913.87 & 7434354.24 & 363.69 & 567.38 \\
\hline 3071 & 263618.62 & 7434155.41 & 567.76 & 263618.53 & 7434155.58 & 567.76 & 263618.58 & 7434155.50 & 567.76 & 568.00 \\
\hline $3071_{\mathrm{A}}$ & 263619.15 & 7434159.89 & 567.72 & 263618.69 & 7434159.86 & 567.68 & 263618.92 & 7434159.88 & 667.70 & 567.84 \\
\hline 3079 & 263481.76 & 7434062.38 & 565.65 & 263481.47 & 7434062.20 & 565.56 & 263481.62 & 7434062.29 & 565.61 & 565.69 \\
\hline 3085 & 263423.39 & 7434075.61 & 556.56 & 263423.21 & 7434075.40 & 556.44 & 263423.30 & 7434075.51 & 556.50 & 556.91 \\
\hline 3092 & 263377.09 & 7433970.85 & 563.43 & 263376.98 & 7433970.92 & 563.49 & 263377.04 & 7433970.89 & 563.46 & 562.72 \\
\hline 3112 & 263256.07 & 7433891.51 & 563.15 & 263255.84 & 7433891.58 & 563.33 & 263255.96 & 7433891.55 & 563.24 & 563.14 \\
\hline 3121 & 263150.05 & 7433800.70 & 564.99 & 263149.76 & 7433800.76 & 565.09 & 263149.91 & 7433800.73 & 565.04 & 564.93 \\
\hline 3135 & 262895.25 & 7433619.89 & 553.98 & 262895.05 & 7433619.84 & 553.99 & 262895.15 & 7433619.87 & 553.99 & 554.07 \\
\hline 3147 & 262750.98 & 7433484.65 & 542.17 & 262750.81 & 7433484.56 & 542.09 & 262750.90 & 7433484.61 & 542.13 & 542.20 \\
\hline 3153 & 62691.87 & 7433427.60 & 537.61 & 262691.73 & 7433427.58 & 537.63 & 262691.80 & 7433427.59 & 537.62 & 537.90 \\
\hline 3158 & 262618.84 & 7433356.89 & 533.82 & 262618.67 & 7433356.82 & 533.82 & 262618.76 & 7433356.86 & 533.82 & 534.41 \\
\hline 3162 & 2576.71 & 7433319.16 & 532.44 & 262576.57 & 7433319.18 & 532.44 & 262576.64 & 7433319.17 & 532.44 & 533.24 \\
\hline 3191 & 265356.61 & 7433346.86 & 535.06 & 265356.60 & 7433346.84 & 534.94 & 265356.61 & 7433346.85 & 535.00 & 535.09 \\
\hline
\end{tabular}




\begin{tabular}{|c|c|c|c|c|c|c|c|c|c|c|}
\hline & & & 535.52 & 265395.30 & 7433321.38 & 535.42 & 265395.22 & 7433321.38 & 535.47 & 536.01 \\
\hline 3194 & 265377.55 & 7433316.02 & 535.50 & 265377.48 & 7433315.98 & 535.38 & 265377.52 & 7433316.00 & 535.44 & 536.07 \\
\hline 197 & 265403.60 & 7433286.86 & 535.79 & 265403.58 & 7433286.88 & 535.76 & 265403.59 & 7433286.87 & 35.78 & 536.26 \\
\hline 3213 & 265140.86 & 7433359.98 & 544.84 & 265141.12 & 7433359.84 & 544.92 & 265140.99 & 7433359.91 & 44.88 & 546.08 \\
\hline 3214 & 265138.17 & 7433125.37 & 555.68 & 265138.08 & 7433125.40 & 555.66 & 265138.13 & 7433125.39 & 555.67 & 557.04 \\
\hline 3219 & 265152.35 & 7433006.07 & 549.06 & 265152.36 & 7433006.12 & 549.06 & 55152.36 & 7433006.10 & 49.06 & 551.07 \\
\hline 3220 & 65401.49 & 7432948.54 & 561.27 & 265401.44 & 7432948.80 & 561.36 & 265401.47 & 7432948.67 & 561.32 & 562.41 \\
\hline 3240 & 263908.52 & 7433035.87 & 511.92 & 263908.59 & 7433035.83 & 511.91 & 63908.56 & 7433035.85 & 11.92 & 513.91 \\
\hline 3242 & 263938.91 & 7433001.75 & 507.27 & 263938.59 & 7433001.55 & 507.51 & 263938.75 & 7433001.65 & 507.39 & 509.10 \\
\hline 3253 & 263667.10 & 7433195.27 & 539.23 & 263666.89 & 7433195.13 & 539.35 & 63667.00 & 7433195.20 & 39.29 & 540.30 \\
\hline 3265 & 263564.20 & 7433637.79 & 566.40 & 263563.90 & 7433638.11 & 566.40 & 263564.05 & 7433637.95 & 566.40 & 568.31 \\
\hline 3271 & 263292.75 & 7433361.98 & 566.64 & 263292.72 & 7433362.01 & 566.54 & 63292.74 & 7433362.00 & 66.59 & 568.71 \\
\hline 3280 & 263259.29 & 7433224.50 & 555.51 & 263258.78 & 7433224.23 & 555.44 & 263259.04 & 7433224.37 & 555.48 & 558.43 \\
\hline 3299 & 264688.59 & 7432476.66 & 535.53 & 264688.44 & 7432476.50 & 535.56 & 264688.52 & 7432476.58 & 35.55 & 337.22 \\
\hline 3300 & 264572.92 & 7432246.45 & 520.40 & 264572.78 & 7432246.58 & 520.28 & 264572.85 & 7432246.52 & 520.34 & 522.85 \\
\hline 3310 & 265275.49 & 7432269.15 & 551.15 & 265275.19 & 7432269.30 & 551.30 & 265275.34 & 7432269.23 & 551.23 & 553.65 \\
\hline 3320 & 265418.76 & 7432125.55 & 552.26 & 265418.47 & 7432125.62 & 552.28 & 265418.62 & 7432125.59 & 552.27 & 553.99 \\
\hline 3332 & 264587.86 & 7431790.69 & 501.02 & 264587.83 & 7431790.88 & 500.74 & 264587.85 & 7431790.79 & 500.88 & 502.32 \\
\hline 3335 & 64555.60 & 7431757.45 & 501.24 & 264555.65 & 7431757.40 & 500.96 & 264555.63 & 7431757.43 & 501.10 & 502.60 \\
\hline 3343 & 264250.25 & 7431540.51 & 522.63 & 264250.11 & 7431540.42 & 522.48 & 4250.18 & 7431540.47 & 522.56 & 524.21 \\
\hline 3345 & 64557.71 & 7431711.01 & 501.49 & 264557.53 & 7431710.98 & 501.22 & 264557.62 & 7431711.00 & 501.36 & 503.14 \\
\hline 3349 & 4731.89 & 7431309.88 & 525.63 & 264731.98 & 7431309.91 & 525.53 & 64731.94 & 7431309.90 & 525.58 & 526.77 \\
\hline 3354 & 34726.29 & 7431290.08 & 525.37 & 264726.26 & 7431290.27 & 525.53 & 4726.28 & 7431290.18 & 525.45 & 526.12 \\
\hline 3359 & 64903.25 & 7431450.39 & 521.62 & 264903.10 & 7431450.05 & 521.65 & 4903.18 & 7431450.22 & 521.64 & 522.79 \\
\hline 3361 & 265362.74 & 7431551.02 & 529.36 & 265362.77 & 7431551.12 & 529.33 & 265362.76 & 7431551.07 & 529.35 & 531.50 \\
\hline 3365 & 263517.60 & 7431922.37 & 534.19 & 263517.45 & 7431922.63 & 534.12 & 263517.53 & 7431922.50 & 534.16 & 536.31 \\
\hline 3380 & 263032.23 & 7431591.39 & 512.86 & 263032.13 & 7431591.64 & 513.03 & 263032.18 & 7431591.52 & 512.95 & 514.08 \\
\hline 3382 & 62813.26 & 7431510.64 & 514.98 & 262813.11 & 7431510.66 & 514.89 & 262813.19 & 7431510.65 & 14.94 & 516.03 \\
\hline 3390 & 262833.31 & 7431407.31 & 517.64 & 262833.41 & 7431407.20 & 517.65 & 262833.36 & 7431407.26 & 517.65 & 518.98 \\
\hline 3399 & 263175.82 & 7431449.80 & 525.57 & 263175.63 & 7431449.90 & 525.71 & 263175.73 & 7431449.85 & 525.64 & 527.25 \\
\hline 3411 & 263260.42 & 7431309.55 & 533.81 & 263260.01 & 7431309.69 & 533.56 & 263260.22 & 7431309.62 & 533.69 & 534.48 \\
\hline 3420 & 263278.38 & 7431236.03 & 535.26 & 263278.13 & 7431236.29 & 534.86 & 263278.26 & 7431236.16 & 535.06 & 536.56 \\
\hline 3428 & 262957.51 & 7431356.76 & 523.74 & 262957.09 & 7431357.02 & 523.67 & 262957.30 & 7431356.89 & 523.71 & 525.67 \\
\hline 3445 & 262746.97 & 7431309.44 & 517.85 & 262746.49 & 7431309.66 & 517.83 & 262746.73 & 7431309.55 & 517.84 & 518.82 \\
\hline 3471 & 263579.49 & 7431405.62 & 542.77 & 263579.73 & 7431405.73 & 542.64 & 263579.61 & 7431405.68 & 542.71 & 542.94 \\
\hline 3474 & 263732.83 & 7431320.11 & 543.11 & 263732.74 & 7431320.21 & 543.14 & 263732.79 & 7431320.16 & 543.13 & 544.13 \\
\hline 3510 & 263751.12 & 7431017.42 & 547.53 & 263750.97 & 7431017.35 & 547.40 & 263751.05 & 7431017.39 & 547.47 & 548.45 \\
\hline 3523 & 265240.25 & 7430733.30 & 539.14 & 265240.19 & 7430733.13 & 538.79 & 265240.22 & 7430733.22 & 538.97 & 537.33 \\
\hline 3524 & 264710.31 & 7430380.49 & 551.15 & 264709.94 & 7430380.67 & 551.24 & 264710.13 & 7430380.58 & 551.20 & 551.76 \\
\hline 3526 & 62987.15 & 7432192.12 & 510.08 & 262987.14 & 7432192.29 & 510.23 & 262987.15 & 7432192.21 & 510.16 & 513.18 \\
\hline 3541 & 264127.27 & 7432610.03 & 515.96 & 264127.15 & 7432610.09 & 515.88 & 264127.21 & 7432610.06 & 515.92 & 518.03 \\
\hline 3546 & 264279.03 & 7432523.65 & 523.91 & 264278.89 & 7432523.75 & 523.88 & 264278.96 & 7432523.70 & 523.90 & 525.62 \\
\hline & 3978.96 & 7432434.04 & 504.78 & 263978.85 & 7432434.03 & 504.92 & 263978.91 & 7432434.04 & 504.85 & 507.24 \\
\hline
\end{tabular}

\section{Observações planimétricas efetuadas por três operadores sobre a ortofoto gerada.}

\begin{tabular}{|r|c|c|c|c|c|c|}
\hline \multirow{2}{*}{ Ponto } & \multicolumn{2}{|c|}{ Operador A } & \multicolumn{2}{c|}{ Operador F } & \multicolumn{2}{c|}{ Operador AD } \\
\cline { 2 - 7 } & $\mathbf{E}$ & $\mathbf{N}$ & $\mathbf{E}$ & $\mathbf{N}$ & $\mathbf{E}$ & $\mathbf{N}$ \\
\hline 8 & 261245.18 & 7438262.87 & 261245.59 & 7438263.47 & 261245.55 & 7438263.62 \\
\hline 13 & 262866.68 & 7438787.33 & 262865.71 & 7438787.40 & 262866.25 & 7438787.39 \\
\hline 22 & 262690.73 & 7438582.00 & 262690.73 & 7438582.00 & 262690.63 & 7438582.50 \\
\hline 46 & 262897.70 & 7438416.81 & 262897.00 & 7438417.40 & 262897.40 & 7438417.33 \\
\hline 50 & 262945.93 & 7438407.07 & 262945.95 & 7438407.59 & 262945.99 & 7438407.70 \\
\hline 59 & 263122.46 & 7438268.42 & 263119.49 & 7438268.53 & 263120.28 & 7438268.79 \\
\hline
\end{tabular}




\begin{tabular}{|c|c|c|c|c|c|c|}
\hline 67 & 263548.04 & 7438143.76 & 263547.90 & 7438143.91 & 263548.72 & 7438144.58 \\
\hline 75 & 264754.30 & 7438667.84 & 264755.50 & 7438668.40 & 264754.67 & 7438668.76 \\
\hline 78 & 264890.26 & 7438795.18 & 264890.65 & 7438795.54 & 264890.37 & 7438796.06 \\
\hline 80 & 264964.07 & 7438307.65 & 264963.28 & 7438308.11 & 264963.77 & 7438308.14 \\
\hline 93 & 259459.12 & 7437793.22 & 259458.58 & 7437794.04 & 259458.74 & 7437793.47 \\
\hline 113 & 259282.87 & 7437676.33 & 259281.97 & 7437676.27 & 259282.57 & 7437676.26 \\
\hline 123 & 259300.15 & 7437618.55 & 259300.75 & 7437619.61 & 259300.70 & 7437619.59 \\
\hline 132 & 259482.14 & 7437623.73 & 259481.70 & 7437624.70 & 259481.37 & 7437624.84 \\
\hline 133 & 260228.85 & 7437871.75 & 260229.09 & 7437872.28 & 260229.18 & 7437872.01 \\
\hline 141 & 260459.28 & 7438048.75 & 260458.77 & 7438048.86 & 260458.87 & 7438048.87 \\
\hline 152 & 260670.09 & 7438081.96 & 260669.20 & 7438081.48 & 260669.74 & 7438081.69 \\
\hline 165 & 260878.39 & 7437998.31 & 260878.45 & 7438000.15 & 260878.56 & 7437999.67 \\
\hline 170 & 259134.73 & 7437263.54 & 259134.01 & 7437264.37 & 259134.14 & 7437263.85 \\
\hline 174 & 260717.03 & 7437272.17 & 260713.76 & 7437271.41 & 260713.27 & 7437271.35 \\
\hline 175 & 259450.51 & 7436683.43 & 259450.48 & 7436683.79 & 259450.31 & 7436683.30 \\
\hline 177 & 262398.67 & 7437040.50 & 262398.18 & 7437041.28 & 262398.30 & 7437041.46 \\
\hline 193 & 263208.24 & 7437806.11 & 263208.43 & 7437807.25 & 263208.51 & 7437806.82 \\
\hline 271 & 263645.36 & 7437749.38 & 263643.32 & 7437750.15 & 263643.89 & 7437749.90 \\
\hline 321 & 263986.50 & 7437944.08 & 263985.30 & 7437944.14 & 263987.39 & 7437944.33 \\
\hline 330 & 264131.45 & 7437926.79 & 264131.19 & 7437927.42 & 264131.27 & 7437927.45 \\
\hline 347 & 264043.89 & 7437766.25 & 264043.31 & 7437766.69 & 264044.21 & 7437766.37 \\
\hline 396 & 264364.92 & 7437736.45 & 264365.16 & 7437736.36 & 264365.30 & 7437736.41 \\
\hline 401 & 264412.56 & 7437682.56 & 264413.44 & 7437683.01 & 264413.66 & 7437682.32 \\
\hline 556 & 263031.62 & 7437456.44 & 263031.46 & 7437457.41 & 263032.09 & 7437457.54 \\
\hline 565 & 263179.94 & 7437387.65 & 263180.28 & 7437388.29 & 263180.30 & 7437388.01 \\
\hline 720 & 263538.13 & 7437319.61 & 263538.34 & 7437320.47 & 263538.39 & 7437320.26 \\
\hline 731 & 263004.34 & 7437197.70 & 263003.68 & 7437198.92 & 263004.54 & 7437198.31 \\
\hline 823 & 264019.50 & 7437196.99 & 264019.85 & 7437198.26 & 264020.13 & 7437197.67 \\
\hline 959 & 263267.77 & 7436876.76 & 263267.97 & 7436877.08 & 263268.62 & 7436877.14 \\
\hline 1001 & 263699.53 & 7436893.25 & 263699.54 & 7436894.00 & 263699.89 & 7436893.25 \\
\hline 1023 & 264010.87 & 7436856.16 & 264010.64 & 7436856.35 & 264011.13 & 7436856.12 \\
\hline 1105 & 264574.23 & 7436833.75 & 264574.35 & 7436834.42 & 264574.80 & 7436834.76 \\
\hline 1348 & 264513.76 & 7436477.95 & 264513.56 & 7436478.00 & 264513.69 & 7436478.23 \\
\hline 1379 & 264051.44 & 7436290.48 & 264050.73 & 7436290.64 & 264051.25 & 7436290.41 \\
\hline 1396 & 263686.72 & 7436225.09 & 263686.34 & 7436225.00 & 263686.60 & 7436224.92 \\
\hline 1424 & 263294.23 & 7436248.89 & 263294.65 & 7436249.55 & 263294.85 & 7436249.42 \\
\hline 1433 & 262781.70 & 7436292.79 & 262781.60 & 7436294.04 & 262781.58 & 7436294.60 \\
\hline 1439 & 262951.68 & 7436202.35 & 262952.28 & 7436203.08 & 262952.45 & 7436202.42 \\
\hline 1451 & 262563.04 & 7436326.12 & 262562.79 & 7436327.58 & 262562.99 & 7436327.07 \\
\hline 1458 & 264072.63 & 7436110.84 & 264072.50 & 7436111.68 & 264072.87 & 7436111.01 \\
\hline 1475 & 264305.87 & 7436222.09 & 264305.63 & 7436222.00 & 264305.66 & 7436222.06 \\
\hline 1521 & 263498.91 & 7436023.11 & 263498.17 & 7436023.14 & 263498.76 & 7436022.95 \\
\hline 1559 & 262517.97 & 7436389.05 & 262517.48 & 7436389.38 & 262517.94 & 7436389.75 \\
\hline 1574 & 262435.03 & 7436587.80 & 262434.76 & 7436588.29 & 262434.97 & 7436588.04 \\
\hline 1582 & 262347.42 & 7436393.12 & 262347.07 & 7436393.62 & 262347.37 & 7436393.58 \\
\hline 1591 & 261945.28 & 7436178.33 & 261944.88 & 7436178.43 & 261944.98 & 7436178.44 \\
\hline 1601 & 262481.50 & 7436186.90 & 262482.35 & 7436188.06 & 262482.16 & 7436188.25 \\
\hline 1732 & 263946.37 & 7435891.75 & 263947.49 & 7435892.37 & 263947.23 & 7435892.22 \\
\hline 1770 & 263810.18 & 7435536.34 & 263809.72 & 7435536.97 & 263810.55 & 7435537.12 \\
\hline 1778 & 263033.25 & 7435858.42 & 263031.85 & 7435859.62 & 263031.97 & 7435859.59 \\
\hline 1808 & 262649.32 & 7435817.52 & 262649.60 & 7435817.41 & 262649.14 & 7435817.23 \\
\hline 1817 & 262482.26 & 7435813.88 & 262482.19 & 7435814.63 & 262481.31 & 7435814.21 \\
\hline 1842 & 265434.18 & 7435928.82 & 265433.32 & 7435929.24 & 265434.05 & 7435928.68 \\
\hline 1844 & 264952.53 & 7435915.80 & 264951.94 & 7435916.54 & 264951.91 & 7435916.76 \\
\hline 1846 & 264537.72 & 7435465.72 & 264538.04 & 7435466.22 & 264537.61 & 7435466.20 \\
\hline 1848 & 261879.34 & 7435332.23 & 261880.31 & 7435333.49 & 261879.64 & 7435332.44 \\
\hline 1850 & 261894.79 & 7435254.27 & 261894.42 & 7435254.67 & 261893.42 & 7435253.92 \\
\hline 1854 & 262182.88 & 7435201.53 & 262182.35 & 7435201.39 & 262182.91 & 7435201.64 \\
\hline 1878 & 262198.22 & 7435174.20 & 262198.31 & 7435174.59 & 262198.63 & 7435174.62 \\
\hline
\end{tabular}




\begin{tabular}{|c|c|c|c|c|c|c|}
\hline 1882 & 262632.16 & 7435234.30 & 262632.02 & 7435234.59 & 262631.21 & 7435233.77 \\
\hline 1891 & 262620.03 & 7434869.18 & 262619.60 & 7434869.14 & 262618.93 & 7434868.35 \\
\hline 1902 & 262804.92 & 7434379.67 & 262803.68 & 7434379.89 & 262803.92 & 7434380.03 \\
\hline 1905 & 262655.32 & 7434329.57 & 262654.25 & 7434330.01 & 262654.06 & 7434329.38 \\
\hline 1908 & 262479.31 & 7434481.46 & 262480.20 & 7434482.53 & 262479.46 & 7434481.34 \\
\hline 1910 & 261975.43 & 7434450.97 & 261975.50 & 7434450.88 & 261975.99 & 7434450.06 \\
\hline 1912 & 262717.45 & 7434160.31 & 262717.51 & 7434161.65 & 262717.42 & 7434161.35 \\
\hline 1922 & 263798.34 & 7434675.32 & 263798.19 & 7434675.19 & 263798.88 & 7434675.04 \\
\hline 1924 & 263792.23 & 7434730.04 & 263791.94 & 7434729.34 & 263792.09 & 7434729.53 \\
\hline 1925 & 264316.91 & 7434671.30 & 264317.25 & 7434672.57 & 264317.33 & 7434672.06 \\
\hline 1926 & 265080.35 & 7435028.16 & 265079.37 & 7435027.03 & 265080.27 & 7435027.68 \\
\hline 1958 & 259569.13 & 7435105.57 & 259568.62 & 7435105.28 & 259569.31 & 7435105.15 \\
\hline 2054 & 259574.12 & 7434788.87 & 259574.28 & 7434790.52 & 259575.02 & 7434789.75 \\
\hline 2079 & 260140.22 & 7434986.57 & 260139.92 & 7434987.51 & 260140.49 & 7434986.92 \\
\hline 2082 & 260248.98 & 7434997.43 & 260249.68 & 7434997.32 & 260249.10 & 7434997.70 \\
\hline 2101 & 260449.34 & 7434838.75 & 260448.77 & 7434839.15 & 260449.59 & 7434838.87 \\
\hline 2105 & 259919.25 & 7434630.05 & 259919.63 & 7434630.78 & 259919.55 & 7434630.34 \\
\hline 2107 & 259876.35 & 7434596.53 & 259876.69 & 7434597.53 & 259876.75 & 7434597.11 \\
\hline 2124 & 259165.87 & 7434336.42 & 259166.34 & 7434336.92 & 259166.56 & 7434337.32 \\
\hline 2127 & 260095.02 & 7434291.11 & 260094.31 & 7434291.39 & 260094.50 & 7434291.21 \\
\hline 2129 & 260476.54 & 7434291.24 & 260476.81 & 7434291.75 & 260477.37 & 7434291.43 \\
\hline 2149 & 260966.03 & 7434301.39 & 260965.55 & 7434302.22 & 260965.71 & 7434302.06 \\
\hline 2154 & 261247.79 & 7434162.64 & 261247.30 & 7434163.96 & 261247.47 & 7434163.72 \\
\hline 2156 & 261282.74 & 7434053.88 & 261281.56 & 7434054.26 & 261280.59 & 7434053.31 \\
\hline 2161 & 260854.43 & 7434010.82 & 260854.48 & 7434011.17 & 260854.84 & 7434010.79 \\
\hline 2172 & 260452.28 & 7433832.72 & 260451.17 & 7433833.20 & 260449.94 & 7433832.47 \\
\hline 2179 & 260429.10 & 7433649.44 & 260428.79 & 7433649.77 & 260428.96 & 7433649.50 \\
\hline 2195 & 260811.56 & 7433505.68 & 260811.49 & 7433506.13 & 260811.58 & 7433506.09 \\
\hline 2208 & 260886.63 & 7433272.07 & 260886.39 & 7433271.72 & 260886.22 & 7433272.22 \\
\hline 2219 & 260447.13 & 7433248.35 & 260446.58 & 7433249.86 & 260447.14 & 7433249.82 \\
\hline 2222 & 261160.78 & 7433170.84 & 261160.00 & 7433170.27 & 261160.18 & 7433169.59 \\
\hline 2225 & 259514.44 & 7433759.11 & 259513.76 & 7433759.84 & 259514.32 & 7433759.53 \\
\hline 2230 & 259088.36 & 7433953.50 & 259086.88 & 7433952.45 & 259087.58 & 7433952.59 \\
\hline 2237 & 258864.21 & 7433853.60 & 258864.03 & 7433853.95 & 258864.23 & 7433854.37 \\
\hline 2255 & 258981.52 & 7433697.04 & 258980.78 & 7433697.58 & 258981.00 & 7433696.89 \\
\hline 2262 & 258748.98 & 7433694.31 & 258748.80 & 7433694.58 & 258749.46 & 7433693.97 \\
\hline 2267 & 258693.73 & 7433613.30 & 258693.72 & 7433613.10 & 258693.93 & 7433612.42 \\
\hline 2286 & 258920.39 & 7433393.53 & 258922.04 & 7433394.90 & 258921.30 & 7433392.86 \\
\hline 2357 & 261838.63 & 7433217.39 & 261838.23 & 7433217.83 & 261838.99 & 7433218.13 \\
\hline 2358 & 261972.20 & 7433057.93 & 261971.26 & 7433058.56 & 261971.32 & 7433058.47 \\
\hline 2365 & 262307.81 & 7433173.49 & 262307.91 & 7433174.08 & 262307.85 & 7433173.91 \\
\hline 2367 & 262361.27 & 7433191.81 & 262361.28 & 7433192.24 & 262361.09 & 7433192.18 \\
\hline 2379 & 261594.44 & 7432944.99 & 261594.39 & 7432946.10 & 261594.70 & 7432946.04 \\
\hline 2380 & 261510.31 & 7432775.85 & 261510.76 & 7432775.06 & 261511.07 & 7432774.56 \\
\hline 2384 & 261887.20 & 7432699.90 & 261887.48 & 7432700.88 & 261887.94 & 7432700.71 \\
\hline 2385 & 262105.57 & 7432884.52 & 262105.90 & 7432884.45 & 262105.55 & 7432884.38 \\
\hline 2401 & 262124.27 & 7432798.59 & 262123.78 & 7432799.72 & 262124.32 & 7432797.98 \\
\hline 2414 & 262152.43 & 7432681.42 & 262152.39 & 7432682.21 & 262152.26 & 7432681.95 \\
\hline 2418 & 262187.59 & 7432613.22 & 262187.69 & 7432613.46 & 262187.64 & 7432613.69 \\
\hline 2427 & 262226.16 & 7432339.67 & 262225.62 & 7432341.40 & 262225.96 & 7432341.10 \\
\hline 2438 & 262270.34 & 7432228.53 & 262270.15 & 7432228.92 & 262270.17 & 7432229.15 \\
\hline 2439 & 262275.25 & 7432205.66 & 262274.99 & 7432206.59 & 262275.06 & 7432206.66 \\
\hline 2458 & 262288.25 & 7432050.49 & 262287.90 & 7432051.88 & 262288.23 & 7432052.04 \\
\hline 2481 & 262347.13 & 7431873.61 & 262346.90 & 7431874.16 & 262346.91 & 7431873.56 \\
\hline 2512 & 262376.34 & 7431644.17 & 262376.09 & 7431645.38 & 262376.43 & 7431644.95 \\
\hline 2550 & 262435.22 & 7431481.65 & 262435.28 & 7431481.32 & 262436.18 & 7431481.28 \\
\hline 2557 & 262445.04 & 7431436.40 & 262445.12 & 7431436.93 & 262444.96 & 7431437.81 \\
\hline 2569 & 262435.66 & 7431373.15 & 262435.25 & 7431373.26 & 262435.53 & 7431373.08 \\
\hline 2571 & 262443.37 & 7431334.27 & 262443.66 & 7431334.73 & 262443.40 & 7431334.54 \\
\hline
\end{tabular}




\begin{tabular}{|c|c|c|c|c|c|c|}
\hline 2577 & 262468.83 & 7431293.72 & 262469.14 & 7431294.60 & 262468.63 & 7431293.41 \\
\hline 2591 & 262473.97 & 7431174.60 & 262473.64 & 7431175.04 & 262474.12 & 7431174.64 \\
\hline 2668 & 262527.97 & 7431053.37 & 262528.27 & 7431053.55 & 262528.60 & 7431053.41 \\
\hline 2714 & 262537.92 & 7430860.42 & 262538.26 & 7430860.83 & 262538.26 & 7430859.98 \\
\hline 2757 & 262599.30 & 7430707.04 & 262602.55 & 7430707.52 & 262602.37 & 7430706.91 \\
\hline 2817 & 262605.57 & 7430565.96 & 262605.68 & 7430566.39 & 262604.89 & 7430565.77 \\
\hline 2824 & 262642.91 & 7430505.25 & 262642.60 & 7430505.25 & 262642.69 & 7430504.74 \\
\hline 2838 & 262639.54 & 7430422.17 & 262639.56 & 7430422.73 & 262640.12 & 7430422.42 \\
\hline 2844 & 262661.23 & 7430321.84 & 262661.53 & 7430321.99 & 262661.50 & 7430321.36 \\
\hline 2846 & 262684.62 & 7430311.46 & 262684.36 & 7430311.18 & 262684.70 & 7430310.74 \\
\hline 2858 & 260270.41 & 7430685.46 & 260270.23 & 7430685.50 & 260270.54 & 7430685.05 \\
\hline 2955 & 260712.58 & 7430560.57 & 260712.31 & 7430560.26 & 260712.27 & 7430560.82 \\
\hline 2958 & 261610.74 & 7432077.75 & 261608.75 & 7432079.51 & 261609.46 & 7432078.82 \\
\hline 2962 & 261682.62 & 7432136.36 & 261682.19 & 7432136.62 & 261682.43 & 7432136.90 \\
\hline 2965 & 262450.36 & 7433235.86 & 262450.07 & 7433236.46 & 262449.64 & 7433236.04 \\
\hline 2967 & 265402.58 & 7434835.12 & 265403.49 & 7434834.83 & 265403.29 & 7434835.12 \\
\hline 2967 & 265391.65 & 7434838.37 & 265390.68 & 7434839.62 & 265390.47 & 7434839.15 \\
\hline 2976 & 265303.91 & 7434821.80 & 265303.84 & 7434822.28 & 265303.84 & 7434822.35 \\
\hline 2997 & 265080.95 & 7434823.87 & 265079.57 & 7434823.72 & 265080.14 & 7434823.90 \\
\hline 3017 & 264797.55 & 7434792.20 & 264796.28 & 7434792.53 & 264796.41 & 7434792.38 \\
\hline 3034 & 264618.24 & 7434761.37 & 264618.32 & 7434761.74 & 264617.96 & 7434761.20 \\
\hline 3047 & 264346.42 & 7434627.73 & 264345.14 & 7434627.54 & 264345.42 & 7434627.34 \\
\hline 3050 & 264246.80 & 7434585.72 & 264245.16 & 7434584.89 & 264245.42 & 7434584.77 \\
\hline 3051 & 263956.36 & 7434384.40 & 263956.36 & 7434384.86 & 263956.45 & 7434384.70 \\
\hline 3055 & 263913.82 & 7434354.55 & 263913.49 & 7434354.93 & 263913.60 & 7434354.69 \\
\hline 3071 & 263618.03 & 7434155.97 & 263618.51 & 7434156.52 & 263618.88 & 7434156.28 \\
\hline 3071 & 263619.39 & 7434160.25 & 263617.62 & 7434160.32 & 263618.82 & 7434160.69 \\
\hline 3079 & 263482.10 & 7434063.56 & 263481.28 & 7434063.54 & 263481.55 & 7434063.38 \\
\hline 3085 & 263423.65 & 7434076.16 & 263423.20 & 7434076.57 & 263423.61 & 7434076.50 \\
\hline 3092 & 263376.85 & 7433971.88 & 263377.12 & 7433972.42 & 263376.70 & 7433971.56 \\
\hline 3112 & 263255.68 & 7433891.74 & 263256.07 & 7433892.05 & 263255.81 & 7433891.87 \\
\hline 3121 & 263149.23 & 7433800.63 & 263149.16 & 7433801.01 & 263149.86 & 7433801.03 \\
\hline 3135 & 262895.26 & 7433619.75 & 262894.85 & 7433620.01 & 262895.16 & 7433620.35 \\
\hline 3147 & 262750.96 & 7433484.98 & 262751.06 & 7433485.25 & 262751.08 & 7433485.16 \\
\hline 3153 & 262692.36 & 7433428.29 & 262691.99 & 7433428.48 & 262691.98 & 7433428.33 \\
\hline 3158 & 262619.41 & 7433357.43 & 262619.37 & 7433358.03 & 262619.23 & 74333557.54 \\
\hline 3162 & 262577.06 & 7433319.41 & 262576.68 & 7433319.87 & 262577.22 & 7433320.14 \\
\hline 3191 & 265356.96 & 7433347.73 & 265357.11 & 7433348.33 & 265356.79 & 7433347.79 \\
\hline 3193 & 265395.20 & 7433322.40 & 265395.44 & 7433322.61 & 265395.26 & 7433321.87 \\
\hline 3194 & 265376.94 & 7433316.30 & 265377.10 & 7433316.55 & 265377.31 & 7433316.36 \\
\hline 3197 & 265403.16 & 7433287.53 & 265404.24 & 7433288.26 & 265403.95 & 7433287.70 \\
\hline 3213 & 265142.53 & 7433360.42 & 265140.84 & 7433361.04 & 265141.33 & 7433360.66 \\
\hline 3214 & 265138.64 & 7433124.93 & 265138.87 & 7433125.91 & 265138.54 & 7433125.83 \\
\hline 3219 & 265153.50 & 7433006.40 & 265153.02 & 7433008.05 & 265152.80 & 7433007.15 \\
\hline 3220 & 265403.71 & 7432948.67 & 265401.38 & 7432948.72 & 265401.12 & 7432949.15 \\
\hline 3240 & 263908.59 & 7433036.01 & 263907.74 & 7433035.79 & 263908.67 & 7433036.52 \\
\hline 3242 & 263938.73 & 7433002.37 & 263938.61 & 7433002.41 & 263938.76 & 7433002.15 \\
\hline 3253 & 263667.19 & 7433195.54 & 263666.98 & 7433195.73 & 263667.30 & 7433195.56 \\
\hline 3255 & 263564.26 & 7433637.94 & 263564.36 & 7433638.36 & 263564.67 & 7433638.15 \\
\hline 3271 & 263291.80 & 7433362.20 & 263292.16 & 7433362.79 & 263292.28 & 7433362.33 \\
\hline 3280 & 263258.63 & 7433224.09 & 263258.82 & 7433223.95 & 263259.03 & 7433225.03 \\
\hline 3299 & 264689.63 & 7432477.66 & 264688.64 & 7432476.95 & 264688.82 & 7432477.12 \\
\hline 3300 & 264572.85 & 7432245.97 & 264573.19 & 7432247.13 & 264573.07 & 7432246.88 \\
\hline 3310 & 265275.43 & 7432269.44 & 265276.46 & 7432269.84 & 265275.42 & 7432269.38 \\
\hline 3320 & 265418.21 & 7432125.90 & 265417.77 & 7432126.62 & 265418.79 & 7432125.10 \\
\hline 3332 & 264587.41 & 7431791.39 & 264587.84 & 7431791.88 & 264587.64 & 7431791.29 \\
\hline 3335 & 264555.27 & 7431758.42 & 264555.31 & 7431758.26 & 264555.32 & 7431758.31 \\
\hline 3343 & 264250.35 & 7431540.69 & 264250.23 & 7431541.49 & 264250.66 & 7431540.48 \\
\hline 3345 & 264557.21 & 7431711.47 & 264557.72 & 7431711.20 & 264557.45 & 7431711.34 \\
\hline
\end{tabular}




\begin{tabular}{|l|l|l|l|l|l|l|}
\hline 3349 & 264732.32 & 7431310.85 & 264732.26 & 7431310.30 & 264732.44 & 7431310.62 \\
\hline 3354 & 264726.67 & 7431290.19 & 264727.09 & 7431291.03 & 264726.93 & 7431290.59 \\
\hline 3359 & 264903.65 & 7431450.66 & 264903.38 & 7431450.27 & 264903.06 & 7431450.43 \\
\hline 3361 & 265362.04 & 7431550.76 & 265362.05 & 7431550.96 & 265362.24 & 7431551.09 \\
\hline 3365 & 263518.13 & 7431923.18 & 263518.27 & 7431923.74 & 263518.09 & 7431923.41 \\
\hline 3380 & 263032.76 & 7431591.26 & 263032.40 & 7431591.43 & 263032.52 & 7431591.43 \\
\hline 3382 & 262812.91 & 7431509.85 & 262813.69 & 7431510.76 & 262813.49 & 7431509.97 \\
\hline 3390 & 262832.72 & 7431408.36 & 262834.04 & 7431407.86 & 262834.04 & 7431407.69 \\
\hline 3399 & 263175.49 & 7431450.27 & 263175.41 & 7431450.51 & 263175.81 & 7431450.71 \\
\hline 3411 & 263260.79 & 7431308.98 & 263260.29 & 7431310.16 & 263260.41 & 7431310.08 \\
\hline 3420 & 263278.78 & 7431236.68 & 263278.37 & 7431237.09 & 263278.47 & 7431236.68 \\
\hline 3428 & 262956.30 & 7431356.92 & 262957.66 & 7431356.36 & 262957.65 & 7431356.92 \\
\hline 3445 & 262747.22 & 7431308.86 & 262746.44 & 7431309.71 & 262747.78 & 7431309.68 \\
\hline 3471 & 263578.98 & 7431405.72 & 263579.34 & 7431406.36 & 263579.46 & 7431405.51 \\
\hline 3474 & 263731.54 & 7431320.13 & 263731.80 & 7431320.58 & 263732.93 & 7431320.10 \\
\hline 3510 & 263750.58 & 7431017.40 & 263750.64 & 7431017.91 & 263751.02 & 7431017.68 \\
\hline 3523 & 265239.45 & 7430733.26 & 265240.23 & 7430733.18 & 265240.35 & 7430733.13 \\
\hline 3524 & 264710.16 & 7430381.06 & 264710.34 & 7430381.14 & 264710.14 & 7430380.97 \\
\hline 3526 & 262987.28 & 7432192.08 & 262987.17 & 7432192.75 & 262987.52 & 7432192.52 \\
\hline 3541 & 264126.95 & 7432611.02 & 264126.94 & 7432610.99 & 264127.21 & 7432611.05 \\
\hline 3546 & 264278.97 & 7432523.34 & 264278.54 & 7432524.13 & 264279.40 & 7432523.55 \\
\hline 3554 & 263978.17 & 7432435.00 & 263978.10 & 7432433.25 & 263979.23 & 7432435.10 \\
\hline & & & & & &
\end{tabular}

Confrontação das leituras planimétricas nas ortofotos com as observações de referência

$$
\frac{\sum\left(E-E_{r e f}\right)}{n_{p}} \frac{\sum\left(N-N_{r e f}\right)}{n_{p}} \quad \frac{\sum\left(\delta_{E}-\mu_{E}\right)^{2}}{n_{p}-1} \quad \frac{\sum\left(\delta_{N}-\mu_{N}\right)^{2}}{n_{p}-1} \quad \frac{\sum\left(E-E_{r e f}\right)^{2}}{n_{p}-1} \quad \frac{\sum\left(N-N_{r e f}\right)^{2}}{n_{p}-1}
$$

\begin{tabular}{|l|c|c|c|c|c|c|}
\hline & $\mu_{E}$ & $\mu_{N}$ & $\sigma_{\mathrm{E}}$ & $\sigma_{\mathrm{N}}$ & DPE & DPN \\
\hline Op A & -0.16 & -0.12 & 0.6 & 0.4 & 0.79 & 0.65 \\
\hline Op F & 0.02 & -0.54 & 0.54 & 0.56 & 0.54 & 0.78 \\
\hline Op AD & -0.14 & -0.35 & 0.41 & 0.44 & 0.43 & 0.56 \\
\hline
\end{tabular}


Altitudes extraídas do MDE gerado, confrontadas com valores de referência,obtidos por obsrvações em aparelhos estereofotogramétricos analítico digitais sobre modelos em escala 1:5.000.

\begin{tabular}{|c|c|c|c|}
\hline $\mathrm{E}_{\text {ref }}$ & $\mathrm{N}_{\text {ref }}$ & $\mathrm{H}_{\text {ref }}$ & $\mathrm{H}_{\text {MDE }}$ \\
\hline 258682.14 & 7434405.00 & 570.10 & 541.75 \\
\hline 261634.50 & 7432328.98 & 532.98 & 504.82 \\
\hline 260346.26 & 7431502.46 & 576.33 & 549.50 \\
\hline 261431.30 & 7434372.37 & 528.24 & 508.92 \\
\hline 260832.58 & 7434688.76 & 497.11 & 512.52 \\
\hline 262872.79 & 7437565.30 & 514.05 & 529.36 \\
\hline 265426.78 & 7431001.48 & 545.62 & 532.32 \\
\hline 265407.50 & 7431188.64 & 538.14 & 525.03 \\
\hline 264453.77 & 7433121.38 & 532.19 & 519.67 \\
\hline 262536.27 & 7438984.37 & 576.28 & 563.77 \\
\hline 263632.95 & 7431172.07 & 565.34 & 553.50 \\
\hline 259275.44 & 7437885.19 & 521.21 & 532.97 \\
\hline 263129.78 & 7436604.60 & 555.77 & 544.25 \\
\hline 261587.94 & 7436730.67 & 540.19 & 529.32 \\
\hline 264098.34 & 7437371.39 & 535.43 & 546.16 \\
\hline 262634.28 & 7435351.43 & 516.56 & 505.91 \\
\hline 263796.82 & 7436031.79 & 570.59 & 560.06 \\
\hline 263066.65 & 7437007.19 & 543.31 & 532.81 \\
\hline 258882.14 & 7434305.00 & 561.38 & 550.89 \\
\hline 264038.09 & 7438719.82 & 544.69 & 554.93 \\
\hline 258882.58 & 7433059.05 & 508.04 & 497.81 \\
\hline 264498.34 & 7436971.39 & 543.15 & 552.89 \\
\hline 259299.56 & 7434673.30 & 544.66 & 535.03 \\
\hline 264498.18 & 7436292.87 & 547.46 & 556.74 \\
\hline 262536.20 & 7438167.35 & 536.37 & 545.62 \\
\hline 264039.60 & 7435935.77 & 560.22 & 551.02 \\
\hline 262093.45 & 7437744.55 & 548.11 & 557.18 \\
\hline 260941.02 & 7431002.46 & 533.35 & 524.59 \\
\hline 264813.64 & 7434961.66 & 573.49 & 564.76 \\
\hline 259082.58 & 7433347.77 & 505.54 & 496.91 \\
\hline 262434.47 & 7436131.50 & 524.73 & 516.17 \\
\hline 261800.10 & 7435351.82 & 510.26 & 501.91 \\
\hline 258681.47 & 7433517.72 & 541.36 & 533.02 \\
\hline 264649.60 & 7431723.85 & 508.01 & 499.70 \\
\hline 258882.14 & 7433705.00 & 539.52 & 531.25 \\
\hline 261493.74 & 7438339.12 & 572.67 & 580.74 \\
\hline 260627.44 & 7434745.43 & 518.58 & 510.52 \\
\hline 258681.47 & 7432881.28 & 495.30 & 503.11 \\
\hline 260345.86 & 7437573.13 & 553.20 & 561.00 \\
\hline 264498.34 & 7437371.39 & 540.56 & 548.34 \\
\hline 259991.53 & 7434485.81 & 494.16 & 501.84 \\
\hline 261634.50 & 7432722.40 & 515.16 & 522.72 \\
\hline 262493.45 & 7437344.55 & 532.65 & 540.20 \\
\hline 263396.82 & 7436631.79 & 555.03 & 547.61 \\
\hline 263234.53 & 7432015.59 & 540.15 & 532.78 \\
\hline 263155.43 & 7437848.26 & 513.21 & 520.45 \\
\hline 263596.82 & 7436731.79 & 537.13 & 530.02 \\
\hline 259675.44 & 7437485.19 & 535.23 & 542.30 \\
\hline 259475.44 & 7437585.19 & 535.54 & 542.40 \\
\hline 263561.35 & 7438883.17 & 513.00 & 519.73 \\
\hline 264763.07 & 7439242.59 & 523.10 & 529.76 \\
\hline 263454.16 & 7436035.21 & 567.41 & 560.77 \\
\hline
\end{tabular}

\begin{tabular}{|l|l|l|l|}
\hline 264689.52 & 7437072.73 & 542.49 & 549.08 \\
\hline 263254.16 & 7435735.21 & 554.45 & 547.87 \\
\hline 265051.85 & 7431712.64 & 524.09 & 530.67 \\
\hline 264851.70 & 7432752.46 & 514.10 & 520.56 \\
\hline 260625.68 & 7438739.10 & 542.28 & 548.66 \\
\hline 261640.43 & 7430907.27 & 556.22 & 549.86 \\
\hline 265818.23 & 7431550.29 & 521.34 & 527.68 \\
\hline 259240.36 & 7437901.05 & 517.18 & 523.39 \\
\hline 262093.45 & 7437944.55 & 560.73 & 566.89 \\
\hline 263234.64 & 7434474.04 & 542.01 & 535.94 \\
\hline 262634.47 & 7435831.50 & 522.61 & 516.75 \\
\hline 265565.15 & 7436209.60 & 583.67 & 577.82 \\
\hline 263839.60 & 7435835.77 & 558.60 & 552.79 \\
\hline 262669.17 & 7437442.11 & 516.95 & 522.75 \\
\hline 262466.65 & 7436507.19 & 519.80 & 514.24 \\
\hline 262634.28 & 7434751.43 & 555.64 & 550.08 \\
\hline 265218.23 & 7431656.87 & 523.64 & 529.17 \\
\hline 262093.45 & 7437544.55 & 528.61 & 534.11 \\
\hline 265416.93 & 7432253.27 & 550.60 & 556.04 \\
\hline 259440.36 & 7437801.05 & 542.01 & 547.43 \\
\hline 264418.20 & 7436137.27 & 552.02 & 546.62 \\
\hline 263361.35 & 7438585.51 & 513.96 & 519.34 \\
\hline 263561.35 & 7438683.17 & 513.18 & 518.56 \\
\hline 263851.29 & 7434752.76 & 540.61 & 545.98 \\
\hline 260101.64 & 7434667.74 & 508.36 & 503.04 \\
\hline 260625.68 & 7438539.10 & 556.58 & 561.85 \\
\hline 261787.94 & 7436230.67 & 518.25 & 523.52 \\
\hline 260343.90 & 7431102.46 & 533.75 & 538.97 \\
\hline 264249.90 & 7432243.01 & 495.96 & 501.17 \\
\hline 259475.44 & 7437785.19 & 544.51 & 549.71 \\
\hline 264649.60 & 7432123.81 & 515.71 & 520.87 \\
\hline 265211.82 & 7436388.72 & 570.62 & 575.69 \\
\hline 263489.89 & 7437054.77 & 518.76 & 523.82 \\
\hline 262234.47 & 7436031.50 & 507.53 & 512.51 \\
\hline 264852.03 & 7431812.64 & 524.37 & 519.49 \\
\hline 262834.92 & 7432339.04 & 496.57 & 501.44 \\
\hline 260301.91 & 7433579.62 & 531.76 & 536.58 \\
\hline 263561.35 & 7437883.17 & 529.41 & 534.19 \\
\hline 263043.92 & 7435631.53 & 534.57 & 539.31 \\
\hline 264763.07 & 7438842.59 & 547.41 & 552.11 \\
\hline 265709.55 & 7432386.14 & 558.30 & 562.94 \\
\hline 265407.56 & 7430788.70 & 538.30 & 533.66 \\
\hline 265416.93 & 7432653.25 & 547.56 & 542.96 \\
\hline 263066.65 & 7436807.19 & 530.04 & 534.58 \\
\hline 261631.63 & 7432854.35 & 514.49 & 518.96 \\
\hline 264763.07 & 7439042.59 & 533.99 & 538.46 \\
\hline 259701.62 & 7434490.04 & 508.11 & 512.57 \\
\hline 260227.44 & 7434532.03 & 504.54 & 500.13 \\
\hline 263887.26 & 7437464.27 & 540.93 & 545.30 \\
\hline 264644.92 & 7430796.91 & 559.80 & 555.44 \\
\hline 265013.64 & 7435061.66 & 561.11 & 556.79 \\
\hline 263234.64 & 7434074.02 & 556.93 & 561.20 \\
\hline & & & \\
\hline
\end{tabular}

\begin{tabular}{|l|l|l|l|}
\hline 258875.44 & 7437685.19 & 515.56 & 519.78 \\
\hline 262031.28 & 7432523.22 & 505.88 & 501.69 \\
\hline 264038.11 & 7438319.77 & 529.46 & 533.65 \\
\hline 263155.43 & 7438648.26 & 525.04 & 529.17 \\
\hline 263289.89 & 7437154.77 & 521.00 & 525.13 \\
\hline 265207.56 & 7430866.60 & 539.84 & 535.72 \\
\hline 262493.45 & 7437144.55 & 524.85 & 528.97 \\
\hline 264962.99 & 7437877.53 & 586.04 & 590.12 \\
\hline 260301.64 & 7433766.66 & 527.20 & 523.13 \\
\hline 265216.93 & 7432554.97 & 526.34 & 530.39 \\
\hline 260427.44 & 7434832.03 & 508.38 & 504.34 \\
\hline 264762.99 & 7437777.52 & 579.49 & 583.52 \\
\hline 264244.92 & 7430796.91 & 525.70 & 529.73 \\
\hline 263069.18 & 7437465.30 & 521.93 & 525.93 \\
\hline 261831.28 & 7432638.90 & 514.72 & 518.70 \\
\hline 262493.45 & 7437944.55 & 543.69 & 547.64 \\
\hline 263329.78 & 7437104.60 & 530.34 & 526.49 \\
\hline 262666.65 & 7436807.19 & 507.26 & 511.10 \\
\hline 264298.34 & 7437071.39 & 540.61 & 544.44 \\
\hline 261234.48 & 7432922.36 & 509.46 & 505.65 \\
\hline 264251.30 & 7433014.45 & 519.67 & 523.44 \\
\hline 264449.60 & 7432023.81 & 508.29 & 504.52 \\
\hline 262736.20 & 7438467.35 & 559.92 & 563.68 \\
\hline 264845.60 & 7430128.05 & 550.74 & 554.50 \\
\hline 263761.35 & 7438583.17 & 524.66 & 528.41 \\
\hline 264049.31 & 7430694.65 & 551.10 & 547.36 \\
\hline 265019.10 & 7433440.02 & 524.02 & 527.75 \\
\hline 264651.70 & 7432252.46 & 528.44 & 532.12 \\
\hline 262955.43 & 7438548.26 & 540.09 & 543.76 \\
\hline 262634.47 & 7435631.50 & 523.25 & 519.60 \\
\hline 264080.78 & 7437018.31 & 548.99 & 552.60 \\
\hline 259240.36 & 7438701.05 & 545.47 & 549.07 \\
\hline 264052.94 & 7432383.52 & 505.07 & 501.50 \\
\hline 259791.53 & 7434432.77 & 505.50 & 509.06 \\
\hline 263858.26 & 7431929.60 & 515.85 & 519.37 \\
\hline 261209.38 & 7431495.35 & 513.85 & 510.34 \\
\hline 264449.60 & 7431601.13 & 495.43 & 498.92 \\
\hline 260227.44 & 7434732.03 & 508.00 & 504.53 \\
\hline 262236.35 & 7435370.55 & 503.15 & 506.61 \\
\hline 260432.58 & 7434074.02 & 517.19 & 520.65 \\
\hline 263880.78 & 7436118.31 & 556.49 & 559.93 \\
\hline 262032.04 & 7430570.99 & 549.93 & 546.55 \\
\hline 261831.28 & 7432406.78 & 494.76 & 498.10 \\
\hline 262434.44 & 7432542.36 & 502.09 & 498.75 \\
\hline 260825.68 & 7438639.10 & 566.07 & 569.40 \\
\hline 264851.83 & 7432012.64 & 534.43 & 531.11 \\
\hline 259985.93 & 7434932.77 & 502.38 & 505.69 \\
\hline 262843.92 & 7435931.53 & 525.17 & 528.47 \\
\hline 262869.18 & 7437765.30 & 510.31 & 513.58 \\
\hline 262536.20 & 7437767.35 & 545.71 & 548.97 \\
\hline 259640.36 & 7438701.05 & 525.09 & 528.33 \\
\hline 262834.28 & 7435251.43 & 511.74 & 514.96 \\
\hline 265509.00 & 7433418.42 & 547.73 & 550.94 \\
\hline & & & \\
\hline
\end{tabular}




\begin{tabular}{|c|c|c|c|}
\hline & & & \\
\hline & & & \\
\hline & & & \\
\hline & & 0 & \\
\hline & & & \\
\hline & 37 & 536 & \\
\hline & & 531.74 & \\
\hline 36 & 7438 & & \\
\hline 97 & 7438 & 524.29 & \\
\hline 00 & 7433 & & \\
\hline 30 & 7432 & 527.97 & \\
\hline 23 & 7431 & & \\
\hline 50 & 7432 & 495.5 & \\
\hline 41 & 7436 & & \\
\hline 32 & 7435 & 563 & \\
\hline 93 & 7432 & & \\
\hline & & & \\
\hline 47 & 7435 & & \\
\hline & 7432 & & \\
\hline 51 & 7431 & & \\
\hline & 743 & & \\
\hline 27 & 7433 & 524.32 & \\
\hline & 7432 & & \\
\hline & 7432 & 510.97 & \\
\hline 04 & 7431 & & \\
\hline & 7436 & & \\
\hline 35 & 7438 & 519 & \\
\hline & 7435 & & \\
\hline 82 & 7436 & 533 & \\
\hline 8 & 7436 & & \\
\hline .10 & 7433 & 518.74 & \\
\hline 34 & 743 & & \\
\hline 00 & 7433 & 553 & \\
\hline 18 & 7437 & & \\
\hline & 27 & & \\
\hline 41 & 7436 & & \\
\hline & & & \\
\hline & 7433 & 549 & \\
\hline & & & \\
\hline & 7432 & 545 & \\
\hline & 7435 & & \\
\hline & 7431 & 524 & \\
\hline & 7431 & 532.42 & \\
\hline & 7435 & & \\
\hline 20 & 7436 & & 564. \\
\hline & 7430 & & \\
\hline & 7437 & & \\
\hline & 7436 & & \\
\hline .18 & 7437 & 517 & 520. \\
\hline & 7433 & & \\
\hline & 7437 & & 547. \\
\hline 94 & 7432 & 501 & 504 \\
\hline & 7431 & & \\
\hline & 7433 & 558.78 & 561. \\
\hline & 7437 & & \\
\hline & 7433 & & \\
\hline & 7430 & 541.14 & 345.1 \\
\hline & & & 5 \\
\hline
\end{tabular}

\begin{tabular}{|c|c|c|c|c|c|c|c|}
\hline 259675.41 & 7436068.02 & 594.72 & 592.14 & 262493.45 & 7437744.55 & 547.25 & 549.51 \\
\hline 264613.72 & 7435646.30 & 530.70 & 528.12 & 264098.34 & 7437571.39 & 552.24 & 554.50 \\
\hline 260832.64 & 7433476.16 & 524.42 & 527.00 & 263652.94 & 7432532.42 & 499.11 & 501.37 \\
\hline 263432.95 & 7430872.07 & 528.38 & 530.96 & 264251.30 & 7433414.43 & 529.09 & 531.35 \\
\hline 263489.89 & 7437293.83 & 523.72 & 526.30 & 263838.11 & 7437819.77 & 557.44 & 559.69 \\
\hline 260627.44 & 7435345.43 & 509.08 & 511.63 & 264038.11 & 7437919.77 & 555.23 & 557.47 \\
\hline 262834.28 & 7435051.43 & 525.60 & 528.15 & 262493.45 & 7436944.55 & 519.61 & 521.84 \\
\hline 264058.26 & 7431829.60 & 513.01 & 515.56 & 263858.26 & 7432129.60 & 504.45 & 506.68 \\
\hline 261093.74 & 7437939.12 & 599.40 & 601.94 & 263887.26 & 7437064.27 & 543.33 & 545.56 \\
\hline 262434.44 & 7432139.42 & 510.81 & 513.35 & 264244.92 & 7430596.91 & 536.52 & \begin{tabular}{|l|}
538.74 \\
\end{tabular} \\
\hline 261234.50 & 7432522.40 & 511.96 & 509.42 & 263852.30 & 7433599.97 & 532.25 & 534.46 \\
\hline 260632.64 & 7433576.16 & 528.92 & 531.45 & 262032.04 & 7431170.99 & 537.39 & \begin{tabular}{|l|}
535.19 \\
\end{tabular} \\
\hline 263234.64 & 77434874.04 & 526.43 & 528.96 & 261587.94 & 7436530.67 & 534.21 & 536.41 \\
\hline 263396.82 & 7437031.79 & 527.33 & 524.81 & 262936.27 & 7438584.37 & 535.32 & 537.52 \\
\hline 263632.95 & 7430972.07 & 541.80 & 544.32 & 262433.81 & 7433067.79 & 538.34 & 540.54 \\
\hline 261431.30 & 7434046.55 & 493.60 & 496.12 & 264644.92 & 7430996.91 & 535.80 & 537.99 \\
\hline 265051.70 & 7432852.46 & 532.32 & 534.84 & 262201.27 & 7433349.42 & 525.02 & 522.83 \\
\hline 264238.05 & 7437831.77 & 557.49 & 560.00 & 265565.15 & 7435409.60 & 583.27 & 581.09 \\
\hline 263652.94 & 7432332.42 & 501.47 & 503.98 & 260145.38 & 7438539.05 & 548.34 & 550.52 \\
\hline \begin{tabular}{|l|}
262666.65 \\
\end{tabular} & 7436207.19 & 529.00 & 531.50 & 261293.74 & 7437839.12 & 591.70 & 593.88 \\
\hline 261209.38 & 7430495.35 & 527.65 & 525.16 & 261631.61 & 7433671.75 & 495.25 & 497.41 \\
\hline 261787.94 & 7436630.67 & 528.87 & 531.36 & 260301.91 & 7433179.62 & 539.42 & 541.57 \\
\hline 262736.20 & 7438667.35 & 559.81 & 562.29 & 263687.26 & 7437164.27 & 524.05 & 526.19 \\
\hline 263651.29 & 7434652.76 & 546.49 & 548.94 & 259475.44 & 7437385.19 & 538.41 & 540.55 \\
\hline 265044.92 & 7430796.91 & 546.94 & 549.38 & 263232.84 & 7432977.45 & 531.64 & 533.78 \\
\hline 262429.81 & 7431953.10 & 517.91 & 520.33 & 263851.83 & 7434378.97 & 561.59 & 563.71 \\
\hline 260825.68 & 7438439.10 & 567.80 & 570.21 & 264652.13 & 7433016.30 & 511.39 & 513.51 \\
\hline 259875.41 & 7436368.02 & 581.60 & 579.19 & 260343.90 & 7431302.46 & 545.21 & 547.32 \\
\hline 263454.16 & 7435835.21 & 554.11 & 556.52 & 263129.78 & 7436804.60 & 530.01 & 532.12 \\
\hline 262031.28 & 7432323.22 & 506.92 & 509.33 & 264049.31 & 7431094.65 & 526.22 & 528.33 \\
\hline 264844.92 & 7431296.91 & 526.18 & 528.58 & 259475.41 & 7436368.02 & 591.26 & 589.16 \\
\hline 262434.28 & 7434651.43 & 555.60 & 553.20 & 263852.30 & 7433199.97 & 535.83 & 537.93 \\
\hline 263361.35 & 7437983.17 & 515.03 & 517.43 & 264444.92 & 7430896.91 & 540.48 & 542.57 \\
\hline 264763.07 & 7438642.59 & 551.03 & 553.43 & 260543.90 & 7430602.46 & 549.47 & 551.55 \\
\hline 264649.60 & 7431323.81 & 522.69 & 525.09 & 263761.35 & 7438383.17 & 524.87 & 526.94 \\
\hline 263043.92 & 7436031.53 & 528.25 & 530.64 & 263852.94 & 7432432.42 & 503.69 & 505.76 \\
\hline 263687.26 & 7437764.27 & 543.57 & 545.96 & 262736.27 & 7439284.37 & 550.18 & 552.24 \\
\hline 265051.85 & 7431912.64 & 544.97 & 542.59 & 264058.26 & 7432029.60 & 503.85 & 505.91 \\
\hline 261232.64 & 7434270.15 & 499.07 & 501.45 & 263329.78 & 7436904.60 & 532.83 & 534.89 \\
\hline 263129.78 & 7436204.60 & 545.27 & 547.65 & 259082.58 & 7433516.85 & 504.64 & 502.60 \\
\hline 263887.26 & 7437864.27 & 563.89 & 566.27 & 262231.28 & 7432635.94 & 506.78 & 508.81 \\
\hline 265818.23 & 7432356.87 & 558.78 & 561.16 & 262001.27 & 7433249.42 & 518.52 & 520.55 \\
\hline 260145.38 & 7438339.05 & 571.17 & 573.54 & 260345.38 & 7438039.05 & 580.43 & 582.45 \\
\hline 261587.94 & 7436130.67 & 526.57 & 528.94 & 264649.60 & 7431515.95 & 498.89 & 500.90 \\
\hline 263880.78 & 7437118.31 & 537.79 & 540.15 & 264649.60 & 7431923.81 & 498.41 & 500.42 \\
\hline 263254.16 & 7435335.21 & 506.73 & 509.09 & 265309.00 & 7433318.42 & 539.07 & 541.08 \\
\hline 260543.90 & 7431202.46 & 522.93 & 525.28 & 261293.74 & 7438239.12 & 583.79 & 585.79 \\
\hline 262866.65 & 7436307.19 & 533.84 & 536.19 & 261631.63 & 7433455.15 & 495.83 & 497.83 \\
\hline 264690.39 & 7437472.73 & 548.74 & 551.09 & 262093.45 & 7437344.55 & 517.79 & 519.79 \\
\hline 263043.92 & 7435831.53 & 541.81 & 544.15 & 258875.44 & 7437885.19 & 524.79 & 526.78 \\
\hline 263651.93 & 7434078.95 & 571.79 & 574.11 & 260745.86 & 7437773.11 & 591.24 & 593.23 \\
\hline 261587.94 & 7436930.67 & 545.11 & 547.42 & 263596.82 & 7436331.79 & 554.01 & 556.00 \\
\hline 264563.07 & 7439342.59 & 527.18 & 524.88 & 264249.60 & 7431723.81 & 520.77 & 522.76 \\
\hline 259299.56 & 7434873.30 & 548.22 & 545.93 & 264851.85 & 7432212.66 & 539.97 & 541.96 \\
\hline 263129.78 & 7437004.60 & 532.90 & 535.19 & 263849.31 & 7430794.65 & 545.06 & 543.07 \\
\hline 261032.64 & 7432976.16 & 507.58 & 509.87 & 260301.64 & 7433966.66 & 515.82 & 513.84 \\
\hline 265709.55 & 7432586.14 & 552.36 & 554.65 & 262031.92 & 7431941.26 & 524.00 & \begin{tabular}{|l|}
525.97 \\
\end{tabular} \\
\hline 263232.84 & 7433577.45 & 573.14 & 575.42 & 263433.55 & 7431728.02 & 535.93 & 537.90 \\
\hline
\end{tabular}




\begin{tabular}{|c|c|c|c|}
\hline & & & \\
\hline & & 7 & \\
\hline & & & \\
\hline & & 530.63 & \\
\hline & & 547.64 & \\
\hline & & 513.63 & \\
\hline 0 & & 530.80 & \\
\hline 95 & & 529.28 & \\
\hline 4 & & 508.29 & \\
\hline 49 & & 559.21 & \\
\hline 35 & & 540.83 & \\
\hline 07 & & 559.15 & \\
\hline 31 & & 534.0 & \\
\hline 05 & & 534.68 & \\
\hline & & 545.4 & \\
\hline 62 & & 499.51 & \\
\hline & & 498.6 & \\
\hline 23 & & 537.84 & \\
\hline & & 521.89 & \\
\hline 35 & & 531.45 & \\
\hline 0 & & 521.98 & \\
\hline 36 & & 542.60 & \\
\hline 35 & & 544.95 & \\
\hline & & 545.6 & \\
\hline 17 & & 514.06 & \\
\hline 53 & & $526.1 \mathrm{~s}$ & \\
\hline 60 & & 512.65 & \\
\hline 47 & & 499.84 & \\
\hline 06 & & 516.03 & \\
\hline 41 & & 585.8 & \\
\hline 06 & & 508.37 & \\
\hline 50 & & 509.66 & \\
\hline 86 & & 576.00 & \\
\hline 16 & & 502.34 & \\
\hline & & 539.99 & \\
\hline 50 & & 502.03 & \\
\hline 41 & & 593.18 & \\
\hline 20 & & 540.68 & \\
\hline 18 & & 571.34 & \\
\hline .44 & 5.19 & 564.14 & \\
\hline 44 & & 496.87 & \\
\hline .29 & & 516.85 & \\
\hline 86 & & 569.16 & \\
\hline .28 & & 512.34 & \\
\hline 60 & & 519.82 & \\
\hline .99 & & 543.29 & \\
\hline 86 & & 583.12 & \\
\hline 16 & & 512.98 & \\
\hline & 743 & 509.2 & \\
\hline & & 511.03 & \\
\hline & & 526.4 & \\
\hline & & 512.43 & \\
\hline & & & \\
\hline .91 & 743 & 531.60 & \\
\hline & & 498.82 & \\
\hline & 7433 & 503.78 & \\
\hline & & 510.02 & \\
\hline & & & \\
\hline
\end{tabular}

\begin{tabular}{|c|c|c|c|c|c|c|c|}
\hline 264452.13 & 7433316.30 & 510.77 & 512.52 & 264762.99 & 7438377.52 & 551.09 & 552.67 \\
\hline 262032.06 & 7436093.58 & 522.81 & 524.55 & 265051.70 & 7432452.46 & 546.44 & 544.88 \\
\hline 264098.34 & 7437971.39 & 551.81 & 553.55 & 261093.74 & 7438339.12 & 588.66 & 590.22 \\
\hline 262869.18 & 7437165.30 & 510.51 & 512.24 & 263361.35 & 7437783.17 & 525.63 & 527.19 \\
\hline 262429.81 & 7431753.10 & 518.59 & 520.32 & 264451.88 & 7434079.03 & 526.52 & 528.08 \\
\hline 261234.50 & 7432122.40 & 501.22 & 502.95 & 264762.99 & 7438177.52 & 564.55 & 566.10 \\
\hline 264249.90 & 7432643.01 & 518.00 & 519.72 & 260832.58 & 7433674.02 & 521.01 & 519.46 \\
\hline 262466.65 & 7436907.19 & 518.44 & 520.16 & 260345.86 & 7437173.13 & 563.06 & 564.60 \\
\hline 263433.55 & 7431928.02 & 533.21 & 534.93 & 260625.68 & 7437739.10 & 583.66 & \begin{tabular}{|l}
585.20 \\
\end{tabular} \\
\hline 261434.16 & 7433132.93 & 499.48 & 501.19 & 263561.35 & 7438483.17 & 523.16 & 524.70 \\
\hline 261093.74 & 7437739.12 & 599.33 & \begin{tabular}{|l|}
601.04 \\
\end{tabular} & 259499.56 & 7434773.30 & 527.60 & 529.14 \\
\hline 265818.23 & 7431756.87 & 537.42 & \begin{tabular}{|l}
539.12 \\
\end{tabular} & 261493.74 & 7438539.12 & 595.92 & 597.45 \\
\hline 259701.62 & 7434090.04 & 503.35 & 505.05 & 263796.82 & 7436631.79 & 535.55 & 537.08 \\
\hline 260743.90 & 7430502.46 & 553.53 & 555.22 & 262493.45 & 7437544.55 & 529.73 & 531.26 \\
\hline 261431.30 & 7433772.39 & 504.14 & 505.83 & 264651.70 & 7432652.80 & 528.70 & 527.18 \\
\hline 260825.68 & 7438039.10 & 593.21 & 594.90 & 262232.06 & 7436993.58 & 520.23 & 521.75 \\
\hline 262232.06 & 7436593.58 & 515.79 & 517.47 & 263034.28 & 7434951.43 & 530.30 & 531.81 \\
\hline 260227.44 & 7434932.03 & 508.00 & 509.68 & 264615.84 & 7433920.32 & 512.52 & 514.03 \\
\hline 261493.74 & 7437739.12 & 556.57 & 558.25 & 260825.68 & 7437839.10 & 596.60 & 598.10 \\
\hline \begin{tabular}{|l|}
262293.45 \\
\end{tabular} & 7437244.55 & 531.81 & 533.48 & \begin{tabular}{|l|}
261293.74 \\
\end{tabular} & 7438439.12 & 591.52 & 593.02 \\
\hline \begin{tabular}{|l|}
263880.78 \\
\end{tabular} & 7436518.31 & 542.09 & 543.76 & 262032.06 & 7436693.58 & 522.69 & \begin{tabular}{|l|}
524.19 \\
\end{tabular} \\
\hline 263651.83 & 7433878.97 & 549.49 & 551.16 & 262669.17 & 7437042.11 & 510.13 & 511.63 \\
\hline 264051.30 & 7433314.43 & 532.71 & 534.38 & 263066.65 & 7436207.19 & 547.17 & 548.67 \\
\hline 265418.23 & 7432156.87 & 555.80 & 557.46 & 262829.51 & 7431166.71 & 513.93 & 515.43 \\
\hline 264651.70 & 7432852.46 & 509.06 & 510.72 & 263858.26 & 7431529.60 & 529.47 & 530.96 \\
\hline 259875.44 & 7437385.19 & 536.50 & 538.16 & 262231.92 & 7431641.26 & 534.32 & 535.81 \\
\hline 261831.28 & 7432838.92 & 514.72 & \begin{tabular}{|l|}
516.38 \\
\end{tabular} & 263234.92 & 7432498.98 & 497.19 & 498.67 \\
\hline 262293.45 & 7437844.55 & 560.11 & 561.77 & 264449.90 & 7432343.01 & 524.26 & 525.74 \\
\hline 263029.51 & 7431066.71 & 523.39 & 525.05 & 263034.28 & 7435351.43 & 511.38 & 512.85 \\
\hline 263254.16 & 7435935.21 & 546.81 & 548.46 & 264613.72 & 7435446.30 & 539.72 & 541.19 \\
\hline 261293.74 & 7438039.12 & 587.11 & 588.76 & 265162.99 & 7437977.52 & 578.88 & 580.35 \\
\hline 262293.45 & 7437444.55 & 538.37 & 540.02 & 263432.95 & 7431072.07 & 536.04 & 537.51 \\
\hline 261634.50 & 7432522.38 & 504.46 & 506.10 & \begin{tabular}{|l|}
262293.45 \\
\end{tabular} & 7438044.55 & 560.13 & 561.59 \\
\hline 260743.90 & 7430902.46 & 525.09 & 526.73 & \begin{tabular}{|l}
259701.62 \\
\end{tabular} & 7433690.04 & 513.67 & 512.21 \\
\hline 264039.60 & 7435535.77 & 521.60 & 523.24 & 263639.60 & 7435735.77 & 544.40 & 542.94 \\
\hline 264218.20 & 7436441.35 & 560.00 & 561.64 & 265218.23 & 7432056.87 & 547.10 & 548.56 \\
\hline 264762.99 & 7438577.52 & 551.45 & 553.09 & 260743.90 & 7430702.46 & 531.87 & 533.32 \\
\hline 262031.28 & 7432123.22 & 516.70 & 518.32 & 262466.65 & 7436107.19 & 511.90 & 513.35 \\
\hline 263887.26 & 7437664.27 & 562.15 & 560.54 & 265216.93 & 7432754.97 & 533.52 & 534.97 \\
\hline 262634.44 & 7432839.42 & 517.77 & 519.38 & 262434.47 & 7435531.50 & 509.87 & 511.32 \\
\hline 264251.30 & 7433214.43 & 520.89 & 522.50 & 264298.34 & 7437471.39 & 553.95 & 555.40 \\
\hline 261032.64 & 7434370.15 & 496.85 & 498.46 & 263032.84 & 7433077.45 & 531.96 & 533.41 \\
\hline 258875.44 & 7437485.19 & 519.65 & 521.25 & 262434.28 & 7434851.43 & 541.56 & 543.00 \\
\hline 261831.63 & 7432954.35 & 515.03 & 516.63 & 262829.51 & 7430966.71 & 509.87 & 511.31 \\
\hline 262031.28 & 7432123.22 & 516.72 & 518.32 & 264889.84 & 7437178.16 & 556.07 & 557.51 \\
\hline 265207.56 & 7431066.60 & 541.94 & 543.54 & \begin{tabular}{|l}
262201.27 \\
\end{tabular} & 7432949.42 & 537.98 & 539.42 \\
\hline 259275.41 & 7436268.02 & 582.76 & 581.17 & 262434.28 & 7435051.43 & 522.42 & 523.85 \\
\hline 261633.80 & 7431300.81 & 522.29 & 523.88 & 263129.78 & 7436404.60 & 546.03 & 547.46 \\
\hline 264098.34 & 7437171.39 & 536.13 & 537.72 & 259299.56 & 7435473.30 & 548.80 & \begin{tabular}{|l|l|}
547.37 \\
\end{tabular} \\
\hline 263852.30 & 7433399.97 & 542.85 & 544.44 & 261093.74 & 7438739.12 & 573.32 & 574.75 \\
\hline 265709.00 & 7433318.42 & 555.17 & 556.76 & 264444.92 & 7430696.91 & 528.20 & 529.63 \\
\hline 263858.26 & 7431329.60 & 540.33 & 541.92 & 264845.60 & 7430528.05 & 547.60 & 546.18 \\
\hline 264963.07 & 7439342.59 & 523.50 & 521.92 & 261633.80 & 7431900.81 & 520.65 & 522.07 \\
\hline 261232.64 & 7434070.15 & 504.59 & 506.17 & 262536.20 & 7438367.35 & 558.56 & 559.98 \\
\hline 263838.11 & 7438019.77 & 554.77 & 556.35 & 263652.30 & 7433499.97 & 557.41 & 558.83 \\
\hline 264452.13 & 7432916.30 & 505.25 & 506.83 & 261431.30 & 7434172.37 & 495.76 & 497.18 \\
\hline 265509.00 & 7433218.42 & 557.79 & 556.21 & 259075.44 & 7437185.19 & 547.88 & 549.30 \\
\hline 262736.20 & 7437867.35 & 521.58 & 523.16 & 259440.36 & 7438401.05 & 519.01 & 520.43 \\
\hline
\end{tabular}




\begin{tabular}{|c|c|c|c|}
\hline & & & \\
\hline & & & \\
\hline & & & \\
\hline & & 39.51 & \\
\hline & & 553 & \\
\hline & & 537 & \\
\hline 30 & & 499.62 & \\
\hline 28 & & 538.94 & \\
\hline 44 & & 547.19 & \\
\hline & & & \\
\hline 64 & & 530.16 & \\
\hline 89 & & 537.38 & \\
\hline & & 531.40 & \\
\hline 11 & & 8.33 & \\
\hline & & 523.1 & \\
\hline 34 & & 544.10 & \\
\hline & & 537.0 & \\
\hline 60 & & 530.90 & \\
\hline & & & \\
\hline 58 & & 505.05 & \\
\hline 0 & & 519.14 & \\
\hline & & 540.2 & \\
\hline 60 & & 529.16 & \\
\hline & & 512 & \\
\hline 41 & & 580.48 & \\
\hline$\underline{0}$ & & & \\
\hline 44 & .03 & 521.54 & \\
\hline 3 & & & \\
\hline 43 & & 507.58 & \\
\hline 1 & & 534.4 & \\
\hline 55 & & 524.13 & \\
\hline 8 & & 523.04 & \\
\hline 8 & & & \\
\hline 14 & & 499.71 & \\
\hline 4 & & & \\
\hline 53 & & 514.21 & \\
\hline & & & \\
\hline 6 & & 524.45 & \\
\hline 43 & & & \\
\hline .80 & & 531.61 & \\
\hline 4 & & 518 & \\
\hline 55 & & 539.63 & \\
\hline 8 & & 529.45 & \\
\hline 55 & & & \\
\hline 50 & & 530.22 & \\
\hline 44 & & & \\
\hline 55 & & 510.3 & \\
\hline 99 & & 572.44 & \\
\hline 0 & & 544.9 & \\
\hline 30 & & 517.60 & \\
\hline & & 534.1 & \\
\hline 30 & & 519.43 & 520 \\
\hline & & 513.75 & \\
\hline 18 & 743 & 574.07 & 575. \\
\hline & & & \\
\hline & 7433 & 533.47 & \\
\hline 90 & & 544.67 & \\
\hline & & & \\
\hline
\end{tabular}

\begin{tabular}{|c|c|c|c|c|c|c|c|}
\hline 264298.18 & 7436792.87 & 565.29 & 566.60 & 262634.28 & 7435151.43 & 523.30 & 524.48 \\
\hline 265309.00 & 7432918.42 & 551.81 & 553.12 & 260627.44 & 7434945.43 & 512.00 & 513.18 \\
\hline 259075.44 & $\begin{array}{l}7437985.19 \\
\end{array}$ & 535.59 & 536.90 & 263880.78 & 7436318.31 & 558.57 & 557.40 \\
\hline 263687.26 & 7437564.27 & 545.96 & 547.27 & 264651.70 & 7432452.04 & 539.84 & 538.67 \\
\hline 263838.11 & 7438219.77 & 539.72 & 541.03 & 264849.60 & 7431440.01 & 521.05 & 522.22 \\
\hline 265364.91 & 7435265.59 & 563.71 & 565.02 & 262629.81 & 7431653.10 & 511.21 & 512.38 \\
\hline 264249.60 & 7431323.81 & 517.69 & 519.00 & 262834.92 & 7432539.04 & 500.99 & 502.16 \\
\hline \begin{tabular}{|l|}
260432.58 \\
\end{tabular} & 7433874.02 & 524.55 & 525.85 & 263254.16 & 7436335.21 & 554.83 & 556.00 \\
\hline 263034.53 & 7431515.59 & 513.77 & 515.07 & 263851.29 & 7435152.76 & 531.11 & 532.28 \\
\hline 263838.11 & 7438619.77 & 532.76 & 534.06 & 258882.14 & 7433905.00 & 539.82 & \begin{tabular}{|l|}
538.66 \\
\end{tabular} \\
\hline 264445.60 & 7430128.05 & 560.84 & 562.14 & 263396.82 & 7436431.79 & 551.41 & 552.57 \\
\hline 263794.00 & 7436831.79 & 549.67 & 550.96 & 262833.81 & 7433267.79 & 550.56 & 551.72 \\
\hline 261831.63 & 7433354.35 & 502.59 & 503.88 & 263234.53 & 7431815.59 & 530.49 & 529.33 \\
\hline 262634.44 & 7432439.42 & 502.77 & 504.06 & 263029.51 & 7431266.71 & 527.83 & 528.99 \\
\hline 262633.81 & 7433567.79 & 534.22 & 535.51 & 260501.91 & 7433279.62 & 545.30 & 546.45 \\
\hline 263234.53 & 7431415.59 & 528.69 & 529.98 & 260145.38 & 7437939.05 & 571.07 & 572.22 \\
\hline 264058.26 & 7431629.60 & 526.69 & 527.98 & 264298.34 & 7437671.39 & 562.99 & 564.14 \\
\hline 260625.68 & 7437939.10 & 592.68 & 593.96 & 264762.99 & 7437977.52 & 564.32 & 565.47 \\
\hline 259275.44 & 7437485.19 & 525.82 & 527.10 & 264644.92 & 7431196.91 & 527.20 & 528.35 \\
\hline 261800.90 & 7433983.98 & 529.23 & 530.51 & 265219.10 & 7432940.02 & 537.40 & 538.55 \\
\hline 262829.51 & 7430766.71 & 517.19 & 518.47 & 263254.16 & 7436135.21 & 546.31 & 547.45 \\
\hline 264051.83 & 7434278.97 & 550.71 & 551.99 & 262829.81 & 7431953.10 & 495.77 & 496.91 \\
\hline 263633.55 & 7432028.02 & 516.79 & 518.06 & 264052.94 & 7432134.02 & 505.53 & 506.67 \\
\hline 264819.10 & 7433740.02 & 514.78 & 516.05 & 259071.93 & 7434602.86 & 546.52 & 545.38 \\
\hline 264363.07 & 77438642.59 & 537.93 & 539.19 & 264819.10 & 7433340.02 & 540.04 & 538.90 \\
\hline 261032.64 & 7433376.16 & 520.04 & 521.30 & 259282.58 & 7433216.85 & 503.82 & 504.96 \\
\hline 261032.64 & 7434170.15 & 506.47 & 507.73 & 263432.95 & 7430672.07 & 518.26 & 519.40 \\
\hline 259791.53 & 7434632.77 & 519.22 & 520.47 & 263833.55 & 7431528.02 & 529.59 & 530.73 \\
\hline 262834.92 & 7432739.04 & 505.61 & 506.86 & 263651.29 & 7435252.76 & 522.31 & 523.44 \\
\hline 259475.44 & 7437185.19 & 553.17 & 554.41 & 261209.38 & 7430695.35 & 518.37 & 517.24 \\
\hline \begin{tabular}{|l|}
261093.74 \\
\end{tabular} & 7438139.12 & 592.22 & 593.46 & 260825.68 & 7438239.10 & 579.78 & 580.91 \\
\hline 262736.27 & 7438684.37 & 561.86 & 563.10 & 265013.72 & 7435474.16 & 533.74 & 534.87 \\
\hline 262736.27 & 7439084.37 & 558.10 & 559.34 & 259271.93 & 7434088.06 & 515.14 & 516.26 \\
\hline 263289.89 & 7437554.77 & 531.48 & 532.72 & 262869.18 & 7436965.30 & 528.01 & 529.13 \\
\hline 263034.92 & 7432239.04 & 511.67 & 512.91 & 262432.04 & 7430970.99 & 511.77 & 512.89 \\
\hline 260627.44 & 7434545.43 & 497.70 & 498.93 & 263852.30 & 7432999.97 & 518.47 & 519.59 \\
\hline 262536.27 & 7438584.37 & 575.00 & 576.23 & 265709.55 & 7432786.14 & 557.86 & 558.98 \\
\hline 262929.78 & 7436704.60 & 522.90 & 524.13 & 261431.30 & 7434772.55 & 514.80 & 515.91 \\
\hline 262000.90 & 7433884.04 & 545.71 & 546.94 & 262536.20 & 7437967.35 & 541.76 & 542.87 \\
\hline 261831.63 & 7433154.35 & 511.51 & 512.73 & 263880.78 & 7436918.31 & 552.29 & 553.40 \\
\hline 262231.92 & 7432041.26 & 523.98 & 525.20 & 264098.34 & 7437771.39 & 565.87 & 566.98 \\
\hline 265709.00 & 7433119.12 & 571.17 & 569.95 & 262232.04 & 7430870.99 & 523.37 & 524.48 \\
\hline 264449.90 & 7432743.01 & 520.92 & 522.13 & 264445.60 & 7430328.05 & 549.18 & 548.07 \\
\hline 260745.86 & 7437173.11 & 575.96 & 577.17 & 260345.86 & 7437373.15 & 565.32 & 566.43 \\
\hline 264644.92 & 7430596.91 & 555.08 & 556.29 & 260745.86 & 7437373.11 & 581.44 & 582.55 \\
\hline 262632.72 & 7430533.35 & 529.54 & 530.74 & 262832.72 & 7430233.43 & 524.12 & 523.02 \\
\hline 264449.60 & 7432223.81 & 505.29 & 506.49 & 265418.23 & 7431556.87 & 536.16 & 535.06 \\
\hline 261587.94 & 7436330.67 & 549.33 & 550.53 & 261293.74 & 7438639.12 & 594.85 & 595.95 \\
\hline 262034.47 & 7435931.50 & 515.69 & 516.89 & 261787.94 & 7436830.67 & 540.91 & 542.01 \\
\hline 264251.88 & 7434379.03 & 556.84 & 558.04 & 262834.28 & 7435451.43 & 514.56 & 515.66 \\
\hline 265618.23 & 7431656.87 & 534.72 & 533.53 & 264498.34 & 7437571.39 & 559.56 & 560.66 \\
\hline 262634.47 & 7436031.50 & 511.25 & 512.44 & 264889.84 & 7436978.16 & 555.66 & 556.76 \\
\hline 258681.47 & 7433117.70 & 503.98 & 505.17 & 265219.39 & 7432256.87 & 554.94 & 553.85 \\
\hline 261631.63 & 7433054.35 & 506.27 & 507.46 & 260543.90 & 7431002.46 & 533.75 & 534.84 \\
\hline 262434.28 & 7435251.43 & 510.42 & 511.61 & 262234.47 & 7435831.50 & 511.75 & 512.84 \\
\hline 261440.43 & 7430804.37 & 543.30 & 542.11 & 262936.27 & 7438784.37 & 553.88 & 554.97 \\
\hline 262834.28 & 7434851.43 & 542.36 & 543.55 & 263155.43 & 7438448.26 & \begin{tabular}{|l|}
525.28 \\
\end{tabular} & \begin{tabular}{|l|}
526.37 \\
\end{tabular} \\
\hline 264363.07 & 7439042.59 & 517.33 & 518.52 & 264298.18 & 7436392.87 & 569.77 & 570.86 \\
\hline
\end{tabular}




\begin{tabular}{|c|c|c|c|}
\hline & & & \\
\hline & & & \\
\hline & & & \\
\hline & & & \\
\hline & & & \\
\hline & 60 & & \\
\hline & 7431 & & \\
\hline 20 & & & \\
\hline 52 & 7437 & 555.42 & \\
\hline 16 & 7433 & & \\
\hline 51 & 7431 & 528. & \\
\hline 68 & 7438 & & \\
\hline 92 & 7431 & 538.16 & \\
\hline 78 & 7436 & & \\
\hline & 743 & & \\
\hline 72 & 7430 & & \\
\hline & & & \\
\hline 82 & 7436 & & \\
\hline & 743 & & \\
\hline 63 & 7433 & 510.23 & \\
\hline & 743 & & \\
\hline 07 & 7439 & 515.23 & \\
\hline & 7432 & & \\
\hline & 7431 & 506.99 & \\
\hline & 743 & & \\
\hline & 7437 & & \\
\hline 58 & 7434 & & \\
\hline & 7436 & & \\
\hline 10 & 7435 & 508 & 507. \\
\hline 88 & 7432 & & \\
\hline 35 & 7437 & 550 & 551. \\
\hline 32 & 7436 & & \\
\hline 34 & 7432 & 543 & \\
\hline 29 & 743 & & \\
\hline 17 & 7437 & & \\
\hline 31 & 7430 & & \\
\hline & & & \\
\hline 50 & 7436 & 567 & 566. \\
\hline & & & \\
\hline 58 & 7433 & 519 & \\
\hline & 7436 & & \\
\hline & 7437 & & \\
\hline & 7436 & & \\
\hline & 7430 & & \\
\hline 92 & 7431 & 505 & 50 \\
\hline & 7433 & & \\
\hline 34 & 7438 & 558 & \\
\hline & 7436 & & \\
\hline .23 & 7432 & 555.8 & \\
\hline & 7433 & & 529.2 \\
\hline .58 & 7432 & & \\
\hline & 7437 & 525.35 & 526. \\
\hline & 7436 & & \\
\hline & 7434 & 561.66 & 562. \\
\hline & 74316 & & \\
\hline & 7434 & 536.30 & 537.2 \\
\hline & 7437 & 526.87 & 527.0 \\
\hline & 7 & & $3 .($ \\
\hline
\end{tabular}

\begin{tabular}{|l|l|l|l|}
\hline 261640.43 & 7431107.27 & 527.62 & 528.58 \\
\hline
\end{tabular} \begin{tabular}{|l|l|l|l|}
\hline 264415.54 & 7434537.28 & 544.39 & 545.35 \\
\hline
\end{tabular} \begin{tabular}{|l|l|l|l|}
\hline 259501.62 & 7433997.88 & 501.33 & 500.37 \\
\hline
\end{tabular} \begin{tabular}{|l|l|l|l|}
\hline 260743.90 & 7431502.46 & 517.97 & 518.93 \\
\hline
\end{tabular} \begin{tabular}{|l|l|l|l|}
\hline 262434.28 & 7434451.43 & 560.08 & 561.04 \\
\hline
\end{tabular} \begin{tabular}{|l|l|l|l|}
\hline 261493.74 & 7438139.12 & 562.99 & 563.94 \\
\hline
\end{tabular} \begin{tabular}{|l|l|l|l|}
\hline 264498.18 & 7436692.87 & 569.63 & 570.58 \\
\hline
\end{tabular} \begin{tabular}{|l|l|l|l|}
\hline 261209.38 & 7430895.35 & 515.97 & 516.92 \\
\hline
\end{tabular} \begin{tabular}{|l|l|l|l|}
\hline 263329.78 & 7436304.60 & 556.83 & 557.78 \\
\hline
\end{tabular} \begin{tabular}{|l|l|l|l|}
\hline 264563.07 & 7438942.59 & 534.23 & 535.18 \\
\hline
\end{tabular} \begin{tabular}{|l|l|l|l|}
\hline 262829.81 & 7431353.10 & 519.57 & 520.52 \\
\hline
\end{tabular} \begin{tabular}{|l|l|l|l|}
\hline 265818.23 & 7432156.87 & 545.56 & 546.50 \\
\hline
\end{tabular} \begin{tabular}{|l|l|l|l|}
\hline 259271.93 & 7433688.06 & 499.82 & 498.88 \\
\hline
\end{tabular} \begin{tabular}{|l|l|l|l|}
\hline 259271.93 & 7433888.06 & 503.84 & 502.90 \\
\hline
\end{tabular} \begin{tabular}{|l|l|l|l|}
\hline 262034.47 & 7435331.50 & 506.45 & 507.39 \\
\hline
\end{tabular} \begin{tabular}{|l|l|l|l|}
\hline 261232.64 & 7434870.15 & 527.63 & 526.69 \\
\hline
\end{tabular} \begin{tabular}{|l|l|l|l|}
\hline 259275.44 & 7437285.19 & 545.48 & 546.42 \\
\hline
\end{tabular} \begin{tabular}{|l|l|l|l|}
\hline 260743.90 & 7431102.46 & 520.41 & 521.34 \\
\hline
\end{tabular} \begin{tabular}{|l|l|l|l|}
\hline 261633.80 & 7431500.81 & 537.41 & 538.34 \\
\hline
\end{tabular} \begin{tabular}{|l|l|l|l|}
\hline 262200.90 & 7434184.00 & 554.39 & 555.32 \\
\hline
\end{tabular} \begin{tabular}{|l|l|l|l|}
\hline 264251.30 & 7433614.43 & 541.89 & 542.82 \\
\hline
\end{tabular} \begin{tabular}{|l|l|l|l|}
\hline 260101.64 & 7434489.86 & 500.16 & 499.23 \\
\hline
\end{tabular} \begin{tabular}{|l|l|l|l|}
\hline 260345.38 & 7437839.05 & 569.35 & 570.28 \\
\hline
\end{tabular} \begin{tabular}{|l|l|l|l|}
\hline 262001.27 & 7432849.42 & 526.74 & 527.67 \\
\hline
\end{tabular} \begin{tabular}{|l|l|l|l|}
\hline 264844.92 & 7431096.91 & 539.60 & 540.53 \\
\hline
\end{tabular} \begin{tabular}{|l|l|l|l|}
\hline 263432.84 & 7433477.45 & 580.20 & 579.28 \\
\hline
\end{tabular} \begin{tabular}{|l|l|l|l|}
\hline 260545.86 & 7437073.13 & 580.68 & 581.60 \\
\hline
\end{tabular} \begin{tabular}{|l|l|l|l|}
\hline 261434.50 & 7432215.14 & 499.10 & 500.02 \\
\hline
\end{tabular} \begin{tabular}{|l|l|l|l|}
\hline 262955.43 & 7437948.26 & 523.71 & 524.63 \\
\hline
\end{tabular} \begin{tabular}{|l|l|l|l|}
\hline 264038.11 & 7438119.77 & 545.82 & 546.74 \\
\hline
\end{tabular} \begin{tabular}{|l|l|l|l|}
\hline 263434.00 & 7432232.81 & 508.11 & 509.03 \\
\hline
\end{tabular} \begin{tabular}{|l|l|l|l|}
\hline 261600.10 & 7435051.82 & 512.94 & 512.03 \\
\hline
\end{tabular} \begin{tabular}{|l|l|l|l|}
\hline 263761.35 & 7438783.17 & 529.31 & 530.22 \\
\hline
\end{tabular} \begin{tabular}{|l|l|l|l|}
\hline 264449.60 & 7431824.05 & 505.53 & 506.44 \\
\hline 261800.90 & 7434384.02 & 533.57 & 534.48 \\
\hline
\end{tabular} \begin{tabular}{|l|l|l|l|}
\hline 261800.90 & 7434384.02 & 533.57 & 534.48 \\
\hline
\end{tabular} \begin{tabular}{|l|l|l|l|}
\hline 263454.16 & 7435635.21 & 538.35 & 539.26 \\
\hline
\end{tabular} \begin{tabular}{|l|l|l|l|}
\hline 262231.28 & 7432835.94 & 535.64 & 536.55 \\
\hline
\end{tabular} \begin{tabular}{|l|l|l|l|}
\hline 264051.83 & 7434078.97 & 545.97 & 546.88 \\
\hline
\end{tabular} \begin{tabular}{|l|l|l|l|}
\hline 264298.34 & 7437871.39 & 562.93 & 563.83 \\
\hline
\end{tabular} \begin{tabular}{|l|l|l|l|}
\hline 261093.74 & 7438539.12 & 594.08 & 594.98 \\
\hline 261600.10 & 7435251.82 & 520.88 & 521.78 \\
\hline
\end{tabular} \begin{tabular}{|l|l|l|l|}
\hline 261600.10 & 7435251.82 & 520.88 & 521.78 \\
\hline
\end{tabular} \begin{tabular}{|l|l|l|l|}
\hline 263639.60 & 7435935.77 & 555.82 & 556.72 \\
\hline
\end{tabular} \begin{tabular}{|l|l|l|l|}
\hline 265162.99 & 7437777.52 & 588.10 & 589.00 \\
\hline
\end{tabular} \begin{tabular}{|l|l|l|l|}
\hline 263031.27 & 7434169.76 & 558.51 & 559.41 \\
\hline
\end{tabular} \begin{tabular}{|l|l|l|l|}
\hline 263433.55 & 7432128.02 & 513.69 & 514.59 \\
\hline
\end{tabular} \begin{tabular}{|l|l|l|l|}
\hline 265019.10 & 7433840.02 & 518.86 & 519.76 \\
\hline
\end{tabular} \begin{tabular}{|l|l|l|l|}
\hline 260345.38 & 7438639.05 & 547.24 & 548.13 \\
\hline
\end{tabular} \begin{tabular}{|l|l|l|l|}
\hline 260832.64 & 7433076.16 & 522.90 & 523.79 \\
\hline
\end{tabular} \begin{tabular}{|l|l|l|l|}
\hline 262866.65 & 7436707.19 & 515.59 & 516.48 \\
\hline
\end{tabular} \begin{tabular}{|l|l|l|l|}
\hline 263887.26 & 7438064.27 & 554.15 & 555.04 \\
\hline
\end{tabular} \begin{tabular}{|l|l|l|l|}
\hline 264080.78 & 7436218.31 & 568.41 & 569.30 \\
\hline
\end{tabular} \begin{tabular}{|l|l|l|l|}
\hline 264251.88 & 7434579.03 & 554.94 & 555.83 \\
\hline
\end{tabular} \begin{tabular}{|l|l|l|l|}
\hline 264615.54 & 7434637.28 & 544.13 & 545.02 \\
\hline
\end{tabular} \begin{tabular}{|l|l|l|l|}
\hline 262629.81 & 7431453.10 & 504.97 & 505.86 \\
\hline
\end{tabular} \begin{tabular}{|l|l|l|l|}
\hline 264844.92 & 7430896.91 & 546.00 & 546.89 \\
\hline
\end{tabular} \begin{tabular}{|l|l|l|l|}
\hline 259075.44 & 7437585.19 & 514.31 & 515.19 \\
\hline
\end{tabular} \begin{tabular}{|l|l|l|l|}
\hline 259499.56 & 7435173.30 & 538.30 & 537.42 \\
\hline
\end{tabular}

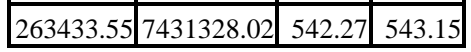

\begin{tabular}{|l|l|l|l|}
\hline 264851.85 & 7431412.64 & 521.19 & 522.07 \\
\hline
\end{tabular} \begin{tabular}{|l|l|l|l|}
\hline 264049.31 & 7430895.35 & 531.68 & 530.81 \\
\hline
\end{tabular} \begin{tabular}{|l|l|l|l|}
\hline 259275.44 & 7437085.19 & 560.34 & 561.21 \\
\hline
\end{tabular} \begin{tabular}{|l|l|l|l|}
\hline 259475.41 & 7436568.02 & 585.82 & 586.69 \\
\hline
\end{tabular} \begin{tabular}{|l|l|l|l|}
\hline 264652.13 & 7433616.30 & 505.71 & 506.58 \\
\hline
\end{tabular} \begin{tabular}{|l|l|l|l|}
\hline 261833.80 & 7431400.81 & 541.49 & 540.63 \\
\hline
\end{tabular} \begin{tabular}{|l|l|l|l|}
\hline 263596.82 & 7436531.79 & 540.99 & 541.85 \\
\hline
\end{tabular} \begin{tabular}{|l|l|l|l|}
\hline 262232.04 & 7431270.99 & 530.97 & 531.83 \\
\hline
\end{tabular} \begin{tabular}{|l|l|l|l|}
\hline 259240.36 & 7438501.05 & 537.76 & 538.61 \\
\hline
\end{tabular} \begin{tabular}{|l|l|l|l|}
\hline 263361.35 & 7438383.17 & 518.34 & 519.19 \\
\hline
\end{tabular} \begin{tabular}{|l|l|l|l|}
\hline 264689.52 & 7437672.73 & 571.91 & 572.76 \\
\hline
\end{tabular} \begin{tabular}{|l|l|l|l|}
\hline 264698.18 & 7436192.87 & 565.22 & 566.07 \\
\hline
\end{tabular} \begin{tabular}{|l|l|l|l|}
\hline 262231.92 & 7431841.26 & 529.16 & 530.01 \\
\hline
\end{tabular} \begin{tabular}{|l|l|l|l|}
\hline 261032.64 & 7433770.15 & 509.97 & 509.13 \\
\hline
\end{tabular} \begin{tabular}{|l|l|l|l|}
\hline 264218.20 & 7435641.35 & 529.20 & 528.36 \\
\hline
\end{tabular} \begin{tabular}{|l|l|l|l|}
\hline 261800.90 & 7433784.02 & 525.65 & 526.49 \\
\hline
\end{tabular} \begin{tabular}{|l|l|l|l|}
\hline 258875.44 & 7436885.19 & 563.79 & 564.62 \\
\hline
\end{tabular} \begin{tabular}{|l|l|l|l|}
\hline 261600.10 & 7434651.82 & 510.10 & 510.93 \\
\hline
\end{tabular} \begin{tabular}{|l|l|l|l|}
\hline 262929.78 & 7436504.60 & 528.97 & 529.80 \\
\hline
\end{tabular} \begin{tabular}{|l|l|l|l|}
\hline 261234.16 & 7433032.93 & 507.68 & 508.50 \\
\hline
\end{tabular} \begin{tabular}{|l|l|l|l|}
\hline 259299.56 & 7435273.30 & 538.60 & 539.42 \\
\hline
\end{tabular} \begin{tabular}{|l|l|l|l|}
\hline 262829.51 & 7430566.71 & 528.49 & 529.31 \\
\hline
\end{tabular} \begin{tabular}{|l|l|l|l|}
\hline 263633.55 & 7431428.02 & 543.85 & 544.67 \\
\hline
\end{tabular} \begin{tabular}{|l|l|l|l|}
\hline 262032.04 & 7430770.99 & 535.45 & 534.64 \\
\hline
\end{tabular} \begin{tabular}{|l|l|l|l|}
\hline 259275.44 & 7437685.19 & 529.64 & 530.45 \\
\hline
\end{tabular} \begin{tabular}{|l|l|l|l|}
\hline 259675.44 & 7436885.19 & 573.76 & 574.57 \\
\hline
\end{tabular} \begin{tabular}{|l|l|l|l|}
\hline 262034.47 & 7435531.50 & 514.81 & 515.62 \\
\hline
\end{tabular} \begin{tabular}{|l|l|l|l|}
\hline 264238.05 & 7438431.77 & 553.31 & 554.12 \\
\hline
\end{tabular} \begin{tabular}{|l|l|l|l|}
\hline 261442.18 & 7432815.84 & 497.88 & 498.69 \\
\hline
\end{tabular} \begin{tabular}{|l|l|l|l|}
\hline 259675.44 & 7437885.19 & 551.21 & 552.02 \\
\hline
\end{tabular} \begin{tabular}{|l|l|l|l|}
\hline 262093.45 & 7436944.55 & 515.49 & 516.30 \\
\hline
\end{tabular} \begin{tabular}{|l|l|l|l|}
\hline 263234.92 & 7432739.22 & 534.21 & 535.02 \\
\hline
\end{tabular} \begin{tabular}{|l|l|l|l|}
\hline 263851.83 & 7433978.97 & 566.81 & 567.61 \\
\hline
\end{tabular} \begin{tabular}{|l|l|l|l|}
\hline 259282.58 & 7433613.31 & 496.70 & 497.50 \\
\hline
\end{tabular} \begin{tabular}{|l|l|l|l|}
\hline 259440.36 & 7438201.05 & 523.96 & 524.76 \\
\hline
\end{tabular} \begin{tabular}{|l|l|l|l|}
\hline 260145.38 & 7437739.05 & 560.45 & 561.25 \\
\hline
\end{tabular} \begin{tabular}{|l|l|l|l|}
\hline 263451.29 & 7435152.76 & 515.83 & 516.63 \\
\hline
\end{tabular} \begin{tabular}{|l|l|l|l|}
\hline 259299.56 & 7434473.30 & 532.92 & 533.71 \\
\hline
\end{tabular} \begin{tabular}{|l|l|l|l|}
\hline 263651.29 & 7434852.76 & 533.17 & 533.96 \\
\hline
\end{tabular} \begin{tabular}{|l|l|l|l|}
\hline 264249.90 & 7432843.01 & 501.90 & 502.69 \\
\hline
\end{tabular} \begin{tabular}{|l|l|l|l|}
\hline 259075.44 & 7437785.19 & 530.07 & 530.86 \\
\hline
\end{tabular} \begin{tabular}{|l|l|l|l|}
\hline 264051.32 & 7433714.41 & 551.07 & 551.86 \\
\hline
\end{tabular} \begin{tabular}{|l|l|l|l|}
\hline 264052.94 & 7432732.20 & 513.11 & 513.90 \\
\hline
\end{tabular} \begin{tabular}{|l|l|l|l|}
\hline 264058.26 & 7431429.60 & 537.63 & 538.42 \\
\hline
\end{tabular} \begin{tabular}{|l|l|l|l|}
\hline 263454.16 & 7435435.21 & 514.93 & 515.71 \\
\hline
\end{tabular} \begin{tabular}{|l|l|l|l|}
\hline 265011.82 & 7436335.44 & 575.30 & 576.08 \\
\hline
\end{tabular} \begin{tabular}{|l|l|l|l|}
\hline 258482.14 & 7433905.00 & 517.02 & 516.24 \\
\hline
\end{tabular} \begin{tabular}{|l|l|l|l|}
\hline 264813.72 & 7435774.16 & 548.68 & 547.90 \\
\hline
\end{tabular} \begin{tabular}{|l|l|l|l|}
\hline 264038.09 & 7438519.82 & 540.24 & 541.02 \\
\hline
\end{tabular}

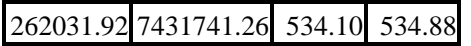
\begin{tabular}{|l|l|l|l|}
\hline 263234.66 & 7434274.04 & 541.85 & 542.63 \\
\hline
\end{tabular} \begin{tabular}{|l|l|l|l|}
\hline 264698.18 & 7436792.87 & 561.92 & 562.69 \\
\hline
\end{tabular} \begin{tabular}{|l|l|l|l|}
\hline 259640.36 & 7437901.05 & 549.38 & 550.15 \\
\hline
\end{tabular} \begin{tabular}{|l|l|l|l|}
\hline 262434.44 & 7432739.40 & 523.45 & 524.22 \\
\hline
\end{tabular} \begin{tabular}{|l|l|l|l|}
\hline 262633.81 & 7432967.79 & 528.58 & 529.35 \\
\hline
\end{tabular} \begin{tabular}{|l|l|l|l|}
\hline 263034.42 & 7434551.42 & 541.75 & 542.52 \\
\hline
\end{tabular} \begin{tabular}{|l|l|l|l|}
\hline 261232.64 & 7434470.15 & 505.35 & 504.59 \\
\hline
\end{tabular}

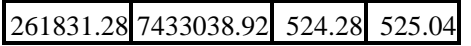




\begin{tabular}{|c|c|c|c|}
\hline & & & \\
\hline & & & \\
\hline & & & \\
\hline & & & \\
\hline & & & \\
\hline & 50 & 520 & \\
\hline & & 519.0 & \\
\hline 14 & 7437 & & \\
\hline 91 & 7432 & 543.58 & \\
\hline 27 & 7438 & & \\
\hline 35 & 7438 & 529.62 & \\
\hline 81 & 7433 & & \\
\hline 13 & 7433 & $504.7 \mathrm{~s}$ & \\
\hline 41 & 7436 & & \\
\hline & 7436 & 580 & \\
\hline 30 & 7433 & 499.50 & \\
\hline & 7430 & & \\
\hline 30 & 7431 & & \\
\hline & 46 & & \\
\hline 92 & 7435 & 531.05 & \\
\hline & 743 & & \\
\hline 60 & 7430 & 539.74 & \\
\hline & 7438 & & \\
\hline & 7436 & 541 & \\
\hline 18 & 7436 & & \\
\hline & 7433 & & \\
\hline 38 & 7434 & 54 & \\
\hline & 7432 & & \\
\hline 64 & 7432 & 520.54 & \\
\hline 4 & 7433 & & \\
\hline 18 & 7436 & 562.36 & \\
\hline 4 & 743 & & \\
\hline 27 & 7433 & 534 & \\
\hline 09 & 7430 & & \\
\hline 26 & 7437 & & \\
\hline 3 & 7435 & & \\
\hline & & & \\
\hline 22 & 7430 & 532 & \\
\hline & & & \\
\hline 77 & 7434 & 574 & \\
\hline & 7436 & & \\
\hline 44 & 7437 & & \\
\hline & 7436 & & \\
\hline & 7438 & & \\
\hline 88 & 7434 & 569 & \\
\hline & 7431 & & \\
\hline 88 & 7433 & 510 & \\
\hline & 7432 & & \\
\hline 92 & 7432 & & \\
\hline & 7431 & & $53 /$. \\
\hline & 7438 & 528 & \\
\hline & 7434 & 550.53 & 551.2 \\
\hline & 7433 & & \\
\hline & 7434 & 536.68 & 537. \\
\hline & 74305 & & \\
\hline & 7434 & 506.77 & 507 \\
\hline & 7436 & 568.57 & 505.2 \\
\hline & 7434 & 51560 & 516. \\
\hline
\end{tabular}

\begin{tabular}{|c|c|c|c|}
\hline 260632.64 & 7433376.16 & 535.88 & 536.56 \\
\hline 264813.72 & 7435574.16 & 528.20 & 528.88 \\
\hline 262633.81 & 7433367.79 & 534.24 & 534.92 \\
\hline 261493.74 & 7437939.12 & 571.31 & 571.98 \\
\hline 260501.91 & 7433879.62 & 520.40 & 521.07 \\
\hline 262000.90 & 7434084.02 & 545.81 & 546.48 \\
\hline 259082.58 & 7432916.87 & 501.12 & 500.45 \\
\hline 259991.53 & 7435132.77 & 510.32 & 510.99 \\
\hline 261032.64 & 7433970.15 & 507.21 & 507.88 \\
\hline 260832.58 & 7433874.02 & 509.85 & 510.52 \\
\hline 263451.29 & 7434752.76 & 548.61 & 549.28 \\
\hline 264563.07 & 7439142.59 & 535.61 & 536.28 \\
\hline 265162.99 & 7438577.52 & 557.37 & 558.04 \\
\hline 260427.44 & 7434632.03 & 502.44 & 503.10 \\
\hline 260101.64 & 7434067.72 & 503.84 & 504.50 \\
\hline 261234.16 & 7433632.93 & 510.52 & 511.18 \\
\hline 259475.44 & 7436991.98 & 567.11 & 567.77 \\
\hline 264238.05 & 7438631.77 & 546.11 & 546.77 \\
\hline 263858.26 & 7431729.60 & 526.13 & 526.79 \\
\hline 264813.72 & 7436174.16 & 561.06 & 561.71 \\
\hline 265365.15 & 7435700.40 & 569.17 & 569.82 \\
\hline 262833.81 & 7433467.79 & 548.30 & 548.95 \\
\hline 261631.63 & 7433194.11 & 498.21 & 498.86 \\
\hline 259875.44 & 7437985.19 & 558.96 & 559.61 \\
\hline 263432.84 & 7433677.45 & 572.96 & 573.61 \\
\hline 264963.07 & 7438942.59 & 550.31 & 550.95 \\
\hline 265618.23 & 7432056.87 & 553.06 & 552.42 \\
\hline 261431.30 & 7434572.39 & 505.56 & 506.20 \\
\hline 264080.78 & 7436618.31 & 555.29 & 555.93 \\
\hline 264615.54 & 7435237.28 & 538.13 & 538.77 \\
\hline 261440.43 & 7430604.37 & 525.40 & 524.77 \\
\hline 261234.16 & 7433232.93 & 514.40 & 515.03 \\
\hline 262036.35 & 7435270.55 & 505.37 & 506.00 \\
\hline 261840.43 & 7430607.27 & 548.02 & 547.40 \\
\hline 265051.85 & 7431512.64 & 531.91 & 531.29 \\
\hline 264698.18 & 7436992.87 & 551.25 & 551.87 \\
\hline 262433.81 & 7432867.79 & 537.84 & 538.46 \\
\hline 263032.84 & 7433477.45 & 553.60 & 554.22 \\
\hline 263434.64 & 7433780.34 & 565.01 & 565.63 \\
\hline 260145.86 & 7437273.15 & 549.58 & 550.19 \\
\hline 260627.44 & 7435545.43 & 516.58 & 517.19 \\
\hline 259901.62 & 7433790.04 & 514.85 & 515.46 \\
\hline 261800.90 & 7434184.00 & 532.93 & 533.54 \\
\hline 262032.06 & 7436893.58 & 521.63 & 522.24 \\
\hline 264498.34 & 7437171.39 & 543.78 & 544.39 \\
\hline 265013.72 & 7435674.16 & 542.46 & 543.07 \\
\hline 262632.04 & 7430670.99 & 529.35 & 529.96 \\
\hline 262634.28 & 7434551.43 & 561.16 & 561.77 \\
\hline 263852.94 & 7432632.42 & 498.47 & 499.08 \\
\hline 264098.34 & 7436971.39 & 553.07 & 553.68 \\
\hline 263849.31 & 7431194.65 & 543.94 & 544.55 \\
\hline 265211.82 & 7435588.72 & 555.48 & 554.88 \\
\hline 259075.44 & 7436985.19 & 561.24 & 561.84 \\
\hline 259240.36 & 7437701.05 & 525.92 & 526.52 \\
\hline 260432.58 & 7434474.02 & 496.37 & 496.97 \\
\hline 265211.82 & 7435388.72 & 554.80 & 555.40 \\
\hline 259640.36 & 7438301.05 & 531.17 & 531.76 \\
\hline 260101.64 & 7433667.72 & 539.36 & 539.95 \\
\hline
\end{tabular}

\begin{tabular}{|c|c|c|c|}
\hline 260543.90 & 7431402.46 & 532.31 & 532.90 \\
\hline 264819.10 & 7433540.02 & 520.54 & 521.13 \\
\hline 265309.00 & 7433518.42 & 522.25 & 522.84 \\
\hline 262834.92 & 7432139.04 & 511.67 & 512.26 \\
\hline 264444.92 & 7431096.91 & 510.68 & 511.27 \\
\hline 264615.84 & 7434320.32 & 531.96 & 532.55 \\
\hline 264849.60 & 7431824.23 & 517.83 & 518.42 \\
\hline 265709.00 & 7432918.42 & 573.09 & 573.68 \\
\hline 264962.99 & 7438677.52 & 562.02 & 562.60 \\
\hline 265013.64 & 7435261.66 & 543.99 & 544.57 \\
\hline 262433.08 & 7433858.18 & 552.53 & 553.11 \\
\hline 261640.43 & 7431307.27 & 523.82 & 524.40 \\
\hline 259075.44 & 7437385.19 & 533.54 & 534.11 \\
\hline 262936.27 & 7439184.37 & 537.40 & 537.97 \\
\hline 265213.64 & 7435361.66 & 552.43 & 553.00 \\
\hline 259282.58 & 7433416.89 & 501.76 & 502.33 \\
\hline 264652.13 & 7433416.30 & 510.51 & 511.08 \\
\hline 262632.04 & 7430870.99 & 521.55 & 520.98 \\
\hline 263796.82 & 7437031.79 & 542.49 & 543.06 \\
\hline 264962.99 & 7438077.52 & 585.13 & 585.69 \\
\hline 265013.64 & 7435461.66 & 534.39 & 534.95 \\
\hline 265162.99 & 7438377.52 & 568.52 & 569.08 \\
\hline 265365.15 & 7436100.40 & 576.77 & 577.33 \\
\hline 258481.47 & 7433417.70 & 506.16 & 506.72 \\
\hline 264851.85 & 7431612.64 & 506.39 & 506.95 \\
\hline 263034.28 & 7435151.43 & 525.52 & 524.96 \\
\hline 263234.53 & 7431615.59 & 521.29 & 520.73 \\
\hline 262036.35 & 7434870.55 & 524.67 & 525.22 \\
\hline 260301.64 & 7434366.66 & 502.02 & 502.57 \\
\hline 262634.28 & 7434951.43 & 539.66 & 539.11 \\
\hline 260301.64 & 7434166.66 & 513.84 & 514.39 \\
\hline 263596.82 & 7436131.79 & 566.17 & 566.71 \\
\hline 262236.35 & 7435570.55 & 520.15 & 519.61 \\
\hline 265509.00 & 7433818.42 & 518.75 & 518.21 \\
\hline 262929.78 & 7436104.60 & 530.39 & 530.93 \\
\hline 263155.43 & 7438248.26 & 527.13 & 527.67 \\
\hline 264251.30 & 7433814.43 & 551.85 & 552.39 \\
\hline 265044.92 & 7431196.91 & 530.02 & 530.56 \\
\hline 264415.54 & 7434937.28 & 557.51 & 558.04 \\
\hline 263029.51 & 7430666.71 & 522.33 & 522.86 \\
\hline 263434.64 & 7433980.34 & 560.19 & 560.72 \\
\hline 264844.92 & 7430696.91 & 552.32 & 552.85 \\
\hline 265365.15 & 7436500.40 & 580.81 & 581.33 \\
\hline 259440.36 & 7438601.05 & 530.10 & 530.62 \\
\hline 260145.86 & 7437073.13 & 561.46 & 561.98 \\
\hline 264889.84 & 7437378.16 & 567.54 & 568.06 \\
\hline 262833.81 & 7432867.79 & 521.40 & 521.92 \\
\hline 265618.23 & 7431456.87 & 523.68 & 524.19 \\
\hline 260501.91 & 7433479.62 & 540.46 & 540.97 \\
\hline 264698.18 & 7436592.87 & 575.33 & 575.84 \\
\hline 265365.15 & 7436300.40 & 575.55 & 576.06 \\
\hline 263652.30 & 7433099.97 & 537.79 & 538.30 \\
\hline 263851.83 & 7434178.97 & 564.91 & 565.42 \\
\hline 263434.64 & 7434380.34 & 558.99 & 558.49 \\
\hline 258875.44 & 7437085.19 & 545.27 & 545.77 \\
\hline 263066.65 & 7436607.19 & 534.98 & 535.48 \\
\hline 262232.04 & 7430670.99 & 540.15 & 539.66 \\
\hline 258482.14 & 7434705.00 & 513.02 & 513.51 \\
\hline
\end{tabular}




\begin{tabular}{|c|c|c|c|}
\hline & & & \\
\hline & & & \\
\hline & & & \\
\hline & & & \\
\hline & & & \\
\hline 0 & & 4.14 & \\
\hline 4 & 743 & 533.71 & \\
\hline 35 & & & \\
\hline 50 & 743 & 538.8 & \\
\hline 1.92 & & & \\
\hline 60 & & 554.46 & \\
\hline .08 & 7434 & & \\
\hline & & 511.90 & \\
\hline 32 & & & \\
\hline & & & \\
\hline 97 & & & \\
\hline & & & \\
\hline 20 & & 574.08 & \\
\hline & & & \\
\hline 18 & 743 & 553. & \\
\hline & & & \\
\hline & 743 & & \\
\hline 08 & 743 & 567.59 & \\
\hline 44 & & & \\
\hline 90 & 743 & 525.64 & \\
\hline 53 & & & \\
\hline 36 & 743 & 545.08 & \\
\hline 6 & & & \\
\hline 27 & 743 & 563 & \\
\hline 4 & 743 & & \\
\hline 72 & & & \\
\hline 1 & 743 & 513 & \\
\hline 14 & & & \\
\hline 58 & 743 & 525 & \\
\hline & & & \\
\hline 38 & 743 & 563 & \\
\hline & & & \\
\hline 30 & 743 & 554 & \\
\hline .29 & & & \\
\hline & & & \\
\hline 72 & 743 & 552 & \\
\hline .15 & & & \\
\hline 08 & 743 & 561 & \\
\hline & & & \\
\hline 36 & 743 & 531 & \\
\hline & 7433 & & \\
\hline & 743 & 515.70 & \\
\hline & & & \\
\hline & 743 & 513 & \\
\hline & & 520.70 & \\
\hline & 743 & & \\
\hline & 743 & 541.15 & 541. \\
\hline & & & \\
\hline .00 & 743 & 509.99 & 510. \\
\hline & & & \\
\hline & 7438 & 569.01 & \\
\hline & & 534.41 & 534.8 \\
\hline & & & \\
\hline
\end{tabular}

\begin{tabular}{|l|l|l|l|}
\hline 258682.14 & 7434005.00 & 527.38 & 526.97 \\
\hline
\end{tabular} \begin{tabular}{|l|l|l|l|}
\hline 260301.91 & 7433379.62 & 549.80 & 550.20 \\
\hline
\end{tabular} \begin{tabular}{|l|l|l|l|}
\hline 260543.90 & 7430802.46 & 547.43 & 547.83 \\
\hline
\end{tabular} \begin{tabular}{|l|l|l|l|}
\hline 263852.94 & 7432232.42 & 502.15 & 502.55 \\
\hline
\end{tabular} \begin{tabular}{|l|l|l|l|}
\hline 259499.56 & 7435373.30 & 529.98 & 529.58 \\
\hline
\end{tabular} \begin{tabular}{|l|l|l|l|}
\hline 260145.38 & 7438739.05 & 534.84 & 535.24 \\
\hline
\end{tabular} \begin{tabular}{|l|l|l|l|}
\hline 260101.64 & 7433867.72 & 520.12 & 520.52 \\
\hline
\end{tabular} \begin{tabular}{|l|l|l|l|}
\hline 264813.72 & 7435974.16 & 552.90 & 553.30 \\
\hline
\end{tabular} \begin{tabular}{|l|l|l|l|}
\hline 262200.90 & 7433784.02 & 536.83 & 537.23 \\
\hline
\end{tabular} \begin{tabular}{|l|l|l|l|}
\hline 262432.04 & 7430570.99 & 541.27 & 541.67 \\
\hline
\end{tabular} \begin{tabular}{|l|l|l|l|}
\hline 262833.81 & 7433067.79 & 539.36 & 539.76 \\
\hline
\end{tabular} \begin{tabular}{|l|l|l|l|}
\hline 261600.10 & 7435451.82 & 524.56 & 524.95 \\
\hline
\end{tabular} \begin{tabular}{|l|l|l|l|}
\hline 259791.53 & 7435432.77 & 525.56 & 525.17 \\
\hline
\end{tabular} \begin{tabular}{|l|l|l|l|}
\hline 261232.64 & 7433870.15 & 507.53 & 507.14 \\
\hline
\end{tabular} \begin{tabular}{|l|l|l|l|}
\hline 263232.84 & 7433177.45 & 555.14 & 554.75 \\
\hline
\end{tabular} \begin{tabular}{|l|l|l|l|}
\hline 264218.20 & 7436041.35 & 560.24 & 560.63 \\
\hline
\end{tabular} \begin{tabular}{|l|l|l|l|}
\hline 265013.72 & 7436074.16 & 565.64 & 566.03 \\
\hline
\end{tabular} \begin{tabular}{|l|l|l|l|}
\hline 263451.29 & 7434952.76 & 536.83 & 536.45 \\
\hline
\end{tabular} \begin{tabular}{|l|l|l|l|}
\hline 259082.58 & 7433716.99 & 519.94 & 520.32 \\
\hline 261840.43 & 7430807.27 & 537.34 & 537.72 \\
\hline
\end{tabular} \begin{tabular}{|l|l|l|l|}
\hline 261840.43 & 7430807.27 & 537.34 & 537.72 \\
\hline
\end{tabular} \begin{tabular}{|l|l|l|l|}
\hline 258882.58 & 7433416.87 & 522.64 & 522.27 \\
\hline
\end{tabular} \begin{tabular}{|l|l|l|l|}
\hline 263289.89 & 7437354.77 & 523.28 & 523.65 \\
\hline
\end{tabular} \begin{tabular}{|l|l|l|l|}
\hline 265211.82 & 7435788.72 & 557.08 & 557.45 \\
\hline
\end{tabular} \begin{tabular}{|l|l|l|l|}
\hline 263155.43 & 7438848.26 & 546.55 & 546.91 \\
\hline
\end{tabular} \begin{tabular}{|l|l|l|l|}
\hline 263851.29 & 7435352.76 & 517.79 & 518.15 \\
\hline
\end{tabular} \begin{tabular}{|l|l|l|l|}
\hline 264249.60 & 7431923.81 & 509.33 & 509.69 \\
\hline
\end{tabular} \begin{tabular}{|l|l|l|l|}
\hline 262434.47 & 7435331.50 & 514.69 & 514.34 \\
\hline
\end{tabular} \begin{tabular}{|l|l|l|l|}
\hline 262536.27 & 7438784.37 & 582.20 & 581.85 \\
\hline
\end{tabular} \begin{tabular}{|l|l|l|l|}
\hline 259701.62 & 7434290.04 & 509.75 & 510.10 \\
\hline
\end{tabular} \begin{tabular}{|l|l|l|l|}
\hline 262634.44 & 7432239.42 & 508.03 & 508.38 \\
\hline
\end{tabular} \begin{tabular}{|l|l|l|l|}
\hline 265407.56 & 7430588.70 & 523.64 & 523.99 \\
\hline
\end{tabular} \begin{tabular}{|l|l|l|l|}
\hline 262001.27 & 7433649.42 & 536.58 & 536.93 \\
\hline
\end{tabular} \begin{tabular}{|l|l|l|l|}
\hline 261800.10 & 7434951.82 & 506.98 & 506.64 \\
\hline
\end{tabular} \begin{tabular}{|l|l|l|l|}
\hline 262834.28 & 7434651.43 & 555.38 & 555.72 \\
\hline
\end{tabular} \begin{tabular}{|l|l|l|l|}
\hline 264415.54 & 7435137.28 & 539.27 & 539.61 \\
\hline
\end{tabular} \begin{tabular}{|l|l|l|l|}
\hline 265365.15 & 7435900.40 & 574.91 & 575.25 \\
\hline
\end{tabular} \begin{tabular}{|l|l|l|l|}
\hline 262831.27 & 7433871.66 & 565.47 & 565.81 \\
\hline
\end{tabular} \begin{tabular}{|l|l|l|l|}
\hline 262433.08 & 7434458.18 & 560.41 & 560.74 \\
\hline
\end{tabular} \begin{tabular}{|l|l|l|l|}
\hline 260427.44 & 7435232.03 & 510.74 & 510.41 \\
\hline
\end{tabular} \begin{tabular}{|l|l|l|l|}
\hline 265364.91 & 7435065.59 & 574.17 & 574.49 \\
\hline
\end{tabular} \begin{tabular}{|l|l|l|l|}
\hline 259791.53 & 7435232.77 & 521.26 & 520.94 \\
\hline
\end{tabular} \begin{tabular}{|l|l|l|l|}
\hline 265213.64 & 7434561.66 & 549.89 & 549.57 \\
\hline
\end{tabular} \begin{tabular}{|l|l|l|l|}
\hline 264452.13 & 7433516.30 & 516.21 & 515.90 \\
\hline
\end{tabular} \begin{tabular}{|l|l|l|l|}
\hline 259299.56 & 7435073.30 & 551.68 & 551.99 \\
\hline
\end{tabular} \begin{tabular}{|l|l|l|l|}
\hline 259282.58 & 7433016.87 & 518.50 & 518.81 \\
\hline
\end{tabular} \begin{tabular}{|l|l|l|l|}
\hline 263232.84 & 7433777.45 & 578.84 & 578.54 \\
\hline
\end{tabular} \begin{tabular}{|l|l|l|l|}
\hline 260145.38 & 7438139.05 & 570.42 & 570.72 \\
\hline
\end{tabular} \begin{tabular}{|l|l|l|l|}
\hline 261831.28 & 7432238.92 & 509.54 & 509.84 \\
\hline
\end{tabular} \begin{tabular}{|l|l|l|l|}
\hline 262432.04 & 7430770.99 & 524.71 & 525.01 \\
\hline
\end{tabular} \begin{tabular}{|l|l|l|l|}
\hline 262633.08 & 7433758.18 & 548.37 & 548.67 \\
\hline
\end{tabular} \begin{tabular}{|l|l|l|l|}
\hline 262736.20 & 7438267.35 & 550.51 & 550.80 \\
\hline
\end{tabular} \begin{tabular}{|l|l|l|l|}
\hline 264615.54 & 7434837.28 & 552.63 & 552.92 \\
\hline 264813.64 & 7435161.66 & 555.77 & 556.06 \\
\hline
\end{tabular} \begin{tabular}{|l|l|l|l|}
\hline 264813.64 & 7435161.66 & 555.77 & 556.06 \\
\hline
\end{tabular} \begin{tabular}{|l|l|l|l|}
\hline 265013.64 & 7434661.66 & 567.35 & 567.64 \\
\hline
\end{tabular} \begin{tabular}{|l|l|l|l|}
\hline 264052.94 & 7432532.78 & 514.31 & 514.03 \\
\hline
\end{tabular} \begin{tabular}{|l|l|l|l|}
\hline 262236.35 & 7434770.55 & 541.23 & 541.51 \\
\hline
\end{tabular} \begin{tabular}{|l|l|l|l|}
\hline 264613.72 & 7436046.30 & 551.12 & 551.40 \\
\hline
\end{tabular} \begin{tabular}{|l|l|l|l|}
\hline 265013.64 & 7434861.66 & 568.57 & 568.85 \\
\hline
\end{tabular} \begin{tabular}{|l|l|l|l|}
\hline 264815.84 & 7433820.32 & 522.98 & 523.26 \\
\hline
\end{tabular} \begin{tabular}{|l|l|l|l|}
\hline 260345.38 & 7438439.05 & 561.19 & 560.92 \\
\hline 262232.06 & 7436193.58 & 516.03 & 515.76 \\
\hline
\end{tabular} \begin{tabular}{|l|l|l|l|}
\hline 262232.06 & 7436193.58 & 516.03 & 515.76 \\
\hline
\end{tabular} \begin{tabular}{|l|l|l|l|}
\hline 258481.47 & 7433217.72 & 500.38 & 500.65 \\
\hline
\end{tabular} \begin{tabular}{|l|l|l|l|}
\hline 259501.62 & 7434397.88 & 521.79 & 522.06 \\
\hline
\end{tabular} \begin{tabular}{|l|l|l|l|}
\hline 263451.29 & 7435352.76 & 508.97 & 509.24 \\
\hline
\end{tabular} \begin{tabular}{|l|l|l|l|}
\hline 263561.35 & 7438283.17 & 535.65 & 535.92 \\
\hline 263032.72 & 7430533.41 & 524.28 & 524.55 \\
\hline
\end{tabular} \begin{tabular}{|l|l|l|l|}
\hline 263032.72 & 7430533.41 & 524.28 & 524.55 \\
\hline
\end{tabular} \begin{tabular}{|l|l|l|l|}
\hline 264244.92 & 7431196.91 & 522.08 & 522.35 \\
\hline
\end{tabular} \begin{tabular}{|l|l|l|l|}
\hline 262634.47 & 7435431.50 & 504.03 & 504.29 \\
\hline 258482.14 & 7434105.00 & 515.66 & 515.40 \\
\hline
\end{tabular} \begin{tabular}{|l|l|l|l|}
\hline 258482.14 & 7434105.00 & 515.66 & 515.40 \\
\hline
\end{tabular} \begin{tabular}{|l|l|l|l|}
\hline 258882.58 & 7432816.87 & 502.62 & 502.88 \\
\hline
\end{tabular} \begin{tabular}{|l|l|l|l|}
\hline 260632.58 & 7434374.02 & 499.01 & 499.27 \\
\hline
\end{tabular} \begin{tabular}{|l|l|l|l|}
\hline 264498.34 & 7437771.39 & 578.69 & 578.95 \\
\hline
\end{tabular} \begin{tabular}{|l|l|l|l|}
\hline 264249.60 & 7432123.81 & 503.55 & 503.81 \\
\hline
\end{tabular} \begin{tabular}{|l|l|l|l|}
\hline 265818.23 & 7431956.87 & 543.32 & 543.58 \\
\hline
\end{tabular} \begin{tabular}{|l|l|l|l|}
\hline 258482.14 & 7434505.00 & 526.86 & 527.11 \\
\hline
\end{tabular} \begin{tabular}{|l|l|l|l|}
\hline 261440.43 & 7431404.37 & 522.22 & 522.47 \\
\hline
\end{tabular} \begin{tabular}{|l|l|l|l|}
\hline 264218.20 & 7435841.35 & 540.92 & 541.17 \\
\hline 265019.10 & 7433040.02 & 551.30 & 551.55 \\
\hline
\end{tabular} \begin{tabular}{|l|l|l|l|}
\hline 265019.10 & 7433040.02 & 551.30 & 551.55 \\
\hline 265218.23 & 7431456.87 & 524.66 & 524.42 \\
\hline
\end{tabular} \begin{tabular}{|l|l|l|l|}
\hline 265218.23 & 7431456.87 & 524.66 & 524.42 \\
\hline 262843.92 & 7435531.53 & 523.01 & 523.25 \\
\hline
\end{tabular} \begin{tabular}{|l|l|l|l|}
\hline 262843.92 & 7435531.53 & 523.01 & 523.25 \\
\hline
\end{tabular} \begin{tabular}{|l|l|l|l|}
\hline 264044.19 & 7434852.76 & 561.03 & 561.27 \\
\hline
\end{tabular} \begin{tabular}{|l|l|l|l|}
\hline 265364.91 & 7434865.59 & 575.47 & 575.71 \\
\hline
\end{tabular} \begin{tabular}{|l|l|l|l|}
\hline 259501.62 & 7434197.88 & 518.27 & 518.04 \\
\hline
\end{tabular} \begin{tabular}{|l|l|l|l|}
\hline 259791.53 & 7434832.77 & 519.80 & 520.03 \\
\hline
\end{tabular} \begin{tabular}{|l|l|l|l|}
\hline 258882.14 & 7434505.00 & 547.48 & 547.71 \\
\hline
\end{tabular} \begin{tabular}{|l|l|l|l|}
\hline 264415.54 & 7434737.28 & 555.23 & 555.46 \\
\hline
\end{tabular} \begin{tabular}{|l|l|l|l|}
\hline 260101.64 & 7434267.72 & 505.08 & 504.85 \\
\hline
\end{tabular} \begin{tabular}{|l|l|l|l|}
\hline 260227.44 & 7435132.03 & 508.80 & 509.03 \\
\hline
\end{tabular} \begin{tabular}{|l|l|l|l|}
\hline 260943.90 & 7430602.46 & 539.33 & 539.56 \\
\hline 262633.08 & 7433958.18 & 566.83 & 567.06 \\
\hline
\end{tabular} \begin{tabular}{|l|l|l|l|}
\hline 262633.08 & 7433958.18 & 566.83 & 567.06 \\
\hline
\end{tabular} \begin{tabular}{|l|l|l|l|}
\hline 262036.35 & 7435070.55 & 521.55 & 521.77 \\
\hline
\end{tabular}

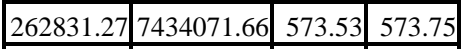
\begin{tabular}{|l|l|l|l|}
\hline 263651.85 & 7434478.95 & 561.49 & 561.28 \\
\hline
\end{tabular} \begin{tabular}{|l|l|l|l|}
\hline 264613.72 & 7435846.30 & 534.74 & 534.95 \\
\hline
\end{tabular} \begin{tabular}{|l|l|l|l|}
\hline 260545.86 & 7437273.11 & 579.24 & 579.44 \\
\hline
\end{tabular} \begin{tabular}{|l|l|l|l|}
\hline 263254.16 & 7435535.21 & 524.39 & 524.59 \\
\hline 264813.64 & 7434761.66 & 554.91 & 555.11 \\
\hline
\end{tabular} \begin{tabular}{|l|l|l|l|}
\hline 264813.64 & 7434761.66 & 554.91 & 555.11 \\
\hline
\end{tabular} \begin{tabular}{|l|l|l|l|}
\hline 262200.90 & 7433984.08 & 553.69 & 553.89 \\
\hline
\end{tabular} \begin{tabular}{|l|l|l|l|}
\hline 265407.54 & 7431388.68 & 527.44 & 527.64 \\
\hline
\end{tabular} \begin{tabular}{|l|l|l|l|}
\hline 264039.60 & 7435735.77 & 538.80 & 538.99 \\
\hline
\end{tabular} \begin{tabular}{|l|l|l|l|}
\hline 261440.43 & 7431204.37 & 522.42 & 522.23 \\
\hline 262632.72 & 7430333.59 & 541.10 & 540.92 \\
\hline
\end{tabular} \begin{tabular}{|l|l|l|l|}
\hline 262632.72 & 7430333.59 & 541.10 & 540.92 \\
\hline
\end{tabular} \begin{tabular}{|l|l|l|l|}
\hline 261800.10 & 7434551.82 & 528.54 & 528.72 \\
\hline
\end{tabular} \begin{tabular}{|l|l|l|l|}
\hline 264645.60 & 7430428.05 & 548.78 & 548.96 \\
\hline
\end{tabular} \begin{tabular}{|l|l|l|l|}
\hline 262236.35 & 7434970.55 & 538.93 & 538.75 \\
\hline 259071.93 & 7434402.86 & 553.76 & 553.93 \\
\hline
\end{tabular} \begin{tabular}{|l|l|l|l|}
\hline 259071.93 & 7434402.86 & 553.76 & 553.93 \\
\hline
\end{tabular} \begin{tabular}{|l|l|l|l|}
\hline 260343.90 & 7430702.46 & 556.63 & 556.80 \\
\hline
\end{tabular} \begin{tabular}{|l|l|l|l|}
\hline 265565.15 & 7436009.60 & 579.21 & 579.05 \\
\hline
\end{tabular} \begin{tabular}{|l|l|l|l|}
\hline 262433.08 & 7433658.18 & 542.53 & 542.69 \\
\hline
\end{tabular} \begin{tabular}{|l|l|l|l|}
\hline 263229.51 & 7430766.71 & 515.53 & 515.69 \\
\hline
\end{tabular} \begin{tabular}{|l|l|l|l|}
\hline 262031.92 & 7431541.26 & 541.28 & 541.12 \\
\hline
\end{tabular} \begin{tabular}{|l|l|l|l|}
\hline 260943.90 & 7431202.46 & 513.87 & 514.03 \\
\hline
\end{tabular} \begin{tabular}{|l|l|l|l|}
\hline 264498.34 & 7437971.39 & 577.45 & 577.30 \\
\hline
\end{tabular} \begin{tabular}{|l|l|l|l|}
\hline 265213.64 & 7435161.66 & 559.83 & 559.68 \\
\hline
\end{tabular} \begin{tabular}{|l|l|l|l|}
\hline 262000.90 & 7434284.02 & 545.31 & 545.46 \\
\hline
\end{tabular} \begin{tabular}{|l|l|l|l|}
\hline 262633.81 & 7433167.79 & 543.06 & 542.91 \\
\hline
\end{tabular} 
\begin{tabular}{|l|l|l|l|}
\hline 259875.44 & 7437185.19 & 553.36 & 553.51 \\
\hline
\end{tabular} \begin{tabular}{|l|l|l|l|}
\hline 260427.44 & 7435032.03 & 501.56 & 501.71 \\
\hline
\end{tabular} \begin{tabular}{|l|l|l|l|}
\hline 264051.88 & 7433879.03 & 559.00 & 559.15 \\
\hline
\end{tabular} \begin{tabular}{|l|l|l|l|}
\hline 263234.64 & 7433874.04 & 563.45 & 563.31 \\
\hline
\end{tabular} \begin{tabular}{|l|l|l|l|}
\hline 259991.53 & 7435332.77 & 519.10 & 518.96 \\
\hline
\end{tabular} \begin{tabular}{|l|l|l|l|}
\hline 262666.65 & 7436607.19 & 518.01 & 517.87 \\
\hline
\end{tabular} \begin{tabular}{|l|l|l|l|}
\hline 264418.20 & 7435737.27 & 534.76 & 534.62 \\
\hline
\end{tabular} \begin{tabular}{|l|l|l|l|}
\hline 264815.84 & 7434420.32 & 554.90 & 554.76 \\
\hline
\end{tabular} \begin{tabular}{|l|l|l|l|}
\hline 264813.64 & 7434561.66 & 553.69 & 553.56 \\
\hline
\end{tabular} \begin{tabular}{|l|l|l|l|}
\hline 258882.58 & 7433216.87 & 513.62 & 513.49 \\
\hline
\end{tabular} \begin{tabular}{|l|l|l|l|}
\hline 262432.74 & 7430233.37 & 552.30 & 552.18 \\
\hline
\end{tabular} \begin{tabular}{|l|l|l|l|}
\hline 262236.35 & 7434570.55 & 545.63 & 545.75 \\
\hline
\end{tabular} \begin{tabular}{|l|l|l|l|}
\hline 264418.20 & 7435337.27 & 529.42 & 529.54 \\
\hline
\end{tabular} \begin{tabular}{|l|l|l|l|}
\hline 265365.15 & 7435500.40 & 567.13 & 567.02 \\
\hline
\end{tabular} \begin{tabular}{|l|l|l|l|}
\hline 262001.27 & 7433449.42 & 514.24 & 514.35 \\
\hline
\end{tabular} \begin{tabular}{|l|l|l|l|}
\hline 263639.60 & 7435335.77 & 518.08 & 517.98 \\
\hline
\end{tabular} \begin{tabular}{|l|l|l|l|}
\hline 263329.78 & 7436704.60 & 549.25 & 549.35 \\
\hline 259275.41 & 7436668.02 & 581.76 & 581.67 \\
\hline
\end{tabular} \begin{tabular}{|l|l|l|l|}
\hline 259275.41 & 7436668.02 & 581.76 & 581.67 \\
\hline
\end{tabular} \begin{tabular}{|l|l|l|l|}
\hline 259275.41 & 7436868.02 & 573.10 & 573.19 \\
\hline
\end{tabular} \begin{tabular}{|l|l|l|l|}
\hline 259271.93 & 7434288.06 & 536.14 & 536.23 \\
\hline
\end{tabular} \begin{tabular}{|l|l|l|l|}
\hline 261833.80 & 7431600.81 & 538.05 & 538.14 \\
\hline
\end{tabular} \begin{tabular}{|l|l|l|l|}
\hline 263032.84 & 7433677.45 & 565.76 & 565.84 \\
\hline
\end{tabular} \begin{tabular}{|l|l|l|l|}
\hline 261600.10 & 7434851.82 & 503.32 & 503.40 \\
\hline
\end{tabular} \begin{tabular}{|l|l|l|l|}
\hline 264615.84 & 7434120.32 & 521.98 & 522.06 \\
\hline
\end{tabular} \begin{tabular}{|l|l|l|l|}
\hline 260943.90 & 7431402.46 & 508.47 & 508.40 \\
\hline
\end{tabular} \begin{tabular}{|l|l|l|l|}
\hline 264963.07 & 7439142.59 & 538.74 & 538.81 \\
\hline
\end{tabular} \begin{tabular}{|l|l|l|l|}
\hline 265364.91 & 7434665.59 & 559.09 & 559.16 \\
\hline
\end{tabular} \begin{tabular}{|l|l|l|l|}
\hline 263034.92 & 7432439.04 & 503.81 & 503.87 \\
\hline
\end{tabular} \begin{tabular}{|l|l|l|l|}
\hline 263852.30 & 7433799.97 & 554.03 & 553.97 \\
\hline
\end{tabular} \begin{tabular}{|l|l|l|l|}
\hline 260345.38 & 7438239.05 & 575.82 & 575.88 \\
\hline
\end{tabular} \begin{tabular}{|l|l|l|l|}
\hline 259071.93 & 7434202.86 & 538.84 & 538.90 \\
\hline
\end{tabular} \begin{tabular}{|l|l|l|l|}
\hline 260227.44 & 7435332.03 & 511.62 & 511.67 \\
\hline
\end{tabular} \begin{tabular}{|l|l|l|l|}
\hline 258482.14 & 7434305.00 & 524.00 & 523.95 \\
\hline
\end{tabular} \begin{tabular}{|l|l|l|l|}
\hline 258682.14 & 7433805.00 & 533.78 & 533.73 \\
\hline
\end{tabular} \begin{tabular}{|l|l|l|l|}
\hline 261640.43 & 7430707.27 & 545.74 & 545.69 \\
\hline
\end{tabular} \begin{tabular}{|l|l|l|l|}
\hline 265565.15 & 7435809.60 & 578.85 & 578.90 \\
\hline
\end{tabular} \begin{tabular}{|l|l|l|l|}
\hline 260427.44 & 7435432.03 & 521.82 & 521.78 \\
\hline
\end{tabular} \begin{tabular}{|l|l|l|l|}
\hline 262736.27 & 7438884.37 & 564.10 & 564.14 \\
\hline
\end{tabular} \begin{tabular}{|l|l|l|l|}
\hline 263329.78 & 7436504.60 & 551.83 & 551.87 \\
\hline
\end{tabular} \begin{tabular}{|l|l|l|l|}
\hline 264889.84 & 7437578.17 & 565.71 & 565.68 \\
\hline
\end{tabular} \begin{tabular}{|l|l|l|l|}
\hline 258681.47 & 7433317.68 & 524.76 & 524.73 \\
\hline
\end{tabular} \begin{tabular}{|l|l|l|l|}
\hline 263651.83 & 7434278.95 & 573.87 & 573.84 \\
\hline
\end{tabular} \begin{tabular}{|l|l|l|l|}
\hline 260432.58 & 7434274.02 & 508.15 & 508.13 \\
\hline
\end{tabular} \begin{tabular}{|l|l|l|l|}
\hline 265013.72 & 7435874.16 & 559.58 & 559.57 \\
\hline
\end{tabular} \begin{tabular}{|l|l|l|l|}
\hline 265509.00 & 7433018.42 & 565.99 & 565.98 \\
\hline
\end{tabular} \begin{tabular}{|l|l|l|l|}
\hline 258882.14 & 7434105.00 & 540.10 & 540.11 \\
\hline
\end{tabular} 